\title{
AGRICULTURAL PRICE ANALYSIS
}


". ... when you can measure what you are speaking about, and express it in numbers, you know something about it; but when you cannot measure it, when you cannot express it in numbers, your knowledge is of a meager and unsatisfactory kind."

- Popular Lectures and Addresses by Lord Kelvin, London, 1889, Vol. 1, p. 73. 


\section{AGRICULTURAL PRICE ANALYSIS}

\section{By GEOFFREY S. SHEPHERD'}

Professor of Economics, Iowa State College

Author of Agricultural Price Control and Marketing Farm Products

SECOND EDITION, REVISED
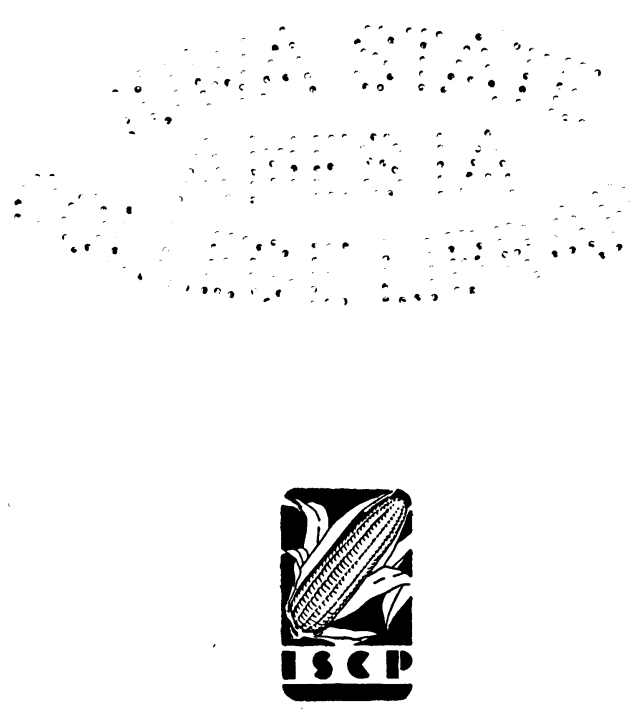

1947

THE IOWA STATE COLLEGE PRESS

Ames, Iowa 
Copyright, 1941 and 1947, by

THE IOWA STATE COLLEGE PRESS

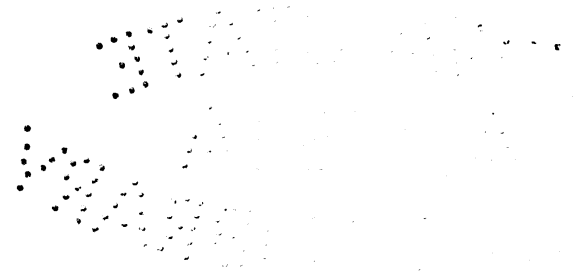

PRINTED AT THE IOWA STATE COLLEGE PRESS

AMES, IOWA, U. S. A. 


\section{Preface}

In this book, principles of economic theory and methods of statistical analysis are applied to the study of agricultural prices.

Intelligent handling of agricultural price problems requires extensive analysis of the causes of changes in agricultural prices. It is not enough to show that agricultural prices decline when the supply increases or the demand decreases, and vice versa. We need to go further, and measure quantitatively how much the supply or demand changes, and how much the price changes in response. The answers differ for different products, and our handling of price problems will be rough and blundering until we know what the answers are.

In technical terms, the agricultural price analyst needs to know how to measure changes in supply and demand, as distinguished from changes in production. He needs also to know how to measure the elasticity, stability, and shape or curvature of the demand and supply curves for the various farm products, just as a chemist needs to know how to measure the valence, molecular weight, and other chemical properties of the different elements.

The economist cannot make these measurements once for all, as the chemist can; the economic properties of specific goods do not remain constant like the chemical properties of specific elements. But in most cases the economic properties of goods change only slowly, so that economic "constants" derived from recent statistical data can be used as first approximations for use in later periods.

The need for thorough analysis of agricultural prices is the greater because we seem to be headed in the direction of more and more control of agricultural prices. Analysis is useful if it can be used only as the basis for forecasting, as we forecast the weather without being able to control it. It is more than useful, it is essential -if we are to go further and attempt to control prices as well as explain and predict them.

Accordingly, this book subjects agricultural prices to technical quantitative analysis. It begins with long-time movements of agricultural prices over the past 150 years, shows the causes of those movements, and projects a long-time forecast into the future. It 
then deals similarly with short-time movements, and with cyclic movements in the prices of individual farm products.

Then comes an analysis of irregular annual movements. This analysis applies statistical methods and technical economic concepts to the derivation of quantitative measurements of several thingsaverage and point elasticities, and total and marginal revenues, using the concrete market price and production data for specific representative farm products. The general theory of price stabilization and price discrimination is then outlined and applied to recent stabilization and price-discrimination programs. The book ends with an appraisal of the statistical significance of the results of price analyses.

This book is the third in the series of three books that replaces my original Agricultural Price Analysis (1941) which has been out of print since 1945. The first of the three books was Agricultural Price Control (1945). The second was Marketing Farm Products (1946). About three-quarters of the present book consists of a revision of the second half of my original Agricultural Price Analysis.

This expansion of the subject matter, and its segregation into separate books, makes it possible to deal with marketing, price analysis, and price control as three separate though related subjects. In addition, the separation of the subject matter into three different books makes it possible to address each book to a different group. Marketing Farm Products constitutes an introduction to the fields of agricultural marketing and prices. Agricultural Price Control deals at an advanced technical level with the problems involved in controlling agricultural prices. It is addressed to farmers, farm leaders, legislators, administrators, and students of agricultural price problems wherever they may be. The present book is addressed to technical experts and advisors involved in the operation of marketing and price programs, and to students of agricultural prices who want to improve their grasp of economic and statistical principles by applying them to technical agricultural price problems.

I cannot hope to have made a fully satisfactory division of the three fields in these three books. The fields are related, and their areas overlap. Suggestions from readers who would like to see the fields divided differently will be welcome.

G. S. S.

Ames, Iowa

December, 1946 


\section{Table of Contents}

CHAPTER

PAGE

Preface

1. Long-Time Movements in Agricultural Prices . . . 1

2. Short-Time Changes in Agricultural Prices . . . . 20

3. Cyclic Variations in Individual Agricultural Prices . . 29

4. The Elasticity of the Demand for Farm Products . . 52

5. Point Elasticity, Total Revenue, and Marginal Revenue . 71

6. The Elasticity of the Supply of Farm Products . . . 88

7. The Measurement of Changes in Demand and Supply . 99

8. The Measurement of Changes in Demand: Deflation . . 111

9. The Measurement of Changes in Demand: Multiple Correlation . . . . . . . . . . . . . 122

10. Individual Sales and Cost Curves . . . . . . . 143

11. The Relation Between Prices and Costs . . . . . 158

12. The Theory of Price Stabilization and Price Discrimination . . . . . . . . . . . . . 170

13. The Significance of the Results of Price Analyses _ . . . 183

14. Parity Prices for Farm Products . . . . . . . 191

15. Appraisal of Parity Prices . . . . . . . . 207

Appendix: Vertical and Horizontal Shifts in Demand and Supply Curves . . . . . . . . . . . . 221

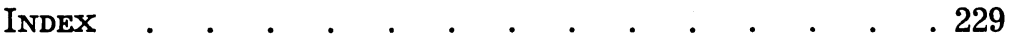


. 


\section{CHAPTER 1}

\section{Long-Time Movements in Agricultural Prices}

The prices of most farm products are highly variable. They change from year to year, from month to month, and from day to day. Some of them change from hour to hour, and even from minute to minute. Changes also take place continuously in the relations between the prices of farm products and the prices of other products.

These changes at times appear irrational or capricious, beyond the realm of reason to explain, and beyond the power of man to control. The tides, storms, and waves of the ocean similarly appeared capricious to the early mariners. Science, however, has laid bare most of the reasons for these movements in the level of the ocean. It has been able to explain them in terms of natural forces which can be measured and predicted, if not controlled. As long ago as 1872 , Lord Kelvin designed a machine that could predict tidal movements with mathematical precision for any desired time in the future. Storms are caused by more complicated forces. They can, however, be predicted several days ahead, and the length of time of prediction is steadily being lengthened.

In economics, progress has been difficult. This is partly because economics is a younger science; partly because the "constants" in economics are not so constant; and partly because the causes are more numerous and complex.

Practically all of the tidal movement of the ocean, for example, can be explained by the gravitational pulls of two heavenly bodies, the moon and the sun. Furthermore, those pulls remain constant over long periods of time. By contrast, economic forces are numerous, and their effects change over periods of time as incomes and tastes change and as production technology changes.

The relatively simple problem of predicting tidal movements is difficult enough. ${ }^{1}$ The actual tidal movement of the ocean's surface at any particular point is determined not only by gravitational forces but also by the configuration of the coast line. At the bay of

\footnotetext{
${ }^{1}$ See, for example, the article on "Tides" in the Encyclopedia Brittanica.
} 
Fundy, for example, the range of tide reaches fifty feet, while at certain islands in the Pacific it never exceeds two feet. The amplitude of the tidal movement, and its shape, therefore, has to be predicted separately for each point. In addition, storms blowing offshore or onshore affect the height of the water at the coast from hour to hour. Occasional seismic shocks create additional disturbances. Tidal predictions are only rough first approximations. The actual level of the water differs considerably from the predicted level. The tidal prediction holds only caeteris paribus; the physicist has to use the qualification much as the economist does.

In economics the price analyst has to take numerous forces into account, and the effects of these forces change over periods of time. The price analyst's problems, therefore, are more complicated than the physicist's tidal prediction problem. In some ways, however, they are more rewarding. Tidal forces can only be predicted; they cannot be controlled. But economic forces can be controlled, and the economist can help to show how to control them.

\section{LONG-TIME PRICE MOVEMENTS}

Agricultural price movements are caused by different forces according to the length of time involved. Long-time movements, for example, are caused by changes in population, in the technology of production, in real income per capita, etc. These forces are slow to move. Short-time movements are caused by different forcesannual variations in weather, wars, booms, and depressions. Still shorter movements are caused by still other forces.

The analysis of agricultural price movements over periods of time, therefore, can be broken down into several parts according to the length of time involved. Our analysis will begin with the broadest perspective-with price movements over long periods of one hundred years or more-and then proceed to shorter and shorter periods.

The wholesale prices of farm products in the United States are shown annually for the past 150 years in Figure 1, along with the wholesale prices of nonagricultural products. ${ }^{2}$ This figure shows how the credit expansions associated with four major wars have thrown up four sharp peaks in agricultural and nonagricultural prices alike. issues.

${ }^{2}$ Data from 1946 Agricultural Outlook Charts, USDA, 1945, p. 10, and earlier 
The inflationary forces at work during World War II were far stronger than in the earlier wars, but they were kept under better control. The price peak during World War II was only about

INDEX NUMBERS $(1910 \cdot 14=100)$,

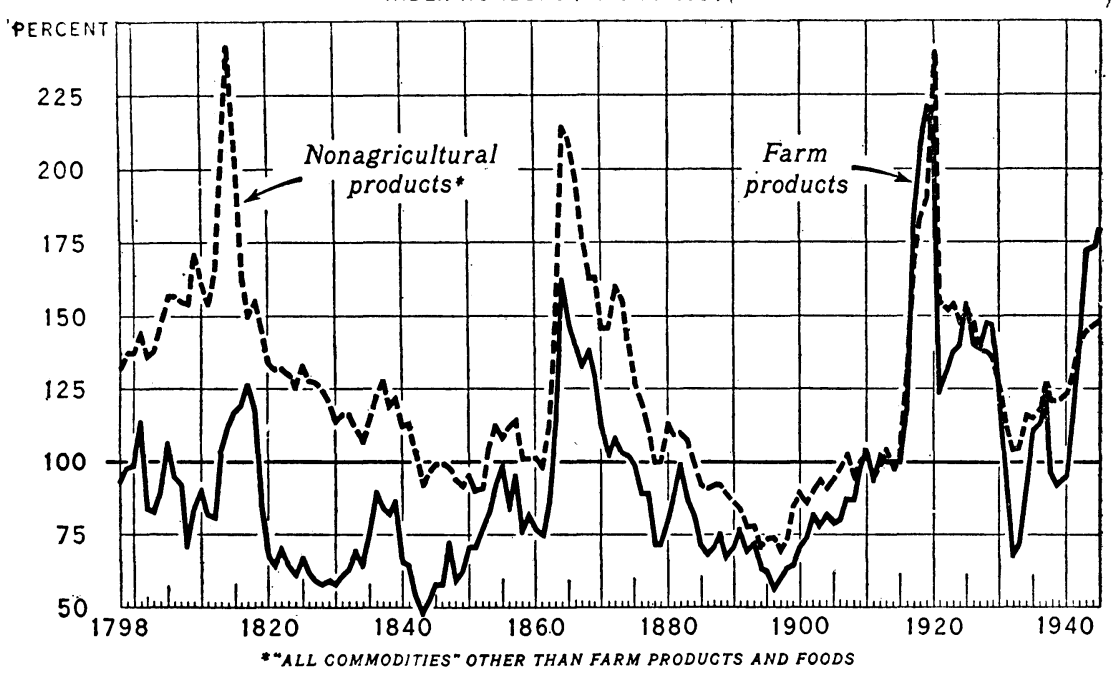

U. S. DEPARTMENT OF AGRICULTURE

Fig. 1.-Wholesale prices of farm products and of all commodities other ikan farm products, United States, 1798-1945. Index numbers $(1910-14=100)$.

two-thirds as high as the previous peaks. After World War II, however, prices rose about as high as after World War I. The nation apparently is not able to control inflation in peacetime as well as in wartime.

This is unfortunate. The evidence is clear that inflation benefits some but injures many, and that it is likely to be followed by a deflation that injures almost everybody who was not injured before.

Farmers benefit from inflation while the inflation is proceeding. Agricultural production changes much less from year to year than industrial production. The increase in the demand for farm products causes a greater rise in agricultural prices than in agricultural production. Many of the charges intervening between the producer and the consumer-freight charges, rents, taxes, interest, some wage rates, etc.-remained fixed, or change only slowly. If farmers were getting half the consumer's dollar originally, and the consumer's 
prices rose 25 per cent with no change in middleman's margins, then prices received by farmers would rise 50 per cent. Since a large share of farmers' expenses are fixed expenses-interest, taxes, etc.farmers' net incomes increase still more than their gross incomes. During World War II, the retail prices of food rose about 40 per cent; agricultural prices (at the farm) rose about 100 per cent; gross farm income more than doubled; and net farm income nearly trebled. ${ }^{3}$

Other groups, who live on incomes that remain fixed in dollars and cents (such as some salary and wage groups, bond holders, those who are living on life insurance, annuities, etc.), suffer during inflation. If prices rise 25 per cent, their fixed incomes will buy only

100 $\frac{100}{125}=80$ per cent as much as before.

In the deflation that usually follows inflation, the shoe goes on the other foot. The prices received by farmers fall farther than other prices. Farms bought at high prices during inflation may be lost during deflation. The receivers of fixed incomes benefit during deflation, or at least the harm they suffered during inflation is reduced. But many workers lose their jobs and have very little income to spend.

Accordingly, one important objective of national policy is to counteract both inflationary and deflationary forces, and to stabilize prices, employment, and incomes at as high a level as possible. A good deal of progress was made in controlling inflationary forces during World War II. It remains to be seen whether as much progress can be made in controlling deflationary forces after the reconversion to peace has been effected. Some progress can be expected, for the monetary and banking system is better able to withstand deflation now than formerly; and much has been learned about the role of fiscal policy-taxing and spending-during the past twentyfive years.

\section{LONG-TIME RELATIVE RISE IN AGRICULTURAL PRICES}

Figure 1 shows how the long-time trend of agricultural prices, insofar as it can be distinguished through the four upheavals just mentioned, has been level or slightly upward over the past 150 years, while the trend of nonagricultural prices has been slightly

${ }^{3} 1946$ Agricultural Outlook Charts, 1945, USDA, p. 3. 
downward. The trend of agricultural prices gradually rose, relative to the trend of nonagricultural prices, up to the time of World War I.

This relative rise in agricultural prices is shown more clearly in Figure 2, where the agricultural price index each year is subtracted from the nonagricultural price index and the difference between the two is plotted as so much below or above a straight base line running across the chart. The gradual rise of agricultural prices relative to nonagricultural prices is shown most clearly by the heavy line connecting the ten-year averages.

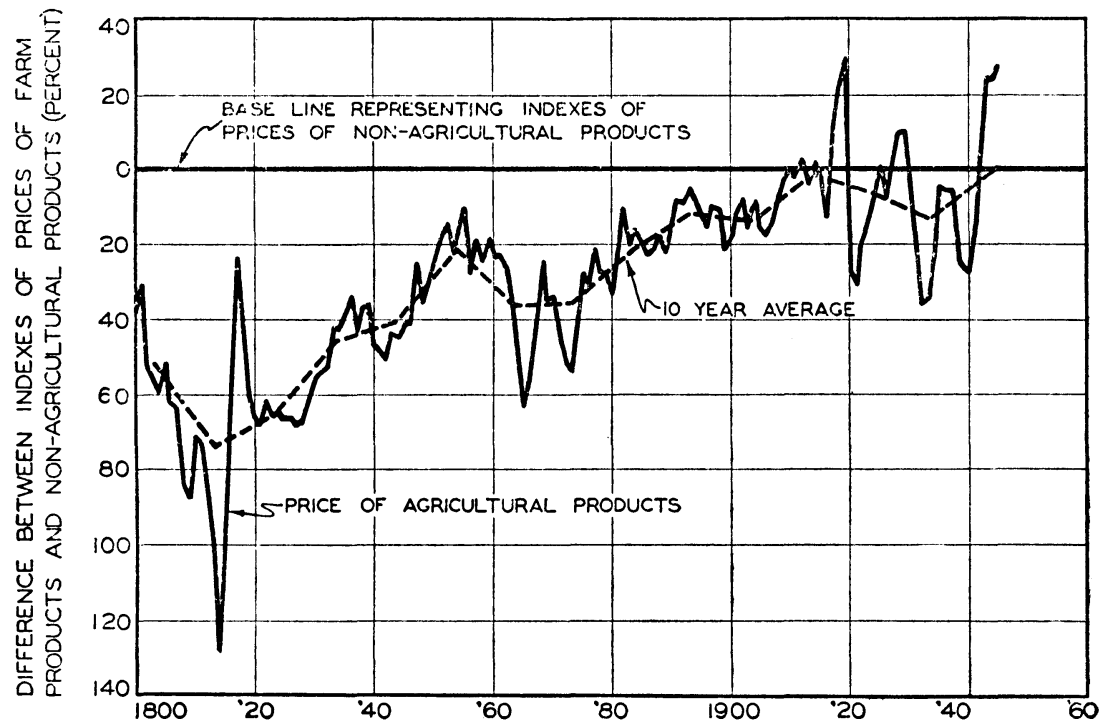

Fig. 2.-Differences between the indexes of wholesale prices of farm products and of all commodities other than farm products, United States 1800-1945. $(1910-14=100)$.

The chart indicates that up to 1914 , the prices of farm products were rising relative to nonagricultural prices. After 1918, however, the opposite happened; agricultural prices began to decline relative to other prices. World War II brought agricultural prices up again, but the decline may reappear after reconversion has been completely effected.

What does this mean? Does it mean that agricultural prices have been below nonagricultural prices most of the past 150 years, or that agricultural prices struggled up for 100 years before attain- 
ing equality with nonagricultural prices in 1910-14, and then relapsed?

It does not mean this. The position of the agricultural price line as a whole, relative to the position of the nonagricultural price line, has no significance in itself. There is no way of measuring the inequality of these two groups of prices-no way of measuring whether one is "above" or "below" the other-except by reference to some base point. If the price of wheat is $\$ 1$ a bushel, and the price of a plow is $\$ 120$, one cannot say merely by direct comparison of the two prices that one is "higher" or "lower" than another. All that can be said is that one is higher or lower than its usual or normal relation to the other.

Strictly speaking, even this statement is open to question. It implies that things do or should stay put. But in a world so full of change as ours, what is usual or normal? If the attempt is made to define it objectively as average, then the question arises-average over what period of years? And the further question remains-can what is usual, normal, or average for one period of years be considered so for a later period?

Even loosely speaking, then, prices or groups of prices can be compared with each other only by reference to some usual or normal relationship between them. Strictly speaking, all that can be done is to compare them with respect to their relation in some other period, without implying that the relation should be the same now as it was then.

Where two groups of prices represented by index numbers (which are expressed in terms ' of some base year or period) are compared, that base year or period usually is taken as the basis of the comparison of two price series. In the case of the two price series shown in Figures 1 and 2, the base is the same for both series; the average of the prices in 1910-14 is taken as 100, in each case. The two price indexes, therefore, necessarily stand at the same figure (100) in the base period. They are "equal" at that time, but only because that is their index base period when both are taken as 100 .

If the same basic data were recomputed with some other year as the base, say the year 1800, the two indexes (agricultural and nonagricultural prices) would both stand at 100 , i.e., be "equal," in 1800. The effect of this on the chart would be to leave the horizontal line representing nonagricultural prices where it is, but to shift the irregular line representing agricultural prices up about 
40 points as a whole. Agricultural prices then would be "above" nonagricultural prices most of the years after about 1840-about 40 points above in 1910-14-and well above every year since. But this appearance would be as misleading as the appearance of Figure 2. All that either chart shows is that agricultural prices are higher or lower in relation to nonagricultural prices than they were in whatever year or period is chosen as a base. The comparison is only as valid as the validity of the base period for representing equality or equilibrium today.

\section{9-14 PRICE PARITY}

The validity of the 1910-14 period as a basis for price comparisons might be merely an academic question. Actually, it is far from academic. It is a question of great practical public importance. Agricultural price control programs use the 1910-14 period as the basis for much of their commodity loans and price floors, and their operations run into billions of dollars.

The basis that these programs use is the relation between the prices received by farmers for the products they sell, and the prices they pay for the goods (and services) they buy. The index base period for the prices received by farmers is the fiveyear period August, 1909, through July, 1914. The index is the same index that is shown in Figures 1 and 2, only computed on a slightly different base (August, 1909-July, 1914, instead of 1910-14). The index of prices paid by farmers is different from the index of nonagricultural products shown in Figures 1 and 2 . It is the index of prices of the goods and services (interest and taxes) used by farmers in production and family living. It runs back only to 1910. The base period for this index is 1910-14. (Calendar years had to be used because this index was compiled only on a calendar year basis from 1910 to 1922 .)

The purpose of the compilation of these price indexes is to provide a measure for determining whether farm products have the same purchasing power as they had in the base period.

Thus if the index of prices received stood at 150 but the index of prices paid stood at 160 , farm products would have less purchasing power, not more, than they had in the base period. They would have only $\frac{150 \times 100}{160}=94$ per cent as much purchasing 
power per unit as they had in the base period. Their purchasing power would be 6 per cent less than equality or parity with their purchasing power in the base period.

The methods by which parity prices are computed, and the strong and weak points of parity prices, are discussed fully in Chapters 14 and 15. It is shown there that parity prices are not good bases for price control programs, nor accurate measures of the economic status of agriculture. The point of chief interest here, however, is comparatively simple. It is the fact that the validity of any measure of parity rests upon the representativeness of its base period, and that the shortcomings of the existing official measure of parity are accentuated with the passage of time, as the base period recedes farther and farther in the past and becomes less and less representative of the present.

One of the most obvious ways to improve the existing measure of parity would be to use a more recent base date than 1910-14. ${ }^{4}$ The five years 1935-39 just before World War II, for example, would be twenty-five years closer to the present than the old 1910-14 base. The Federal Reserve Board revised the weights and content of its monthly index of industrial production in 1940, shifting it from its previous 1923-25 base to 1935-39 base. Three of the four members of a committee appointed by the president of the American Farm Economics Association in 1940 to report on the problem of an adequate base for agricultural price indexes voted in favor of adopting the 1935-39 base, but no further action on the matter has yet been taken.

\section{CHANGES IN SUPPLY AND DEMAND}

Study of Figure 2 raises several questions. Why did agricultural prices rise, relative to nonagricultural prices, from 1800 to 1920 , and decline thereafter until World War II?

The long-time movements in agricultural prices are caused, like any other price movements, by changes in supply and in demand. The extent of the price movements depends upon the elasticities of supply and demand, as well as upon the extent of the changes in the supply and demand.

For analytical purposes, it is essential to keep clearly in mind

\footnotetext{
${ }^{4}$ For two opposing views on this proposal, see F. A. Pearson and K. R. Bennett, "The Case for the 1910-14 Base," and E. L. Butz, "A Base in the 1920-29 Period for Farm Price Studies," Journal of Farm Economics, XXI, No. 1, February, 1939, pp. 243-46 and 247-52.
} 
the distinction between supply and production, and demand and consumption. Supply is the whole series of quantities that would be produced at a series of different prices. It is the whole supply schedule; in graphic terms, it is the whole supply curve. A change in supply means a change in the location or position of the whole curve. But production is simply the quantity produced at a specified point on the supply curve. It is the horizontal distance from zero on the quantity axis to the point where the demand and supply curves cross at a particular point in time. Production may change while supply remains constant. The same sort of thing is true of demand as distinguished from consumption.

\section{RELATIVE SHIFTS IN SUPPLY AND DEMAND CURVES}

What happened from 1800 to 1920 was this: Agricultural prices rose because the demand curve for farm products moved to the right more rapidly than the supply curve moved.

Can we measure this movement to the right in the position of the supply and demand curves?

Bluntly, we can't. We can measure the movements of the intersection points of the demand and supply curves, but we do not have enough data to enable us to measure the movements of the curves themselves. We can only measure some of the chief factors that cause the supply and demand curves to move.

\section{CHANGES IN SUPPLY}

Two or three of these factors are shown in Table $1 .^{5}$ This table shows that the farm labor force (persons on farms ten years old and over) increased steadily from 1870 to 1910 , but declined, slowly at first and then more and more rapidly, from 1910 to 1940 . Technological improvements, however, increased the productivity per worker, so that total production increased continuously up to 1940 . The data are shown in graphic form in Figure 3.

The effects of technological changes that increase yields without requiring extra labor, on the position of the supply curve, can be measured fairly accurately. If hybrid seed corn, for example, has increased yields per acre 20 per cent, it has shifted the supply curve 20 per cent to the right.

${ }^{5}$ This table, Figure 3, and some of the analysis in this section are taken from John M. Brewster, "Farm Technological Advance and Total Population Growth," Journal of Farm Economics, XXVII, No. 3, August, 1945. 
TABLE 1

Change in farm Labor Force, Agricultural Production, Farm Worker Productivity, and Total Population Growth, 1870-1940

$(1870=100$ for all indexes)

\begin{tabular}{|c|c|c|c|c|c|c|c|c|c|c|}
\hline \multicolumn{4}{|c|}{$\begin{array}{c}\text { Farm Labor Force } \\
\text { (Persons } 10 \text { years and over) }\end{array}$} & \multicolumn{2}{|c|}{$\begin{array}{l}\text { Agricultural } \\
\text { Production }\end{array}$} & \multicolumn{2}{|c|}{$\begin{array}{l}\text { Productivity } \\
\text { Per Worker }\end{array}$} & \multicolumn{3}{|c|}{ Total Population } \\
\hline Year & Number* & Index & $\begin{array}{l}\text { Percentage } \\
\text { Change } \dagger\end{array}$ & Index $\ddagger$ & $\begin{array}{c}\text { Percentage } \\
\text { Change } f\end{array}$ & Index & $\begin{array}{c}\text { Percentage } \\
\text { Change } \dagger\end{array}$ & Number $\S$ & Index & $\begin{array}{l}\text { Percentage } \\
\text { Change } \dagger\end{array}$ \\
\hline $\begin{array}{l}1870 \ldots \ldots \\
1880 \ldots \ldots \\
1890 \ldots \ldots \\
1900 \ldots \ldots \\
1910 \ldots \ldots \\
1920 \ldots \ldots \\
1930 \ldots \ldots \\
1940 \ldots \ldots\end{array}$ & $\begin{array}{r}6,849,772 \\
8,584,810 \\
9,938,373 \\
10,911,998 \\
11,591,767 \\
11,448,770 \\
10,471,998 \\
9,162,574\end{array}$ & $\begin{array}{l}100 \\
125 \\
145 \\
159 \\
169 \\
167 \\
153 \\
134\end{array}$ & $\begin{array}{r}25 \\
16 \\
10 \\
6 \\
-1 \\
-9 \\
-13\end{array}$ & $\begin{array}{l}100 \\
152 \\
190 \\
242 \\
276 \\
304 \\
338 \\
378\end{array}$ & $\begin{array}{l}\cdots \\
52 \\
25 \\
27 \\
15 \\
10 \\
11 \\
12\end{array}$ & $\begin{array}{l}100 \\
122 \\
131 \\
152 \\
163 \\
182 \\
221 \\
282\end{array}$ & $\begin{array}{r}\cdots \\
22 \\
7 \\
16 \\
7 \\
12 \\
21 \\
28\end{array}$ & $\begin{array}{r}38,558,371 \\
50,155,783 \\
62,947,714 \\
75,994,575 \\
91,972,226 \\
105,710,620 \\
122,775,046 \\
131,669,275\end{array}$ & $\begin{array}{l}100 \\
130 \\
163 \\
197 \\
239 \\
274 \\
318 \\
341\end{array}$ & $\begin{array}{r}30 \\
26 \\
21 \\
21 \\
15 \\
16 \\
7\end{array}$ \\
\hline
\end{tabular}

* U. S. Bureau of the Census, Population (Sixteenth Census of the U. S.), Series P-9, No. 11, December 8, 1944.

$\dagger$ From preceding decade.

$\ddagger$ For 1870 , three-year average centered on year indicated. For other years, five-year averages similarly centered. Data since 1909 are derived from BAE index of volume of agricultural production for sale and for consumption in the farm home, Agricultural Statistics 1943, USDA. Data prior to 1909 derived from the Ideal Index computed by Frederick Strauss and Louis H. Bean, Tech. Bul. No. 703, December 1940, Gross Farm Income and Indices of Farm Production and Prices in the United States, 1869-1937, Table 59, p. 125. $\S U$. S. Census, 1940, Series P-44, No. 21.

(Source of entire table: John M. Brewster, "Farm Technological Advance and Total Population Growth," Fournal of Farm Economics, XXVII, No. 3, August, 1945, p. 513.) 
Technological changes that reduce the cost of producing the same yield, say 20 per cent, also can be measured; they shift the supply curve 20 per cent downward. ${ }^{6}$ The difficulty comes in determining

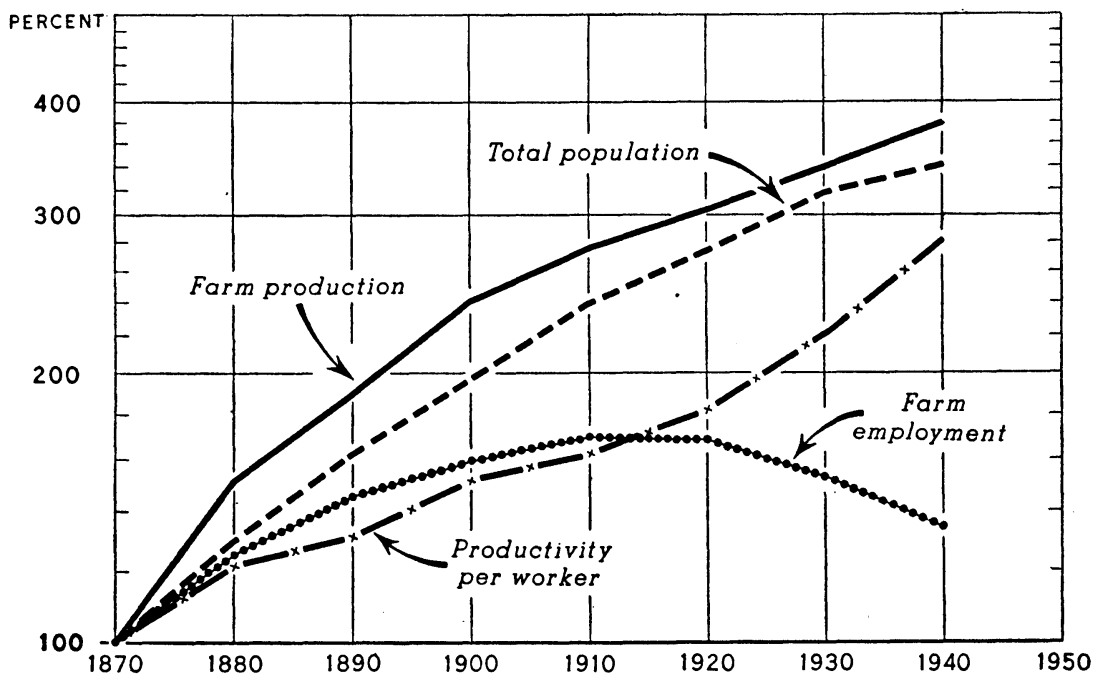

O. S. DEPARTMENT OF AGRICULTURE

NEG. 45182 BUREAU OF AGRICULTURAL ECONOMICS

Fig. 3.-Farm production, farm employment, farm labor productivity, and total population, United States, 1870-1940. Index numbers $(1870=100)$.

how much a technological change of this sort has decreased production costs. The job of adding up these effects for each product, and determining how much the supply curve for farm products as a whole has shifted, is almost impossible. Therefore, it is almost impossible to measure accurately how much the position of the supply curve for farm products has moved over the past 150 years. The relative rise in prices from 1800 to 1914 shows that up to World War I, the demand curve moved to the right faster than the supply curve did, so that the demand curve cut the supply curve at higher and higher points. It is almost impossible to say how much of the increase in production was the result of the demand curve's cutting the supply curve at a higher point, and how much was the result of the supply curve's moving to the right also. Conceivably, although not probably, the supply curve might have been very elastic and might not have moved at all.

\footnotetext{
${ }^{6}$ See Chapter 6 and the Appendix for an elaboration of the distinction between vertical and horizontal shifts in the position of supply and demand curves.
} 
The trend of agricultural prices since World War I has been roughly horizontal. This means that the supply curve for farm products since World War I has been moving to the right at about the same rate as the production. That rate has been nearly 1 per cent per year. Prospects for the rate of movement in the future are discussed at the end of this chapter.

\section{CHANGES IN DEMAND}

Changes in demand are also hard to measure. Some of the chief factors that determine the demand can be measured, but not all of them.

The chief factor is the rate of population growth in the United States. This rate is shown in Table 1 and Figure 3. The figure shows how the rate of growth is slowing down with the passage of time, from about 3 per cent per year in the decade of the 1870's to less than 1 per cent per year at present.

This would not necessarily mean an equal slowing down in the rate of increase in the demand for food. The per capita demand for food might be increasing, because of changes in income, in tastes, in technology, or in the composition of the population; and this increase might be great enough to offset or more than offset the declining rate of population growth. Actually, however, the trend of the per capita demand for food (insofar as it can be measured by the per capita consumption of food) has remained practically constant over the past forty years at about five pounds per day. ${ }^{7}$

The composition of the demand for food, however, has changed materially during the past thirty-five years. Figure 4 shows that the per capita consumption of fruits and vegetables has increased about 40 per cent since 1911, while the consumption of grain products and of potatoes has declined 30 per cent. These changes in the consumption of different foods could have resulted entirely from changes in the supplies of those foods causing the supply curves to cut the demand curves at different points from their previous points, the demand curves remaining unchanged. But the evidence points the other way. The greatest reduction in labor costs have been made since 1910 in the production of field crops such as grain and potatoes, and the least, in the case of fruits and vegetables,

'Harold Barger and Hans H. Landsberg, American Agriculture, 1899-1939: A Study of Output, Employment, and Productivity. National Bureau of Economic Research, 1942, p. 309. 
dairy products and other animal products. ${ }^{8}$ This indicates that changes in demand induced most of the changes in production (and consumption) shown in Figure 4.

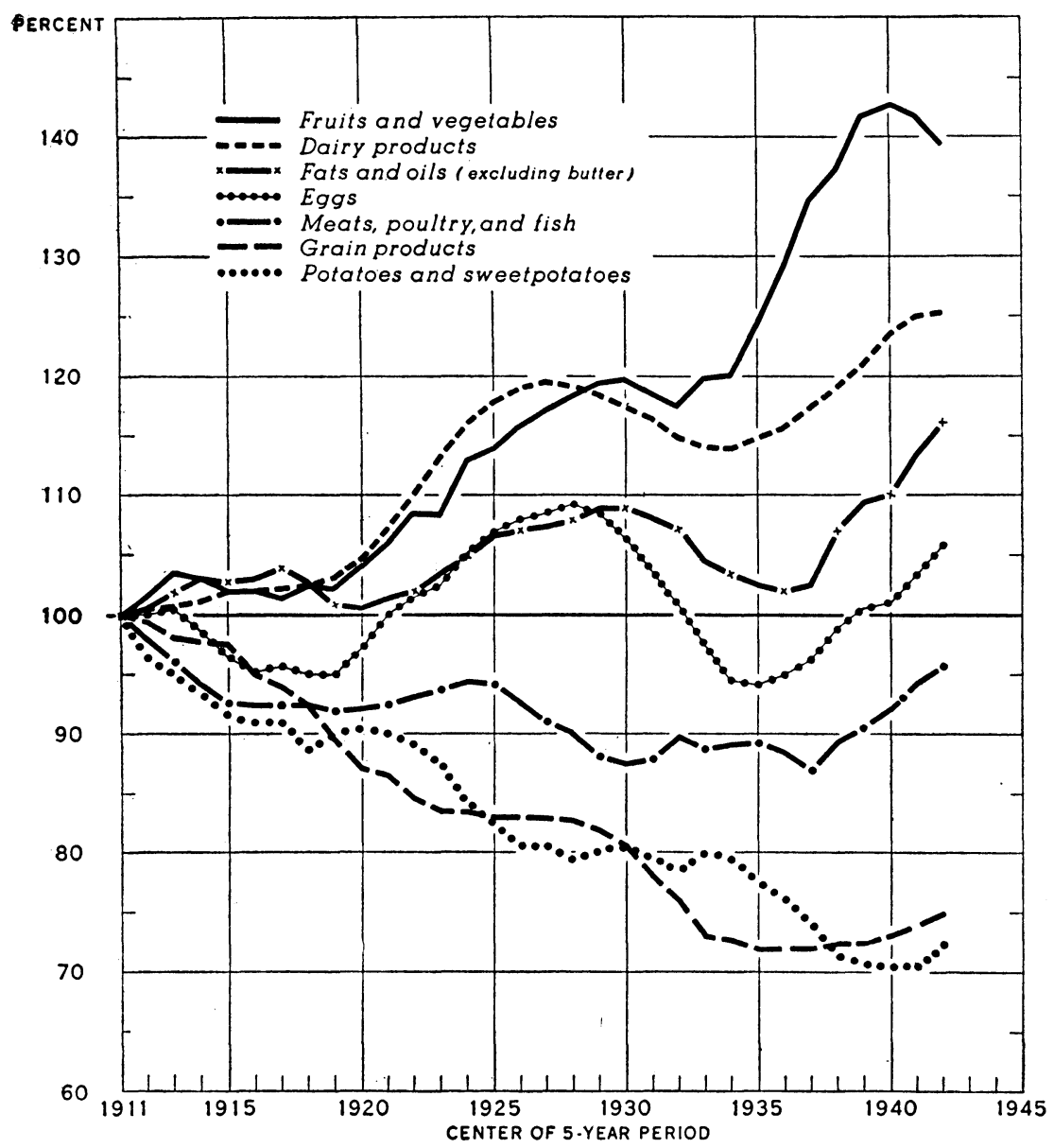

U. S. DEPARTMENT OF AGRICULTURE

NEG. 43787 BUREAU OF AGRICUUTURAL ECONOMICS

Fig. 4.-Trends in per capita consumption of foods, by groups. Five-year moving averages $(1909-13=100)$.

${ }^{8} \mathrm{John}$ A. Hopkins, Changing Technology and Employment in Agriculture, BAE, USDA, May, 1941, pp. 118 and 123. J. C. Schilletter, Robert B. Elwood, and Harry E. Knowlton, Vegetables, WPA, National Research Project, September, 1939, p. 85. 
These changes in demand apparently resulted from the steady shift out of muscular occupations into sedentary ones; from nutritional education; and in some cases, from advertising.

An important factor that affects the per capita demand for food as a whole, as well as the relative demand for different foods, is income. If income changes, the demand for food changes. The relation between the two changes is examined in the next section.

\section{LONG-TIME ELASTICITIES OF SUPPLY AND DEMAND}

The effects of long-time changes in supply and demand depend upon the long-time elasticities of supply and demand as well as upon the extent of the change.

Supply: The long-time elasticity of supply of farm products is unknown. Only a very rough estimate of it can be made.

During World War I, agricultural prices more than doubled. Agricultural production, however, increased only 5 per cent. During World War II, agricultural prices nearly doubled. The total acreage in crops increased very little over the 1935-39 average, (only 1 or 2 per cent) but total agricultural production increased about 33 per cent. ${ }^{9}$ Most of this increase resulted from other things than high prices-good weather (especially as contrasted with poor weather in 1935-39), technological progress, the large carryover of grains from earlier years, patriotism, etc. Perhaps only one-third to one-half of the increase resulted from the 100 per cent rise in prices. If so, the elasticity of supply would be only 0.1 or 0.16 .

Over a longer period of years, and with other prices constant, the elasticity of agricultural supply probably would be higher than this-perhaps two or three times as high. But that would still leave it below 0.5. ${ }^{10}$

The elasticity of agricultural supply when prices decline is probably smaller than when prices rise. It is harder to drive land out of production by low prices than to bring it in by high prices. In cases where prices and employment are declining in other industries as well as in agriculture, for a few years at least the elasticity of supply is likely to be negative. From 1929 to 1932, while

\footnotetext{
- Agricultural Statistics, 1944, pp. 408 and 423.

${ }^{10}$ Gerhard Tintner, in a paper designed to demonstrate a method of statistical analysis rather than to reach conclusions useful for policy makers, comes up with an estimate of the elasticity of agricultural supply of 6.401. But he hastens to add: "This estimate seems much too high." Gerhard Tintner, "Multiple Regression for Systems of Equations," Econometrica, XIV, No. 1, January, 1946, p. 36.
} 
agricultural prices were drastically declining, the total acreage of fifty-two crops planted in the United States increased each year over the preceding year. ${ }^{11}$ If other prices had not been declining also, it is probable that the acreage would have decreased, rather than increased. But how much it would have decreased, it is impossible to say. One can only estimate that the average long-time elasticity of supply must be low, probably below 0.5 .

Demand: Later chapters of this book show that the short-time (year-to-year) elasticity of demand for most individual farm products (at the farm) is less than unity. The long-time demand probably is more elastic than this; people will change their consumption of different products more in one direction over a period of years than they will back and forth from year to year.

On the other hand, the demand for food as a whole undoubtedly is less elastic than the demand for any one food item. If the supply of pork decreases, for example, consumers will turn to other meats, and to other foods than meats, rather easily; but if the supply of other foods decreases too, consumers will pay high prices in an attempt to avoid having to get along with less total food. Thus the long-time elasticity of the demand for food at the farm may even be lower than the short-time elasticities of most individual farm products.

Studies of the relation between income and expenditures for food throw a little more light on this matter. The income-elasticity of food expenditures is variously estimated.12 Schultz uses a rough average, 0.25 . The sources he quotes seem to us rather to indicate a figure of about 0.4 over the income range that includes the bulk of the people in the United States. Some of the most recent data show a considerably higher elasticity than this-about 1.06 for the income range $\$ 545-\$ 994$, about 0.95 for the range $\$ 545-\$ 3,979$, and about 0.54 for the range $\$ 3,979-\$ 11,941 .^{13}$ This relation is shown graphically in Figure 5.

In any case, the price-elasticity for food must be somewhat greater than this income-elasticity. Changes in income have much

\footnotetext{
${ }^{11}$ Agricultural Statistics 1944, USDA, p. 408.

${ }^{12} \mathrm{~A}$ dozen or more authors' estimates are referred to, for instance, in T. W. Schultz, Agriculture in an Unstable Economy, McGraw-Hill, 1945, pp. 65-68.

${ }^{13}$ Willard W. Cochrane, High-Level Food Consumption in the United States, BAE, USDA Misc. Pub. No. 581, p. 33. These computations are based on data from A. C. Hanson and J. Cornfield, Spending and Saving of the Nation's Families in Wartime, U. S. Bur. Labor Statistics Bul. 723, Washington, 1942.
} 
the same effect on the proportion of income spent for food as changes in the level of all prices with income constant. And the effect would be greater if only the level of agricultural prices changed. Thus the price elasticity of the demand for food probably exceeds 0.4 ; but nobody knows for sure how much it exceeds 0.4 . The elasticity may lie between 0.6 or 0.8 , the figure used by the USDA a few years ago. ${ }^{14}$ Or it may be as high as 0.9 or 1.0 , the figure indicated by the most recent income studies.

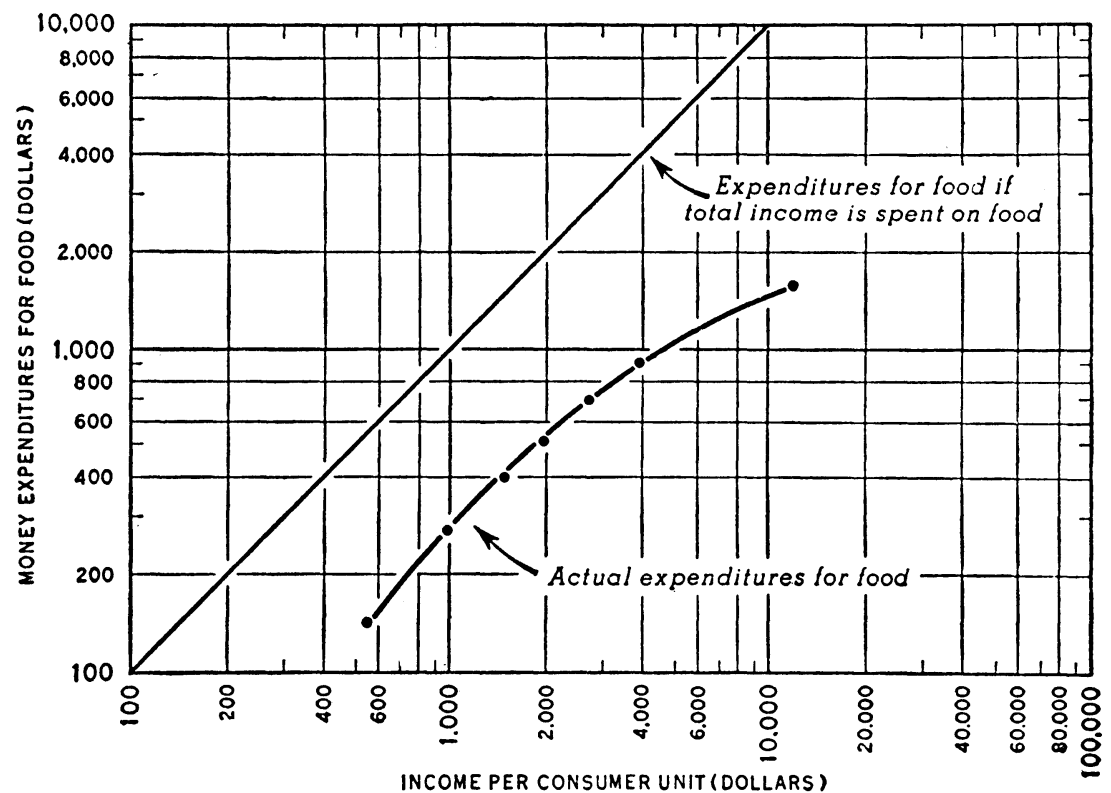

Fig. 5.-Total expenditure for food related to income, all family and single consumer units, United States, 1941. (Source, USDA Misc. Pub. 581, 1945, p. 34.)

This is the elasticity at the retail store. Farmers get about half of the consumer's dollar spent for food, and the marketing margin varies less in dollars and cents than retail food prices vary. ${ }^{15}$ The elasticity of the demand for food at the farm, therefore, must be less than the elasticity at the retail store.

Finally, a considerable proportion of farm products is fiber

${ }^{14}$ USDA, Report of the Interbureau Planning Committee on Distribution Programs, December, 1941, mimeo., pp. 44 and 59.

${ }^{15}$ Price Spreads Between Farmers and Consumers for Food Products, 1913-44, BAE, USDA Misc. Pub. No. 576, 1945, pp. 22-24. 
(used for clothing and other purposes), not food. If agricultural fiber becomes scarce, it is easier to replace it by nonagricultural fiber than it is to substitute other things for food if food becomes scarce. The demand for farm products, therefore, must be somewhat more elastic than the demand for food alone.

It is difficult to sum up all this in a sentence. Perhaps about the best that can be done is to say that the elasticity of the demand for food, at farm prices, probably is higher than 0.5 but lower than 1.0.16

\section{PROSPECTS FOR THE FUTURE}

In the light of the analysis of past agricultural prices movements given above, what are the prospects for agricultural prices over the predictable future?

${ }^{16}$ This raises an interesting question. If the demand for agricultural products is inelastic, a large production brings in a smaller total income to agriculture than a small production. Technological improvements in agriculture that increase agricultural production, therefore, leave agriculture with a smaller gross income than before.

Suppose, for instance, that agricultural gross income is 10 billion dollars, and that an increase in agricultural production of 10 per cent lowers agricultural prices 15 per cent. Agricultural gross income then would fall from 10 billion to . $110 \times 85=9.35$ billion dollars. This would be a decline of 6.5 per cent.

Would agriculture improve its position, therefore, by waging a campaign against technological improvements in agriculture?

It would of course be impossible to enforce such a program. Native Yankee ingenuity on six million farms would continue to figure out better ways of producing things. And this activity would not be limited merely to mechanical gadgets. A Pfister would still, as an individual, develop such things as hybrid seed corn, as he did during the 1920's. Agriculture would hardly try to police all its members and forcibly head off that sort of ingenuity.

Would agriculture benefit in any case, if it were possible to police six million farmers?

In the short run, "agriculture" might. "Agriculture" might retain a higher share of the national income by producing only one blade of grass instead of two. But that would not benefit individual farmers, and it would obviously harm the rest of the economy. It would not benefit individual farmers, for the birth rate in agriculture is higher than necessary to provide enough farmers to grow the food and fiber needed by the nation as a whole, and a steady stream of people must move off the farm to keep agriculture from becoming overcrowded. Increasing agriculture's share of the national income would merely slow down the emigration from agriculture and the larger share would simply be divided into smaller pieces.

If technological progress were stopped and agricultural production ceased to expand, the increase in total population in the United States would continue to increase the demand for farm products. That would increase total agricultural income, perhaps 5 per cent within ten years. But the effect would be merely to slow down the rate of movement off farms, to the point where income per farmer would remain about the same as before. The thing that keeps individual farmers' incomes at all in line with urban incomes is the movement of surplus farmers off farms. Measures that reduced or stopped this movement would defeat themselves, and leave the rest of the nation of course worse off than before. 
Supply: It was shown above that most of the factors causing the recent increase in agricultural production were permanent factors. After only a slight and temporary recession, therefore, most of the increase in production will persist. Further increases are likely to take place as further improvements are made in production practices.

The supply of agricultural products is likely to continue to increase in the future, at about the same rate as it has since about 1900 , and for the same reasons. By 1900 most of the farming territory in the United States was settled. Most of the increase in agricultural supply since that time has resulted from improvements in production practices, and further improvements are likely to continue to be made in the future. For some time to come, agricultural supply is likely to continue to increase at its twentieth century rate of about 1 per cent per year.

Demand: The domestic demand for farm products, however, is likely to increase less rapidly than the supply.

The chief determinant of the demand is the size of the population. The rate of population growth has been slowing down, and this slowing down is likely to continue in the future. The rate of population growth already has declined below 1 per cent per year. It already is increasing less rapidly than the supply is increasing, and the difference between the two rates of increase is likely to become greater in the future.

It is unlikely that increases in per capita income will be great enough to offset the relative decline in the rate of population growth (relative to the rate of increase of agricultural supply). This means that the long-time trend of agricultural prices in the future is likely to decline.

Before World War I, most people believed that the prices of farm products in the United States, and the prices of farm land, would continue to rise in the future relative to other products, much as they had risen in the past. This seemed the more likely since most of the farm land in the United States had been taken up by that time, and the previous rapid expansion in farming area had about reached its limits.

Events after World War I, however, rudely shook this belief. Some of these events, such as the passage of the immigration laws, could not well have been foreseen. In any case, agricultural prices 
by 1938 and 1939 were lower than they had been in 1909-14, in dollars and cents; and they were 25 per cent below parity.

It took another war (World War II) to bring agricultural prices up again. There is every reason to suppose that within a few years after World War II, agricultural prices will decline again toward their prewar levels. The long run outlook is for prices to decline still further. 


\section{CHAPTER 2}

\section{Short-Time Changes in Agricultural Prices}

Over a long period of time, as Figures 1 and 2 show, agricultural prices have gradually risen and then fallen relative to nonagricultural prices. In addition to this long-time, gradual dissimilarity of price movements, there is a more marked dissimilarity within short periods of a decade or so in length. Over these shorter periods of time, agricultural and nonagricultural prices may move in opposite directions, or at least move different amounts in the same direction, more markedly than they do over long periods of time.

This dissimilarity of short-time movements is clearly revealed if attention is focused on the movements of agricultural and non-

INDEX NUMBERS $(1910-14=100)$

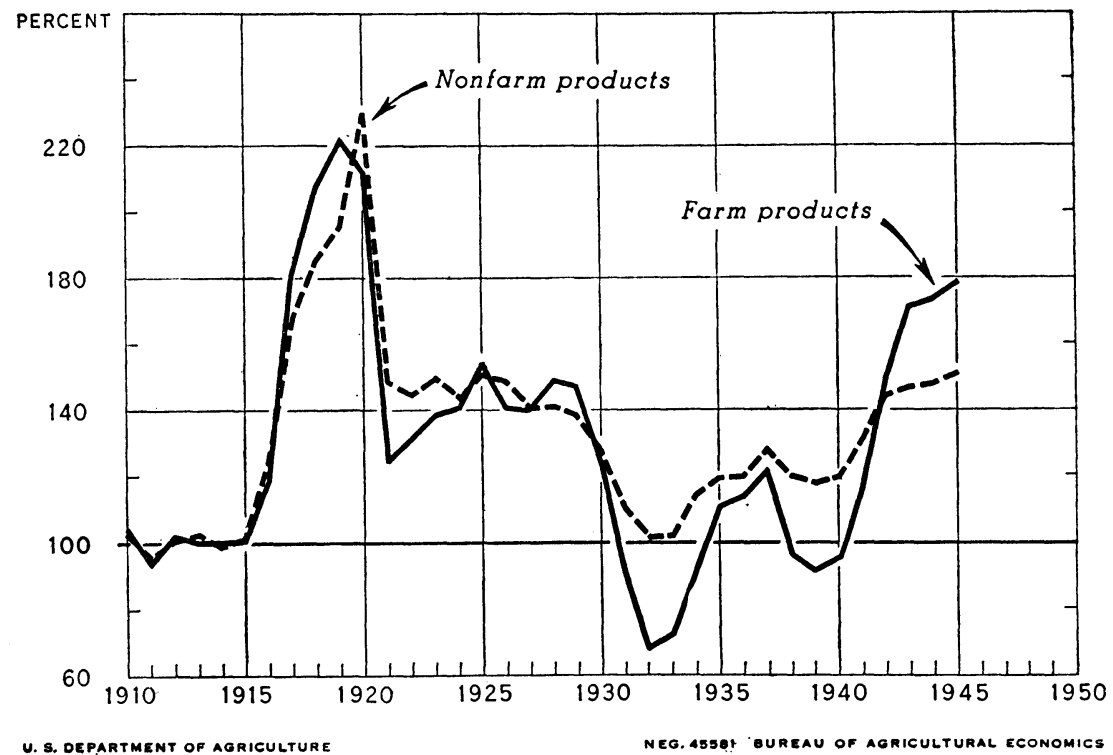

Fig. 6.-Wholesale prices of farm products, and of all commodities other than farm, United States, 1910-45. Index numbers $(1910-14=100)$. 
agricultural prices during the past twenty years. These movements are shown in Figure 6, on a larger scale than was possible in Figure 1. The basic data are the same as those shown in Figure 1.

The chief difference between the movements of agricultural and nonagricultural prices over the past thirty years is shown in Figure 6 to be the difference in the amplitude (size) of their movements. During World War I the two price series rose to about the same extent, but since that time agricultural prices have fluctuated about twice as much (that is, over about twice as great a range) as nonagricultural prices. This was true during World War II as well as during peacetime (nonagricultural prices were held down more by price controls during the war than agricultural prices were).

\section{WHY ARE INDUSTRIAL PRICES MORE STABLE THAN AGRICULTURAL PRICES?}

Why are nonagricultural prices (or to use a less clumsy term, industrial prices) so much more stable than agricultural prices?

It is not because the demand for industrial products is more stable than the demand for agricultural products. The demand for industrial products fluctuates as much as the demand for agricultural

INDEX NUMBERS $(1910-14: 100)$

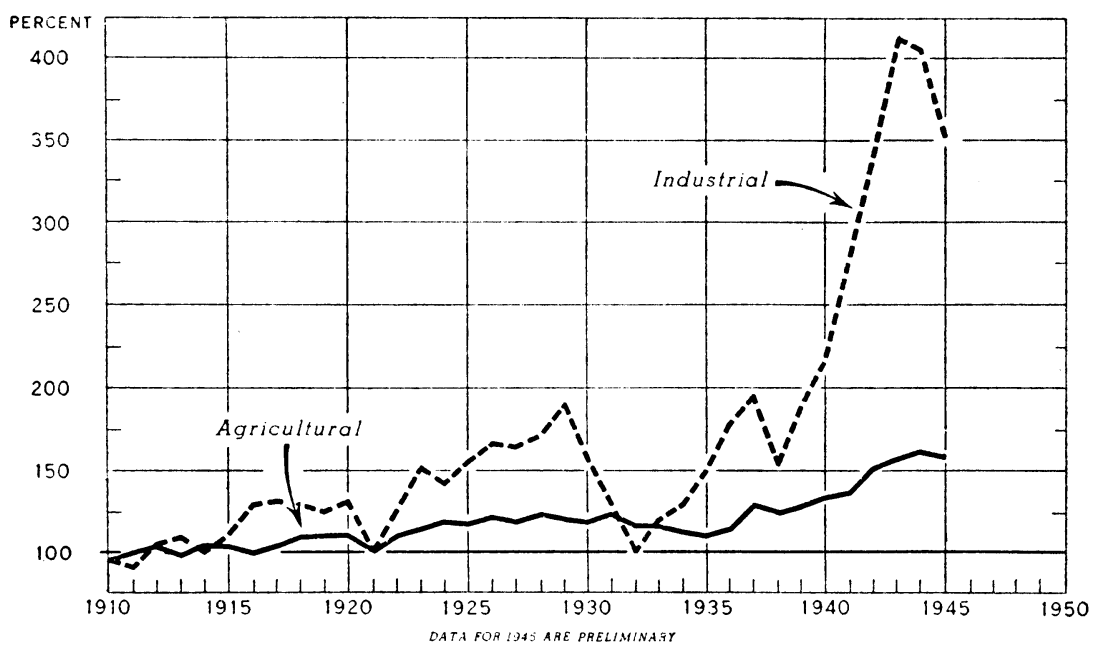

Fig. 7.-Volume of production: Agricultural and industrial, United States, 1910-45. Index numbers $(1910-14=100)$. 
products-perhaps more. The reasons for the comparative stability of industrial prices must-lie in the conditions of supply.

Figure 7 shows that this is true. The production of industrial products has fluctuated widely, while the total production of farm products, in spite of the effects of the record-breaking drouths of 1934 and 1936, has remained comparatively stable.

This chart shows that industrial prices are comparatively stable, in spite of the great fluctuations in demand that go with prosperity and depression, because industrial production fluctuates greatly and concurrently with those fluctuations in demand. The changes in demand are largely offset, in their effects on price, by corresponding changes in supply. The chart also shows that agricultural prices are unstable because agricultural production remains comparatively constant in the face of great fluctuations in demand. The small changes in agricultural production that do take place result chiefly from changes in such physical things as weather, and show practically no correlation with fluctuations in demand. Since agricultural supply is relatively constant, great fluctuations in demand cause great fluctuations in agricultural prices.

The question, therefore, boils down to this. Why is agricultural production stable, in spite of great cyclic changes in demand, and why is industrial production unstable, fluctuating with cyclic changes in demand?

\section{WHY DOES AGRICULTURAL PRODUCTION REMAIN STABLE WHEN DEMAND FLUCTUATES?}

It may seem strange that agricultural production remains stable when demand fluctuates greatly. Elementary economic theory teaches that under a freely competitive system, with positive sloping supply curves, a decrease in demand reduces prices; and this reduces production to the point where equilibrium between costs and prices is restored, at lower levels than before. An increase in demand brings about similar but opposite adjustments.

But this is true only of long-time changes and adjustments. Things work out differently when the changes in demand are severe and sudden. So high a proportion of the costs in agriculture are fixed that once the investment is made, when prices decline suddenly the farmer cannot reduce his costs much by reducing his production. In fact, in the face of falling prices he may attempt to meet his fixed costs by producing more, not less. 
The situation is complicated by the further fact that in the short run a farmer has even less control over the prices at which he sells his products than he has over his costs of production. If he does reduce production, as an individual act, that will have no appreciable bolstering effect on the prices of his products. If all farmers reduced production, that would at least reduce the fall in agricultural prices. But since no one farmer has any assurance that the bulk of his competitors (other farmers) will reduce their production, he dares not reduce his; so nobody reduces production.

Even nation-wide programs for reducing agricultural production, organized by the federal government, have not been very successful. The AAA programs of the 1930's reduced the acreage of cotton, wheat, corn, etc., by percentages ranging from 10 to 40 , but yields per acre increased (partly as a result of the reductions in acreage). Except for cotton, production was not reduced appreciably below previous levels.

Conversely, when agricultural prices rise, agricultural production as a whole cannot expand very much. The expansion during World War I was slight_-only about 5 per cent. During World War II, the expansion was considerably greater-about 33 per cent-but a large share of this expansion was the result of good weather, a large carryover of feed grains, etc., as shown in the preceding chapter. The plain fact is that agricultural production runs close to capacity all the time, and cannot be expanded much under any circumstances. Livestock production, for example, is limited by livestock feed production, and that cannot be expanded much. Additional fertilizer can be applied if prices are high, and land farmed somewhat more intensively, but the agricultural "plant" cannot run more than twenty-four hours a day, and only very small additions to the plant can be made. To put it in a sentence: The shorttime elasticity of agricultural supply is low-even lower than the long-time elasticity, which we saw was probably less than 0.5 .

Agriculture, then, faces an inelastic short-time demand for its products with an inelastic short-time supply. Under those conditions, a small change in either demand or supply causes a large change in price. Until some means is found for keeping the demand for farm products more stable than it has been in the past, the shorttime changes in agricultural prices are likely to continue to be violent. 


\section{REASONS WHY INDUSTRIAL PRODUCTION FLUCTUATES WITH FLUCTUATIONS IN DEMAND}

Industrial production is not stable like agricultural production. It fluctuates concurrently with fluctuations in demand. This offsets or at least reduces the effect of fluctuations in demand upon industrial prices.

Why does industrial production fluctuate with fluctuations in demand, while agricultural production remains stable?

The answer to this question has been phrased by some economists in terms of the amount of administrative control existing over production and prices in the different industries. As goods move from the raw-materials stage through successive stages of fabrication and distribution to the consumer, the market for each product narrows down. This narrowing down may be geographical, or it may be functional (i. e., the uses of the product may become more restricted) or both. Thus wheat can be produced for a world market, but fresh-baked bread in one city cannot well be supplied to another more than one hundred or two hundred miles away. That is a geographical limitation. In addition, wheat as grain can be used for stock feed, chicken feed, seed, or flour. But once it has been made into flour it cannot be used for any other purposes; and once the flour has been baked into bread it cannot be used to make crackers or macaroni. That is a functional limitation.

This geographical and functional narrowing down of the market reduces the number of processors in each successive market stage. This tendency is reinforced by the economies of large-scale manufacturing or processing plants as contrasted with the economies of small-scale farms where the product was originally grown. The most efficient farm unit is small; the family-sized farm is still dominant. But the most efficient flour mill or steel mill or aluminum plant is very large (before World War II, four plants supplied all the new pig aluminum produced in the United States). It takes a million wheat farmers to supply the wheat market. But a few hundred or thousand flour mills supply the flour market, and a few bakers supply a small town or city market with bread.

"This same tendency appears in industry after industry: as cotton moves into yarn, into cloth, into clothing, onto the shelves or racks of the local store; as iron ore moves into pig iron, into steel, into particular standard shapes, and finally into a place in a particular building; and as timber moves into wood pulp, into paper, into a 
printed book, and onto the counter of a local drug store. Sometimes there is a return flow as the worn-out auto reappears as scrap iron or as the book is collected as waste paper, but on the whole the market for goods at each successive stage tends to be narrower, sometimes geographically, sometimes functionally, and sometimes both."1

The narrowing down of the market and the increasing size of the business unit both operate to reduce the number of processors in successive market stages. This reduction in number of business units makes it easier for them to exert some administrative control over prices. Each one of the million wheat, or cotton, or corn, or hog farmers has to take the market price for his product; but farther along the line, the number of processors gets small, and they are in a position to exercise some control over their prices.

This may or may not involve outright collusion, or complete concentration into one unit such as exists in the case of nickel and virgin aluminum. The arrangement may be very loose and informal, perhaps reinforced by patents or through control of natural resources or through strategic location. However the arrangement is maintained, it results in more or less complete administrative . control over prices. It is "abundantly clear that a considerable degree of administrative control is inherent in the narrowing of markets and the willingness of buyers to accept the one-price system of American merchandising. Further administrative control is implicit if the efficiencies of modern technology are to be realized. Only to the extent that administrative controls arise from collusion between enterprises or through the bringing of production under common control beyond the extent necessary for efficient operation is there an opportunity to reduce the existing degree of administrative control without incurring a cost of decreased efficiency in the use of resources. Thus a considerable degree of administrative control over prices appears to be inherent in the modern economy. Administered prices and their depression insensitivity seem to be an integral part of the structure of economic activity. With the centurylong transition of this country from a predominantly agricultural to a predominantly industrial country, the administration-dominated. prices of industry have gradually displaced the market-dominated prices of agriculture as the more characteristic form of price. As recently as 1870 , over half of the gainfully employed workers in the

1 The Structure of the American Economy, Part 1. Basic Characteristics, U. S. National Resources Committee, 1939, p. 144. 
United States were engaged in agriculture, whereas in 1930 little over a fifth were so engaged. However much of a role price administration may have played in the earlier years of this century, there can be little question that it plays a dominant role today."

Further investigation of the behavior of industrial prices requires the application of analytical concepts in the theory of imperfect or monopolistic competition. This application is made in later chapters.

\section{PROSPECTS FOR THE NEAR FUTURE}

The conclusion was reached at the end of the preceding chapter that agricultural prices, were likely to decline relative to other prices over the long run in the future. What are the prospects over the shorter run-over the next five or ten years?

Figure 8 shows that agricultural prices during World War II rose almost as much as they did during World War I; they nearly doubled. After the end of World War II, they rose more than they did after World War I. But the prices of nonfarm products during World War II rose only about 20 per cent, whereas in World War I they rose nearly 100 per cent. Only after the end of World War II did they rise sharply.

If all prices during and after World War II had risen 100 per cent there would be some grounds for believing that they might all remain high after the war-although not much grounds, for agricultural prices normally rise during war and fall afterwards. But only the prices of farm products rose 100 per cent, and they have a weight of only 17 per cent in the total index of all wholesale prices; that is, only 17 per cent of the weight in the total index has risen 100 per cent. Food products, whose prices are dependent mainly on the prices of farm products, have a weight of 18 per cent. The prices of other commodities, with the remaining weight of 65 per cent, rose only 20 per cent during World War II, and only 30 per cent shortly after the end of the war.

Farmers during the war lived in an atmosphere of high prices for their products, and they were inclined to suppose that all prices were up about like theirs. If that had been true, that would have made it more likely that agricultural prices would remain permanently high after the war. But Figure 8 shows how agricultural prices rose more than other prices. The two price indexes will probably come together again after the war (or cross over, as they did after World War I). And when they come together or cross

\footnotetext{
${ }^{2}$ Ibid., p. 145.
} 
over, it seems likely that most of the readjustment will be made by a marked decline in the relatively unimportant agricultural prices

UNITED STATES, 1914-23 AND 1939-46

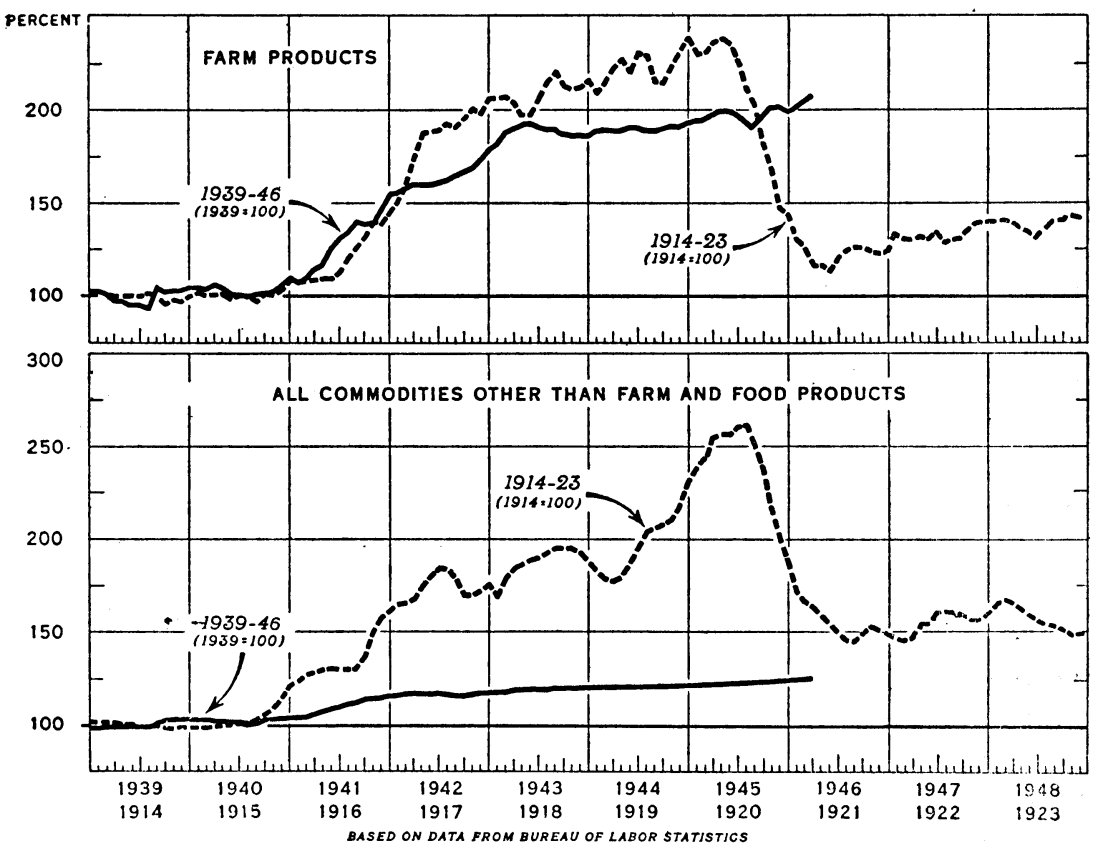

U. S. DEPARTMENT OF AGRICULTUAE

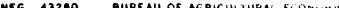

FIG. 8.-Wholesale prices of farm products, and of all commodities other than farm and food products, United States, 1914-23 and 1939-46. $(1914=100$ and $1939=100$, respectively).

that have a weight of only 17 in the general index, and by only a comparatively small rise in the levels of the nonagricultural prices, with their weight of 65 .

Thus if the reconversion to peacetime conditions is made without any postwar depression developing at all; if employment and industrial activity are maintained at about the levels existing just before the war; the probabilities are that even so, agricultural prices will decline toward the levels of nonagricultural prices. During the war these nonagricultural prices rose only about 20 per cent higher than they were before the war, and only about 10 additional points just after the war. If agricultural prices return to similar levels, they will not be much more than half as high as they were during and immediately after the war. 
A few price data will make clear what this means in dollars and cents. Most of the time from 1943 to 1946 (before the OPA was finally abandoned) the price of hogs at Chicago ranged between $\$ 13$ and $\$ 15$ per one hundred pounds. ${ }^{3}$ Prices before the war were less than half as high as this; in 1940 they averaged only $\$ 5.71$, and in 1939 they averaged only $\$ 6.57$. Similarly, most of the time from 1943 to 1946 , the farm price of wheat ranged between $\$ 1.30$ and $\$ 1.60$ per bushel; ${ }^{4}$ in 1940 it averaged only 68.2 cents, and in 1939 it averaged only 69.1 cents.

Even if full employment (a condition only rarely attained in the past) is maintained for several years, the BAE has estimated that "allowing ... for moderate improvements in technology between now and 1950, all the products required to meet foreign and domestic demand at that time under conditions of full employment could be produced on 327 million acres of cropland or about 23 million acres less than was used in 1943. This suggests the possibility that agricultural production generally might outrun demand even under full employment.

"A government program to supplement the diets of low-income people would provide an outlet for the product of additional cropland totaling about 5 million acres.

"Should unemployment reach such a huge total as 17 millions, a level for 1950 comparable to that reached in the early thirties, the national income would be hardly more than one-third of what it would be under full employment, and agriculture would be prostrate again-as it was then.

"Even conditions under which 7 millions of the 60 million workers were out of work would create great difficulties for agriculture. Farm income would fall to two-thirds of what it would be under full employment, the average level of farm prices would be only threefourths as high, and the parity ratio for average farm prices would stand as less than 90 per cent.

"The net conclusion from all this is that with full employment the postwar adjustments required in agriculture will be manageable but that the difficulties will multiply as the number of unemployed is increased."

\footnotetext{
${ }^{3}$ Livestock, Meats, and Wool Market Statistics and Related Data, p. 47.

${ }^{4}$ Agricultural Statistics, USDA. 1945, p. 9.

${ }^{5}$ What Peace Can Mean to American Farmers, USDA Misc. Pub. No. 562, 1945, p. 28.
} 


\section{CHAPTER 3}

\section{Cyclic Variations in Individual Agricultural Prices}

Under conditions of atomistic competition, the price and production of a commodity are determined at the point where the supply and demand curves intersect. Under static conditions a disturbance that moves the price and production from that intersection point sets in motion forces which tend to bring them back to the original point.

Where there is a considerable time lag in the response of production to a change in price, however, the price and production may not return to the original equilibrium point; instead, they may circulate around it.

A drouth, for example, which reduces the size of the corn crop, will raise the price of corn. Ordinarily, this induces farmers to raise fewer hogs. When those hogs reach the market the small size of the market receipts raises the price of hogs. This rise in the price of hogs induces farmers to raise more hogs; then when this large crop of hogs reaches the market, it depresses the price of hogs below

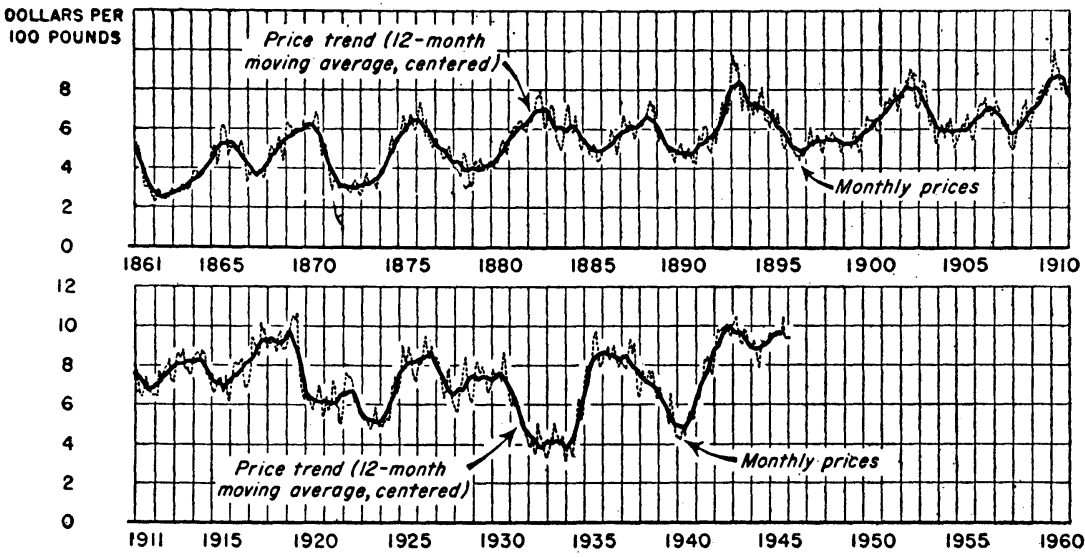

Fic. 9.-Cyclic changes in heavy hog prices at Chicago, 1861-1945, adjusted to 1909-14 prices level. 
the equilibrium point. This leads farmers to produce fewer hogs, and so on. The price and production of hogs continues to swing round and round the equilibrium point rather than settle at it.

Figure 9 shows that this in fact is what actually takes place. The figure shows that the price of hogs in the United States moves in characteristic cycles averaging about four years in length. These cycles in hog prices are caused by opposite cycles in hog production.

The situation is shown in terms of supply and demand curves in the upper part of Figure 10. ${ }^{1}$ The demand curve is represented by $D_{t} D_{t}^{\prime}$. It shows the schedule of prices received for various quantities.

The supply curve is represented by $\mathrm{S}_{\mathrm{t}} \mathrm{S}_{\mathrm{t}}{ }^{\prime}$. It shows the quantities that farmers will produce in response to various prices. But these quantities do not reach the market until a production and marketing period has elapsed. $O Q_{1}$ is the quantity that sets the price in period 1 (the first crop-disposal year), but $O Q_{2}$ is the quantity produced in period 2 (the second crop-disposal year) in response to the price in period 1 . These two quantities are by no means identical; they may be quite different, as they are in this case. The two curves shown in Figure 10 lie in two different planes reflecting two different time periods. They do not intersect; the one laps over the other.

\section{THE "COBWEB THEOREM"}

This situation has been given a generalized explanation, referred to as the "cobweb theorem."

\section{CASE 1: CONTINUOUS FLUCTUATION}

In the lower portion of Figure 10, the series of reactions is portrayed for the curves shown in the upper portion of the figure. The quantity in the initial period $\left(Q_{1}\right)$ is large, producing a relatively low price where it intersects the demand curve, at $P_{1}$. This low price, intersecting the supply curve, calls forth in the next period a relatively short supply, $Q_{2}$. This short supply intersects the supply curve at a high price point, $\mathrm{P}_{2}$. This high price calls forth a corresponding increased production $\mathrm{Q}_{3}$ in the third period, with a corresponding low price, $\mathrm{P}_{3}$. Since this low price in the third period is identical with the original price in the first period, the production

${ }^{1}$ This figure and Figures 11, 12, 13, and 19 are reproduced from Mordecai Ezekiel, "The Cobweb Theorem," Quarterly Journal of Economics, LII, February, 1938. Part of the discussion is based on this excellent article. 

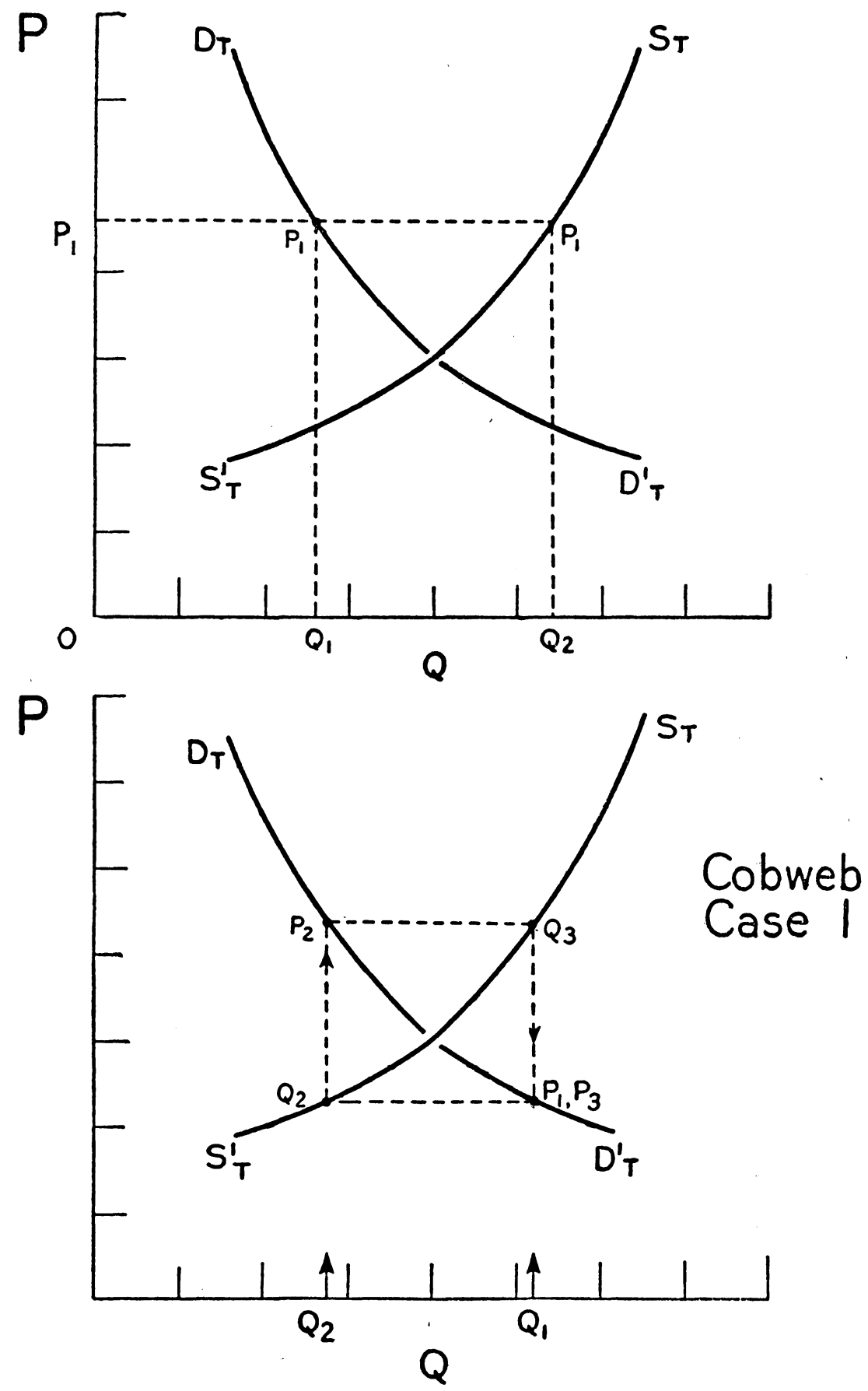

FIG. 10.-The mechanics of continuous cycles in prices and production. (From Ezekiel, see footnote 1, page 30.) 
and price in the fourth, fifth, and subsequent periods will continue to rotate around the path $Q_{2}, P_{2}, Q_{3}, P_{3}$, etc.

As long as price is completely determined by the current supply, and supply is completely determined by the preceding price, fluctuation in price and production will continue in this unchanging pattern indefinitely, without an equilibrium being approached or reached. This is true in this particular case because the demand curve is the exact reverse of the supply curve, so that at their overlap each has the same elasticity. This is a case of "continuous fluctuation."

\section{CASE 2: DIVERGENT FLUCTUATION}

Where the elasticity of supply is greater than the elasticity of demand, the series of reactions works out as shown in the upper portion of Figure 11. Starting with the moderately large supply, $Q_{1}$, and the corresponding price, $\mathrm{P}_{1}$, the series of reactions is traced by the dotted line. In the second period, there is a moderately reduced supply, $\mathrm{Q}_{2}$, with the corresponding higher price, $\mathrm{P}_{2}$. This high price calls forth a considerable increase in supply, $Q_{3}$, in the third period, with a resulting material reduction in price, to $P_{3}$. This is followed by a sharp reduction in quantity produced in the next period to $Q_{4}$, with a corresponding very high price, $P_{4}$. The fifth period sees a still greater expansion in supply to $Q_{5}$, and so on.

Under these conditions the situation might continue to grow more and more unstable, until price fell to absolute zero, or production was completely abandoned, or a limit was reached to available resources (where the elasticity of supply would change) so that production could no longer expand. This is a case of "divergent fluctuation."

\section{CASE 3: CONVERGENT FLUCTUATION}

The reverse situation, with supply less elastic than demand, is shown in the lower portion of Figure 11. Starting with a large supply and low price in the first period, $P_{1}$, there would be a very short supply and high price, $Q_{2}$, and $P_{2}$, in the second period. Production would expand again in the third period, to $Q_{3}$, but to a smaller production than that in the first period. This would set a moderately low price, $\mathrm{P}_{3}$, in the third period, with a moderate reduction to $\mathrm{Q}_{4}$ in the fourth period; and a moderately high price, $\mathrm{P}_{4}$. Continuing through $Q_{5}, P_{5}$, and $Q_{6}$ and $P_{6}$, production and price approach more 
$P$
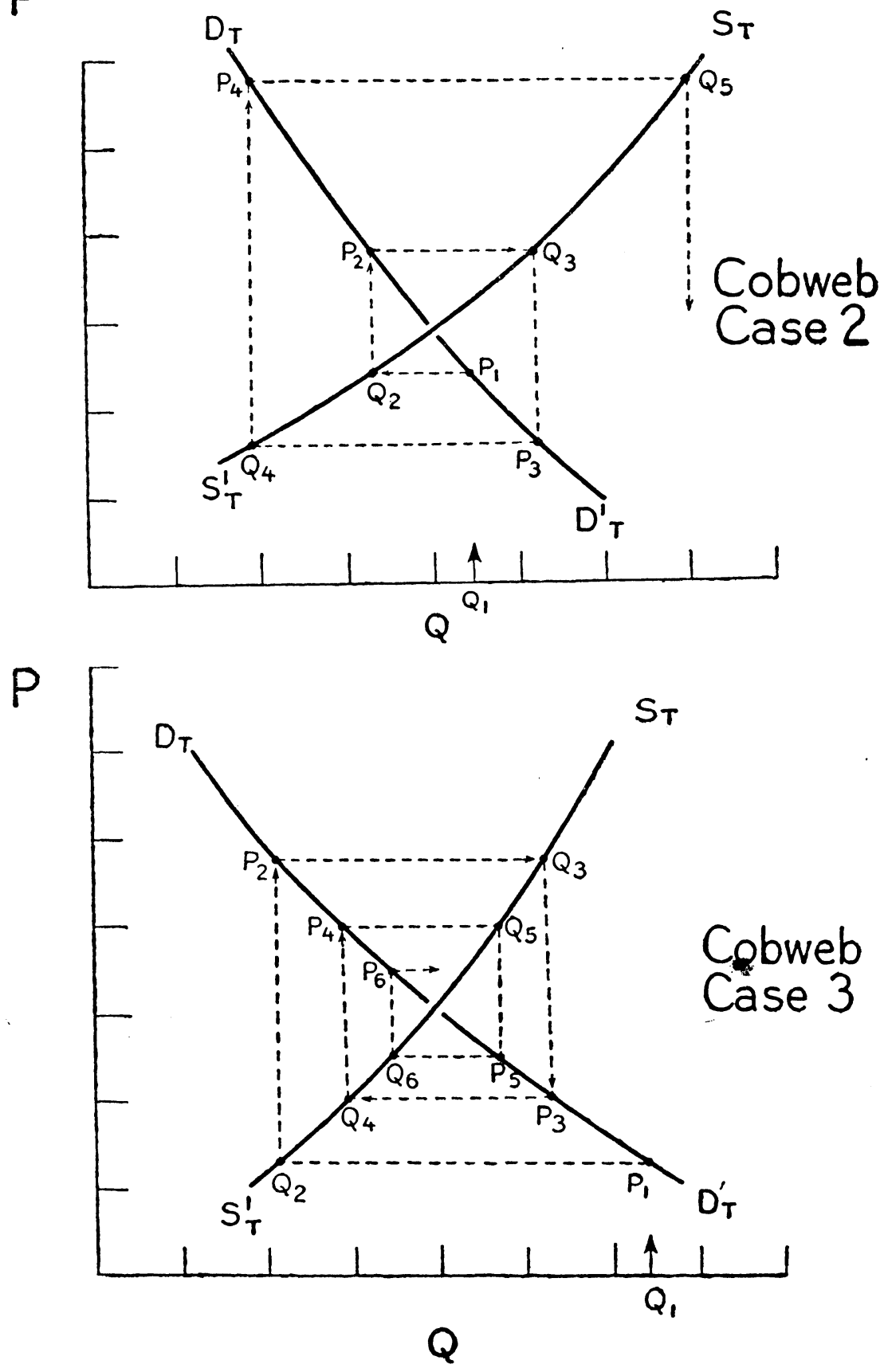

FIG. 11.-The mechanics of divergent and convergent cycles in prices and production. (From Ezekiel, see footnote 1, page 30.) 
and more closely to the equilibrium condition where no further changes would occur.

Of the three cases considered thus far, only this one behaves in the manner assumed by equilibrium theory; and even it converges rapidly only if the supply curve is markedly less elastic than the demand curve. This is a case of "convergent fluctuation."

\section{LONG CYCLES}

The cobweb theorem as developed above explains two-year cycles in production and prices, alternating up one year and down the next. It does not fully explain the longer cycles observed for some commodities; that requires a further extension of the cobweb analysis.

In the cases considered thus far, it has been assumed that a change of price in one period was reflected in a corresponding change in production in the next succeeding period. In some commodities (such as hogs, beef cattle, apples, etc.) two or more seasons may be required for the production process, so that two or more periods may elapse before the effect of price upon production becomes apparent. If we assume that the effect of price upon production appears entirely in the second succeeding period, how will the "cobweb" work out? This further condition may be examined for any one of the three cases shown. The upper portion of Figure 12 shows it for Case 1. It may be regarded as Case 1 .

\section{CASE 1A: TWO-PERIOD LAG IN SUPPLY, CONTINUOUS FLUCTUATION}

Since two years are required for the result of the first year to appear, the supplies for the first two years, $Q_{1}$ and $Q_{2}$, must be assumed, with the resulting prices $P_{1}$ and $P_{2}$. In response to the initial low price, production two years later, in the third period, is reduced to $Q_{3}$, with the resulting high price, $P_{3}$. This is followed in the fifth year by a corresponding increase to $Q_{5}$, with a corresponding low price, $P_{5}$. Since this is a subclass of Case 1 , the reaction continues in alternate years around the same pathway, $P_{5}, Q_{7} ; P_{7}, Q_{9}$; etc. Likewise, the price and supply of the second year, $Q_{2}$ and $P_{2}$, are followed two years later by reduced supply, $Q_{4}$, and increased price, $\mathrm{P}_{4}$; four years later by $\mathrm{Q}_{6}$, and $\mathrm{P}_{6}$, and so on ad infinitum.

CASE 3B: THREE-YEAR LAG IN SUPPLY, CONVERGENT FLUCTUATION

A further illustration of delayed response may be developed by assuming a production period three years in length. This also may 

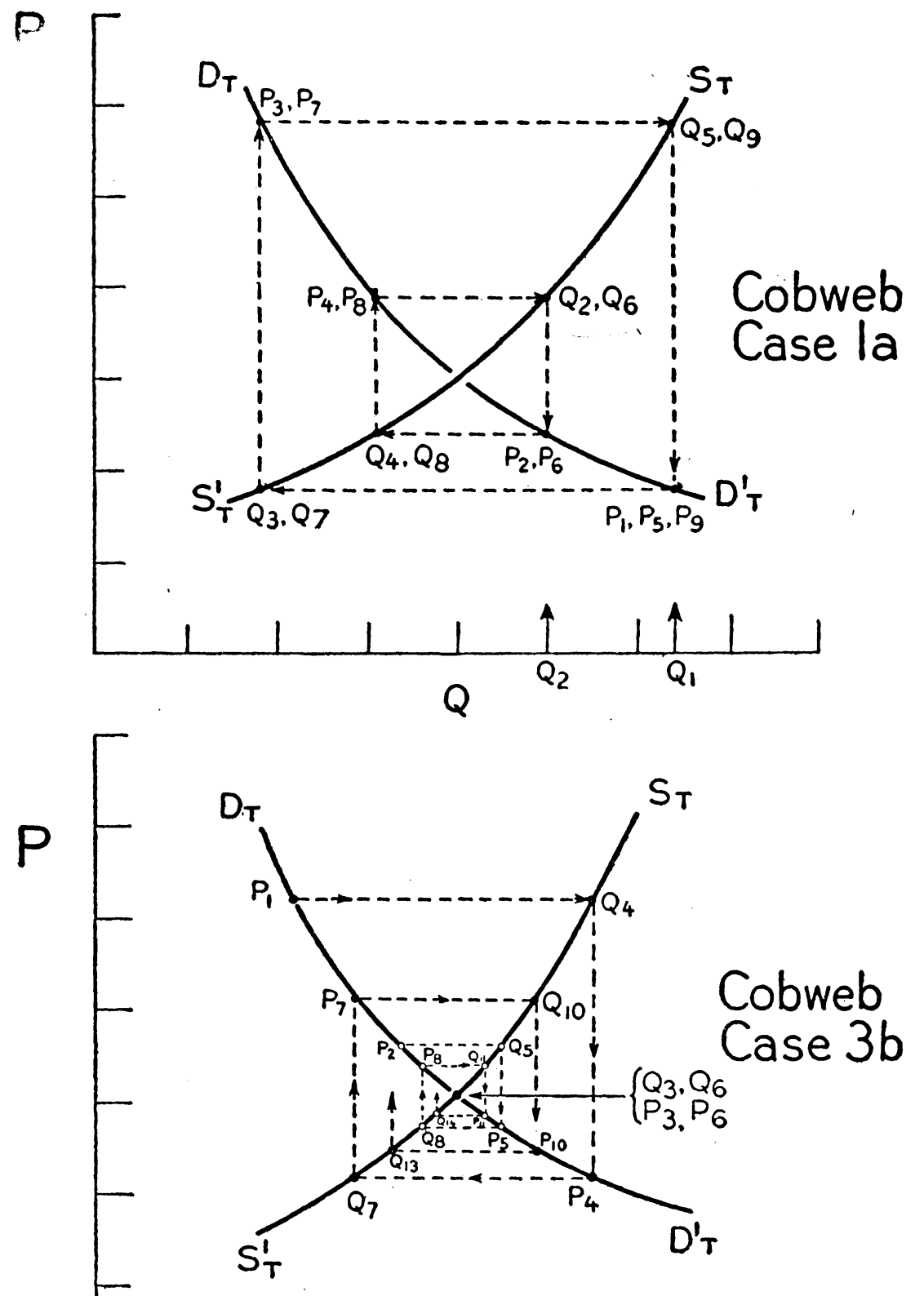
be combined with any of the three original cases. Applying it to the third case, results are secured as shown in the lower portion of Figure 12, which may be regarded as Case $3 \mathrm{~b}$.

Here three initial supplies are assumed: $Q_{1}$, very small; $Q_{2}$, moderately small; and $Q_{3}$, just equal to the normal supply. The corresponding prices, $\mathrm{P}_{1}, \mathrm{P}_{2}$ and $\mathrm{P}_{3}$, produce reactions in production three years later as shown: $Q_{4}$, a great expansion; $Q_{5}$, a moderate expansion; and $Q_{6}$, no expansion. The resulting prices, $P_{4}, P_{5}$, and $\mathrm{P}_{6}$, produce corresponding effects on production three years further on, at $Q_{7}, Q_{8}$, and $Q_{9}$; and so on. Since the case is of the convergent type, the "cobwebs" traced by the 1-, 4-, 7-, 10-series and the 2-, 5-, 8-, 11-series converge slowly, while the 3-, 6-, 9-series, starting at equilibrium, remains there.

Various other combinations could be developed by assuming even longer periods of response, or by making other combinations with the three basic cases.

\section{THE TIME SERIES TRACED BY PRICE AND PRODUCTION}

Figure 13, which is a time series chart of prices and production in the successive periods shown in Figures 10 to 12, reveals more clearly the cyclical character of the resulting processes. Cases 1,2 , and 3, with a one-year lag in response, all produce two-year cycles. The continuous, divergent, and convergent character of the three cases is clearly evident, both in production and in price. Case 1a, with a two-year lag in production, has a four-year period from peak to peak; and Case 3c, with a three-year lag, a six-year period. The continuous character of the cycle in Case 1a, and the slow convergence of the cycle in Case $3 \mathrm{c}$, are also apparent.

\section{ILLUSTRATIONS OF CYCLIC BEHAVIOR}

It is interesting to compare this synthetic time series with the actual price and production cycles for some specific commodities.

\section{HOGS}

Case 1a is similar to the actual four-year price and production cycles for hogs shown in Figure 9. The length of the lag in production response is shown clearly in Figure 14. The regularity of the simple cycles that would result if production were determined entirely by price is affected, in actual life, by the irregular fluctuations in the size of the corn crop, which are due chiefly to irregular 


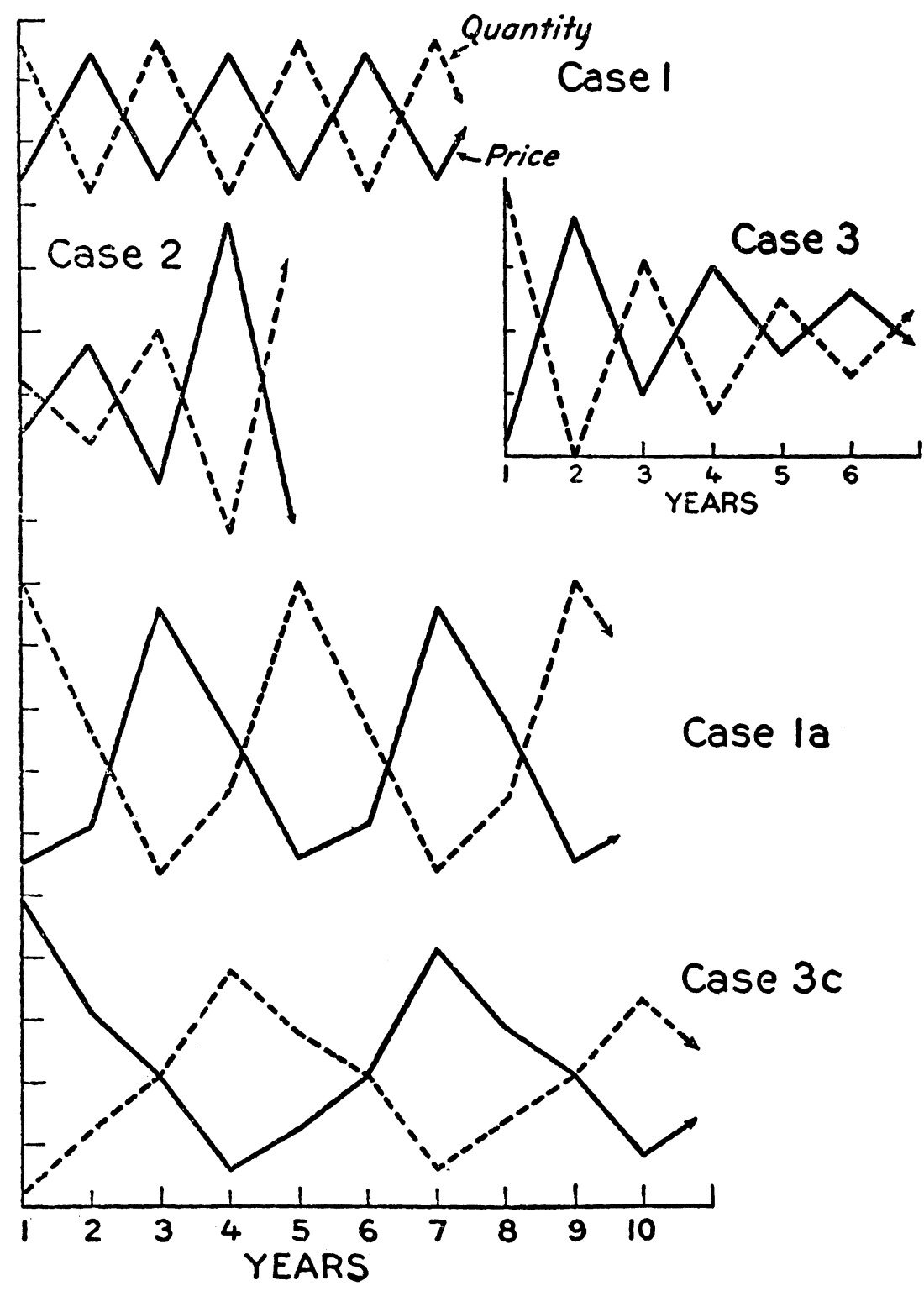

Fig. 13.-Time series of prices and production resulting from the cases shown in Figures 10 to 12. (From Ezekiel, see footnote 1, page 30.) 
fluctuations in the weather. These irregular natural variations affect the regularity of the cycles that would result if production were determined entirely by price.

HOG-CORN PRICE RATIO AND HOG MARKETINGS, $1901-45$

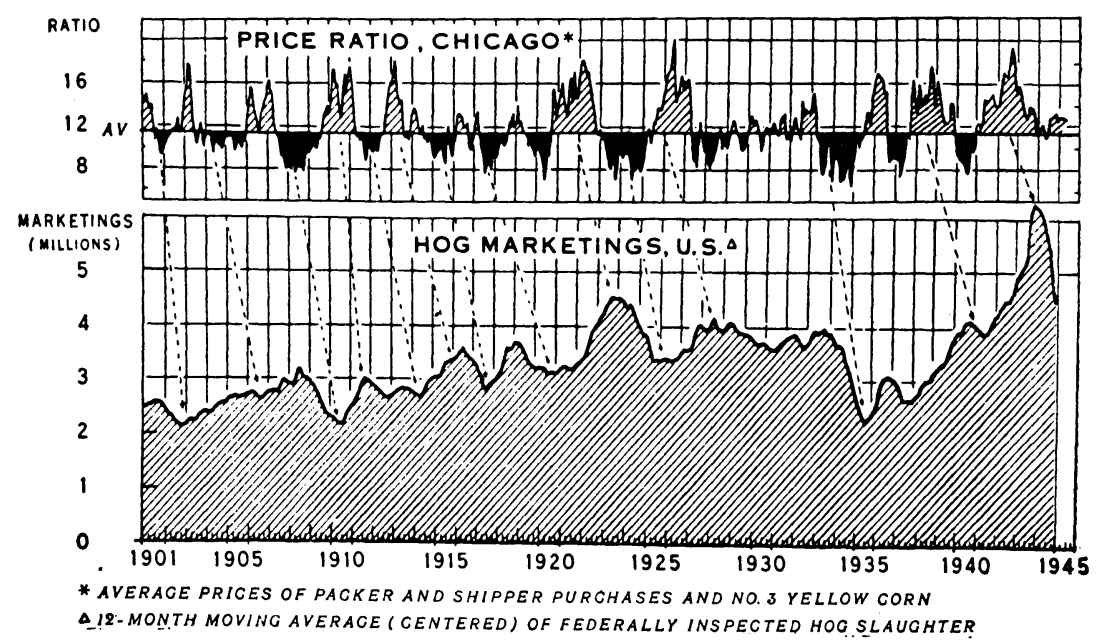

U. S. DEPARTMENT OF AGRICULTURE

NEG. IS2A2 BUREAU OF AGRICULTURAL ECONOMLE

FIg. 14.-Cyclic changes in the hog-corn price ratio and the production of hogs, 1901 to 1945.

Even in commodities which follow the convergent pattern, the actual cycles may be quite similar to those of either of the other types, if abnormally large or small crops occur frequently enough to cause a marked departure from normal and to start again a long series of convergent cycles before stability is again approached. The combination of "cobweb" reactions with occasional crop disasters or gluts may be sufficient to produce recurring cyclical changes in production and prices, rather than stability, as the normal situation.

\section{ALTÉRNATE MAJOR AND MINOR CYCLES}

The alternation between major and minor hog price and production cycles shown in Figures 9 and 14 is interesting. It could mean that the hog price and production cycles converge, at least from extreme departures from normal. Perhaps something gives it a vigorous push and sets it in motion about every 8 years, starting a major cycle which converges or damps down to a minor one. 

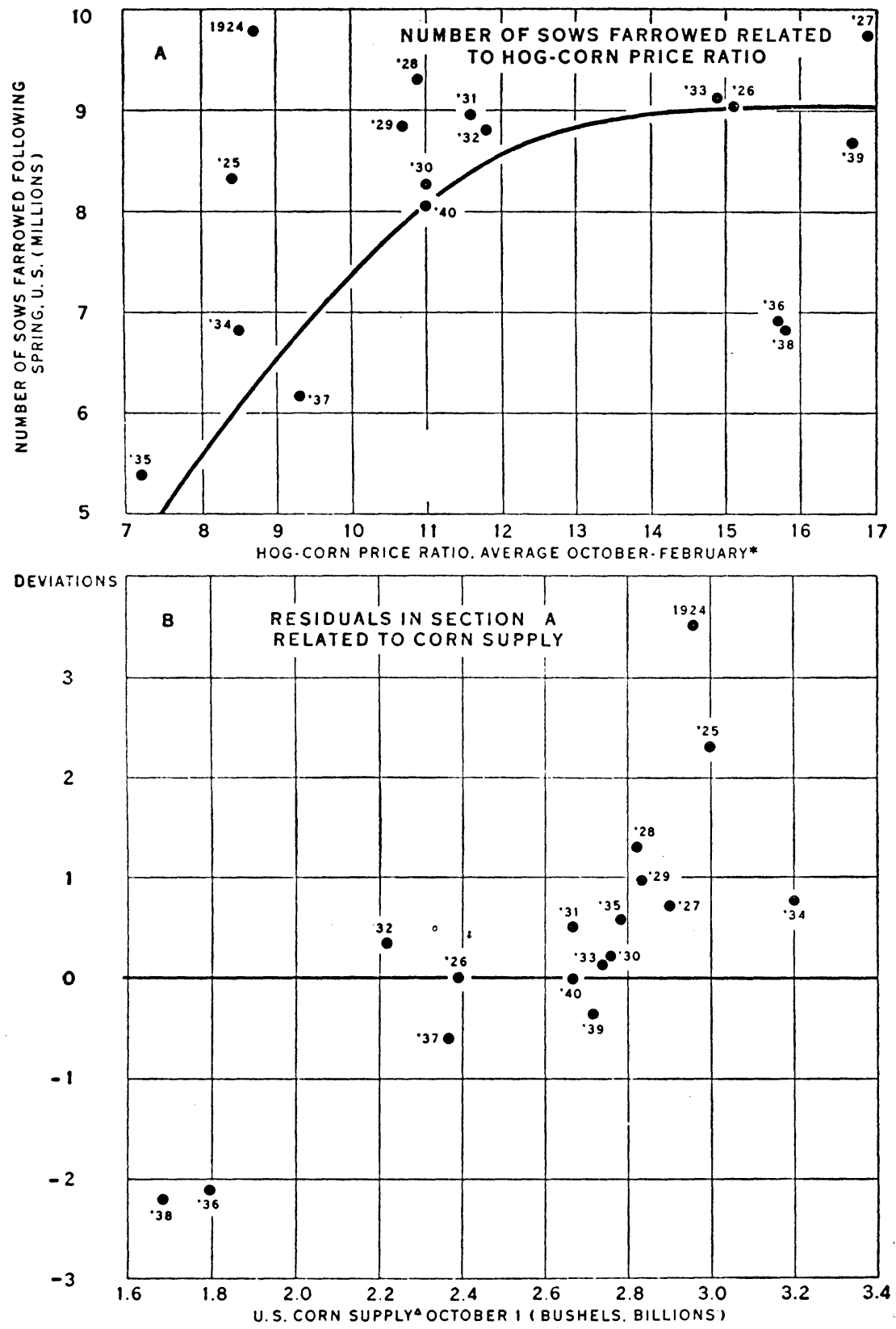

- BASED ON U.S AVERACE PRICES RECEIVED BY FARMERS. OCTOBER OF PRECEDINC YEAR TO FEBRUARY OF YEAR SHOWN.

$\triangle P R O D U C T I O N$. PLUS FARM AND COMMERCIAL STOCKS OCTOBER I. $1922-38$ (2.YEAR LAC)

BAE 39540

Fig. 15.-Relations between the United States hog-corn ratio, corn production, and sows farrowed: (A) average hog-corn price ratio October-February against United States sows farrowed the next spring; (B) residuals from (A) against corn production the year before. (The effect of corn production in the current year is already reflected in the hog-corn price ratio.) 
This may be true. It is clear from Figures 10 and 11 that when the slopes of the supply and demand curves are equal, the cycle is self-perpetuating; it runs on without expanding or contracting. It is also clear that when the supply curve slopes upward more steeply than the demand curve, the cycle converges; and conversely. Let us examine the actual slopes of the actual market demand and supply curves for hogs, and see whether they would cause self-convergent, or continuous, cycles.

Figure 43 in Chapter 9 of this book, together with other evidence, shows that the actual market demand curve for hogs is a straight line on arithmetic paper, with an average elasticity of about -0.65 . The elasticity of supply, in terms of hog-corn price ratios rather than hog prices, and in terms of the number of sows farrowing in the spring, is shown by Figure 15 to be about 1.0 for moderate departures

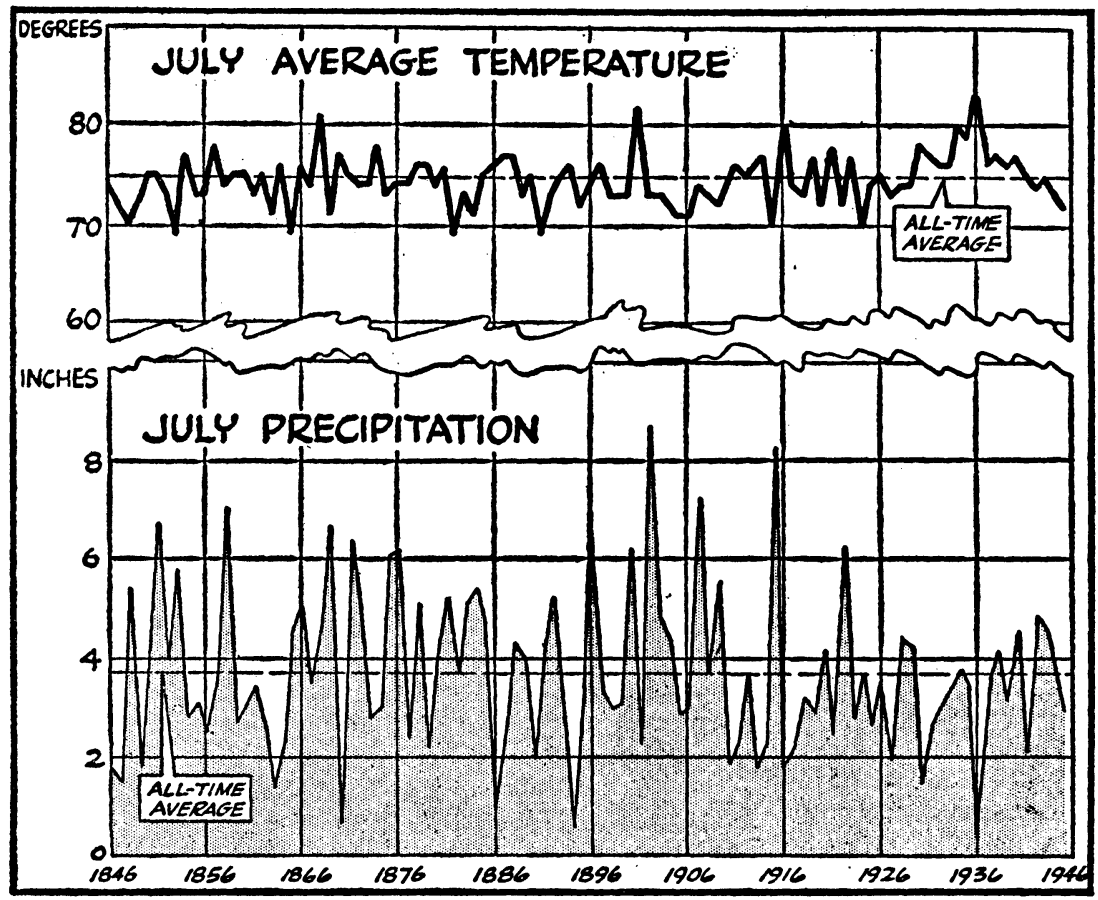

Fig. 16.-July average temperature and precipitation in Iowa, 1846 to 1946. The temperature is relatively stable, but the rainfall fluctuates markedly. There appears to be no trends or cycles in either series. (Source, The Des Moines Register, July 14, 1946.) 
from equilibrium. ${ }^{2}$ But the elasticity declines almost to zero for extreme departure above the equilibrium point.

If these curves were plotted on the same kind of charts as Figures 10 and 11, the demand curve for hogs would be a straight line with

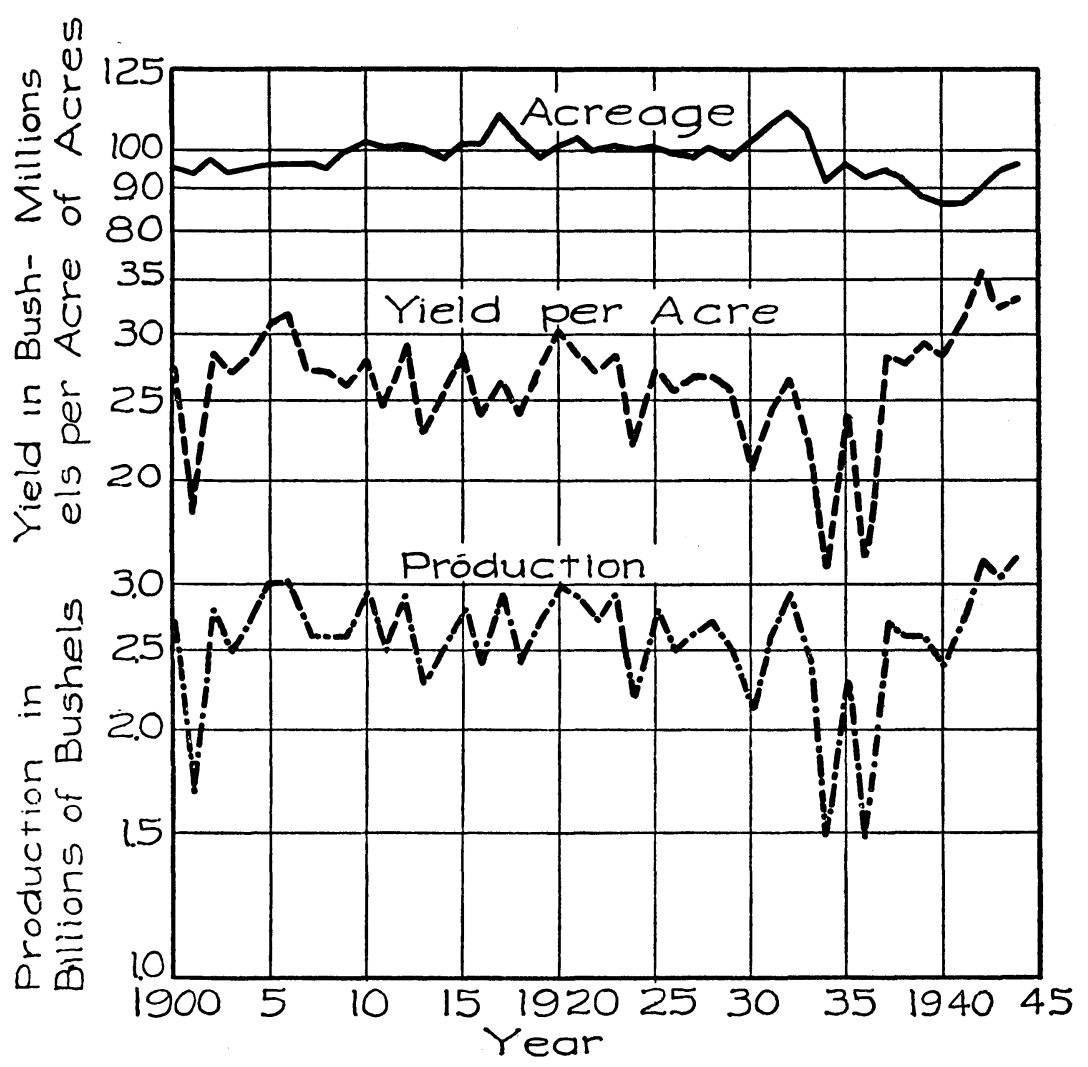

Fig. 17.-Corn acreage, yield per acre, and production, United States 1900-1945.

a slope of about 60 degrees (downward and to the right). The supply curve for hogs would have a slope of 45 degrees upward and to the right at the equilibrium point, but about 20 per cent above that point would curve upward until it gradually approached a vertical line going straight up. This means that the hog cycle, set in motion by some outside force such as a war (affecting the demand) or a

\footnotetext{
${ }^{2}$ For another chart bearing on this subject, and a more detailed discussion, see Controlling Corn and Hog Supplies and Prices, Tech. Bul. No. 826, USDA, 1942, by the present author.
} 
drouth (affecting the supply) would converge down to about 20 per cent above equilibrium but self-perpetuating at that point and indeed expanding (divergent) below that point.

\section{CYCLES IN WEATHER?}

It is more difficult to discover any periodic disturbances, recurring about eight years apart, that would set the hog cycle in motion.

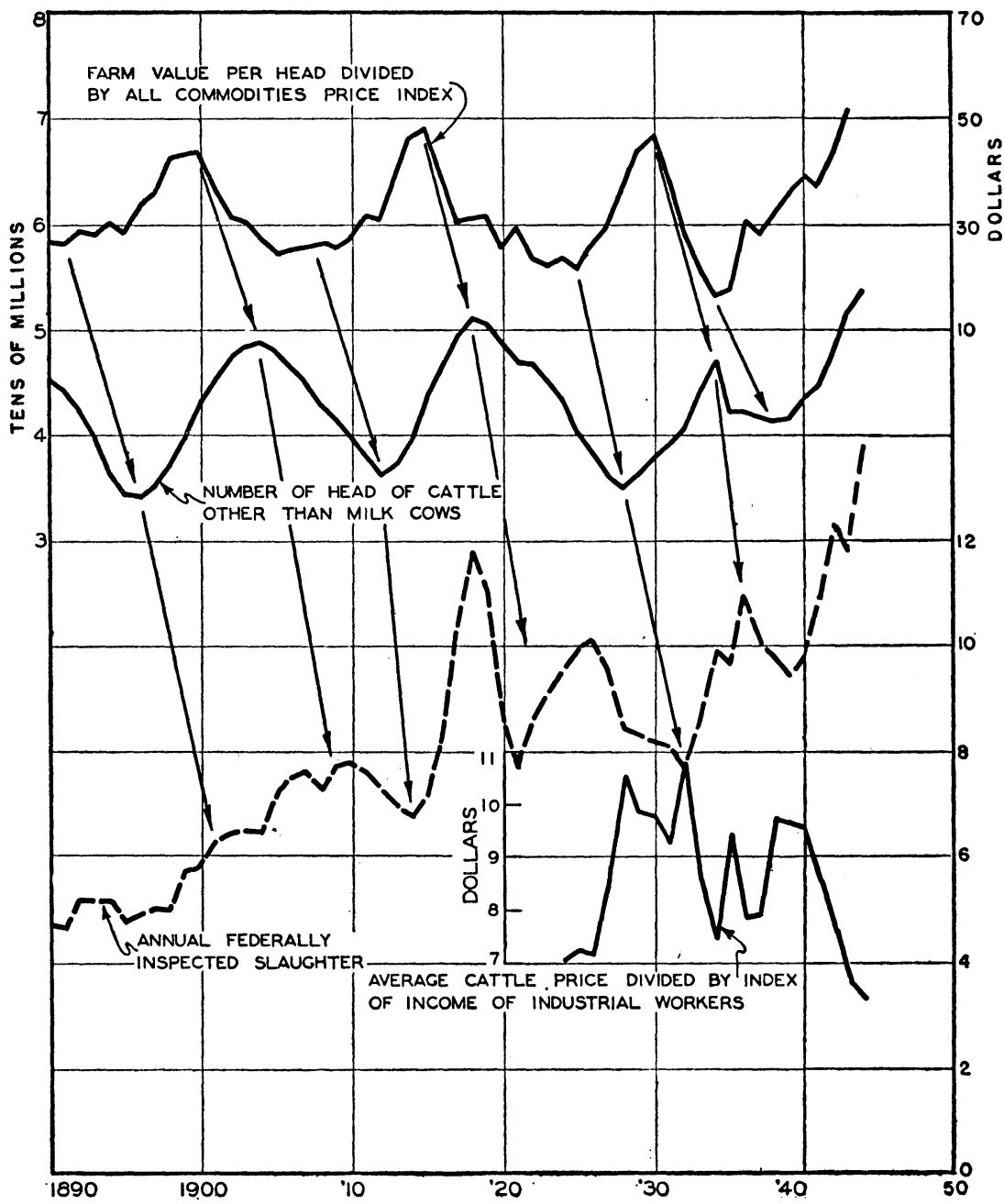

Fra. 18.-Beef cattle cycles. Farm value per head, number of cattle other than milk cows, federally inspected slaughter of cattle, and average price of cattle slaughtered, 1890 to 1946 . 
Various investigators in the past have thought that by the use of mathematical methods they had discovered cycles in the weatherthree-year cycles, eight-year cycles, eleven-year cycles, etc. These periods are so varied, and the cycles are so poorly defined, that there is real question whether there really are any cycles at all. Certainly, direct visual inspection of one hundred years of weather data in the heart of the Corn Belt, such as those shown in Figure 16, reveals no marked periodic eight-year cycles sufficient to give the hog cycles a recurring big push. Neither do the corn yield and production data shown in Figure 17.

\section{BEEF CATTLE CYCLES}

The price and production of beef cattle also move in cycles. These cycles are clearly shown in the upper part of Figure 18. The data are given in Table 2. The farm value per head of cattle other than milk cows, divided each year by corresponding Bureau of Labor Statistics index of all commodity prices at wholesale, shows four prominent peaks about fifteen years apart from 1890 to 1944 .

Some investigators believe that these movements in the production and prices of beef cattle are not really cyclic or periodic. A study of the five outstanding cyclic movements during the period 1866-1924 led Hopkins to conclude: "Each of these five movements was caused by a set of forces or conditions which were unusual, at least none of them recurred and caused another cyclical movement of like sort. Thus, it is not possible to predict any future cyclical movements on the basis of a further rapid extension of the range area like that which occurred from 1876 to 1884 , nor is it possible to foresee that in any particular period there will be further economies introduced into the methods of producing beef such as those introduced from 1895 to 1905 or 1907.

"This study has uncovered no evidence that would lead one to expect a continuation of large upward and downward swings of cattle prices at any particular periodicity. On the other hand, as will be shown later, most of the fluctuations are closely related to natural and economic phonomena directly or indirectly connected with the production and consumption of beef, and which usually cast their shadows before them for a short period at least."3

Several other investigators, however, differ with Hopkins. They

\footnotetext{
${ }^{3}$ John A. Hopkins, Jr., A Statistical Study of the Prices and Production of Beef Cattle, Iowa Agr. Exp. Sta. Res. Bul. No. 101, December, 1926.
} 
TABLE 2

Cattle Numbers, Value Per Head, Slaughter, and Price Per 100 Pounds*

\begin{tabular}{|c|c|c|c|c|}
\hline Year & $\begin{array}{c}\text { (1) } \\
\text { Farm Value per } \\
\text { Head Divided } \\
\text { by the B.L.S. } \\
\text { Wholesale } \\
\text { Price Index }\end{array}$ & $\begin{array}{l}\text { (2) } \\
\text { Number Head } \\
\text { of Cattle Other } \\
\text { Than Milk Cows } \\
(000)\end{array}$ & $\begin{array}{l}\quad(3) \\
\text { Federally } \\
\text { Inspected } \\
\text { Slaughter } \\
\quad(000)\end{array}$ & $\begin{array}{c}(4) \\
\text { Annual Average } \\
\text { Cattle Price } \\
\text { Divided by the } \\
\text { Income of } \\
\text { Industrial } \\
\text { Workers }\end{array}$ \\
\hline $\begin{array}{l}1890 \ldots \\
1891 \ldots \\
1892 \ldots \\
1893 \ldots \\
1894 \ldots \\
1895 \ldots \\
1896 \ldots \\
1897 \ldots \\
1898 \ldots \\
1899 \ldots\end{array}$ & $\begin{array}{l}27.00 \\
26.40 \\
29.00 \\
23.40 \\
30.80 \\
28.90 \\
33.90 \\
35.80 \\
43.10 \\
43.20\end{array}$ & $\begin{array}{l}45,014 \\
44,835 \\
42,949 \\
39,955 \\
36,476 \\
34,280 \\
33,939 \\
35,065 \\
37,227 \\
39,833\end{array}$ & $\begin{array}{l}4,748 \\
4,687 \\
5,206 \\
5,190 \\
5,190 \\
4,809 \\
4,939 \\
5,053 \\
5,045 \\
5,748\end{array}$ & 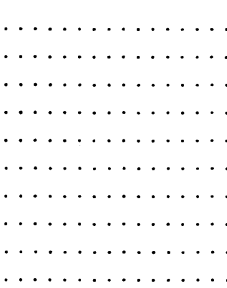 \\
\hline $\begin{array}{l}1900 \ldots \\
1901 \ldots \\
1902 \ldots \\
1903 \ldots \\
1904 \ldots \\
1905 \ldots \\
1906 \ldots \\
1907 \ldots \\
1908 \ldots \\
1909 \ldots \\
1910 \ldots\end{array}$ & $\begin{array}{l}44.00 \\
36.30 \\
31.80 \\
31.10 \\
27.40 \\
25.20 \\
25.70 \\
25.90 \\
26.60 \\
25.60 \\
27.30\end{array}$ & $\begin{array}{l}43,195 \\
45,868 \\
47,426 \\
48,787 \\
48,957 \\
48,288 \\
46,779 \\
45,125 \\
42,997 \\
41,573 \\
39,543\end{array}$ & $\begin{array}{l}5,801 \\
6,312 \\
6,465 \\
6,755 \\
6,702 \\
7,259 \\
7,541 \\
7,633 \\
7,279 \\
7,714 \\
7,808\end{array}$ & 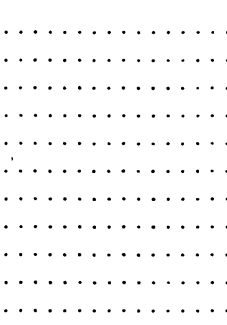 \\
\hline $\begin{array}{l}1911 \ldots \\
1912 \ldots \\
1913 \ldots \\
1914 \ldots \\
1915 \ldots \\
1916 \ldots \\
1917 \ldots \\
1918 \ldots \\
1919 \ldots \\
1920 \ldots\end{array}$ & $\begin{array}{l}31.80 \\
30.90 \\
38.30 \\
46.30 \\
48.70 \\
39.80 \\
31.00 \\
31.50 \\
32.10 \\
25.90\end{array}$ & $\begin{array}{l}37,803 \\
36,158 \\
37,012 \\
39,640 \\
43,579 \\
46,686 \\
49,767 \\
51,504 \\
50,549 \\
48,945\end{array}$ & $\begin{array}{r}7,619 \\
7,253 \\
6,978 \\
6,757 \\
7,153 \\
8,310 \\
10,350 \\
11,829 \\
10,091 \\
8,609\end{array}$ & 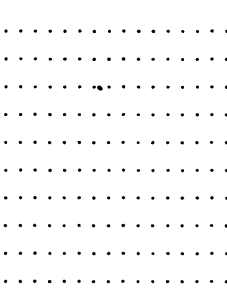 \\
\hline $\begin{array}{l}1921 \ldots \\
1922 \ldots \\
1923 \ldots \\
1924 \ldots \\
1925 \ldots \\
1926 \ldots \\
1927 \ldots \\
1928 \ldots \\
1929 \ldots \\
1930 \ldots\end{array}$ & $\begin{array}{l}29.80 \\
22.60 \\
23.20 \\
23.50 \\
21.80 \\
26.30 \\
29.50 \\
37.50 \\
44.90 \\
46.70\end{array}$ & $\begin{array}{l}47,258 \\
46,944 \\
45,408 \\
43,665 \\
40,798 \\
38,166 \\
35,927 \\
35,091 \\
36,437 \\
37,971\end{array}$ & $\begin{array}{r}7,608 \\
8,678 \\
9,163 \\
9,593 \\
9,953 \\
10,180 \\
9,520 \\
8,467 \\
8,324 \\
8,170\end{array}$ & $\begin{array}{c}7.05 \\
7.23 \\
7.15 \\
8.60 \\
10.50 \\
9.87 \\
9.70\end{array}$ \\
\hline
\end{tabular}


TABLE 2-Continued

\begin{tabular}{|c|c|c|c|c|}
\hline Year & $\begin{array}{c}(1) \\
\text { Farm Value per } \\
\text { Head Divided } \\
\text { by the B.L.S. } \\
\text { Wholesale } \\
\text { Price Index }\end{array}$ & $\begin{array}{c}(2) \\
\text { Number Head } \\
\text { of Cattle Other } \\
\text { Than Milk Cows } \\
(000)\end{array}$ & $\begin{array}{l}\quad(3) \\
\text { Federally } \\
\text { Inspected } \\
\text { Slaughter } \\
(000)\end{array}$ & $\begin{array}{c}\text { Annual Average } \\
\text { Cattle Price } \\
\text { Divided by the } \\
\text { Income of } \\
\text { Industrial } \\
\text { Workers }\end{array}$ \\
\hline $\begin{array}{l}1931 \ldots \\
1932 \ldots \\
1933 \ldots \\
1934 \ldots \\
1935 \ldots \\
1936 \ldots \\
1937 \ldots \\
1938 \ldots \\
1939 \ldots \\
1940 \ldots\end{array}$ & $\begin{array}{l}38.40 \\
28.40 \\
21.60 \\
16.70 \\
17.70 \\
30.90 \\
28.20 \\
32.80 \\
36.40 \\
39.39\end{array}$ & $\begin{array}{l}39,210 \\
40,905 \\
44,344 \\
47,438 \\
42,764 \\
42,651 \\
41,449 \\
40,783 \\
41,429 \\
43,271\end{array}$ & $\begin{array}{r}8,108 \\
7,625 \\
8,655 \\
9,943 \\
9,666 \\
10,972 \\
10,070 \\
9,776 \\
9,446 \\
9,756\end{array}$ & $\begin{array}{r}9.26 \\
10.62 \\
8.54 \\
7.42 \\
9.42 \\
7.82 \\
7.91 \\
9.75 \\
9.64 \\
6.68\end{array}$ \\
\hline $\begin{array}{l}1941 \ldots \\
1942 \ldots \\
1943 \ldots \\
1944 \ldots\end{array}$ & $\begin{array}{l}38.35 \\
43.35 \\
52.17 \\
49.83\end{array}$ & $\begin{array}{l}45,983 \\
48,764 \\
52,008 \\
54,585\end{array}$ & $\begin{array}{l}10,946 \\
12,347 \\
11,727 \\
13,960\end{array}$ & $\begin{array}{l}5.41 \\
4.56 \\
3.84 \\
3.39\end{array}$ \\
\hline
\end{tabular}

* Sources of data: (1) Agricultural Statistics, USDA, 1939, p. 308. Farm value per head of all cattle other than milk cows divided by the Bureau of Labor All Commodities Index of wholesale prices $(1926=100)$. (2) Number of head of cattle other than milk cows. Agricultural Statistics, USDA, 1939, p. 308. (3) Livestock, Meats and Wool Statistics and Related Data, 1939, p. 21. (4) Average United States price of cattle (calendar year) divided by the index of income of industrial workers $(1924-29=100)$. Cattle prices from Livestock, Meats and Wool Market Statistics and Related Data, 1939, p. 91. Income index from "Demand, Credit and Prices," 1941 Agricultural Outlook Charts, p. 4. Recent data from recent editions of same sources.

believe that the movements in the production and prices of beef cattle are cyclic, self-perpetuating in character. The behavior of the production and price series since Hopkins wrote seems to support the cyclic hypothesis rather than his episodic theory. Well-marked peaks have continued to occur about fifteen years apart. They show up most clearly in the value series plotted in the upper part of Figure 18.

These cyclic movements in the value of beef cattle per head at the farm cause corresponding changes in the numbers of head of beef cattle on farms-not immediately, but after a lag of several years. This is shown by the second line from the top in Figure 18 which represents the number of head of beef cattle on farms January 1 each year. The downward sloping arrows between that line and the line at the top of Figure 18 show how high beef cattle values at the farm lead to increases in beef cattle numbers, and how low beef 
cattle prices lead to liquidation of beef herds. There is a four- or five-year lag between the two series; it takes several years to build up a herd, and even liquidation is usually a slow process. (The sudden liquidation in 1934 was an exception, due not to low prices but to severe drouth.)

The relations from then on are more complex. Large numbers of cattle on farms January 1 do not lead directly to high cattle slaughter the same year, as in the case of hogs. Hogs are ready for market less than a year after they are farrowed, but steers used to be carried to three, four, and five years of age before being sent to market. Even now, finished steers average about two years old at the time of slaughter. So there is a lag of about two years between numbers on farms and number slaughtered. When prices are high and numbers of cattle on farms are increasing, slaughter may be decreasing, since a larger than normal proportion of heifers may be kept on farms for building up breeding herds. This happened for several years after 1912,1928, and 1938. On the other hand, if prices are low and numbers of cattle on farms are decreasing, liquidation of breeding stock may cause the market supplies to increase. This happened for several years after 1908, 1921, and 1934.

These things are well shown in Figure 18, where the annual federally-inspected slaughter of beef is shown by the next to lowest line in the chart. This line follows a cyclic pattern lagging from two to four years after the cycles in numbers of beef cattle on farms shown by the line above it, with only one conspicuous interruption. The wartime demand for beef during World War I moved the peak of slaughter that normally would have come in 1920-22 forward to 1918 , and the spot from which the peak was moved became a trough.

The final link in the chain of causation is the concurrent inverse correlation between the slaughter and the price of beef cattle. This is revealed by a comparison of the cyclic movements in the slaughter line in the lower part of the chart with the farm-value-per-head line at the top. This relation is not very close, for (1) prices at the farm are affected by the demand for breeding purposes as well as by the amount of slaughter, and (2) the effects of changes in demand upon beef cattle prices are only partly removed by dividing the value-perhead series through by the index of the general price level. The inverse relation between slaughter and prices is shown more accurately if the prices used are the prices of the beef cattle slaughtered 
(what is called the cost to packers) with the effects of changes in demand removed by division of the prices each year by the corresponding index of the income of industrial workers. (This index is available only as far back as 1924, and the cost to packers goes back only to 1921.) This "deflated" beef cattle price is shown by the lowest line in Figure 18.

\section{POTATOES}

Another application of the cobweb analysis to actual commodity data is provided by the data for potato prices and production, given in Table 3. The farm price for the crop season is adjusted for changes in price level by dividing by the index of wholesale price level. The relation of these deflated prices, both to production of the current year and to production of the subsequent year, is shown in Figure 19.

This figure shows two points for each year, one point shown as a dot and the other shown as a hollow square. The dot labeled "37,"

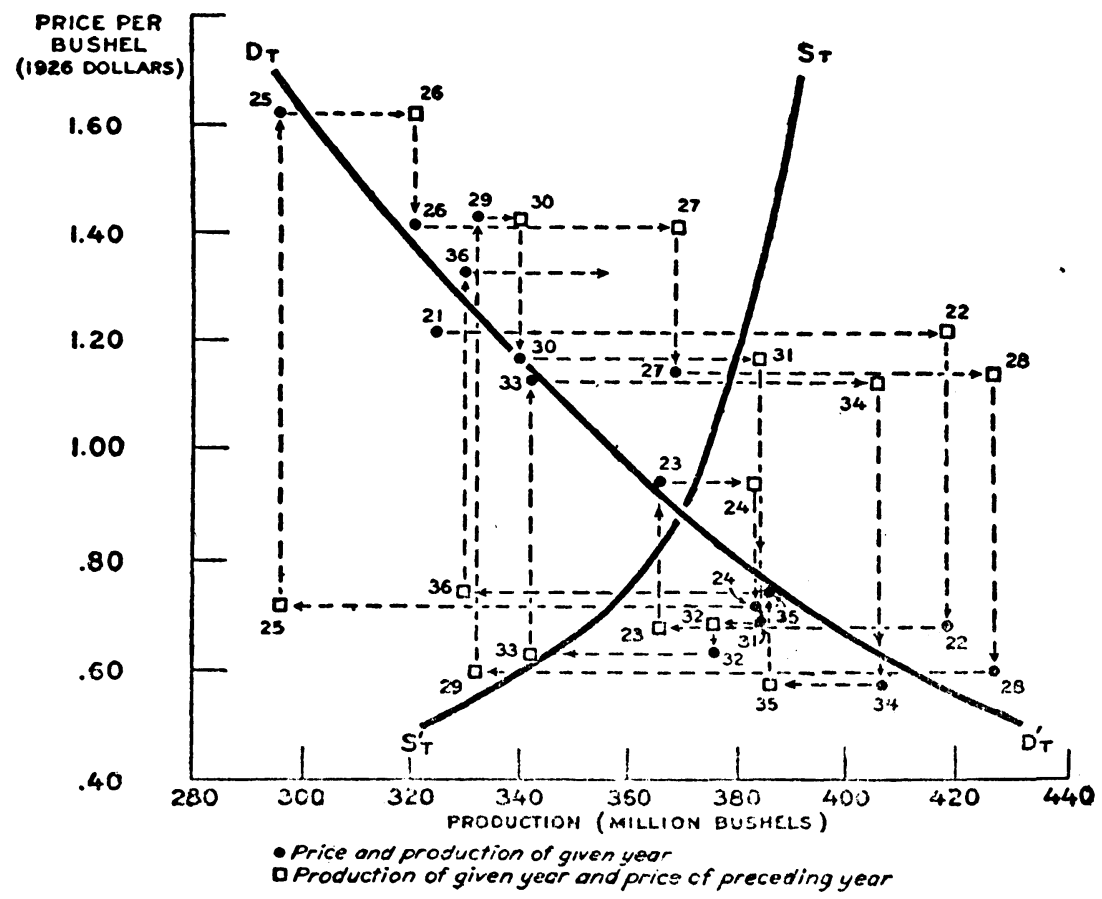

FIG. 19.-Cycles in the prices and production of potatoes, United States, 1921-36. (From Ezekiel, see footnote 1, page 30.) 
TABLE 3

Potato Agreage, Yield, Produgtion, and Season Average Prige: United States, 1921-45

\begin{tabular}{|c|c|c|c|c|c|c|}
\hline Crop Year* & $\underset{(000)}{\text { Acres Planted }}$ & $\begin{array}{l}\text { Yield Per Acre } \\
\text { (bushels) }\end{array}$ & $\begin{array}{c}\text { Production } \\
\text { (million bushels) }\end{array}$ & $\begin{array}{c}\text { Average } \\
\text { Farm Price } \\
\text { (cents per bushel) }\end{array}$ & $\begin{array}{l}\text { Wholesale } \\
\text { Price Level } \\
(1926=100)\end{array}$ & $\begin{array}{c}\text { Deflated } \\
\text { Farm Price } \\
\text { (cents per bushel) }\end{array}$ \\
\hline \multicolumn{7}{|c|}{ Data for Figure 19} \\
\hline $\begin{array}{l}1921 \ldots \ldots \ldots \\
1922 \ldots \ldots \ldots \\
1923 \ldots \ldots \ldots \\
1924 \ldots \ldots \ldots \\
1925 \ldots \ldots \ldots \\
1926 \ldots \ldots \ldots \\
1927 \ldots \ldots \ldots \\
1928 \ldots \ldots \ldots \\
1929 \ldots \ldots \ldots \\
1930 \ldots \ldots \ldots\end{array}$ & $\begin{array}{l}3,598 \\
3,946 \\
3,378 \\
3,106 \\
2,810 \\
2,811 \\
3,182 \\
3,499 \\
3,019 \\
3,103\end{array}$ & $\begin{array}{r}90.4 \\
106.3 \\
108.5 \\
123.7 \\
105.5 \\
114.4 \\
116.2 \\
122.1 \\
110.0 \\
109.8\end{array}$ & $\begin{array}{l}325.3 \\
419.3 \\
366.4 \\
384.2 \\
296.5 \\
321.6 \\
369.6 \\
427.2 \\
332.2 \\
340.6\end{array}$ & $\begin{array}{r}113.5 \\
68.6 \\
91.5 \\
71.2 \\
165.8 \\
136.3 \\
108.5 \\
57.1 \\
131.8 \\
91.8\end{array}$ & $\begin{array}{r}93.7 \\
101.2 \\
98.1 \\
100.5 \\
102.5 \\
97.0 \\
96.1 \\
96.2 \\
92.5 \\
79.0\end{array}$ & $\begin{array}{r}121.1 \\
67.8 \\
93.3 \\
70.8 \\
161.8 \\
140.5 \\
112.9 \\
59.4 \\
142.5 \\
116.2\end{array}$ \\
\hline $\begin{array}{l}1931 \ldots \ldots \ldots \\
1932 \ldots \ldots \ldots \\
1933 \ldots \ldots \ldots \\
1934 \ldots \ldots \ldots \\
1935 \ldots \ldots \ldots \ldots \\
1936 \ldots \ldots \ldots\end{array}$ & $\begin{array}{l}3,467 \\
3,549 \\
3,412 \\
3,597 \\
3,551 \\
3,058\end{array}$ & $\begin{array}{l}110.8 \\
106.1 \\
100.3 \\
112.9 \\
109.1 \\
107.9\end{array}$ & $\begin{array}{l}384.1 \\
376.4 \\
342.3 \\
406.1 \\
386.4 \\
330.0\end{array}$ & $\begin{array}{r}46.3 \\
39.2 \\
82.1 \\
44.8 \\
59.7 \\
111.3\end{array}$ & $\begin{array}{l}68.2 \\
62.9 \\
72.0 \\
78.0 \\
80.1 \\
84.0 \dagger\end{array}$ & $\begin{array}{r}67.9 \\
62.3 \\
114.0 \\
57.4 \\
74.5 \\
132.5\end{array}$ \\
\hline \multicolumn{7}{|c|}{ Data for Figure 20} \\
\hline $\begin{array}{l}1937 \ldots \ldots \ldots \\
1938 \ldots \ldots \\
1939 \ldots \ldots \\
1940 \ldots \ldots \\
1941 \ldots \ldots \ldots \\
1942 \ldots \ldots \ldots \\
1943 \ldots \ldots \ldots \\
1944 \ldots \ldots \ldots \\
1945 \ldots \ldots \ldots\end{array}$ & $\begin{array}{l}3,119 \\
2,944 \\
2,867 \\
2,900 \\
2,768 \\
2,789 \\
3,441 \\
2,922 \\
2,824\end{array}$ & $\begin{array}{l}123.2 \\
124.0 \\
121.7 \\
132.1 \\
131.2 \\
136.9 \\
139.6 \\
131.1 \\
150.6\end{array}$ & $\begin{array}{l}376.4 \\
355.8 \\
342.4 \\
375.8 \\
355.6 \\
370.5 \\
464.9 \\
383.1 \\
425.1\end{array}$ & $\begin{array}{r}52.9 \\
55.7 \\
69.7 \\
54.1 \\
80.7 \\
117.0 \\
131.0 \\
149.0 \\
141.0\end{array}$ & $\begin{array}{r}86.3 \\
78.6 \\
77.1 \\
78.6 \\
87.3 \\
98.8 \\
103.1 \\
104.0 \\
106.0\end{array}$ & $\begin{array}{r}61.2 \\
70.9 \\
90.4 \\
68.8 \\
92.4 \\
118.4 \\
127.1 \\
143.3 \\
133.0\end{array}$ \\
\hline
\end{tabular}

* July to June, inclusive.

t On basis of first ten months.

Source: Bureau of Agricultural Economics. 
for example, has for co-ordinates the 1937 price and the 1937 production; the hollow square labeled " 38 " has for co-ordinates the 1937 price and the 1938 production. The dots should indicate the demand curve, the squares the supply curve (insofar as it can be shown by such a simple analysis). The supply and demand curves have been drawn roughly, according to these indications. ${ }^{4}$ The successive readjustments between production, price, and production are indicated by the dotted lines.

This figure presents the potato data according to a one-year response analysis. Actually, potato acreage is influenced by prices of both one year and two years previous, so that an average of the two preceding prices would give a better explanation of acreage changes than the preceding price alone. Furthermore, increase in acreage of potatoes in any one year is limited; Bean has shown that a 10 per cent increase is the limit of response, regardless of price. ${ }^{5}$ This successive accumulation of increases is shown clearly in Figure 19. Following the high price of 1925 , production increased each year until 1928; following the high price of 1929, production increased in 1930 and 1931. The very large increase in production in the single year 1922 was due more to a great difference in yield than in acreage. On the downside, however, single-year changes predominate, as from 1924 to 1925,1922 to 1923 , and 1928 to 1929 . The line $\mathrm{S}_{\mathrm{t}} \mathrm{S}_{\mathrm{t}}{ }^{\prime}$ is therefore not the true supply curve, in the sense that a price of $\$ 1.60$ will call forth a production of 390 million bushels the next year.

'In drawing the curves, production has been regarded as the independent factor determining the dependent factor, price, and price as the independent factor determining the dependent factor, subsequent production. Accordingly, the curves have been roughly drawn so as to minimize the price (or vertical) departures of the dots from the demand curve, and the production (or horizontal) departures of the squares from the supply curve. This is not the most accurate way to determine either demand or supply curves; for the former, price level, consumer buying power, and other related factors may need to be considered as separate variables; for the latter, changes in acreage should be studied, prices one, two and more years preceding, and prices of cost factors or alternative commodities, may all need to be considered. The present illustration is not an example of price analysis, but merely an oversimplified illustration.

The carryover of potatoes has been neglected in computing the total supply, since potatoes are so perishable that the carryover from the previous year's crop has no perceptible effect on prices, except upon new-crop potatoes from southern points early in the season.

The elasticity of the demand curve shown is -0.37 . This is very close to the elasticity derived by more complicated multiple regression analyses reported later in this book. The elasticity of supply shown here is similarly confirmed by later studies.

${ }^{5}$ Louis H. Bean, "The Farmers' Response to Price," Journal of Farm Economics XI, No. 3, July, 1929 , p. 380. 
Rather; it shows that at prices above 90 cents, production the next year will usually increase, though within a limited range, while at prices below 90 cents, production the next year will usually decrease.

With these reservations in mind, we may examine Figure 19 for evidence of "cobwebbiness." There is an apparent tendency for

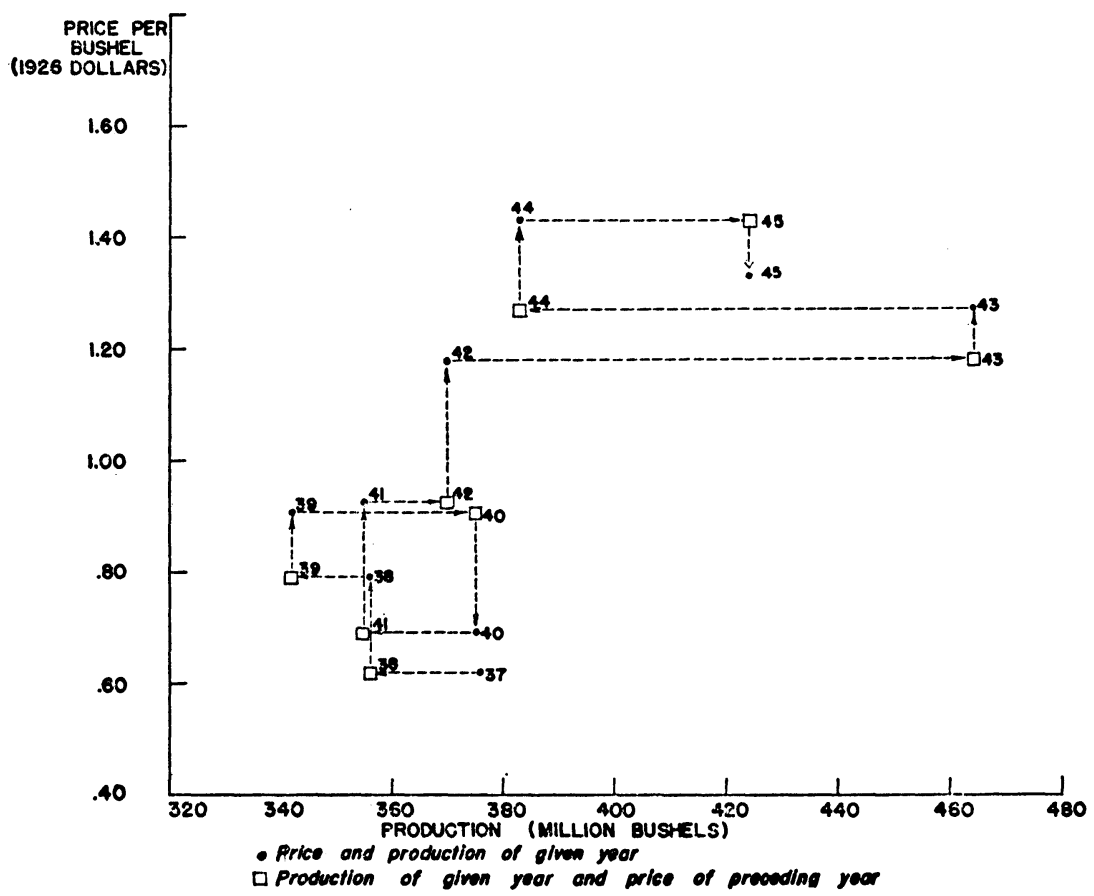

Fig. 20.-Cycles in the prices and production of potatoes, United States, $1937-45$.

the reaction to swing around the point of overlap (long-time equilibrium). From 1921 to 1924 the cycle converged. In 1925 an exceptionally low yield per acre started a new cycle under way, which appeared to "damp down" until 1928, when an unusually high yield per acre threw it out of balance again. Again in 1932, production was near the equilibrium amount (though price was low because of depressed demand); a very low acre yield in 1933 started a new cycle under way. Potatoes thus illustrate the case of a commodity where the supply-demand relation tends to converge towards equilibrium, but where occasional years of high or low yields occur often enough to maintain practically continuous oscillation. 
Figure 19 was originally prepared in 1937, and the last data that appear in it are those for 1936 . If the data since 1936 were added to the chart they would crowd it so full of dots and lines that it would be difficult to read. The data since 1936, therefore, are shown separately in Figure 20.

This figure shows that the data from 1937 to 1941 exhibit the same kind of clockwise rotation about an equilibrium point that the earlier data show in Figure 19. The great demand for food after 1941 shifted the demand curve upward and to the right, taking the large crop of 1942 and the extremely large crop of 1943 at higher prices, not lower prices, than before. After 1943, however, the cyclic rotation began to re-establish itself about a new and higher point.

\section{CYCLIC SEASONAL MOVEMENTS}

The prices of most farm products exhibit a regular cyclic movement within the season-from a low price point during the weeks of heaviest market receipts to a high price peak later in the season when supplies are at their lowest. On the average, the rise from low to high is about equal to the extra cost of producing the commodity "off-season"; or, in the case of annual crops, the rise in price is equal to the cost of storage from harvest time until later in the year. But there is much variation from year to year.

This is a comparatively simple phenomenon, requiring only simple statistical techniques for its analysis. For this reason, and because it is discussed fully elsewhere, ${ }^{6}$ it is not investigated here.

${ }^{\circ}$ Warren C. Waite and Rex W. Cox, Seasonal Variations of Prices and Marketings of Minnesota Agricultural Products, 1921-1935, Minnesota Agr. Exp. Sta. Tech. Bul. 127, March, 1938. See also Marketing Farm Products, Chapter 8, Iowa State College Press, 1946, by the present author. 


\section{The Elasticity of the Demand for Farm Products}

In most cases in economics, it is difficult to draw a sharp line between the long run and the short run. In agricultural economics, however, one kind of short run is clearly marked off. Most crops are produced once a year, and the yield per acre is determined chiefly by the weather. Variations in the weather from year to year are almost entirely random in character. A tendency toward cyclic variations has been "discovered" by a number of different investigators, but the length of the cycles differs so much among the different investigators that there is a real question whether there actually are any cycles at all. Crop production series show almost completely random variations from year to year. Each crop is like a flip of a coin or a roll of the dice-a new item, practically independent of the other items in the series. Crop production series, and other series closely associated with them (such as crop price series in times of stable demand, or independent of variations in demand), therefore lend themselves well to statistical analysis.

\section{RELATIONS AMONG PRODUCTION, PRICE, AND INCOME}

Each year farmers plant their crops, not knowing whether the weather will be good, bad, or indifferent; their crops accordingly large, small or average; and their prices accordingly low, high, or average.

Large crops bring low prices, and small crops, high prices. But will large crops bring high incomes, or low incomes?

The answer depends upon the extent to which prices vary (inversely) with variations in production. In the case of some crops, an increase in production of 10 per cent decreases price 20 per cent. The price falls twice as far as the size of the crop increases. In this case, a large crop brings a lower income than an average crop. In other cases, the price falls less than the size of the crop increases; a large crop then is worth more than an average crop.

This relation between the extent of the change in the size of the crop and the extent of the change in price is called the price elasti- 
city of the demand. Each crop has its own price elasticity of demand, differing from the elasticity for other crops. It is important to measure this elasticity for each crop. In a free-market economy, it is important to know how much, and in which direction, variations in the size of the crop affect income as well as price. This knowledge is still more important in a controlled economy or sector of an economy, such as a price or income stabilization program.

\section{THE MEASUREMENT OF THE ELASTICITY OF DEMAND}

The concept of elasticity is basically simple. People will buy more carrots, for example, when they are cheap than when they are highpriced. A reduction in the price of almost anything ordinarily increases the amount of the thing that can be sold. This responsiveness of quantity to price is called the elasticity of the good in question. ${ }^{1}$

With some goods, for example peaches, a change in the price will result in a large change in the amount that can be sold. With other goods, for example, salt, the same change in the price has only a small effect on the amount that can be sold. In practically no case is the quantity of a good completely unresponsive to a change in price; that is, the demand is very seldom completely inelastic. With most goods a change in price has an appreciable effect upon the quantity that can be sold-a small effect in the case of some goods, a large effect in the case of some others.

This definition of elasticity of demand is phrased in terms of the change in quantity per unit change in price. This does not mean that the change in price is regarded as the cause, and the change in quantity as the effect. In many cases the line of causation runs the other way; in agriculture, farmers determine the acreage and the weather determines the yield of the crop, and the quantity produced "sets the price." But the term elasticity here as elsewhere refers to the change in quantity, neither causing nor caused by, but associated with a given change in price.

\footnotetext{
${ }^{1}$ The term elasticity is not very clear. Frank Knight believes that the term "responsiveness of consumption" expresses the concept better. (Frank H. Knight, "Demand," Encyclopaedia of the Social Sciences, Vol. V, 1931, p. 70.) It makes clear that elasticity refers to the responsiveness of quantity to price, not vice versa (which Moore has called the "flexibility of prices"). Knight's term, "responsiveness of consumption," is clearer or at least more self-explanatory than "elasticity of demand"; but it has one shortcoming, namely that it cannot, strictly speaking, be applied to the purchases of dealers who do not consume the product, whereas "elasticity of demand" can be thus applied. The term "elasticity of purchases" would meet this objection, but it is not so clear as the other. In any case, "elasticity of demand" has become so well established in use that it probably will remain in use (like the established width of railroad tracks, even though a greater width would be better suited to present needs).
} 
The concept of elasticity has been familiar to economists for generations. Gregory King two or three centuries ago attempted to measure the elasticity of the demand for wheat in quantitative terms, ${ }^{2}$ but nothing much else was done until Moore in 1914 published his empirical studies of the elasticity of the demand for corn, hay, and potatoes. ${ }^{3}$ After World War I, a great increase took place in the quantity of statistical data available concerning production, prices, demand, and supply, and analytical statistical methods were applied to economic data on an extensive scale. Many studies of the elasticities of demand for different products have been published, and one of the first things a student of price analysis should be able to do is to measure the elasticity of the demand for a given product and interpret his results properly.

\section{MEASURING ELASTICITY}

Let us take a concrete example. The price and production data for potatoes for the years 1929-39 are given in Table 4. They are plotted in scatter-diagram form in Figure 21. The prices are the average United States farm prices December 15 each year, adjusted for changes in the general price level. ${ }^{4}$ The production figures show the total production of potatoes in the United States.

2 "We take it, that a defect in the harvest may raise the price of corn in the following proportions:

\begin{tabular}{|c|c|c|}
\hline $\begin{array}{l}\text { Defect } \\
1 \text { Tenth } \\
2 \text { Tenths } \\
3 \text { Tenths } \\
4 \text { Tenths } \\
5 \text { Tenths }\end{array}$ & $\begin{array}{l}\text { Raises the } \\
\text { price }\end{array}$ & $\begin{array}{c}\text { Above the Common Rate } \\
3 \text { Tenths } \\
8 \text { Tenths } \\
16 \text { Tenths } \\
28 \text { Tenths } \\
45 \text { Tenths }\end{array}$ \\
\hline
\end{tabular}

so that when corn rises to treble the common rate, it may be presumed that we want above $1 / 3 \mathrm{rd}$ (one-third) of the common produce; and if we should want $5 / 10$ ths, or half the common produce, the price would rise to near five times the common rates." C. D'Avenant, Political and Commercial Works, Vol. II, 1771, p. 224, quoted in Farm Economics, Cornell Univ., May, 1939, p. 2758.

${ }^{3}$ Henry L. Moore, Economic Cycles, Their Law and Cause, Macmillan, 1914.

${ }^{4}$ December prices are used here rather than the season average price used in Table 3, because they reflect the size of the crop just produced more accurately than the season average price. The season average price is affected by other events occurring later in the season.

The adjustment for changes in the general price level here consists in dividing the price data by the corresponding Bureau of Labor Statistics all-commodity wholesale price index inflated by 50 per cent (because the relation between the two is not 1 to 1 but 1 to 1.5 ). This procedure, probably not clear to the reader at this point, is explained in detail in Chapter 8, along with a general discussion of the adjustment of prices to take care of the effect of changes in demand.

The simple analytical methods used have resulted in the straight-line demand curve shown. More complicated and accurate analyses show that the demand curve has a concave curvature at the lower end. 
TABLE 4

Potatoes: United States Production and Average Farm Price, December 15, 1929-39*

\begin{tabular}{|c|c|c|c|c|c|c|c|}
\hline \multirow[b]{2}{*}{ Year } & \multirow{2}{*}{$\begin{array}{c}\text { Potatoes } \\
\text { (000 bushels })\end{array}$} & \multirow{2}{*}{$\begin{array}{c}(2) \\
\text { Potatoes } \\
\text { Average Price } \\
\text { per Bushel } \\
\text { December } 15 \\
\text { (cents) }\end{array}$} & \multirow{2}{*}{$\begin{array}{c}\cdot(3) \\
\text { Wholesale } \\
\text { Price Index, All } \\
\text { Commodities } \\
\text { Dec. } 1926=100\end{array}$} & \multirow[b]{2}{*}[(3)\times1.50-50]{} & \multirow[b]{2}{*}{$(2) \div(4)$} & \multicolumn{2}{|c|}{$\begin{array}{l}\text { Data in (1) and (5) Expressed } \\
\text { in Percentages of Average }\end{array}$} \\
\hline & & & & & & Production & Deflated Prices \\
\hline $\begin{array}{l}1929 \ldots \ldots \ldots \\
1930 \ldots \ldots \ldots \\
1931 \ldots \ldots \ldots \\
1932 \ldots \ldots \ldots \\
1933 \ldots \ldots \ldots \\
1934 \ldots \ldots \ldots\end{array}$ & $\begin{array}{l}322,204 \\
340,572 \\
-384,125 \\
376,425 \\
342,306 \\
406,105\end{array}$ & $\begin{array}{r}134.6 \\
89.8 \\
45.0 \\
36.8 \\
69.2 \\
44.9\end{array}$ & $\begin{array}{l}93.3 \\
79.6 \\
68.6 \\
62.6 \\
70.8 \\
76.9\end{array}$ & $\begin{array}{l}89.95 \\
69.40 \\
52.90 \\
43.90 \\
56.20 \\
65.35\end{array}$ & $\begin{array}{r}149.6 \\
129.4 \\
85.1 \\
83.8 \\
123.1 \\
68.7\end{array}$ & $\begin{array}{r}88.1 \\
93.1 \\
105.0 \\
102.9 \\
93.6 \\
111.0\end{array}$ & $\begin{array}{r}144.5 \\
125.0 \\
82.2 \\
81.0 \\
118.9 \\
66.4\end{array}$ \\
\hline $\begin{array}{l}1935 \ldots \ldots \ldots \\
1936 \ldots \ldots \ldots \\
1937 \ldots \ldots \ldots \\
1938 \ldots \ldots \ldots \\
1939 \ldots \ldots \ldots\end{array}$ & $\begin{array}{l}386,380 \\
331,918 \\
395,294 \\
374,163 \\
364,016\end{array}$ & $\begin{array}{r}63.7 \\
106.3 \\
53.0 \\
61.3 \\
70.8\end{array}$ & $\begin{array}{l}80.9 \\
84.0 \\
81.7 \\
77.0 \\
79.0\end{array}$ & $\begin{array}{l}71.35 \\
76.0 \\
72.55 \\
65.5 \\
68.5\end{array}$ & $\begin{array}{r}89.3 \\
139.9 \\
73.1 \\
93.6 \\
103.4\end{array}$ & $\begin{array}{r}105.6 \\
90.7 \\
108.1 \\
102.3 \\
99.5\end{array}$ & $\begin{array}{r}86.2 \\
135.2 \\
70.6 \\
90.4 \\
99.9\end{array}$ \\
\hline
\end{tabular}

* Sources of data: (1) and (2) Agricultural Statistics, 1940, pp. 262, 269; Crops and Markets (monthly); current data from Wholesale Prices (monthly). "(3) Mimeo. 1313, Bureau of Labor Statistics, U. S. Department of Labor. 
The dots in Figure 21 fall closely around a sloping line, which can be fitted to the data mathematically by the method of least squares, or simply drawn in freehand. In either case, the investigator must decide whether to use a straight line or a curved line to fit the dots. The decision must be based on (1) the appearance of the data, (2) the investigator's knowledge of the particular product,

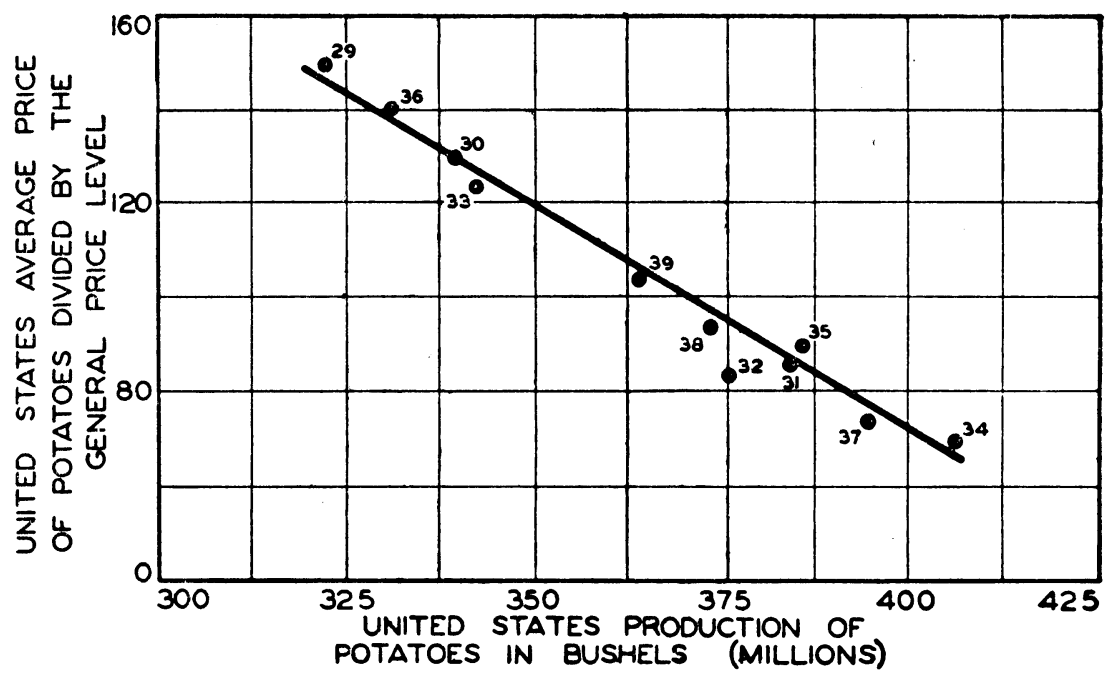

FIG. 21.-Potatoes: United States average farm price, December 1, and total production, 1929-39.

and (3) his grasp of economic theory. That is, the line chosen should be a reasonable one from all three of these points of view. In Figure 21 the dots fall about a straight line, and in the absence of any reason for using a curved line, a straight line is chosen. The line in this case is drawn in freehand. It does not necessarily go through any of the dots, but merely represents the average relationship between production and price shown by the data. The line should not be extrapolated (extended) beyond the dots.

The job now is to measure the elasticity of the demand represented by this line-that is, to measure the change in quantity associated with a unit change in price. ${ }^{5}$ Inspection of the chart

${ }^{5}$ The computation of the elasticity of the demand should be based upon two points on the line rather than upon two actual data dots, because a line joining and two dots (1938 and 1939, for example, or still more obviously, 1931 and 1932) may have a different slope from the line representing the average rela- 
shows that a change in quantity from 325 million bushels to 400 million bushels (using round numbers near the ends of the line) is associated with a change in price in the opposite direction, from 144 to 70 cents per bushel. That is, a change in quantity of 75 million bushels is associated with an opposite change in price of 74 cents; the change in quantity per unit change in price is $\frac{75}{-74}=-1.01$.

But this is not the elasticity of the demand for potatoes, for it is evident that the result is determined largely by the particular units in which the quantity and price changes are measured. If the quantity had been measured in bushels, for example, instead of millions of bushels, the answer obtained by the formula above would have been $-1,013,389$, clearly an absurd answer. Or if the price had been measured in English money, the change in price would have been about 3 shillings instead of 75 cents; and this again would have given a different answer. The basic situation remains unchanged when different units of computation are used, but the numerical results obtained above are quite different. This is not as it should be. What is needed is a measure of elasticity that will be unaffected by the units of measurement chosen-a coefficient of elasticity.

\section{THE COEFFICIENT OF ELASTICITY}

One good way to compute such a coefficient of elasticity is to divide the observed change in quantity by the average of the two quantities (i. e., to divide $400-325=75$ by $\frac{400+325}{2}=367.5$ ).

tionship of all the dots, and it is the average relationship that is being measured. Furthermore, two points at the ends of the line shown in Figure 21 should be used, rather than two anywhere along the line, since it is the elasticity of the line as a whole that is to be measured, not just the elasticity of a part of it.

This concept of the elasticity of the line as a whole, or of a part of it, may be referred to as the average elasticity in much the same way that reference is made to one's average speed, say 50 miles an hour, on a trip. It is contrasted with point elasticity, as in physics the empirical concept of average speed is contrasted with the limiting concept of velocity. Point elasticity is taken up in the next chapter.

For a full discussion of the measurement of elasticity, see A. P. Lerner, "The Diagrammatical Representation of Elasticity of Demand," Review of Economic Studies, I, No. 1, 1933-34, pp. 39-44, and R. G. D. Allen, "The Concept of Arc Elasticity of Demand," same volume, pp. 226-29, and the accompanying note by Lerner. 
The same thing can be done with the prices. The formula thus becomes a complex fraction,

$$
\frac{\text { change in quantity }}{\frac{\text { average quantity }}{\text { change in price }}}
$$

Now the average is simply the total sum divided by the number of items. The number of quantity items is the same as the number of price items (in this case two) so the result will be the same if the sum of the quantities and the sum of the prices is used instead of the average prices and quantities (the 2's in the numerator and denominator cancel out). This will save some computation. The formula may then be expressed:

$$
\frac{q_{1}-q_{2}}{\frac{q_{1}+q_{2}}{p_{1}-p_{2}}} \frac{p_{1}+p_{2}}{p_{1}}
$$

The same formula can also be written in the form

$$
\frac{q_{1}-q_{2}}{p_{1}-p_{2}} \cdot \frac{p_{1}+p_{2}}{q_{1}+q_{2}}
$$

This was substantially the form which Marshall used, ${ }^{6}$ although he restricted the concept to infinitesimally small changes, in which case the change is represented by " $d$," and there is no need to use the average or the sum of the quantities and prices. His formula was merely $\frac{d q}{d p} \cdot \frac{p}{q}$. The complex-fraction formula is clumsier in appearance than the Marshallian form of the formula; it is superior to the other form for introductory expository purposes, because it shows more clearly just what elasticity is, but Marshall's form of the formula is standard and we will use it henceforth.

The data for potatoes substituted in this formula yield the following coefficient of elasticity:

${ }^{6}$ Marshall, Principles of Economics, 8th edition, Mathematical Appendix, Note III, p. $103 \mathrm{n}$. 


$$
\frac{400-325}{70-144} \cdot \frac{70+144}{400+325}=\frac{75}{-74} \cdot \frac{214}{725}=\frac{1605}{-5365}=-0.299
$$

Exactly the same result is obtained when the original quantity data are expressed in tons instead of bushels. The figures then become

$$
\frac{12-9.75}{70-144} \cdot \frac{70+144}{12+9.75}=\frac{2.25}{-74} \cdot \frac{214}{21.75}=\frac{481.5}{1609.5}=-0.299
$$

The same thing is obviously true if the prices are expressed in some other units.

We can now refine our definition of elasticity and make it more precise and definite, thus: Elasticity is the proportional change in quantity associated with a proportional change in price. The strict mathematical definition runs in terms of infinitesimals, but for students without mathematical training, the concept can be expressed in terms of percentages. The definition in that case is: Elasticity is the percentage change in quantity associated with a 1 per cent change in price (other things remaining constant). The computation for potatoes given above shows that a change in quantity of 0.299 per cent (roughly, 0.3 per cent) is associated with a 1 per cent change in price. That is, the elasticity of the demand for potatoes is -0.3 .

\section{EFFECT OF CROP SIZE ON TOTAL INCOME}

The chart discussed in the preceding pages shows the effect of the size of the potato crop upon the price of potatoes. Another question now arises. What is the effect of the size of the potato crop upon the total revenue from the crop? Does a large crop depress prices so much that the low price per bushel more than offsets the large number of bushels sold, or not?

It takes only a moment to answer this question. The smallest crop shown in Figure 21 was 322 million bushels; it sold at a price of $\$ 1.50$ per bushel; the total revenue, therefore, was 322 million $\times \$ 1.50$, or $\$ 483$ million. The largest crop was 406 million bushels; it sold at a price of 69 cents per bushel; the total revenue therefore was 406 million $\times \$ .69$, or $\$ 289$ million. The small crop was worth more than the large crop. The larger the crop, the smaller the total income. The demand in this case is said to be inelastic. In the case of some goods, a small reduction in price results in a larger increase, proportionally, in sales, and the larger the crop, the larger the total revenue. The demand in this case is referred to as elastic. 
What these terms elastic and inelastic really mean is "relatively elastic" and "relatively inelastic." The term "relatively" is dropped only for brevity; it really belongs in. "Relatively" here means relative to unit elasticity, the borderline case between relatively elastic and relatively inelastic. If the elasticity of demand for a good were such that any percentage increase in supply depressed the price by an equal percentage, then the total value of a large crop would be the same as that of a small crop. ${ }^{7}$ In fact, no matter what the size of the crop, it would be offset by an opposite change in price, so that the total value of the crop would be constant no matter what its size. In this case, in the formula presented a few paragraphs back, a 10 per cent (or any other) change would yield the following results:

$$
\frac{10}{-10} \cdot \frac{100}{100}=\frac{1000}{-1000}=-1.0
$$

This is called unit elasticity. It is the dividing line or borderline case between elastic demand and inelastic demand. If the elasticity is less than 1 it is called inelastic; if it is more than 1 it is called elastic. For technical accuracy, the terms, "relatively inelastic" (that is, less elastic than unity, inelastic relative to unit elasticity) and "relatively elastic" (more elastic than unity) should be used. But the word "relatively" is understood, and may be omitted in ordinary discussion.

In the illustration just given, an increase in quantity, a plus, is associated with a decrease in price, a minus. The measure of elasticity, therefore, carries a minus sign, as shown. Curves of this sort, with minus signs, all slope downward to the right, that is, from northwest to southeast. Practically all demand curves are of this character. If a case were found where increases in quantities were associated with increases in prices, the numerical expression of elasticity would have a positive sign and the curve would slope upwards to the right.

\section{ELASTICITY GRAPHICALLY REPRESENTED}

Elasticity can be represented graphically, but proper attention must be given to the scales of the charts. One might think that a

\footnotetext{
'Strictly speaking, this is true only when the percentage changes involved are infinitesimally small. Large changes introduce slight arithmetic discrepancies. For example, if the crop increased 10 per cent and the price decreased 10 per cent, the total value would be $90 \times 110=9,900$, not 10,000 . This question is discussed fully in the next chapter.
} 
demand curve of unit elasticity would be the hypotenuse of a rightangled triangle lying on one side, and that the slope of the curve would therefore be $45^{\circ}$; and, further, one might conclude that all curves that were more steeply sloped than $45^{\circ}$-say $50^{\circ}, 60^{\circ}$, or $70^{\circ}$ -would be inelastic, and all curves less steeply sloped than $45^{\circ}$ would be elastic.

Reference back to Figure 21, however, shows that the demand curve for potatoes shown in that figure has a slope that is definitely less than $45^{\circ}$. It is about $30^{\circ}$. This would seem to place it in the elastic category. Yet the numerical computations a few pages back showed that the elasticity was $-0.3^{\circ}$. This is clearly inelastic. Which is wrong, our graphics or our arithmetic?

A moment's reflection shows that it is our graphics that is at fault. The scales in Figure 21 are laid out in absolute, not percentage, terms. But elasticity is a proportional concept. The scales in the graph should run in percentage terms, and 10 per cent on the quantity scale should cover as much distance as 10 per cent on the price scale. If this procedure is followed, the chart will show elasticity correctly; the category into which the curve falls-inelastic or elastic-can then be determined directly from the chart by observing whether its slope is steeper or flatter than $45^{\circ}$.

The data, expressed in percentage terms and plotted on a properly scaled chart, are shown in the left hand section of Figure 22. The curve in this chart is much steeper than the one in Figure 21. It is clearly in the inelastic category. The proper arrangement of scales for representing elasticity directly is that which is used in Figure 22, with the data expressed as percentages and the horizontal and vertical scales equal, so that 10 per cent on one scale equals the same distance as 10 per cent on the other.

It is not the conversion of the original data into percentage form alone that enables elasticity to be read directly from the slope of the line on a chart with arithmetic scales. It is this, plus the setting of the horizontal and vertical scales so that 10 per cent on the one scale is represented by the same distance as 10 per cent on the other scale, that does the trick.

This could be accomplished just as well by plotting the data in their original form, on a chart with the horizontal and vertical scales set so that the average price equals (say) 5 inches on the vertical scale, and the average production equals the same distance, 5 inches, on the horizontal scale. The elasticity could then be read directly 
from the slope of the line on a chart with arithmetic scales, regardless of what units the original data were expressed in. This sounds easier than converting the data into index form. But, as a matter of fact, it turns out that it is more trouble to do this than to convert
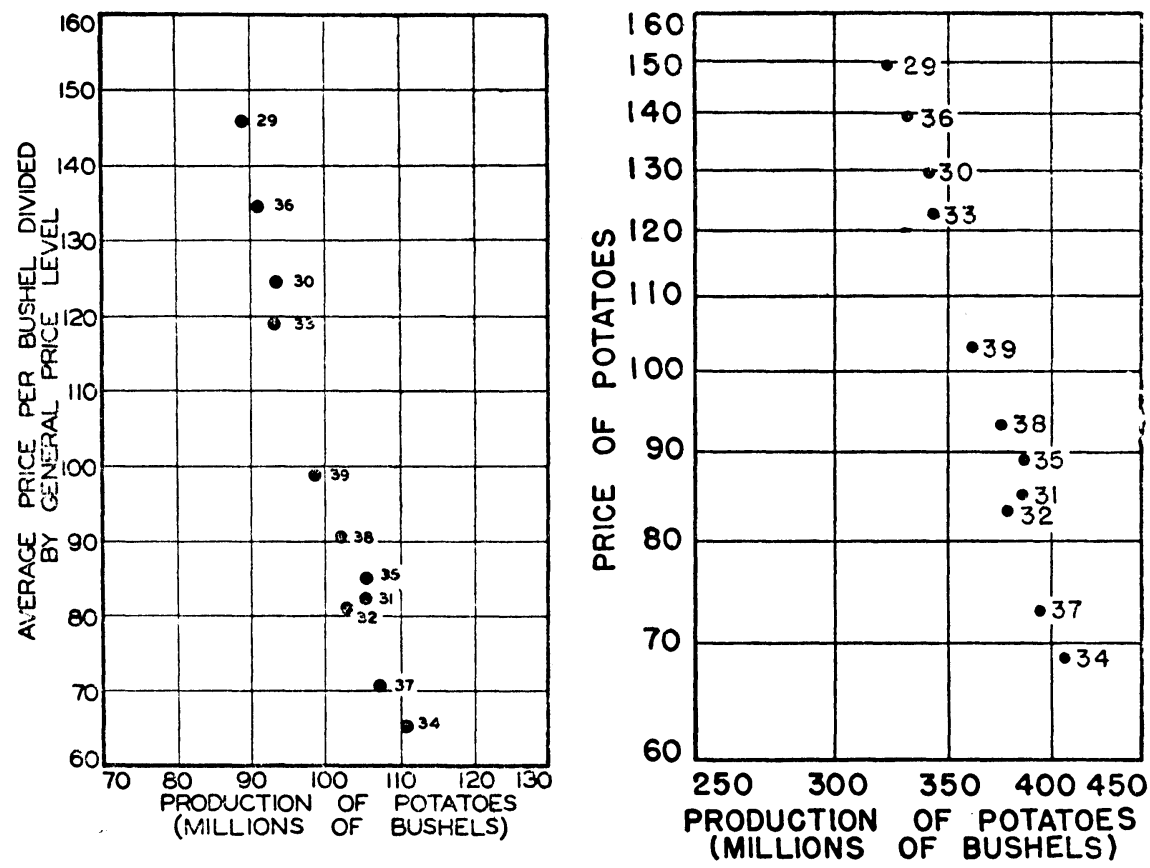

FIG. 22.-Potatoes: United States average farm price, December 1, and total production, 1929-39. (A) Data in percentage terms; arithmetic scales. (B) Data in original form; logarithmic scales.

the data into index form and plot them in that form. For suppose that the average price comes out to be 77 cents, or some other figure that is not an easy multiple of 5 ; the resulting scale is very awkward to plot, especially when the production scale is probably awkward too. It is easier after all to convert the data into index form (i. e., into percentages) and set the scales so that 100 per cent equals 5 or 10 inches, or some other easy divisor of 100 .

Elasticity can also be shown graphically by plotting the data in their original form on double logarithmic paper, that is, paper in which both the horizontal and vertical scales are logarithmic. No matter what units the original data are expressed in-dollars, francs, pounds, ounces, etc.-when they are plotted on double logarithmic 
scales, the slope of the line shows the elasticity directly. ${ }^{8}$ The data plotted in this manner are shown in the right hand section of Figure 22. The slope of the curve here is identical with the slope of the curve in the left hand section of Figure 22. This is really the simplest way to show the relation between price and production data; but most people are not familiar with logarithmic scales, so for purposes of presentation it is better to plot the data in percentage terms on ordinary arithmetic paper.

Considerations similar to those which hold for ordinary arithmetic paper rule here. It is not the plotting of the data on logarithmic scales that enables elasticity to be read directly from the chart; it is the fact that the horizontal and vertical scales are equal that does it.

\section{EFFECT OF MIDDLEMAN'S MARGINS ON ELASTICITY}

The factors that determine elasticity are discussed in any good textbook on elementary economic theory, and there is no need to repeat the discussion here. But most discussions of this sort deal with the elasticity of demand at the retail store, or wherever the consumer buys the goods. The elasticity of demand at the farm is affected by still another thing in addition to these-by the size and stability of the middleman's charges, that is, the margins between the prices of goods at the farm and at the retail store.

Middleman's margins remain rather stable through periods of high prices and low prices resulting from fluctuations in supplies. ${ }^{9}$ They change from periods of prosperity to periods of depression (fluctuations in general demand) because wages, although.comparatively stable, do change to some extent from peak to trough of industrial activity. But during periods of relatively stable industrial activity, the margin between potato prices at the farm and potato prices at the retail store, for example, remains much the same when potato supplies are short and prices high as when supplies are plentiful and prices low.

In that case, if the demand curves for potatoes at retail and for potatoes at the farm were plotted on the same chart with arithmetic

\footnotetext{
${ }^{8}$ Technically speaking, the elasticity is not the same as the slope; it is the reciprocal of the slope. For the slope is the number of units that the curve rises per unit of horizontal run; it is $\frac{p}{q}$. But elasticity is $\frac{q}{p}$. The greater (i.e., steeper) the slope the less the elasticity.

${ }^{8}$ See Price Spreads Between Farmers and Consumers for Food Products, 1913-44, USDA Misc. Pub. No. 576, 1945, pp. 20-24.
} 
scales, the two curves would be parallel, the one lying above the other. The curves would look something like those in Figure 23. This figure is based on hypothetical data, that enable the exposition to be made arithmetically simple.

In this chart the average price of potatoes at the retail store is 20 cents a pound, the average price of potatoes at the farm is 10 cents a pound, and the margin between the two prices remains fixed at 10 cents a pound. The elasticity of the demand for potatoes at retail is represented as unity. From the parallelism of the two curves, one might conclude that the elasticity of the demand for potatoes at the farm must be unity also.

But that would be a mistake. Application of the regular elasticity formula to these hypothetical data shows that whereas the elasticity of the demand at retail is unity, that at the farm is only - 0.5. The two calculations, based upon figures read off the chart, follow:

For potatoes at retail

$$
\frac{12-8}{16-24} \cdot \frac{20}{10}=\frac{80}{-80}=-1.0
$$

For potatoes at the farm $\frac{12-8}{6-14} \cdot \frac{10}{10}=\frac{40}{-80}=-0.5$

Looking at the two sets of calculations, we see that they are identical in all respects except the average price. For potatoes at retail, the average price is 20 ; for potatoes at the farm it is 10 .

It is clear from this formula that if you halve the average price, other things being the same, you halve the elasticity. It shows that the width and fixity of the margin between farm prices and retail prices affects the elasticity of the demand at the farm. The wider and more stable the margin, the less elastic is the demand at the farm compared with the demand at the retail store. ${ }^{10}$

\section{EFFECT OF TIME UPON ELASTICITY}

Economists since at least as far back as Marshall ${ }^{11}$ have recog-

\footnotetext{
${ }^{10}$ The effects of changes in middlemen's margins are shown in Appendix $\mathrm{C}$ of Marketing Farm Products, The Iowa State College Press, 1946, by the present author.

${ }^{11}$ Marshall, Principles of Economics, pp. 109-12. For more recent discussions see E. J. Working, "Statistical Demand Curves." Encyclopaedia of the Social Sciences, V, 1931, pp. 74-75, and R. L. Mighell and R. H. Allen, "Demand Schedules-Normal and Instantaneous," Journal of Farm Economics, XXI, No. 3, Part I, August, 1939, pp. 555-69.

A broader treatment of dynamic demand is given in C. F. Roos, Dynamic Economics, Principia Press, 1934. The subject is treated mathematically in Griffith C. Evans, Mathematical Introduction to Economics, McGraw-Hill, 1930, Chap. IV, and in Gerhard Tintner, "The Theoretical Derivation of Dynamic Demand Curves," Econometrica, VI, No. 4, October, 1938, pp. 375-80.
} 
nized that it is incorrect to speak of "the elasticity" of the demand for a commodity, for the elasticity differs according to the length of time involved. The subject has been given extensive theoretical discussion, with the aid of hypothetical data, but not much has been offered in the way of empirical demonstration. A few studies may be brought together to serve this purpose.

Short-time elasticities. Statements have been made that "the elasticity" of the demand for hogs is $-0.65^{12}$ or $-0.7 .^{13}$ But all that these statements mean is that the elasticity of the demand for hogs based upon annual data is (or, more accurately, was) -0.65 or -0.7 . Other empirical studies have shown that the elasticity of the demand for hogs derived from weekly data is much greater

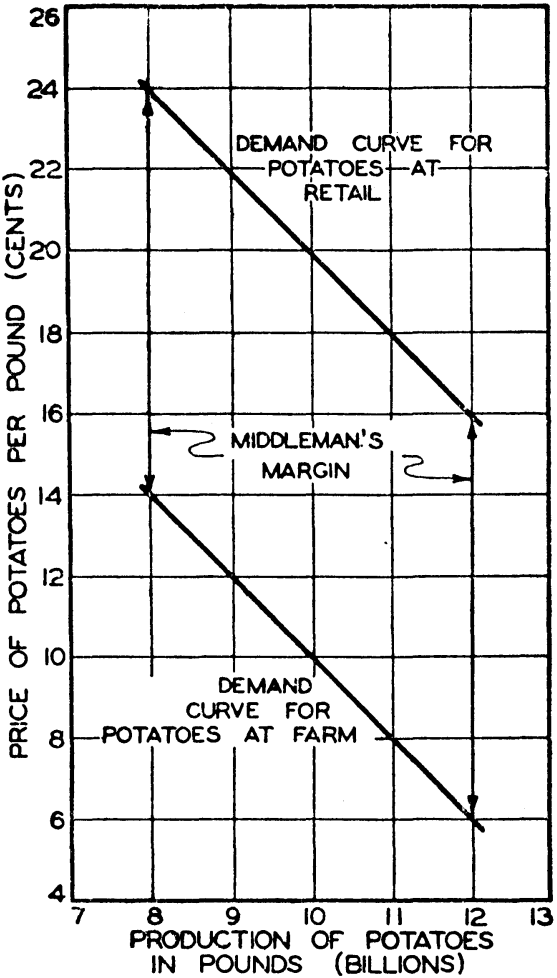

Fig. 23.-Hypothetical demand curves for potatoes at the retail store and at the farm. than this, and that the elasticity derived from daily data is still greater. Stover ${ }^{14}$ found that over the period 1921-28, inclusive, the elasticities of the demand for hogs at Chicago based on daily, weekly, and yearly data were as follows:

Saturday $-5.8$

Wednesday $-2.8$

Week $-2.5$

Year $-1.0$

Among the various days of the week, the elasticity was greatest

${ }^{12}$ Geoffrey Shepherd and Walter Wilcox, Stabilizing Corn Supplies by Storage, Iowa Agr. Exp. Sta., Bul. 368, 1937, pp. 337-38.

${ }^{13}$ Preston Richards, "Livestock Marketing Methods and Livestock Prices," Journal of Farm Economics, XXI, No. 1, February, 1939, pp. 219-27.

${ }^{14}$ Howard J. Stover, Relation of Daily Prices to the Marketing of Hogs at Chicago, Cornell Univ. Agr. Exp. Sta., Bul. 534, 1932, p. 33. 
on Saturday and least on Wednesday; the elasticity on Wednesday was almost as high as the elasticity for the week as a whole. ${ }^{15}$

Similarly, the elasticity of the demand for eggs, based upon annual data, is about $-0.4,{ }^{16}$ whereas the elasticity based upon monthly data averages about $-3.0 .^{17}$ Other instances of this sort could be given. It is not surprising that the short-time elasticities differ from the annual-data elasticities; they refer to different demands. The short-time elasticities should be greater than the longtime elasticities, because a large part of the short-time fluctuations in supplies thrown on the market are absorbed by short-time storage operations. Dealers buy eggs, for example, for storage, whenever they believe that the price of eggs some time in the future (within the probable storage life of an egg) will be higher than it is at present-and higher by more than the cost of storage to that future time. The future changes in prices that dealers can predict most confidently are those associated with regular seasonal changes in egg receipts, so that storage is largely a seasonal phenomenon. At the time of large egg receipts and low prices, therefore, the storage dealer's demand for eggs is added to the consumer's demand; this keeps prices from falling as low as they would in the absence of purchases for storage. Later on in the season, when egg receipts are light and prices high, the storage dealer's eggs are added to the current receipts from producers. This keeps prices from rising as high as they would otherwise. Longer-time (annual) fluctuations in supplies, however, cannot be thus absorbed, because the commodity is too perishable to stand storage for more than a few months.

Long-time elasticities. The elasticities of demand based on daily, weekly, or monthly data are likely to be greater than for annual data. What about the elasticities based on items each of which covers more than a year, perhaps five or ten years?

There are reasons for believing that these elasticities based on long-time data may be greater than the elasticities based on annual data. These reasons are not the same as those which make the

\footnotetext{
${ }^{15}$ The elasticity he found for the yearly data was higher than that which has been found in the more recent studies referred to in the two preceding footnotes, because his data were Chicago (not national) data, and he found the gross regression of receipts on prices, not the net regression.

${ }^{16}$ Henry DeGraff, unpublished study, Economics Department, Iowa State College, 1940.

${ }^{17}$ K. L. Cannon, unpublished study, Economics Department, Iowa State College, 1939.
} 
elasticities for weekly data greater than for annual data; they are related not to storage, but to the ease of substitution.

If some year the grapefruit crop is short, for example, consumers who have established a place for it on their breakfast table may bid grapefruit prices up to a high point in an attempt to keep it there. They know that grapefruit will probably be plentiful again within another year, and they dislike to change their consuming habits merely for a year only to change them back again when the year is over. But if grapefruit acreages were more or less permanently reduced and grapefruit rose to a place in the luxury price class, many consumers would replace it on their breakfast table with something else, and prices would not be bid so high as for a one-year shortage.

Another example is corn. The demand for corn, based upon annual data, is only about -0.5 at its lower end; but if large supplies and low prices seemed likely to persist for years in the future, power alcohol plants would be set up to use the cheap corn, and would open up a demand that would be very elastic indeed. Similarly, at the upper end of the scale, if scarcity and high prices appeared likely to persist for a decade or more, consumers" would have time to cultivate new tastes and manufacturers would have time to bring new substitute products on the market, which would render the upper part of the curve more elastic also.

This boils down to the simple fact that the more time you give people to change their tastes, the more they will change them. This principle operates continuously, from the shortest periods of time, only a few moments long, up to the longest periods, decades and more in length. Within the short periods of time, however, the effect of this principle is more than offset by the opposite effect of storage and subsequent "unstorage" of temporary surpluses. The lowest elasticity of demand for a good, therefore, is that which is based on data each of which represents a period just a little longer than the storage life of that good. For extremely perishable goods like strawberries, this period is only a few days or weeks in length. For many farm products which are semiperishables, such as meat, eggs, and butter, this period is a year. Most analyses of the demand for farm products are based on annual data, and the elasticities found for the semiperishables are likely to be the minimum elasticities; both shorter-period and longer-period data yield higher elasticities than the annual data. For grains, which are stored to some extent for longer periods than one year, the minimum elasticity period is 
likely to be longer than one year. For cotton, which is stored for still longer periods than grain, the minimum elasticity period is likely to be still longer.

\section{DIFFERENT KINDS OF ELASTICITY}

The elasticity of demand dealt with in this chapter has been the price elasticity of demand-the responsiveness of quantity to changes in price. There are many other kinds of elasticity. The income elasticity of demand, for example, shows the responsiveness of quantity to differences in incomes. A chart showing the income elasticity of demand would have the income scale plotted up the side and the quantity scale for the good in question along the bottom.

The income elasticity for the staple foods is low. A man with twice as much income as another does not eat twice as much bread and potatoes; he may in fact eat less of these foods than the man with the low income; but he may buy more than twice as much of luxury goods, housing, medical care, savings, etc. The income elasticity for bread and potatoes is low, and may even be negative; but for these other products it is high, and of course positive.

Most of the empirical investigations of the income elasticity of demand show the different per capita expenditures for specific goods, not the different per capita quantities of the goods taken, by people with different incomes. The scale along the bottom of the chart represents the expenditures for the particular good, not the quantities. This shows the income elasticity of expenditure rather than the income elasticity of demand (which is expressed in quantities). This type of curve is called an income-expenditure curve.

Curves of this sort differ from price elasticity demand curves. The latter show the changes in quantity taken when the price changes, all other things except the price of the good remaining the same; income-expenditure curves measure approximately the changes in quantity taken when all prices, including the price of the good in question, change in the same proportions.

Income-expenditure curves based on 1935-36 data ${ }^{18}$ show that the curve for savings has the greatest elasticity of all the curves shown. The curve for food becomes very inelastic as incomes increase above $\$ 4,000$ per year. Similar information is given in greater

\footnotetext{
${ }^{18}$ Consumer Expenditures in the United States, U. S. National Resources Committee, 1939, pp. 38-39. The charts are plotted with income alcng the bottom and expenditures up the side, the reverse of the usual procedure as defined above.
} 
detail in a study of data for wage earners and lower-salaried groups in two different areas-New England and the Southeast-in 1935. ${ }^{19}$ The income-expenditure elasticities for the most important food items, as computed by Waite and Cassady, ${ }^{20}$ are shown by districts in Table 5.

TABLE 5

InCOME EXPENDITURE ElASTICITIES

(Arranged in order of magnitude)

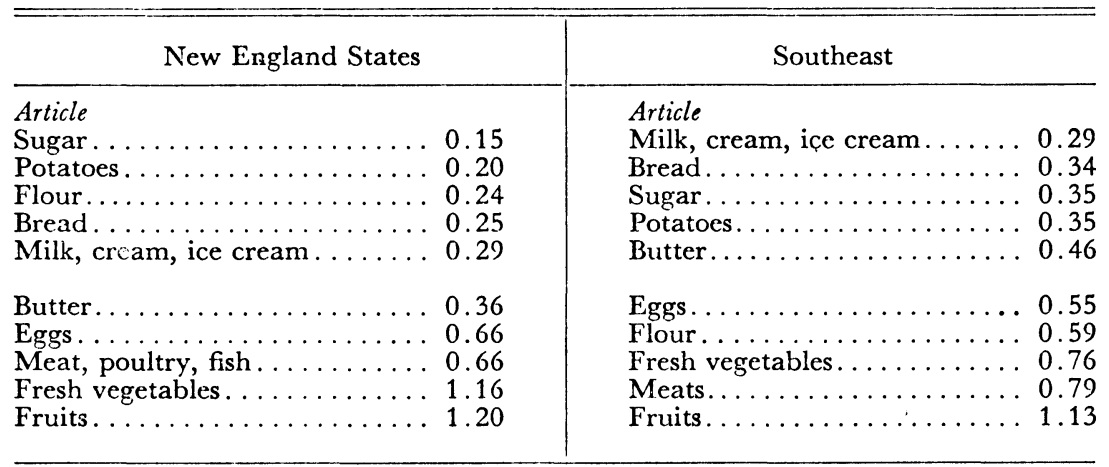

Another sort of elasticity is the elasticity of substitution. This has been defined as "the proportionate change in the ratio of the amounts of the factors employed divided by the proportionate change in the ratio of their prices to which it is due." "I1 "It represents the additional amount of the factor $B$, from the given combination of factors, necessary to maintain product unchanged when a small unit reduction is made in the use of the factor A."22 The definition with respect to consumers' goods is similar to this.

An illustration with reference to consumers' goods is the elasticity of substitution between two classes of wheat-Soft Red Winter and Hard Red Winter. ${ }^{23}$ This is shown in Figure 24. The elasticity of substitution here is about -3.0 . The elasticity of substitution

${ }^{19}$ Monthly Labor Review, U. S. Department of Labor, XLII, April, 1936, p. 892 .

${ }^{20}$ Warren C. Waite and Ralph Cassady, Jr., The Consumer and the Economic Order, McGraw-Hill, 1939, p. 158.

${ }^{21}$ Joan Robinson, Economics of Imperfect Competition, Macmillan, London, 1933, p. 256.

${ }^{22}$ R. G. D. Allen, Mathematical Analysis for Economists, Macmillan, London, 1939, p. 341.

${ }^{23}$ D. R. Kaldor, unpublished marketing study, Economics Department, Iowa State College, 1940. 
between White and Hard Red Winter shown in Figure 24 is lower than this; it is about - 2.0. Apparently, Soft Red Winter wheat can

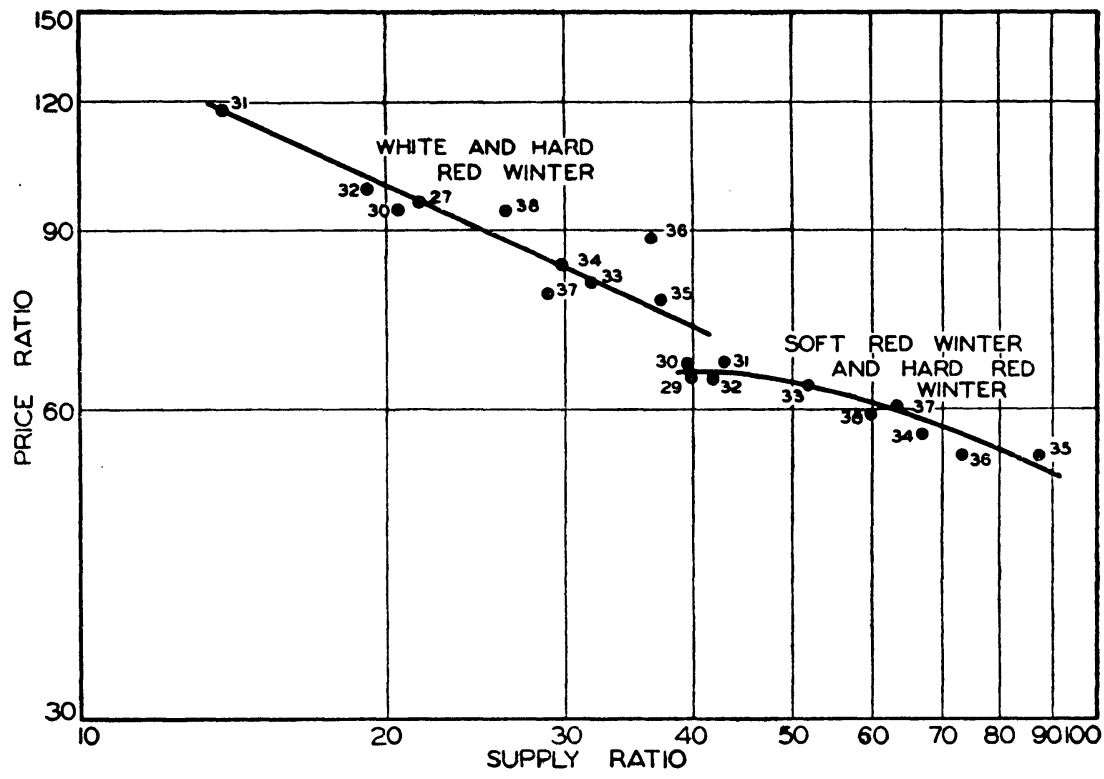

FIG. 24.-Elasticities of substitution between White wheat and Hard Red Winter wheat, shown by the upper line, and between Soft Red Winter wheat and Hard Red Winter wheat, shown by the lower line, 1928-38.

be substituted for Hard Red Winter wheat more easily than White wheat can.

One more kind of elasticity is "cross-elasticity." This is found by computing the changes in the quantity of a good that will be taken per unit change in the price, not of that good but of a related good; for example, by computing the changes in the sales of Fords per unit change in the price of Chevrolets. 


\section{Point Elasticity, Total Revenue, and Marginal Revenue}

The discussion in the preceding chapter dealt only with the elasticity of the curve as a whole. But this is rather a rough-andready concept, for "the elasticity" of a curve is really a sort of average of the elasticities at different points along the curve. "The elasticity" we have been dealing with is often called arc elasticity, the elasticity of the arc of the curve. It is a sort of average elasticity. Whatever term is used (arc or average), it relates to the elasticity of the curve or arc as a whole. We come now to consider point elasticity, the elasticity at any point on a curve.

\section{CURVES WITH AVERAGE ELASTICITY OF UNITY}

Elasticity is a proportional concept, and the elasticity of a straight line curve on a chart with arithmetic scales therefore is not constant from point to point along the line. It varies from point to point. This shows up most clearly in the simplest case of a straight-line curve with an average or arc elasticity of unity; such a curve is represented by the straight line marked A in section A of Figure 25.

This straight-line curve has an elasticity of unity at its central point where price $=5$, and quantity $=5$; for if $d x=d y$, as it does here when the slope of the line is $45^{\circ}$, then $\frac{d x}{-d y} \cdot \frac{5}{5}=-1.0$.

But at other points along the line the elasticity is not -1 . At the point where price $=6$, and quantity $=4$, for example, the elasticity is $\frac{d x}{d y} \cdot \frac{6}{-4}=-1.5$. At the point where price $=8$, and quantity $=2$, the elasticity is -4.0 . Conversely, at points below and to the right of the center of the line, the elasticities are less than -1 .

What would a curve of constant unit elasticity at all points look like? It follows from the preceding paragraph that the slope of the line $\left(\frac{d y}{d x}\right)$ at every point would have to be proportional to the 
relation between $y$ and $x$ at every point. A curve of this sort would be a rectangular hyperbola, approaching the $x$ and $y$ axes as asymptotes. Several constant-unit elasticity curves of this sort, lettered $B, C, D$, etc., are plotted in section $A$ of Figure 25 along with
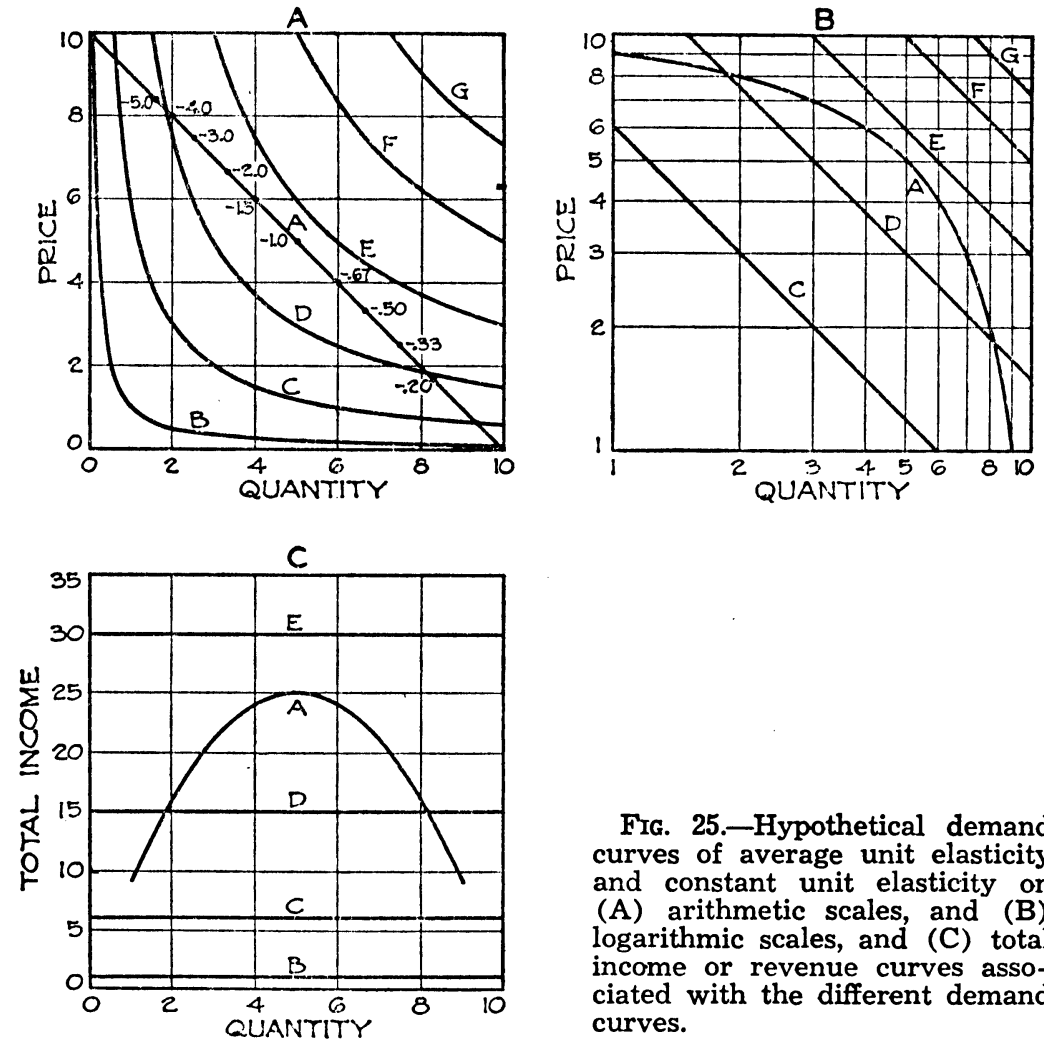

Fig. 25.-Hypothetical demand curves of average unit elasticity and constant unit elasticity on (A) arithmetic scales, and (B) logarithmic scales, and (C) total income or revenue curves associated with the different demand curves.

the straight-line curve $A$ that has an average elasticity of unity.

This figure shows graphically how the elasticity of a straight line changes from point to point. It shows this by comparison of the straight-line curve, $A$, with the constant elasticity curves, $B, C, D$, etc., beside it. This comparison shows that the upper part of the straight-line curve is less steeply sloped than the constant unit elasticity curves; that is, it is more elastic than unity. Conversely, the lower part of the straight-line curve is less elastic than unity. The elasticity is highest at the upper end and lowest at the lower 
end. It is higher than unity at the top, decreases to unity at the middle, and gets less and less than unity from there on down. The elasticity at different points along the straight line is shown by the series of figures written beside the line.

The situation can be shown on double logarithmic paper, as in section B of Figure 25. The constant unit elasticity curves, B. C, D, etc., shown in section $A$ of Figure 25, become straight lines with slopes of $45^{\circ}$ on the logarithmic paper used in section $B$. The straightline curve, $A$, on arithmetic paper in section A undergoes the opposite change to become a curved line, convex from above, ${ }^{1}$ on the logarithmic paper used in section B.

\section{TOTAL REVENUE OR INCOME}

The total revenue (that is, total income) that would be realized from the sale of different quantities of a commodity depends upon the shape or curvature of the demand curve, as well as upon its elasticity. The total revenue curve is directly related to the demand curve (which is in other words the average revenue curve). They can be shown on similar charts, the only difference being that in the total revenue chart the vertical scale shows total revenues instead of average revenues (prices).

The total revenue curve associated with a straight-line demand curve on arithmetic paper, with an average elasticity of unity, is shown in section $\mathbf{C}$ in Figure 25. This shows that with this sort of a demand curve the maximum total revenue is realized from an average crop. Large crops and small crops both bring in less money than average crops. The point of highest total revenue comes at the point where the elasticity of the demand curve is unity.

The total revenue curves derived from constant unit elasticity

${ }^{1}$ There are two ways of verbally describing the curvature of lines plotted on co-ordinate paper. Both of them are in common use. The one way is to describe curves as concave or convex from above (a basin with water in it is concave from above) while the other way is to describe them as concave or convex to the origin.

There are objections to both systems. The objection to the "from above" reference is that it cannot be applied to curves whose ends lie on the same vertical line. The objection to the "origin" reference is that it cannot be applied to curves that go through the origin. This objection is perhaps more important than the other, because some important economic curves necessarily start from the origin - total revenue curves, positive sloping curves of unit elasticity, etc. In addition, most mathematicians (although not R. G. D. Allen) and some economists use the reference "from above"-Joan Robinson in England, and Tintner, Waugh, and Thomsen in the United States, to name only a few. We are accordingly using the reference "from above" in the present work. 
curves like $B, C, D$, etc., are horizontal straight lines. If the elasticity is unity at all points, the total revenue remains constant, whatever the size of the crop, as shown for the curves $B, C, D$, and $E$ in section C of Figure 25.

Concave demand curves with an average elasticity of unity, but less curved on arithmetic paper than the constant elasticity curves shown in section A of Figure 25, undergo an interesting transformation when plotted on logarithmic paper. Their curvature is reversed. They are concave on arithmetic paper, but they become convex on logarithmic paper. The point of highest total revenue appears (in their case as in the case of straight-line curves on arithmetic paper) at the central point of the curve where the point elasticity is unity.

Concave demand curves with an average elasticity of unity, but more curved on arithmetic paper than constant-elasticity curves, lose some of their curvature when plotted on logarithmic paper. But they retain their concavity. Accordingly, with this kind of demand curve, the minimum total revenue is realized from the sale of an average crop. Large crops and small crops both bring in more money than an average crop. The point where the elasticity of the demand curve is unity is the point of lowest total revenue.

\section{ELASTICITIES OTHER THAN UNITY}

Demand curves whose elasticity is constant but higher or lower than unity are straight lines on logarithmic scales, like the curves $B, C, D$, etc., in section $B$ of Figure 25, but their slopes are other than $45^{\circ}$. The slopes of the inelastic curves are steeper than $45^{\circ}$, and those of the elastic curves, flatter than $45^{\circ}$.

The total revenue curves associated with these constant (but not unit) elasticity demand curves are sloping curved lines, not horizontal straight lines like the total revenue curves associated with constant unit elasticity curves. They are curved lines. The total revenue curves for constant but less than unit elasticity demand curves are rectangular hyperbolas like the curves of constant elasticity shown earlier in section A of Figure 25. And like those curves, they would be straight lines with a negative slope on double logarithmic paper. A demand curve with constant elasticity of -0.5 is shown on arithmetic and logarithmic paper, together with the total income or revenue curve based upon it, in sections $\mathrm{A}$ and $\mathrm{C}$ of Figure 26.

The total revenue curves for constant but more than unit 
elasticity demand curves are also curved, but they are parabolas, with apex at the origin of the $x$ and $y$ axes. They, too, are straight lines on double logarithmic paper; but they have a positive slope.
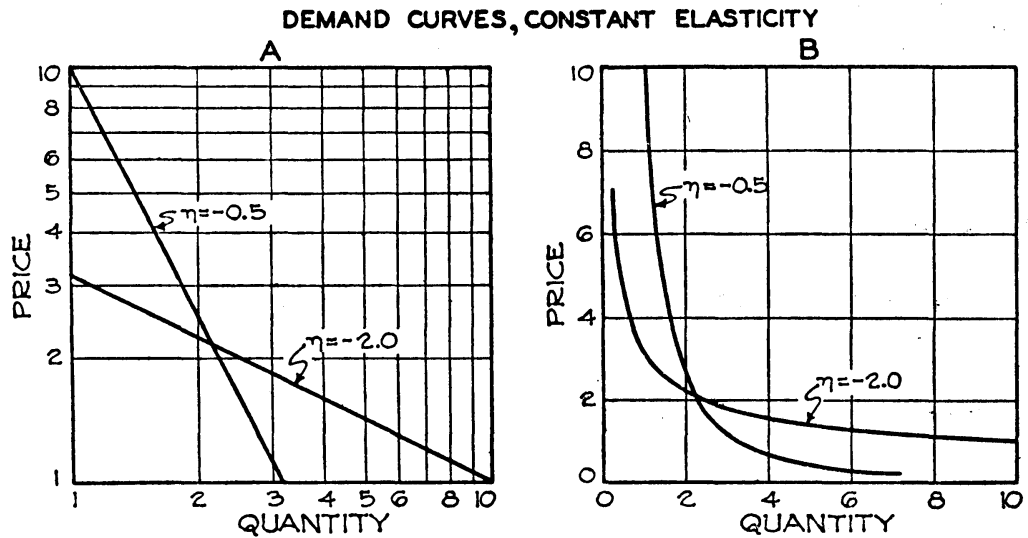

TOTAL INCOME CURVES
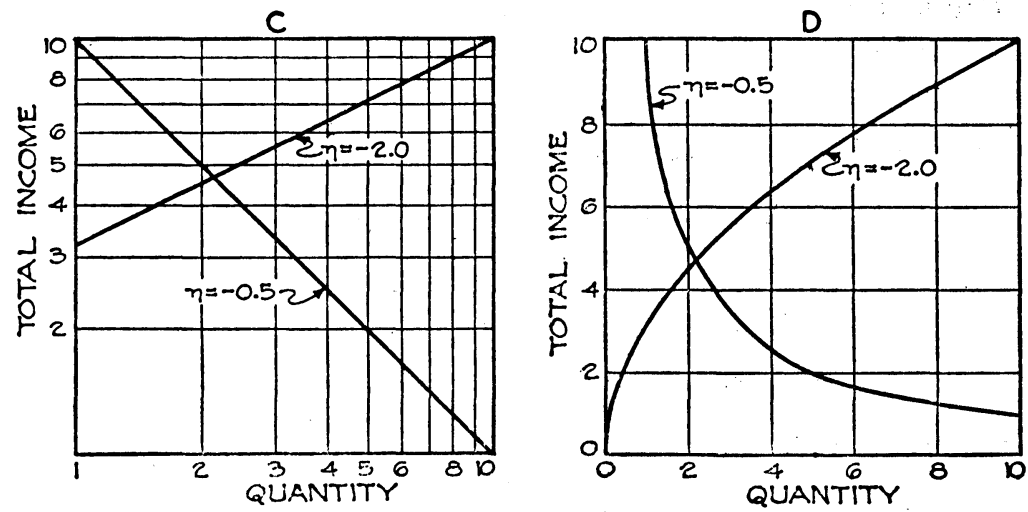

Fig. 26.- (A and B) Hypothetical constant elasticity demand curves and (C and D) total income (revenue) curves associated with them.

A demand curve with a constant elasticity of -2.0 , and the total revenue curve based upon it, is shown also in sections $A$ and $B$ of Figure 26.

The elasticity figures given beside the total revenue curves in the lower sections of this chart are only identification-elasticities, showing in each case the elasticity of the demand curve from which the total revenue curve was derived, not the elasticity of the total 
revenue curve itself. That elasticity can be figured mathematically from the elasticity of the demand curve. The mathematical relationship between the elasticity of the demand curve and that of its associated total revenue curve is comparatively simple. If $E=$ the elasticity of the total revenue curve, defined in an analogous manner to the Marshallian definition of the elasticity of the demand curve (i. e., as $\frac{d q}{d(p q)} \cdot \frac{p q}{q}$ or $\frac{d q}{q} / \frac{d(p q)}{p q}$ ) and $e=$ the elasticity of the demand curve, the relationship 2 is $E=\frac{e}{e+1}$

This formula may be solved for $e$ in terms of $E$, giving the elasticity of the demand curve in terms of the elasticity of the total revenue curve, as follows: $e=\frac{E}{1-E}$

\section{THE MEASUREMENT OF POINT ELASTICITY}

Point elasticity can be measured mathematically by the use of the same formula that was used for average or arc elasticity in the preceding chapter. If the demand curve is a straight line, the

${ }^{2}$ This relationship may be derived as follows:

$$
\begin{aligned}
& E=\frac{d q}{q} / \frac{d(p q)}{p q}=1 / \frac{d(p q)}{p d q}=1 / \frac{p d q+q d p}{p d q} \\
& =1 /\left(1+\frac{q d p}{q d p}\right)=1 \quad\left(1+\frac{1}{e}\right)=\frac{e}{e+1}
\end{aligned}
$$

It is interesting to observe that if $E$ and $e$ are both defined as reciprocals of the usual definitions, that is, as $\frac{d(p q)}{d q} \cdot \frac{q}{p q}$ and $\frac{d p}{d q} \cdot \frac{q}{p}$ respectively, then the relation between $E$ and $e$ is very simple. It is

$$
E=\frac{d(p q)}{d q} \cdot \frac{q}{p q}=\frac{d(p q)}{d q} \cdot \frac{1}{p}=\frac{q d p+p d q}{p d q}=\frac{q d p}{p d q}+1=e+1 .
$$

(See R. G. D. Allen, Mathematical Analysis for Economists, Macmillan, London, 1938, p. 252.) That is, $E$ as thus defined is always greater by 1 than $e$ as thus defined.

If $e$ is defined as usual (as $\left.\frac{d q}{d p} \cdot \frac{p}{q}\right)$ and $E$ defined as above (as $\frac{d(p q)}{d q} \cdot \frac{q}{p q}$ ) then $E=\frac{1}{e}+1$

I am indebted to Gerhard Tintner and Adolf Kozlik for this footnote. 
formula is merely the original Marshallian formula, with the $p$ and $q$ at the particular point used in place of the average $p$ and average $q$ over the range used when average elasticity is computed. If the curve is not a straight line, then a tangent must be drawn to it at the point where the elasticity is to be measured. The $\frac{d q}{d p}$ is then computed from the tangent.

Point elasticity can also be measured graphically. The way to do it is shown in Figure 27. If the demand curve is a straight line and the elasticity at the point $p$ is to be found, that can be done by laying a ruler along the demand curve and measuring the two distances (1) from $p$ to the point where the ruler cuts the $y$ axis ( $p c$ in the diagram) and (2) from $p$ to the point

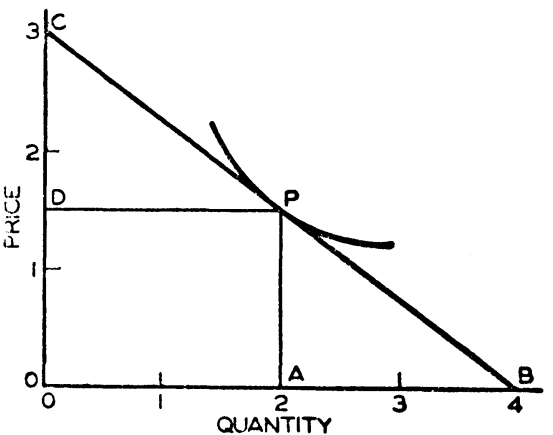

Fig. 27.-Diagram for the measurement of point elasticity. where the ruler cuts the $x$ axis ( $p b$ in the diagram). The latter distance divided by the former (that is, $\frac{p b}{p c}$ ) then gives the elasticity at the point $p$.

If the demand curve is a curved line, the procedure is the same, but the ruler is laid tangent to the curve at the point where the elasticity is to be measured. The ratio $\frac{p b}{p c}$ then gives the elasticity at that point. ${ }^{3}$ It can then be shown that the elasticity at $p$ is also given by $\frac{a b}{o a}$.

\section{MARGINAL REVENUE}

The preceding sections have shown the relation between elasticity and total income or revenue. We turn now to a third concept, marginal revenue.

"The proof of these relations is simple. The elasticity, $\frac{d q}{d p} \cdot \frac{p}{q}$, is the change in quantity divided by the change in price, multiplied by the price divided by 
The concept or definition of marginal revenue is perfectly clearcut. The total revenue (or total income, which means the same thing) is the total revenue from the sale of a given amount of the product, say $x$ bushels. It is computed by multiplying $x$ bushels by the price at which that number of bushels can be sold. This total revenue may be compared with the total revenue from the sale of $x+1$ bushels; this is computed by multiplying $x+1$ bushels by the price at which that number of bushels can be sold. The difference between the two total revenues is the marginal revenue. ${ }^{4}$

For example, a dealer may be able to sell 10 boxes of apples a day for $\$ 2.00$ a box. His total revenue from the sale of apples then is $\$ 20.00$. Suppose now that more apples come on the market; he now has 11 boxes a day to sell. He has to cut the price to move them all. He cannot merely cut the price of the eleventh box; the buyers of the 10 boxes would object; so he has to cut the price of all the boxes of apples. If he has to cut the price to $\$ 1.90$ per box, his total revenue then is $\$ 1.90 \times 11$, which is $\$ 20.90$. What is the marginal revenue, then? It is the difference between $\$ 20.00$ and $\$ 20.90$; it is 90 cents.

Suppose then that still more apples come on the market, so that the dealer now has 12 boxes a day to sell. If he has to cut the price

the quantity. In Figure 27, the first term of the elasticity formula, $\frac{d q}{d p}$ is $\frac{A B}{A P}$. The second term, $\frac{p}{q}$ is $\frac{A P}{O A}$. The formula as a whole then is $\frac{A B}{A P} \cdot \frac{A P}{O A}$. This reduces by cancellation of the two $A P$ 's to $\frac{A B}{O A}$.

Since a line parallel to the base of a triangle divides the other sides proportionally, $\frac{A B}{O A}=\frac{B P}{P C}$.

I am indebted to A. G. Hart for this proof, which is simpler than Marshall's. (Marshall, Principles of Economics, pp. 102-03, footnote 1, and the mathematical appendix, note 3 , p. 839.)

" "It is clear that a marginal concept is only precise when it is considered in the limiting sense, as the variations in $X$ are made smaller and smaller. It is then to be interpreted by means of the derivative of the function which relates $X$ and $\mathrm{Y}$... Marginal revenue is thus an abstract concept only definable for continuous variations in revenue and output. But it is always approximately equal to the added revenue obtained from a small unit increase in output from the level $x "-$ R. G. D. Allen, Mathematical Analysis for Economists, pp. 152-53. 
perhaps another 10 cents a box, to $\$ 1.80$, what is the marginal revenue in that case? The total revenue now is $\$ 1.80 \times 12$, which is $\$ 21.60$. If we subtract from this the total revenue from the sale of 11 boxes, which is $\$ 20.90$, we see that the marginal revenue in this case is 70 cents.

For brevity, we say that the marginal revenue from the sale of the twelfth box of apples was 70 cents, whereas in the previous case, the marginal revenue from the sale of the eleventh box was 90 cents. But we must be careful to remember that it was not the sale of the twelfth box that brought in 70 cents, for actually that twelfth box brought in $\$ 1.80$ like all the other boxes. It was the increase in total revenue when 12 boxes were sold, over the total revenue when only 11 boxes were sold, that was 70 cents.

The marginal revenue, then, ordinarily changes as more and

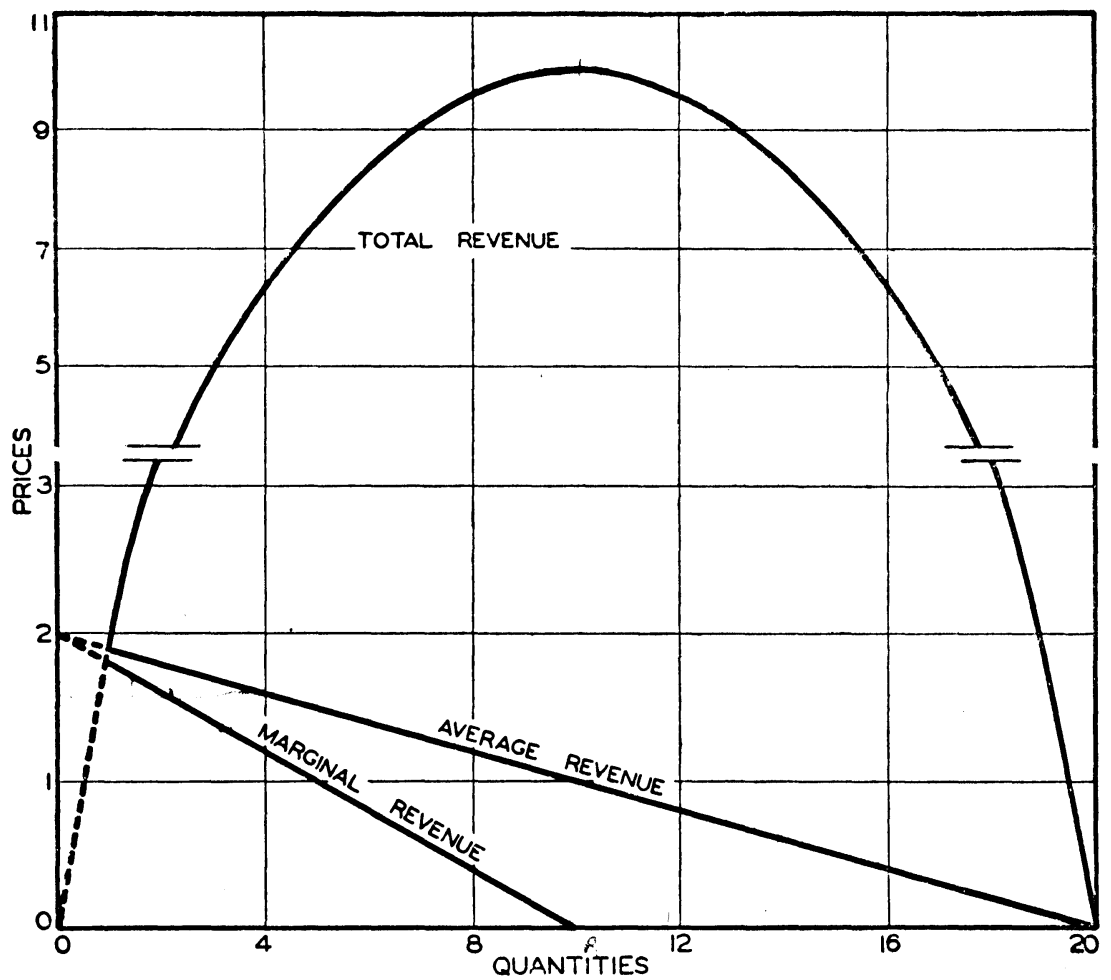

Fig. 28.-Relations between marginal, average, and total revenue. Hypothetical data. 
more units are sold. The changes in total revenue, average revenue (i. e., price), and marginal revenue for various numbers of boxes of apples are shown together in Table 6. The data are plotted in Figure 28. This figure shows the simple case where the demand

TABLE 6

Apples: Total, Average, and Marginal Revenues From the Sale of Various Quantities

(Hypothetical Data)

\begin{tabular}{|c|c|c|c|}
\hline Boxes of Apples & $\begin{array}{c}\text { Price } \\
\text { (and Average } \\
\text { Revenue) }\end{array}$ & $\begin{array}{c}\text { Total } \\
\text { Revenue }\end{array}$ & $\begin{array}{l}\text { Marginal } \\
\text { Revenue } \\
\text { (Successive } \\
\text { Differences } \\
\text { in Totals) }\end{array}$ \\
\hline & & & $\$ 1.90$ \\
\hline 1. & $\$ 1.70$ & $\$ 1.70$ & 1.70 \\
\hline 2. & 1.80 & 3.60 & 50 \\
\hline 3. & 1.70 & 5.10 & 1.00 \\
\hline $4 \ldots$ & 1.60 & 6.40 & 1.00 \\
\hline 5. & 1.50 & 7.50 & 1.10 \\
\hline $6 \ldots$ & 1.40 & 8.40 & .90 \\
\hline 7. & 1.30 & 9.10 & \\
\hline 8. & 1.20 & 9.60 & .2 \\
\hline $9 \ldots$ & 1.10 & 9.90 & .25 \\
\hline 10. & 1.00 & 10.00 & .10 \\
\hline 11. & .90 & 9.90 & \\
\hline 12. & .80 & 9.60 & \\
\hline 13. & .70 & 9.10 & \\
\hline 14. & .60 & 8.40 & \\
\hline 15. & .50 & 7.50 & \\
\hline
\end{tabular}

curve (or what may be called the average revenue curve, to give it a name analogous to the marginal revenue curve) is a straight line on arithmetic paper, with an average elasticity of unity.

It is clear from this figure that the slope of the marginal revenue curve is twice as steep as the slope of the average revenue curve. If the average revenue curve is a straight line, the location of the 
marginal revenue curve can be determined graphically without going through the calculations given above as follows: at any point on the average revenue curve, a horizontal line may be run across to the $y$ axis. Then the marginal revenue curve cuts this line at the midpoint of the line. This holds true no matter what the elasticity of the average revenue curve may be. It also holds true for curved average revenue curves as well as straight ones, but applies in that case to the tangents to the curves. ${ }^{5}$

It is also clear from the chart that the values of the marginal revenue curve are positive or plus (the curve lies above the $x$ axis) wherever the elasticity of the average revenue curve is greater than unity. (We know from previous discussion that this elasticity is greater than unity in the upper half of this particular curve.) Conversely, the values of the marginal revenue curve are negative or minus (the curve lies below the $x$ axis) wherever the elasticity of the average revenue curve is less than unity (as it is in the lower half of this particular curve). And finally, the value of the marginal curve is zero at the point where the elasticity of the average revenue curve is unity; and at that point the total revenue reaches its maximum.

The mathematical relation between the elasticity of the average revenue curve and the values of the average and marginal revenue curves is expressed by the formula:

$$
\mathrm{E}=\frac{\mathrm{AR}}{\mathrm{AR}-\mathrm{MR}}
$$

In this formula,

$\mathrm{E}=$ Elasticity of average revenue curve

$\mathrm{AR}=$ Value of the average revenue curve $\mathrm{MR}=$ Value of the marginal revenue curve

\section{PLOTTING DISCRETE SERIES}

When discrete quantity and price series are plotted so as to show the average, total, and marginal revenue curves, the plotter may be

\footnotetext{
${ }^{5}$ Care is needed in this application, for where the average revenue curve is curved, the midpoint of the horizontal line from the point of tangency to the $y$ axis does not lie on the marginal revenue curve. It is the line running through that point from the point where the tangent cuts the $y$ axis, extended "southeast" until it cuts a line dropped from the point of tangency to the $x$ axis that gives the marginal revenue at the point of tangency. This may be explained more clearly by reference to Figure 28. Obviously, the marginal revenue when 10 units are sold, at an average revenue (price) of $\$ 1.00$, is 0 ; that is where a line dropped from the average revenue point $(\$ 1.00)$ when 10 units are sold, is cut by the line running from $\$ 2.00$ and a quantity of 0 through the midpoint of the horizontal line from the point $\$ 1.00$ at quantity 10 , and the $y$ axis.
} 
puzzled by the fact that the marginal revenue curve apparently falls half a unit too far to the right on the chart.

This results when the curve is plotted incorrectly. The marginal revenue and average curves appear similar, but actually the two curves show not merely different things but different kinds of things.

The average revenue curve (actually, series of steps) shows the upper right-hand corners of a series of rectangles each extending to the $x$ and $y$ axes. The area of each rectangle shows the total revenue for each quantity and price in the series. Each figure in the scale along the bottom of the chart should be put under the mark representing the right-hand edge of each rectangle. A line drawn through the extreme point of each corner represents the average revenue curve. This curve remains the same (in the same place) for different size units of production and price.

The marginal revenue curve or series of steps, however, shows merely the tops of successive vertical bars, each one only one unit wide, showing the marginal revenue at each successive scale of production. Each figure in the scale along the bottom of the chart should be put under the center of each vertical bar. A line drawn through the center of the top of each vertical bar represents the marginal revenue curve. This line remains the same no matter how large or small the units are.

The total revenue curve is similar in kind to the average revenue curve. It should be handled in the same manner.

\section{FORMULA FOR DETERMINING THE PRODUCTION THAT WILL BRING THE MAXIMUM TOTAL REVENUE}

The size of the crop or production that will bring in the highest total revenue can be computed quickly and easily by means of a simple formula. The derivation of this formula can be visualized by remembering that if the data are plotted in index form, so that the base is $100=$ the average of the series, a tangent to the demand curve would cut the $x$ axis to the right of 100 at a point equal to the coefficient of elasticity (ignoring sign) multiplied by 100 .

If, for example, the elasticity were -0.5 , the tangent would cut the $x$ axis at 150. The marginal revenue curve then would cut the $x$ axis halfway between 0 and 150 , that is, at 75 . This would be the size of crop or production that would bring in the maximum total revenue. 
The formula is $P=(1+E) 100$

\section{2}

where $\mathrm{P}$ is the production that maximizes total revenue, and $\mathrm{E}$ is the coefficient of elasticity of demand, with the sign ignored.

BEARING UPON AGRICULTURAL POLICY

The relations between elasticity and total revenue shown above have a great deal of significance for agricultural policy.

The AAA production control program during the 1930's was designed to increase agricultural income by reducing agricultural production.

The program actually was only an acreage control program.

TABLE 7

Factors Determining the United States Average Farm Price of Corn, 1921-40

\begin{tabular}{|c|c|c|c|c|}
\hline $\begin{array}{l}\text { Year Beginning } \\
\text { Month Specified }\end{array}$ & $\begin{array}{c}\text { Average } \\
\text { United States } \\
\text { Farm Price of } \\
\text { Corn per Bushel, } \\
\text { December- } \\
\text { May* }\end{array}$ & $\begin{array}{l}\text { Total Corn } \\
\text { Supply } \\
\text { October } 1 \dagger\end{array}$ & $\begin{array}{c}\text { Index Numbers } \\
\text { of Prices } \\
\text { Received by } \\
\text { Farmers } \\
\text { December- } \\
\text { May (August } \\
\text { 1909-July } 1914 \\
=100) \ddagger\end{array}$ & $\begin{array}{l}\text { Feed Grain } \\
\text { Animal Units } \\
\text { January } 1 \\
\text { of Next Year } \S\end{array}$ \\
\hline 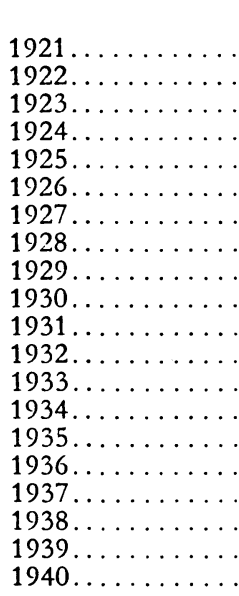 & $\begin{array}{r}\text { (cents) } \\
52.0 \\
74.9 \\
76.0 \\
109.2 \\
68.0 \\
66.5 \\
85.0 \\
84.3 \\
77.2 \\
59.4 \\
32.4 \\
24.2 \\
45.7 \\
84.6 \\
55.9 \\
107.6 \\
51.5 \\
45.0 \\
56.0 \\
58.6\end{array}$ & \begin{tabular}{|c|} 
(million bushels) \\
3,290 \\
2,960 \\
3,000 \\
2,390 \\
2,900 \\
2,825 \\
2,833 \\
2,757 \\
2,669 \\
2,217 \\
2,743 \\
3,202 \\
2,786 \\
1,798 \\
2,369 \\
1,687 \\
2,718 \\
2,925 \\
3,192 \\
3,144
\end{tabular} & $\begin{array}{r}129 \\
143 \\
143 \\
153 \\
152 \\
133 \\
148 \\
145 \\
140 \\
98 \\
69 \\
60 \\
81 \\
108 \\
107 \\
128 \\
98 \\
92 \\
98 \\
106\end{array}$ & $\begin{array}{l}\text { (million) } \\
138.7 \\
145.9 \\
143.2 \\
138.7 \\
133.6 \\
135.5 \\
140.5 \\
137.0 \\
135.8 \\
134.9 \\
139.5 \\
144.5 \\
143.1 \\
120.3 \\
123.1 \\
122.8 \\
121.6 \\
127.3 \\
138.4 \\
132.9\end{array}$ \\
\hline
\end{tabular}

* Agricultural Statistics 1940, XXIV, p. 55, and Crops and Markets 1935, XXIII, p. 530 , both BAE, USDA.

$\dagger$ Feed Statistics, FdS-Sup. 2, processed, March, 1941, p. 11.

$\ddagger$ Agricultural Situation (22).

\$ Livestock, Meats, and Wool Market Statistics and Related Data 1940, U. S. Agr. Mktg. Serv., processed, 1941, p. 7. 

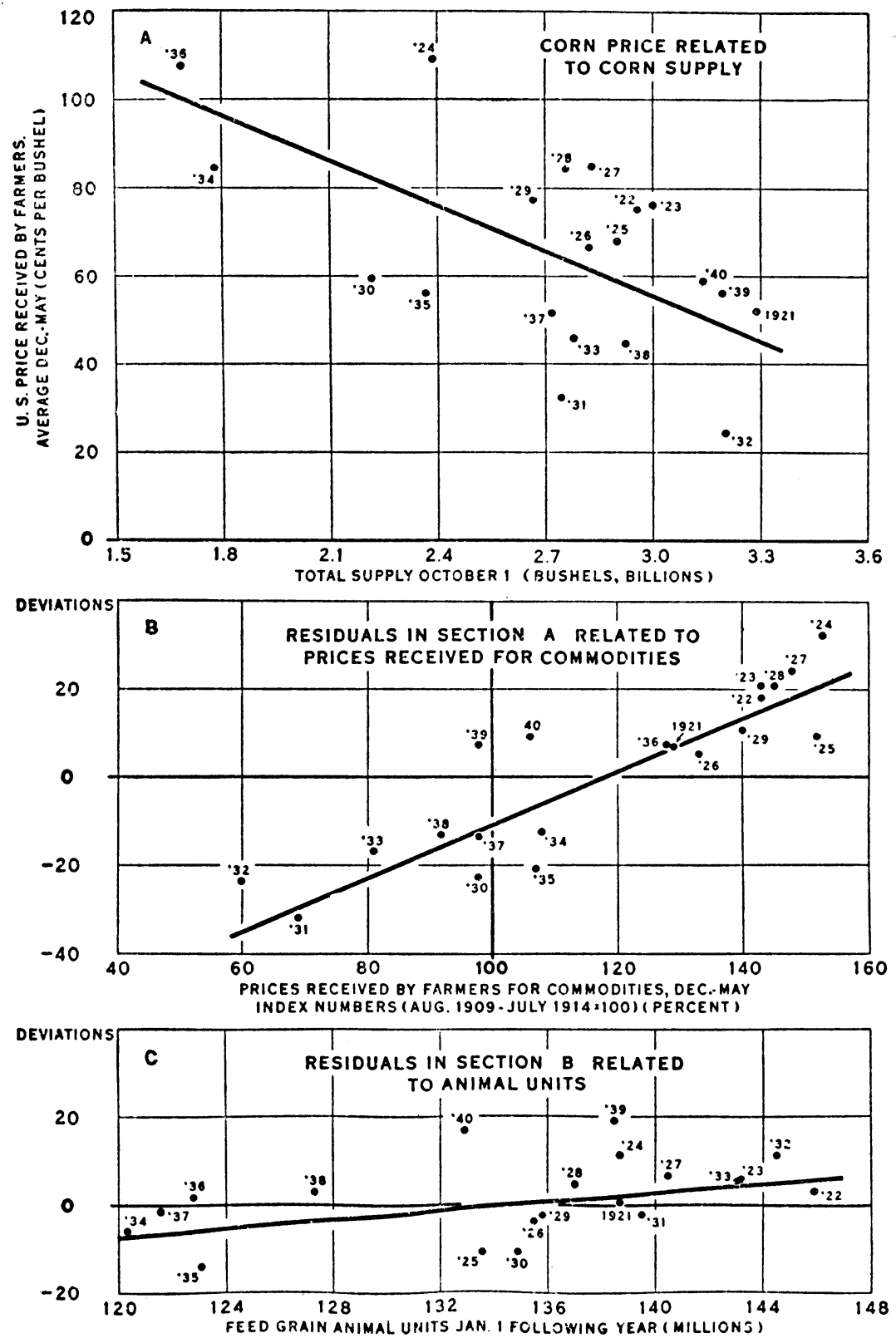

BAE 39467

FIG. 29.-Relations between the United States average farm price of corn December-May and (A) total United States corn supply October 1; (B) prices received by farmers December-May; and (C) number of animal units on farms January 1, 1921-22 to 1937-38. 
Except in the case of cotton, it failed to reduce production below previous levels, because farmers offset the reduced acreage by recourse to production practices which increased yields. This left total production as high as before, or higher.

Even if the program had succeeded in reducing agricultural production, that would not have had much effect on agricultural income. The smaller supplies would have raised prices, but the effect of the higher price upon income would have been partially offset, completely offset, or more than offset, by the smaller supplies, depending upon the elasticities of the demand for the products concerned.

Statistical analyses have shown that the elasticity of the demand for corn in the United States, based on annual data, ${ }^{6}$ is about -0.65 . This is shown in Figure 29, based on the data given in Table 7. The elasticity for hogs is about the same.

The general relation between hog supplies, prices, and total income, can be set forth as in Table 8. For simplicity, the figures used are percentages, with 100 representing average size. The relation

TABLE 8

Relation Between Hog Supplies, Prices, and Total Income

(Percentage of average)

\begin{tabular}{c|c|c}
\hline Hog Supply & Hog Price & Total Income \\
\hline 65 & 150 & 97 \\
70 & 144 & 101 \\
75 & 138 & 103 \\
80 & 131 & 105 \\
85 & 124 & 105 \\
90 & 116 & 104 \\
95 & 108 & 103 \\
100 & 100 & 100 \\
105 & 92 & 97 \\
110 & 84 & 92 \\
115 & 76 & 87 \\
\hline
\end{tabular}

between hog supplies and prices is shown in section A of Figure 30; the relation between hog supplies and total hog income is shown in section B of Figure 30.

Table 6 shows that a large crop of hogs is worth less than a small crop. It shows that a 110 per cent crop, for example, brings a total

\footnotetext{
${ }^{6}$ Controlling Corn and Hog Supplies and Prices, USDA Tech. Bul. No. 826, 1942, pp. 18-19, by the present author.
} 
income only 92 per cent of average, but a 90 per cent crop brings a total income 104 per cent of average. The large crop of hogs is worth 12 per cent less than the small crop.
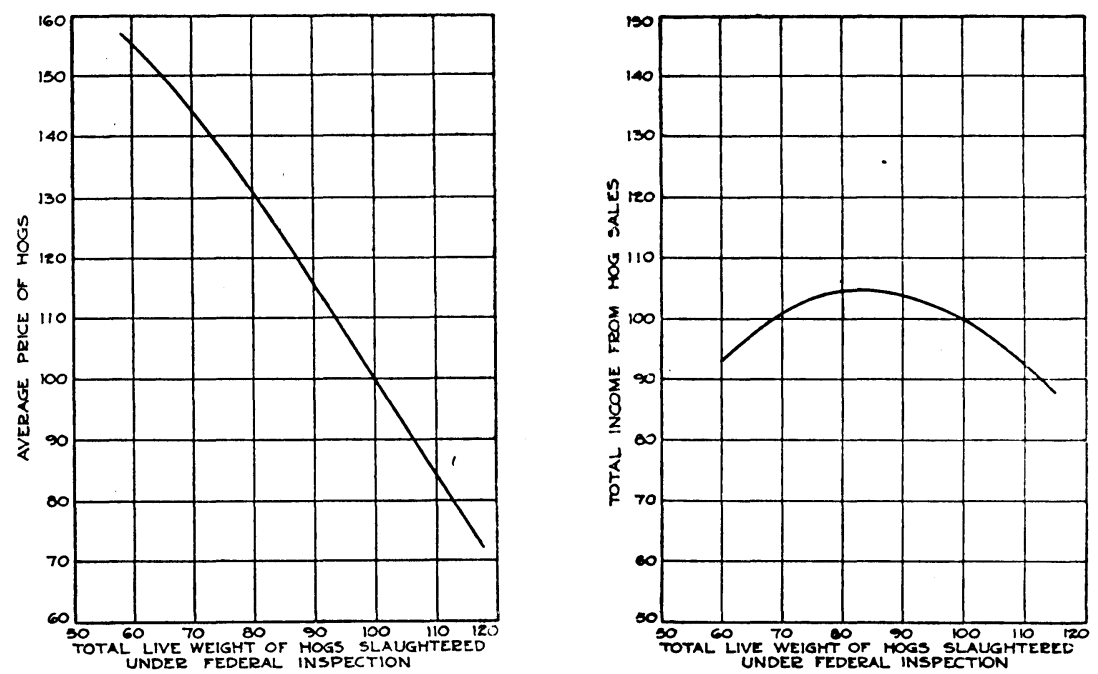

Fig. 30.-Relation between total live weight of hogs slaughtered under federal inspection, and (A) average hog prices, and (B) total revenue from hog sales.

The difference between the total values of still larger and smaller crops is still greater than this. A 115 per cent hog crop brings an 87 per cent income. This is 18 per cent less than the income from an 85 per cent crop, which is 105 per cent of average. The rise in total income with decreasing size of crop, however, stops below crop sizes of about 83 per cent. A reduction in the size of below 69 per cent of normal would reduce the total value of the crop below the value even of an average crop.

The demand curve for hogs is compared with a demand curve of constant unit elasticity at every point (which would result in a constant income no matter what the size of the crop) in Figure 31. The figure shows how the upper parts of the two curves, over the range shown, lie close together. The lower parts of the curves diverge strongly, the divergence increasing with the size of the crop. The bigger the crop, the farther does total income decline.

The conclusions given above are based upon the relations between annual data. If longer periods of time were used, the elasticity would increase and the maximum increase in total value that could 
be brought about by reductions in supply would decline to less than 5 per cent.

It is evident, therefore, that programs to restrict the production

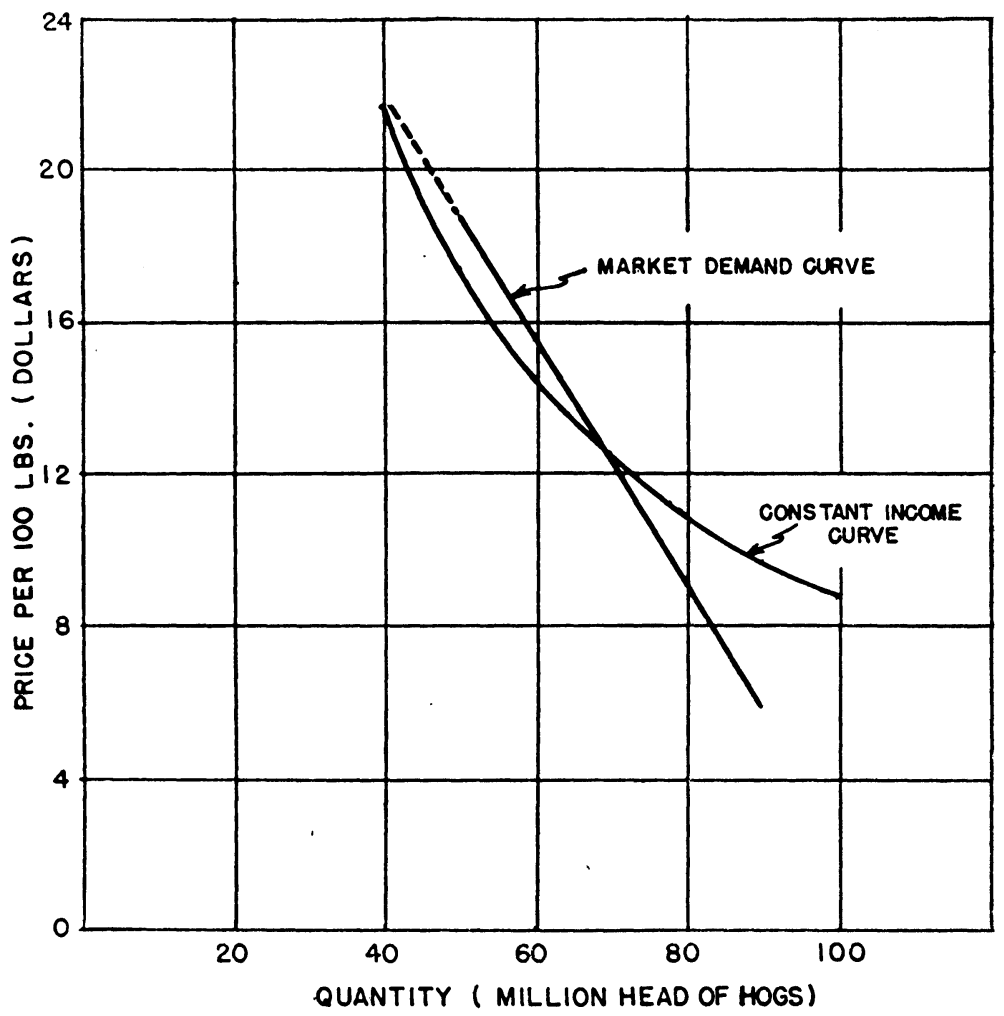

Fig. 31.-Actual market demand curve for hogs, and constant-income curve.

of crops with demand curves like those for corn and hogs could increase gross incomes only to a small extent in the short run, and probably not at all in the long run. 


\section{CHAPTER 6 \\ The Elasticity of the Supply of Farm Products}

Supply curves are more difficult to measure than demand curves. Many statistical studies of demand have been published, but statistical studies of supply are not so numerous.

Warren and Pearson ${ }^{1}$ did some pioneering work on the response of agricultural production to price, using mostly annual data for the period previous to World War I. They found that the elasticity of supply of potatoes (the change in potato acreage resulting from a change in potato prices at the farm) over the period 1895-1911, was low; it was 0.1 for the United States as a whole. For Minnesota it was .18, but for Illinois it was actually slightly negative. The elasticities of supply for most of the other products they studied were also low. They were as follows: for hay, 0.07 ; for (Iowa) corn, 0.08; for (North Dakota) wheat, 0.12 the first year, and 0.20 the second year after the price change. The elasticities of supply of livestock were higher; for hogs, two to three years after the price change, the elasticity was about 1.0; for beef cattle, eight years after the price change, 1.6. There was a good deal of scatter about these supply curves in most cases, but as a path-breaking effort the work had great value.

More recent investigations have led to modification of some of these early findings, and have distinguished between short-time and long-time elasticities of supply.

\section{SHORT-TIME ELASTICITIES OF SUPPLY}

Day-to-day changes: O. V. Wells investigated the effect of changes in hog prices upon the market receipts of hogs. ${ }^{2}$ In a study of short-time, day-to-day changes in prices and receipts of hogs at Sioux City in 1929-30, he found a positive relation between

\footnotetext{
${ }^{1}$ G. F. Warren and F. A. Pearson, Interrelationships of Supply and Price, Cornell Univ. Agr. Exp. Sta., Bul. 466, March, 1928.

${ }^{2} \mathrm{O}$. V. Wells, Farmers' Response to Price in Hog Production and Marketing, USDA Tech. Bul. 359, 1933.
} 
changes in price from Monday to Tuesday, and changes in truck receipts from Tuesday to Wednesday. A change of 10 cents per 100 pounds in hog prices was followed, on the average, by a change in the same direction of 15 per cent in hog receipts. At Chicago, served mainly by railroads that bring in hogs from longer distances than the trucks that serve Sioux City, a longer lag between changes in prices and changes in receipts was observed; the effects of price changes from Saturday to Monday showed up most strongly on receipts from Monday to Thursday. At this market and with this lag, a change of 10 cents in prices was followed, on the average, by a change of 10 per cent in receipts.

The price of hogs during 1929-30 averaged, in round figures, $\$ 10.00$ per 100 pounds. The change of 10 cents per 100 pounds was, therefore, a change of 1 per cent. The elasticity of supply (shorttime supply) at Sioux City, therefore, was 15, and at Chicago, 10.

$\mathrm{H}$. J. Stover found that a change in the price of hogs at Chicago from Saturday to the next Monday had a direct effect on hog receipts at Chicago on the later days of the week..$^{3}$ The elasticity of this response of hog receipts to changes in prices were as follows:

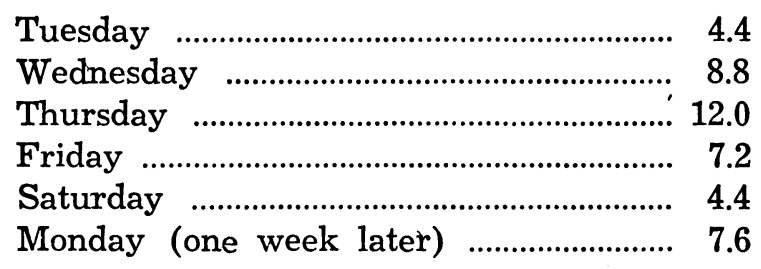

Year-to-year changes: How do these short-time elasticities compare with the elasticities based upon longer periods? Wells also investigated that question, and found that whereas the elasticities of supply of hogs based on daily data were high (much higher than unity, as we have just seen), the elasticities based upon annual data were low, only a fraction of unity. He used data for various states and markets, among them the average western Cornbelt corn-hog price ratio for October through March for the preceding two years (instead of the price of hogs) and the western Cornbelt hog marketings (October through September) as the measure of receipts. The elasticity of supply based upon the changes in these annual data (from the year before in each case) was only about

\footnotetext{
${ }^{3}$ Howard J. Stover, Relation of Daily Prices to the Marketing of Hogs at Chicago, Cornell Univ. Agr. Exp. Sta., Bul. 534, 1932, pp. 46-48.
} 
0.56. For Iowa data the elasticity was about 0.50 ; for Ohio and Missouri data the elasticities were nearly as high as unity; for the other states the elasticities ranged between 0.5 and 1.0.

This is interesting. It was shown in Chapter 5 that the elasticity of demand for hogs, based on daily data, ranged from 5.8 on Saturdays to 2.8 on Wednesdays, whereas the elasticity based on annual data was about 0.6. Apparently, the elasticity of supply and demand for hogs are both high in the short run (day-to-day), and low in the long run (year-to-year).

Less is known about other products. Louis Bean found that the elasticities of supply for several other agricultural products were all less than unity, ${ }^{4}$ although his curves were less steeply sloped in their central parts, and in those parts the curves for rye, flax, and watermelons were more elastic than unity. The elasticity of the supply of broomcorn (acreage) is reported to be about 0.9, and of sweet potatoes, $\mathbf{0 . 5}$. The elasticity of the supply of cotton also appears to be less than 1.0.5 Cox and Quintus reached some interesting conclusions, difficult to summarize briefly, concerning the response of acreage, not to changes in price but to changes in the ratio between the acre-returns of various crops. ${ }^{6}$ Pubols and Klaman found that a change of 10 per cent in the (deflated) price of potatoes in the United States was associated with a change in the same direction of 2.3 per cent in acreage one and two years later. ${ }^{7}$

\section{LIMITATIONS OF SHORT-TIME STUDIES}

The results of these studies are open to some question. The chief cause of variations in potato prices from year to year is variation in the size of the crop, caused chiefly by good or bad weather. $\mathrm{Bad}$ weather and a resulting short crop and high price for potatoes one year should not induce much increase in potato acreage the next year. The new crop could only be expected to be average in size; this would bring only an average price, not a high price like the preceding year's short crop. High prices resulting from a strong

'Louis H. Bean, Characteristics of Agricultural Supply and Demand Curves, USDA 1932, mimeo.

${ }^{5}$ F. L. Thomsen, Agricultural Prices, McGraw-Hill, 1936, pp. 41, 43, and 227.

${ }^{6}$ R. W. Cox and P. E. Quintus, "Minnesota Farmers' Response to Price Relationships in the Production of Selected Crops," Journal of Farm Economics, XIV, No. 4, October, 1932, pp. 697-700.

'Ben H. Pubols and Saul B. Klaman. Farmers' Response to Price in the Production of Potatoes, 1922-41, BAE, USDA, processed, 1945. 
demand should result in an increase in acreage, but high prices resulting merely from a short crop should not.

\section{LONG-TIME SUPPLY SCHEDULES}

The elasticity of supply curves is greatly affected by "the element of time, the source of many of the greatest difficulties in economics." Ever since Marshall illustrated the effect of time upon productionresponse by reference to short, medium, and long-time changes in the demand for fish, ${ }^{9}$ economists have been conscious of its importance. "There is no curve which can be regarded as the one-and-only supply curve for any particular commodity. The character of each depends on the time specifically allowed for variations in output to take place. What we have, as a matter of fact, is a whole series of supply curves for each commodity representing all possible conditions between the most perfect long-run normal adjustment and most rigid momentary fixity of supply. Graphically speaking we may think of the supply curve for the very shortest period as a vertical line on the familiar two-dimensional chart and the supply curve for the very longest period as a line approaching the horizontal. Then, between these two extremes there will be a fanlike system of curves, each with a slope of its own, representing the various conditions of supply when adjustment periods of intermediate lengths are allowed for." 10

Accordingly, the length of time involved should be carefully noted in studies of the elasticity of supply, by the investigator so that he can adapt his methods to them, and by the reader so that he can appraise the results. The statistical supply curves discussed in this chapter so far have been mostly short-time curves. We will turn next to long-time supply curves.

It is difficult to derive long-time supply schedules. If each item in the series is to be the average of five years, or ten years, the conditions of supply may change (the whole supply curve may shift up or down). If production has changed, the investigator may not be able to tell how much of the change is due to a change in price and how much is due to the change in supply. The same difficulty is present in the derivation of demand schedules, but it is easier to

\footnotetext{
${ }^{8}$ Marshall, Principles of Economics, p. 109.

Ibid., pp. 369-71.

${ }^{10}$ J. M. Cassels, "The Nature of Statistical Supply Curves," Journul of Farm Economics, XV, No. 2, April, 1933, pp. 382-83.
} 
solve, because fairly adequate measures of changes in demand exist (changes in the total national income, or in the general price level, for example). Measures of changes in supply of a similar sort are difficult to work out. Many variables have to be taken into account, and not all of them can be measured quantitatively-changes in the prices of various cost-items, in rents and interest, in technological production processes, and the like.

One possible way of getting around these difficulties is to analyze data on a geographical basis. If several different areas can be found with similar conditions of production but different prices, and if these price differences have persisted long enough for the production in the different areas to become adjusted to them, then the prices and production per square mile in the different areas can be used as points on a long-time supply curve. One illustration of this is the differences in the prices for fluid milk at various distances from the market, which result in great differences in output from different farms that are otherwise quite similar.

Another possibility is the experimental method. It would cost too much to guarantee certain farmers higher prices than the regular market prices for their products over a period of ten or fifteen years in order to measure the resulting changes in their production, but some research can be done on the physical relations which underlie the responses of production to price. An example of the latter is Einar Jensen's study of the response of dairy cows to varying inputs of feed. ${ }^{11}$ Similar studies could be conducted with the feeding of hogs and cattle, and the application of fertilizer and different cultural practices to crops.

Still another possibility is the budget method. This method is based upon the study of individual records from representative samples of farms. It consists in going over the records for each farm and working out budget estimates of production for each farm separately, ten years hence, under several different price situationshigher prices for the product (say 15 per cent higher), constant prices, and lower prices. These estimates, added up, then provide three points on a long-time supply curve.

This method presents difficulties of its own, and involves a good deal of estimation, but it is realistic and shows promise. The results of applying this method to a study of milk production in the Cabot-

\footnotetext{
${ }^{11}$ Einar Jensen, "Determining Input-Output Relationships in Milk Production," Journal of Farm Economics, XXII, No. 1, February, 1940, pp. 249-58.
} 
Marshfield area of Vermont are shown in Figure 32. The heavy solid line $B A C$ shows the estimated responses of production ten years later to milk prices 15 per cent higher, constant, and 15 per cent lower than they were originally. A short-term (three-month) supply curve for the same area, worked out by another investi-

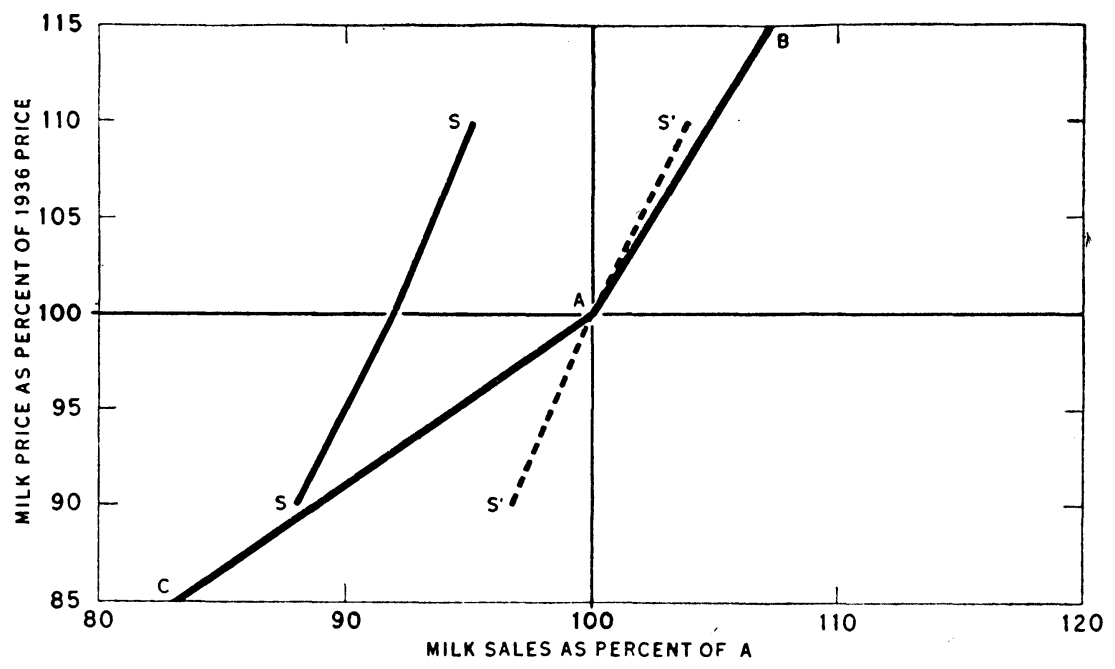

Fig. 32.-Long-time and short-time responses of milk production to price changes. (From Allen, Hole, and Mighell. ${ }^{12}$ )

gator by other methods, is shown by the curve $S S$, shifted over to $\mathbf{S}^{\prime} \mathbf{S}^{\prime}$ in order to allow closer comparison with $B A C$. The long-time curve is more elastic than the short-time curve, as would be expected. ${ }^{12}$

\section{SUPPLY CURVES, "OTHER THINGS BEING UNEQUAL"}

Most of the supply curves reported above represent the supply curves of economic theory-that is, they show the response of producers to changes in the price of a particular commodity, "other things being equal." They show what happens when a short crop, for example, raises the price of potatoes. Even though farmers know that the price is as likely to be low again as it is to be high when the new crop is harvested, still they increase their acreage of potatoes in response to the temporarily higher price.

${ }^{12}$ R. H. Allen, Erling Hole, and R. L. Mighell, Supply Responses in Milk Production in the Cabot-Marshfield Area, Vermont, USDA Tech. Bul. 709, 1940. See also R. L. Mighell and R. H. Allen, "Supply Schedules-Long-Time' and 'Short-Time'" Journal of Farm Economics, XXII, No. 3, August, 1940, pp. 551-56. 
This type of supply-response should be carefully distinguished from another type that results when all prices move up and down more or less together, as they do in periods of prosperity and depression. The supply curves derived above, "other things being equal," do not hold when "other things" (prices) are changing too, even though the periods of time involved may be similar.

Most demand curves are free from this sort of complication. The fluctuations in supply that make it possible to measure demand curves for agricultural products are fluctuations in the supply of individual products. They are large, rapid, and random, because they result chiefly from changes in weather. Moreover, the fluctuations in the supply of any one product are usually independent of those of other products. It is not often that shortages in one food are accompanied by shortages in another. Even in the record-breaking widespread drouth of 1934, total agricultural production fell only 3 per cent from the year before; and in the drouth year of 1936, it rose 3 per cent. The condition caeteris paribus (other things being equal) of classical economic theory is usually well fulfilled in the case of fluctuations in the supply of agricultural crops; the effect of changes in the supply of one commodity can be measured "other things being equal" (i. e., unchanged), or at least having changes that are uncorrelated with the changes in the particular commodity being studied.

By contrast, the big fluctuations in demand that make it possible to measure supply curves are those that come with prosperity and depression; they affect all goods (not identically, but similarly). Other things do not remain equal; they change too. A decrease in demand for hogs is accompanied by a decrease in the demand for beef, lamb, poultry, butter, and eggs. The only changes in demand that affect one particular farm product and not others (like fluctuations in supply) are usually slow and gradual changes in consumers' tastes that take years to express themselves in sizeable figures. We now eat less starchy foods than our ancestors did, and more vegetables; but it has taken two or three generations to effect the change.

When a sudden change in supply takes place, as for instance when severe drouth cuts the production of butter 10 or 20 per cent, prices rise and less butter is bought; consumers eat something else instead. The readjustment in consumption takes place at once. But 
if an industrial depression comes, and the demand for butter declines 10 or 20 per cent, producers cannot make adjustments in production quickly. They are all set up to produce butter, and they cannot readily turn to produce something else. Even if they could change their setup rapidly and easily, it would do them no good; for the demand for other goods they might produce instead has also fallen.

Statistical demand curves show or at least purport to show what happens to prices when the supply of one product changes, the supplies of other products either remaining unchanged or else undergoing changes uncorrelated with the changes in the supply of the first product. But during periods of rapid change in general demand, statistical supply curves show what happens to prices when the demand for a specific product changes, the demand for other products changing too and in a similar manner to the changes in the demand for the specific product. This sort of supply curve is considerably less elastic than the supply curve "other things being equal."

One-Way Curves: There is an additional complication. When a general change in demand takes place, the supply curve is a more complex thing than the supply curve of classical economic theory. The situation is simple enough when the demand for butter, for example, is increasing in response to growth in human population, increase in per capita purchasing power, or a reduction in the costs of distribution. The demand curve shifts to the right and/or upwards, the price of butter rises, and butter production goes up. These things take place without much friction; agricultural production expands easily.

But when the demand for butter decreases, the situation is different. Farmers do not decrease their production of butter as readily as they formerly increased it. Their investment has been made, their plant is a going concern; it cannot be shut down without loss of the time and money invested. Most of the labor is supplied by the farmer and his family, and they cannot be discharged. It does no good to turn to beef cattle or other products instead, for the demand for those products has fallen too. Farmers take a lower return than they anticipated, rather than take no return at all. They continue to produce, perhaps almost as much as before, perhaps even more, but at lower prices than before. The path marked out by the intersection points of the demand and supply curves 
when the demand for butter increases is not retraced when the demand for butter declines.

Figure 33 represents the situation. The demand is shown as increasing from $D$ to $D_{1}$ and then decreasing to $D_{2}$. The curve $S S$ is the supply curve under conditions of increasing demand. The

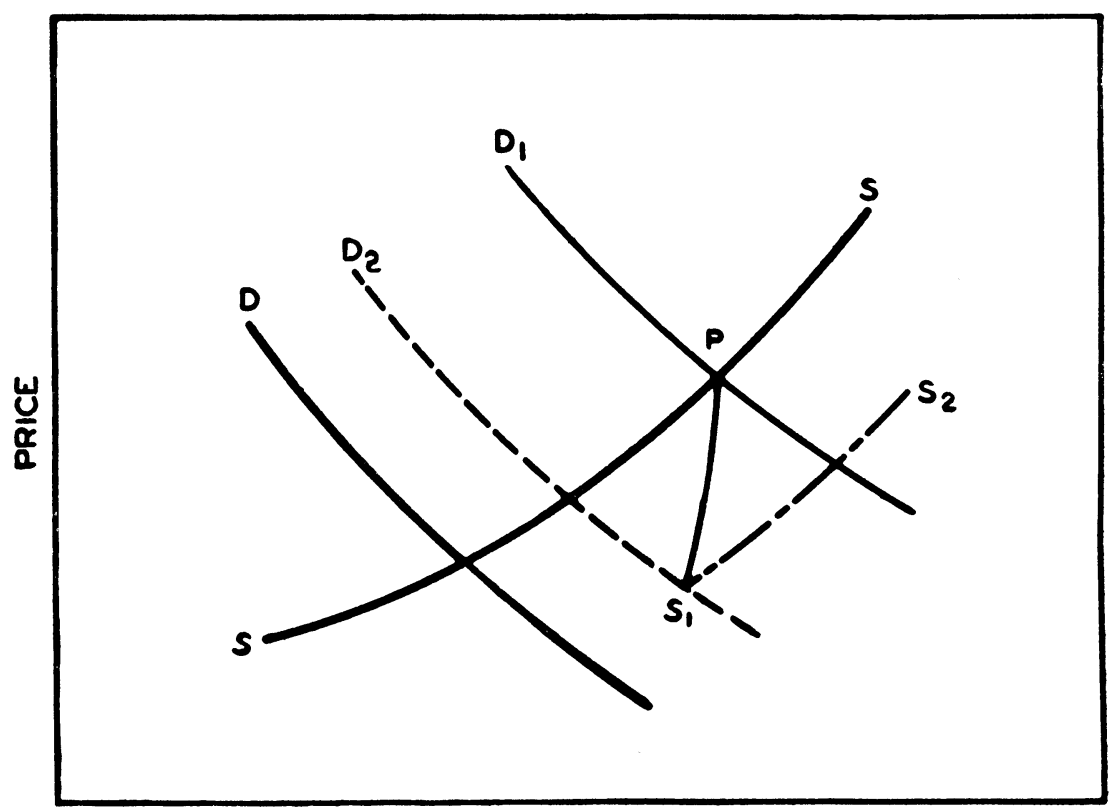

\section{QUANTITY}

FIG. 33.-“One-way" supply curves. Hypothetical data.

other curve, running from $P$ to $S_{1}$, is the supply curve established under conditions of decreasing demand. It is highly inelastic.

We saw in the section dealing with demand curves that "the elasticity" of the demand for a product varies according to the length of time represented by each unit in the series. The same phenomenon exists in the case of supply curves. But the complication shown in Figure 33 is a different and additional complication; it results not from different lengths of time (for it is revealed by annual data throughout) but from different directions of change in demand.

The one-way nature of the supply curves for most agricultural products is shown in the statistics of crop acreage and livestock population or slaughter, both after World War I and after the 
beginning of the industrial depression in 1929. In the case of most products, the production increased, rather than decreased, when prices fell; the supply curve actually had a slight negative slope for a time, as farmers attempted to offset lower prices by increasing production.

As to the effect of the passage of time on the difference between the elasticities of a supply curve "going up" and "coming down" on the curve, the evidence is inconclusive. After a few years of low prices after World War I, large wheat areas in the northwestern states-the "black triangle"-were abandoned. But by 1938 wheat acreage in the United States was the largest in history, with the single exception of 1919. Corn acreage in 1932 was also almost the largest in history, being only slightly exceeded in one previous year, 1917. It was reduced after 1932 only under the combined influence of two record-breaking drouths and the AAA programs. Hog and beef cattle production also held up. But so many other variables are also involved-changes in production costs, changes in domestic human population and in export demand-that clear-cut, simple conclusions can hardly be drawn.

\section{GRAPHIC REPRESENTATION OF ELASTICITY OF SUPPLY}

An interesting feature of the graphic representation of the elasticity of supply ${ }^{13}$ is the fact that two straight lines such as $A$ and $B$ in Figure 34, which have obviously different slopes, have the same elasticity, namely, +1.0 . As a matter of fact, all straight lines passing through the origin have the same elasticity, +1.0 .

A moment's reflection, however, shows that this is necessarily true, from the definition of or formula for elasticity. The figures for a line with a 1 to 1 slope (where $y=x$ ) at the point where $x=10$ and $y=10$, give the following result:

$$
\frac{1}{1} \cdot \frac{10}{10}=1.0
$$

The figures for a 2 to 1 slope (where $y=2 x$ ) at the point where $x=5$ and $y=10$, give the same result:

$$
\frac{2}{1} \cdot \frac{5}{10}=1.0
$$

All that this shows, however, is that elasticity is a proportional

${ }^{13}$ Henry J. Bitterman, "Elasticity of Supply," American Economic Review, XXIV, No. 3, September, 1934, pp. 417-29. 
concept, as we found earlier in the study of demand. All it means is that if the second case just given $(y=2 x)$ were plotted in its original data form, on arithmetic paper, the diagram would be twice as high as it was wide. If the diagram were squashed down

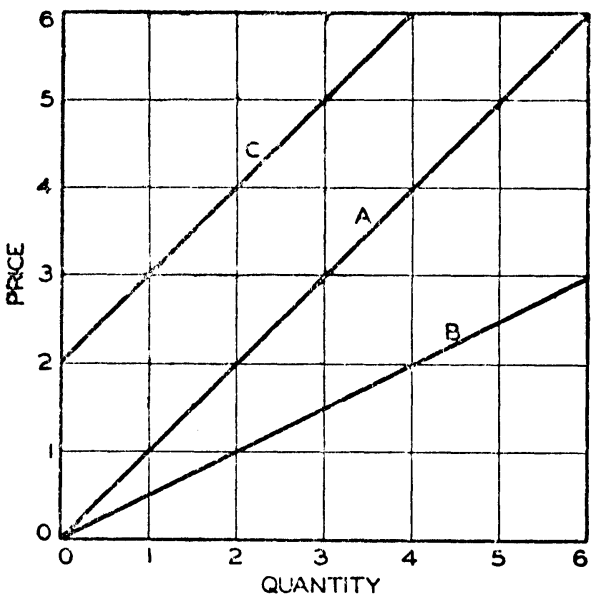

FIG. 34.-Supply curves of different slopes and elasticities. Hypothetical data.

(scales, supply curves, and all) until it were square, it would then be identical in appearance with the first case given above $(y=x)$. The slope of the supply curve would be the same as in that case $\left(45^{\circ}\right)$. True, the slope of the curve would still be expressed numerically, as $y=2 x$, but $2 x$ in the second case means the same thing proportionally as $x$ in the first case. That is, $2 x$ would equal, for example, 10 per cent (of the average) in the one case, and $x$ would equal 10 per cent (of the average) in the other, so the two elasticities should be the same, as in fact they are. This is shown clearly enough if the two cases are plotted on double logarithmic paper, which as we saw earlier is the proper paper for representing elasticity accurately. The curves then appear as two parallel lines, with identical slopes $\left(45^{\circ}\right)$.

The discussion above does not mean, of course, that all straight line positively sloping curves have an elasticity of unity. It is only straight lines that go through the origin that do so. Straight lines that cut the $Y$ axis at some positive value (i. e., above zero), like the line $C$ shown in Figure 34, all have elasticities that are greater than unity. Conversely, lines that cut the $Y$ axis at some negative value below zero (or, to put the same thing in other words, that cut the $X$ axis at some positive value, to the right of zero) have elasticities that are less than unity. As with straight line demand curves (with negative slopes), the elasticity varies from point to point along any straight line positively sloping curve, if it does not go through the origin. 


\section{CHAPTER 7}

\section{The Measurement of Changes in Demand and Supply}

The demand curve for potatoes portrayed in Chapter 3 clearly shows how a large crop of potatoes depresses the price of potatoes, and a short crop raises it. It shows how the large crop of 1935, for example, depressed the price of potatoes to 90 cents per bushel, and the short crop of 1936 raised the price to $\$ 1.40$.

Exactly what was the change that took place from 1935 to 1936? We know that prices change in response to changes in demand, or supply, or both. In this case, did the demand decrease, increase, or remain constant? And what about the supply?

Looking at the small crop in 1936 one might say, that the price rose and cut off part of the demand; that is, demand decreased. But looking at the high price, one might say that the demand must have increased. Which is right?

As a matter of fact, both of these statements would be wrong, for demand is the whole series of prices at which different quantities can be sold (or, the whole series of quantities that can be sold at different prices). The series of prices at which different quantities of potatoes can be sold was shown in Table 2 in Chapter 3. This whole table shows the demand for potatoes. In graphic terms, the demand is a line or curve, not just a single quantity and price; that is only a point on a demand curve.

The demand for potatoes, then, is the whole series of prices and quantities represented by the demand curve in Figure 9, Chapter 3. Different-sized crops merely cut the curve at different points. From 1935 to 1936 it may be assumed for our purposes here that the demand did not change at all; only the supply changed; the two different-sized crops simply cut the (stationary) demand curve at two different points.

To some people this concept of demand as a whole series of prices and quantities seems unduly complicated. They ask: "When a large crop comes on the market, why not say simply that the price fell, and that brought more buyers into the market, i. e., increased the 
demand, which thereupon was great enough to take the large crop off the market? That is, why not simply say that the demand increased in 1935 (when the crop was large) and decreased in 1936 when it was small?"

But you can soon see the difficulties you would get into using this concept of demand. For then you would say that the demand decreased from 1935 to 1936 when prices rose. You would say that the rise in price reduced the demand, or, as some of the earlier elementary textbooks used to say, inaccurately, "Demand varies inversely with price."1 But that would be a flat contradiction of everyday experience embodied in the elementary law of supply and demand, for everybody knows that a decrease in demand lowers prices, and an increase in demand raises prices; we know that demand varies directly with price.

\section{WHEN DEMAND CHANGES, THE WHOLE CURVE SHIFTS}

The only way to keep from contradicting yourself like this is to recognize that demand is the whole series of prices and quantities, the whole curve, in graphic terms. From 1935 to 1936 the demand remained constant (the curve remained stationary); all that happened was that the supply changed, and cut the demand curve at a different point.

This definition of demand as the whole series of quantities that can be sold at different prices is unequivocal. In the light of this definition, it is clearly inaccurate to say, "The demand is greater than the supply," or less than the supply, or equal to it. Each is a whole series of prices and quantities, which are usually negatively corre-

1 ". . . popular thought and usage do not distinguish between demand as the actual quantity of a commodity bought, which 'under given conditions' depends on the price, and the 'given conditions' which determine how much the market will take at any named price. Thus in general usage demand is, as J. S. Mill remarked, both the effect and the cause of price. In scientific usage the term is now defined in the latter sense only. Thus a change in price occurs only when there is a change in sales without a change in price alone. When the reference is to actual quantity bought as a result of a certain price, the term to be used is sales or consumption, but this distinction in terminology is not always carefully observed."-Frank H. Knight, "Demand," Encyclopaedia of the Social Sciences, V, 1931, p. 69.

Even some modern advanced books on economics use the term demand erroneously. Strangely enough, British writers are the worst sinners in this respect. See R. G. D. Allen, Mathematical Analysis for Economists, p. 117, where the statement is made, "Since price decreases as demand increases ..." where the author clearly means output or production, not demand. Similar misuses of the term occur in pp. 254-58. See also J. R. Hicks, Value and Capital, Oxford, The Clarendon Press, 1939, at numerous points throughout the book. 
lated in the case of demand and positively correlated in the case of supply. What is meant by the quotation just given is that the amount demanded at a certain price is greater or less than the amount offered at that price. If the amount demanded at $\$ 1.00$ is more than the amount supplied at $\$ 1.00$, some buyers will offer more than $\$ 1.00$ (say $\$ 1.05$ ); no seller then will sell for less than $\$ 1.00$, so one or two buyers will drop out (the amount demanded at $\$ 1.05$ is less than the amount demanded at $\$ 1.00$ ) and one or two new suppliers will come in (the amount supplied at $\$ 1.05$ is higher than the amount supplied at $\$ 1.00$ ) until a price will be reached somewhere between $\$ 1.00$ and $\$ 1.05$, at which the amount demanded will just equal the amount supplied.

A change in demand has taken place only when the whole price or quantity series changes. If some years later than those shown in Table 2 you found that the quantities of potatoes given could be sold only at 25 cents per bushel less than the series of prices given in Table 2 (that is, if you found that you had to set up a new price series 25 cents per bushel less than the series of prices given in Table $2)$, then you could say that the demand for potatoes had decreased. The whole curve would have shifted downward. ${ }^{2}$

\section{SHIFTS IN DEMAND AND SUPPLY CURVES}

It is easy to discover the elasticity of the demand for a product when the demand remains constant and only the supply changes. It is much more difficult, however, when the demand is changing (the demand curve is shifting) as well as the supply. For in that case the intersection points of the shifting demand and supply curves are likely to be scattered all over the chart, and the shifts are mixed up with the elasticity so that it is impossible to measure the elasticity directly.

The sort of price-quantity scatter-diagram the investigator gets out of his figures depends upon the shiftiness or instability of the demand and supply. Four broad classifications of these scatter diagrams may be made. ${ }^{3}$

\footnotetext{
${ }^{2}$ A distinction between vertical and horizontal shifts in demand curves is elaborated in the Appendix.

${ }^{3}$ For pioneer discussions of this subject along these lines, see E. J. Working, "What Do Statistical 'Demand Curves' Show," Quarterly Journal of Economics, XLI, February, 1927, p. 212, and Ezekiel's reply in the same Journal, XLII, November, 1927, p. 199.
} 


\section{DEMAND CONSTANT AND SUPPLY FLUCTUATING}

In section $\mathrm{A}$ of Figure 35 is shown a typical scatter-diagram for an agricultural product when demand remains fairly constant. (The series is entirely too short for analytical purposes; the chart is used here only for illustration. It is, as a matter of fact, difficult to find any longer series of years when demand was stable.) Changes in the weather from one year to another cause rather marked changes
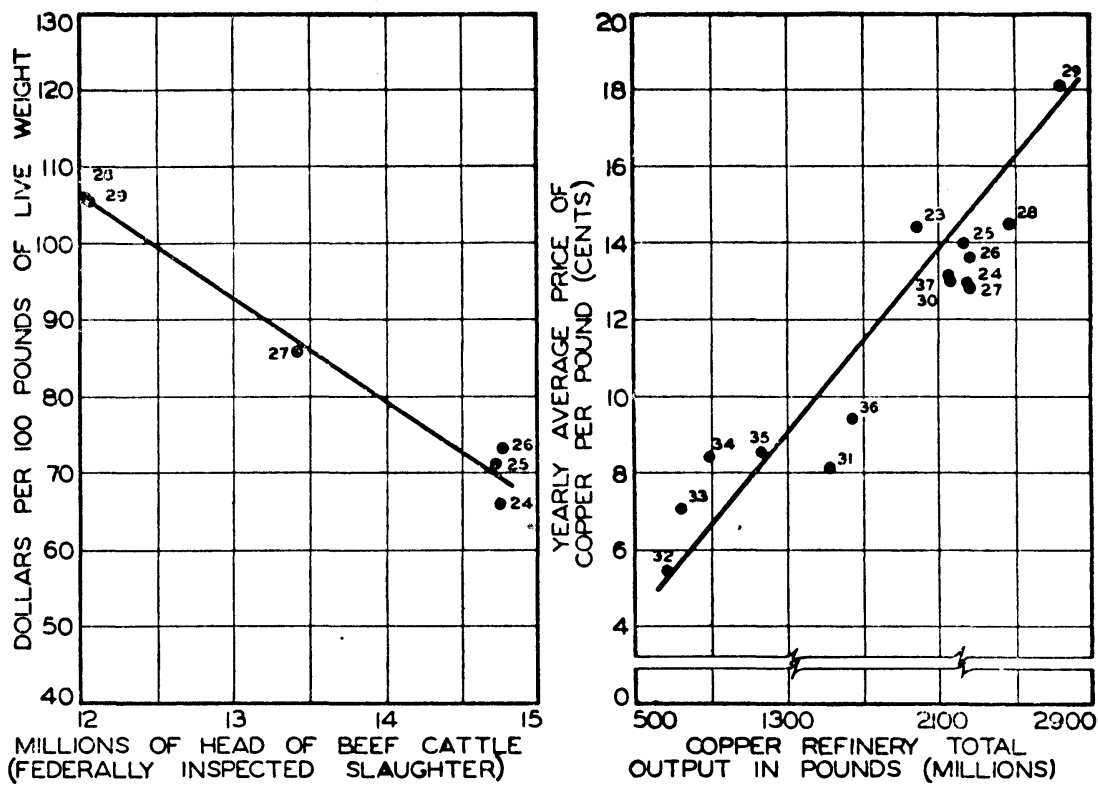

Fig. 35.-(A) Average price and federally inspected slaughter of beef cattle, 1922-29; and (B) average price and total refinery output of copper, 1923-38.

in supply, but if the demand remains fairly constant, the dots will cluster along a line with a negative slope; for each dot is the intersection of the demand and supply curve of that year. If demand remains absolutely constant, the supply curve, shifting back and forth from year to year, leaves its intersection points with the demand curve scattered along a single line; this line is the (stationary) demand curve. If, as is more likely, the demand is not absolutely constant, but changes slightly from one year to another, then the dots will be scattered along a path or band about the average demand curve. A single line drawn along the middle of this pathway will represent the average demand curve closely, if the pathway is narrow. 


\section{SUPPLY CONSTANT AND DEMAND FLUCTUATING}

In section $B$ of Figure 35 is shown the reverse situation, found in the case of some industrial products. The relation between production and price here is positive. The supply remains constant or nearly constant, but the demand shifts violently. This sort of diagram used to puzzle the early investigators. Thus Moore, in 1914, finding that the scatter diagram for steel looked like the scatter diagram for copper shown in section $\mathrm{B}$, concluded that the demand curve for steel was positively sloped. ${ }^{4}$ But actually what he had

TABLE 9

Copper, United States Production and Prices, 1923-38*

\begin{tabular}{|c|c|c|}
\hline Year & $\begin{array}{c}\text { United States } \\
\text { New Copper } \\
\text { (Refinery Output) } \\
\text { Total }\end{array}$ & $\begin{array}{c}\text { Copper } \\
\text { (Electrolytic) } \\
\text { New York } \\
\text { Yearly } \\
\text { Average Price }\end{array}$ \\
\hline 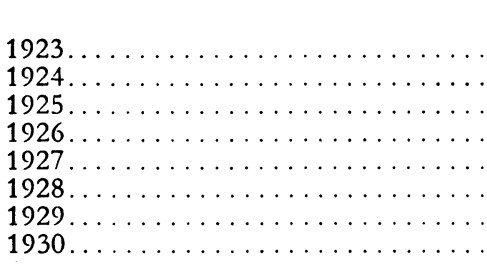 & $\begin{array}{c}\text { Millions of lbs. } \\
1,980 \\
2,260 \\
2,205 \\
2,322 \\
2,326 \\
2,488 \\
2,740 \\
2,157\end{array}$ & $\begin{array}{l}\text { Cents per lb. } \\
14.421 \\
13.024 \\
14.042 \\
13.795 \\
12.920 \\
14.570 \\
18.107 \\
12.982\end{array}$ \\
\hline 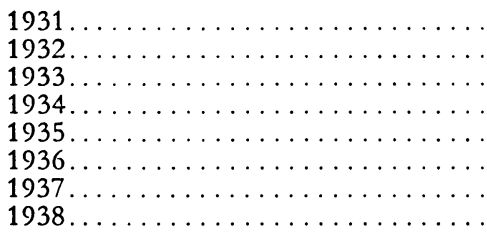 & $\begin{array}{r}1,501 \\
681 \\
742 \\
891 \\
1,178 \\
1,645 \\
2,134 \\
1,585\end{array}$ & $\begin{array}{r}8.116 \\
5.555 \\
7.025 \\
8.428 \\
8.649 \\
9.474 \\
13.167 \\
10.000\end{array}$ \\
\hline
\end{tabular}

* Statistical Abstract of the United States, 1939, pp. 728 and 747.

found was something approximating the supply curve for steel. Henry Wallace a few years later, pondering over Moore's results, began to grumble about the law of supply and demand. There was one law of supply and demand for farm products, he said-the

4 "Our representative crops and representative producers' good (pig iron) exemplify types of demand curves of contrary character. In the one case, as the product increases or decreases the price falls or rises, while, in the other case, the price rises with an increase of the product and falls with its decrease."Henry L. Moore, Economic Cycles, Their Law and Cause, Macmillan, 1914, p. 114. 
higher the supply, the lower the price-and another law for industrial products-the higher the supply, the higher the price.

What Wallace had really found was that the two cases illustrated the two parts of the law of supply and demand. Most agricultural products illustrate the one part-that if the demand is constant, the price varies inversely with the supply. Many industrial products illustrate the other part-that if the supply is constant, the price

TABLE 10

Cattle, United States Production and Prices, 1924-29*

\begin{tabular}{|c|c|c|}
\hline Year & $\begin{array}{c}\text { Beef Cattle, } \\
\text { Number Head } \\
\text { Federally Inspected } \\
\text { Slaughter }\end{array}$ & $\begin{array}{l}\text { Average Cost of } \\
\text { Cattle Slaughtered, } \\
\text { Live Weight Basis }\end{array}$ \\
\hline 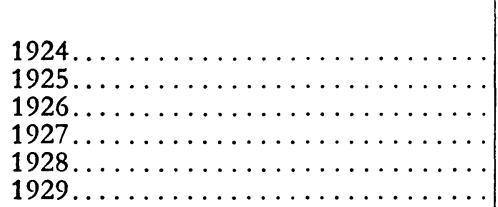 & $\begin{array}{l}(000) \\
14,750 \\
14,704 \\
14,766 \\
13,413 \\
12,028 \\
12,038\end{array}$ & $\begin{array}{c}\text { Dollars per } 100 \mathrm{lbs} . \\
6.64 \\
7.11 \\
7.32 \\
8.62 \\
10.59 \\
10.58\end{array}$ \\
\hline
\end{tabular}

* Livestock, Meats, and Wool Market Statistics, 1939, A.M.S., U.S.D.A., pp. 21, 91, and 93.

varies directly with demand. The two groups of products are represented by the two sets of conditions shown in sections A and B. In the one case, the demand remains constant and the supply changes, while in the other, supply remains constant and the demand changes.

\section{CORRELATED SHIFTS IN DEMAND AND SUPPLY CURVES}

When the supply and the demand are both changing, the situation is more complicated. The changes in demand and supply may have no relation to each other, or they may be correlated, either positively or negatively. If they are correlated, care must be exercised in interpreting results.

Let us take an extreme case for illustration. The annual price and quantity data for sulfur for the period 1927-37 are shown in section A of Figure 36. It should be noted that the price and production scales in the chart both run down to zero. The dots show that from 1927 to 1937 the production of sulfur changed greatly from year to year, but the price remained absolutely constant. The 
data all fall on a horizontal straight line. What does that line represent-a demand curve, a supply curve, or neither one?
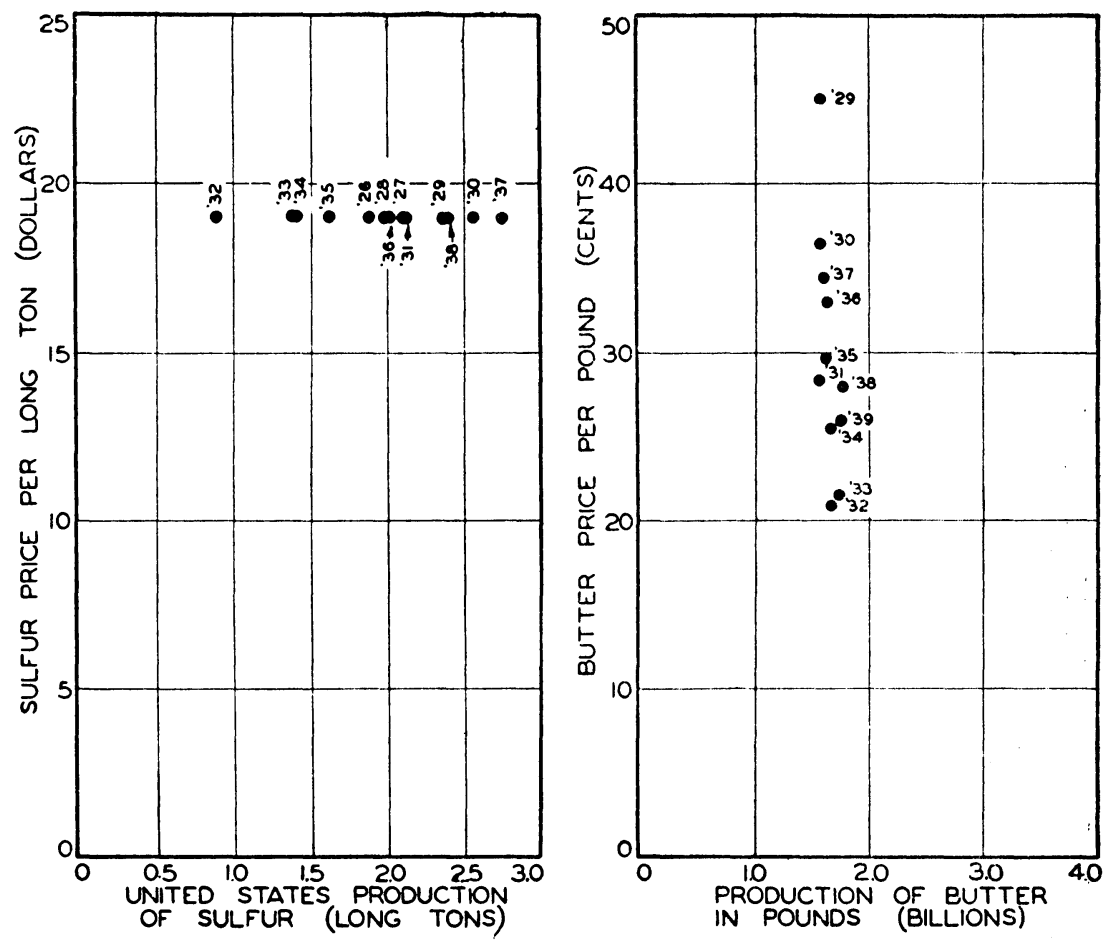

Fig. 36.-(A) Average price and total production of sulfur, 1926-37; and (B) average price and total production of butter, 1929-38.

The dots almost certainly do not represent a demand curve. It does not seem reasonable that the demand for sulfur would be infinitely elastic over the range shown. It seems very unlikely that consumers would pay as much per ton for sulfur when 2,741,970 tons are offered for sale as when less than a third of that quantity, 890,440 tons, is offered, unless their demand curve shifted its position meanwhile. It must have shifted to the right when larger quantities were offered (or larger quantities must have been offered when the demand curve shifted to the right) and conversely. The dots must represent not a demand curve, but a series of intersections of a negatively sloping demand curve with a supply curve or series of supply curves. 
Do the dots therefore represent a supply curve-an infinitely elastic supply curve? This also seems unlikely; but the question should be answered on the basis of a knowledge of the industry rather than any deductive reasoning. It is possible that the industry

TABLE 11

Sulfur, United States Production and Prices, 1926-37

\begin{tabular}{|c|c|c|}
\hline Year & $\begin{array}{c}\text { Sulfur } \\
\text { Produced }\end{array}$ & Price $\nmid$ \\
\hline 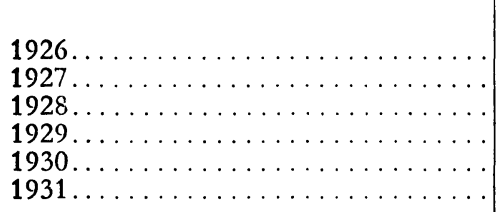 & $\begin{array}{l}\text { Long tons } \\
1,890,027 \\
2,111,618 \\
1,981,873 \\
2,362,389 \\
2,558,981 \\
2,128,930\end{array}$ & $\begin{array}{c}\text { Dollars per ton } \\
18 \\
18 \\
18 \\
18 \\
18 \\
18\end{array}$ \\
\hline 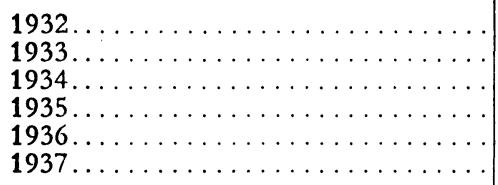 & $\begin{array}{r}890,440 \\
1,406,063 \\
1,421,473 \\
1,632,590 \\
2,016,338 \\
2,741,970\end{array}$ & $\begin{array}{l}18 \\
18 \\
18 \\
18 \\
18 \\
18\end{array}$ \\
\hline
\end{tabular}

* Production data for 1927 from the Mineral Resources of the U.S., U. S. Bureau of Mines, 1929, Part II, p. 176; for 1928-32, from The Minerals Yearbook, U. S. Bureau of Mines, 1932-33, p. 671; for 1933-36, same yearbook, 1937, p. 1303; for 1937, same yearbook, 1939, p. 1245.

† Price data, 1927-37, "The price of sulfur was reduced in 1938-the first change in the quotations since 1926 . The price at the mines dropped from $\$ 18$ to $\$ 16$ per long ton at the beginning of the last quarter (of 1938)." Quotation taken from The Minerals Yearbook, U. S. Bureau of Mines, 1939, pp. 1243-44.

is a constant cost industry-that all that needs to be done when demand increases is (1) to run the plants more shifts per day, the higher labor costs exactly offsetting the lower overhead costs per unit, or else (2) put up new plants with the same costs as the old. However, there is some question about this. Sulfur ${ }^{5}$ is produced under oligopolistic conditions, and the stability of its prices probably results from this rather than from cost considerations.

The chart apparently represents a high short-time elasticity of supply, or, what amounts to the same thing, a succession of intersection points of a negatively sloping demand curve with a positively

" "In 1922 a Sulphur Export Corporation was formed under the provisions of the Webb-Pomerene Act which permitted combinations designed to promote exports. This has served effectively ever since, preventing price competition not only in the foreign market but also in the home market." T. J. Kreps, The Economics of the Sulfuric Acid Industry, Stanford University Press, 1938, p. 103. 
sloping, long-time supply curve, the changes being positively correlated. It should be emphasized that the interpretation of the chart Tas to rest upon knowledge of the industry and economic reasoning, not merely upon the data themselves.

TABLE 12

Butter, United States Production and Prices, 1929-39*

\begin{tabular}{|c|c|c|}
\hline Year & $\begin{array}{c}\text { Creamery } \\
\text { Butter Produced } \\
\text { in Factories }\end{array}$ & $\begin{array}{l}\text { 92-Score } \\
\text { Creamery } \\
\text { New York }\end{array}$ \\
\hline 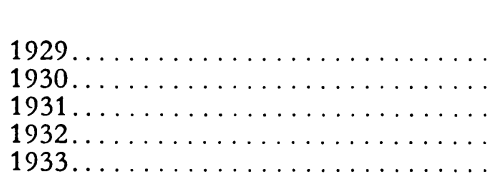 & $\begin{array}{c}\text { Millions of lbs. } \\
1,597 \\
1,595 \\
1,667 \\
1,694 \\
1,763\end{array}$ & $\begin{array}{l}\text { Cents per lb. } \\
45.01 \\
36.51 \\
28.31 \\
21.00 \\
21.66\end{array}$ \\
\hline 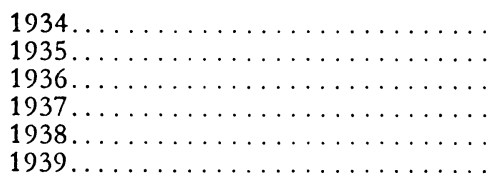 & $\begin{array}{l}1,695 \\
1,632 \\
1,629 \\
1,624 \\
1,786 \\
1,759\end{array}$ & $\begin{array}{l}25.70 \\
29.79 \\
33.05 \\
34.39 \\
27.97 \\
26.00\end{array}$ \\
\hline
\end{tabular}

* Source of data: Agricultural Statistics, U.S.D.A., 1940, p. 449.

The opposite situation-a high negative correlation between changes in supply and demand-existed in the case of many agricultural products during the ten years from 1929 to 1938 . The price and production data for butter are plotted in section B of Figure 36. The dots fall closely about a practically vertical line. It is obvious that the elasticity of the demand for butter cannot be practically zero. It is also obvious that the demand for butter declined greatly during the first few years of the depression that began in 1929, and recovered during the latter part. The vertical scatter of the dots, therefore, must represent a series of intersection points of a negatively sloping demand curve with a supply curve or series of supply curves.

Again the question arises-is there a single supply curve, practically a vertical line in this case, or a series of different supply curves? Do the dots all fall about a single supply curve of practically zero elasticity, or do they represent a succession of intersection points with a series of sloping supply curves?

It seems obvious enough that the long-time supply curve for 
butter must have some positive elasticity. The vertical supply curve shown in section B of Figure 36 must show merely the short-time elasticity of supply from plant and equipment already in production and unlikely to be shut down or junked during a short-time decrease in demand. It is a case where a short-time decrease in demand causes a short-time increase in supply; the correlation between changes in demand and supply here is high, and negative.

It goes without saying that most commodities do not fall neatly in one or the other of the classes indicated above-constant demand, constant supply, positive correlation between changes in demand and supply, negative correlation, or no correlation at all. Most

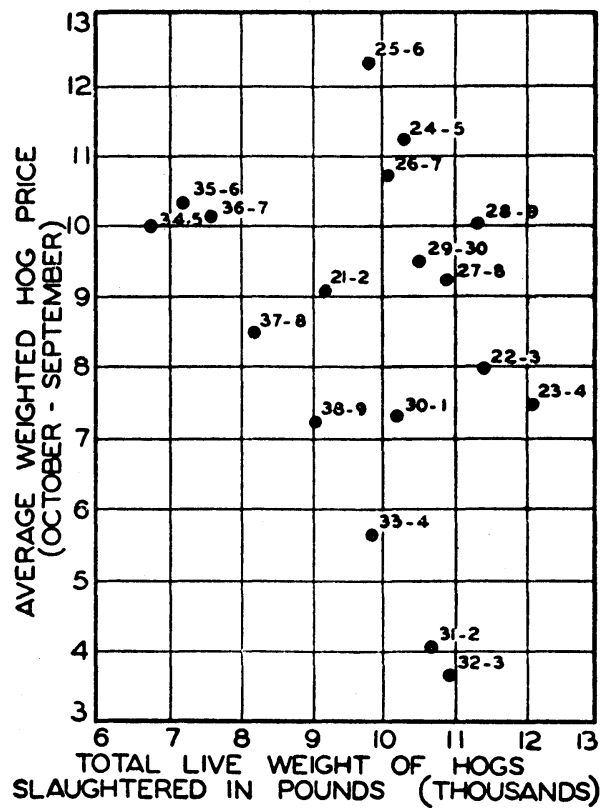

FrG. 37.-Relation between weighted average hog prices and total weight of hogs slaughtered, 1921-39. commodities fall somewhere along the lines between the several extremes, and care must be taken in the interpretation of all charts and statistical analyses of this character.

The quántity-price curves for many farm products have a negative slope, and it is easy to suppose that they show the demand curves for those products. Actually, as the charts on the preceding pages show, the curves may have very little relation to demand curves. It is fairly easy to keep from misinterpreting the curves in clearcut cases like those shown in these charts. It is more difficult in the majority of cases, which lie somewhere between the extremes. Many "demand curves" are not demand curves at all, but only mixtures of demand and supply curves that move with some degree of positive or negative correlation and leave a track of intersection points that represents neither a demand curve nor a supply curve.

This does not mean that such curves are not useful. They may 
in fact be more useful than demand curves. If changes in demand cause changes in supply, or vice versa, it may be more useful to know what the price-quantity relationship is, under those conditions, than to know what the elasticity of demand or supply is.

A concrete illustration may make this clear. The price-quantity relationship for corn shows an elasticity of -0.65 , but the demand

TABLE 13

Hogs, United States Production and Prices, 1921-39*

\begin{tabular}{|c|c|c|}
\hline Year & $\begin{array}{c}\text { Total Live } \\
\text { Weight of Hogs } \\
\text { Slaughtered } \\
\text { Annually } \\
\text { (Oct.-Sept.) }\end{array}$ & $\begin{array}{c}\text { Annual Average } \\
\text { Hog Price } \\
\text { Weighted } \\
\text { (Oct.-Sept.) }\end{array}$ \\
\hline 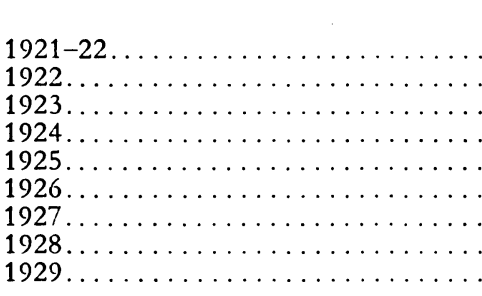 & $\begin{array}{c}\text { Millions of lbs. } \\
9,156 \\
11,440 \\
12,013 \\
10,258 \\
9,776 \\
10,009 \\
10,823 \\
11,343 \\
10,530\end{array}$ & $\begin{array}{c}\text { Dollars per } 100 \mathrm{lbs} \text {. } \\
9.06 \\
7.98 \\
7.41 \\
11.18 \\
12.29 \\
10.70 \\
9.24 \\
10.01 \\
9.57\end{array}$ \\
\hline $\begin{array}{l}1930 \ldots \ldots \\
1931 \ldots \ldots\end{array}$ & $\begin{array}{c}10,200 \\
10,625 \\
10,918 \\
9,872 \\
6,742 \\
7,191 \\
7,538 \\
8,089 \\
9,000\end{array}$ & $\begin{array}{r}7.25 \\
4.05 \\
3.68 \\
5.64 \\
10.00 \\
10.32 \\
10.18 \\
8.41 \\
7.22\end{array}$ \\
\hline
\end{tabular}

* Livestock, Meats, and Wool Market Statistics, 1940, A.M.S., U.S.D.A.

curve for corn is probably less elastic than this. A short crop of corn lowers the hog-corn price ratio and leads to a considerable reduction in hog production. This reduces the demand for corn, so that the price of corn rises less than it would if the demand for corn had remained constant. The opposite happens in years of large corn crops; hog production increases-i. e., the demand increases-and this causes prices to fall less than if hog production (the demand for corn) had remained constant. Thus the demand for corn, "other things being equal," is less elastic than the demand for corn, "other things changing as they do when the supply of corn changes." But 
it may be more useful to know the elasticity of the latter kind of demand than the former.

\section{UNCORRELATED SHIFTS IN DEMAND AND SUPPLY CURVES}

In many cases, particularly with agricultural goods, the changes in demand and supply are uncorrelated.

For nearly a decade after World War I-from 1921 to 1929-the general demand for agricultural products was fairly constant. From 1929 on, however, the demand became unstable, shifting down and up with depression and recovery, recession, etc. The supply of agricultural products, under the influence of the usual fluctuations in the weather, was also unstable. Both the demand and the supply of farm products shifted up and down so much that the intersection points lay scattered all over the page, as in Figure 37, which shows the annual price and production data for hogs from 1921 to 1939.

When this happens, how can the investigator sort out the shifts in demand from the shifts in supply and determine the elasticities of each? On the face of it, it looks like an impossible job. But methods have been worked out to handle it. They are presented in the next two chapters. 


\section{CHAPTER 8}

\section{The Measurement of Changes in Demand: Deflation}

The pioneer quantitative price analysts, from Moore on, had difficulty in dealing with changes in the position of the demand curve.

If the position of the demand curve remains constant, it is easy to determine the elasticity; one simply plots the price data against the production data in an ordinary scatter-diagram, and draws in the demand curve through the dots. But in actual life, demand curves constantly shift their position-sometimes only to a small extent, but sometimes violently. These shifts in demand curves scatter the intersection points all over the scatter-diagram, so that the dots do not fall on a single negatively sloping line; they may even cluster around a positively sloping line, or show no tendency to cluster around any line at all. ${ }^{1}$

This caused the early price analysts a good deal of trouble. They were well aware that the demand for most of the products they were working with showed an upward trend with the passage of time, resulting from the steady increase in population if from nothing else. They knew that rising trends in prices and production both, such as are shown by the data for many commodities in the United States from 1893 to 1914, may be strong enough to convert a normal negative relation between prices and production to the appearance of a positive relation on a simple price-production chart; or at the least, it may obscure the normal negative relationship. Accordingly, they used two or three methods to take these rising trends into account. They recast their data in the form of ratios or percentages of the preceding year's data, or expressed them as ratios of their trends (usually straight line or slightly curved trends fitted by the method of least squares)..$^{2}$

\footnotetext{
${ }^{1}$ E. J. Working, "What Do Statistical 'Demand Curves' Show?" Quarterly Journal of Economics, XLI, February, 1927, pp. 212-35.

2 "In the older type of statistical study of demand, the chief purpose was the determination of 'the demand curve,' or in some cases the more limited purpose
} 


\section{DEFLATING PRICES}

After World War I, economists became acutely conscious of the changes in demand associated with inflation and deflation. For a time they attempted to take these changes into account by "deflating" the original prices by an index of the general price level. Most economists used this deflating procedure with misgivings. ${ }^{3}$ They knew that changes in demand could take place (in fact were taking place from 1933 to 1939) without causing much change in the commodity price level. They knew, furthermore, that even if changes in demand were always associated with changes in the commodity price level, there was no reason to believe that these changes were associated in 1 to 1 ratio. The ratio was just as likely to be 1 to 0.8 , or 1 to 1.5 , or some other figure; and furthermore, it was likely to differ from one price level to another. ${ }^{4}$

of determining the percentage decrease in demand corresponding to a 1 per cent increase in price (elasticity of demand). From the standpoint of such studies all factors other than price were regarded as 'disturbing factors' whose effect should be eliminated. Various devices invented for performing this elimination included the method of trend ratios, of link relatives, and of first differences. On the whole this older type of study proceeded on the assumption that changes in demand due to factors other than price were of a gradual nature due to changes in habit, customs and the growth of population. Under the assumptions it appeared to be desirable to remove the effects of trends.

"But by 1934 it is more and more being recognized that the use of a trend in statistical analysis of economic relationships is a confession of ignorance of some of the important factors involved or is a desire to discuss these factors without identifying them." Charles F. Roos, Dynamic Economics, Principia Press, 1934, pp. 4 and 14.

${ }^{3}$ Henry Schultz, in his Theory and Measurement of Demand, University of Chicago Press, 1938, devotes most of pages 149 and 150 to a discussion of the shortcomings of deflation, but finally adopts it because it reduces the number of variables. He then compares his results with those based on undeflated data in an appendix.

" "The rationale of this sort of 'deflation' (to remove the effects of changes in the general price level) is not clear: either the statistician adheres to the quantity theory in a form that even Jean Bodin would not accept, or else he believes that some, perhaps most, of the monetary disturbance is somehow removed.

"The former alternative cannot charitably be attributed to anyone; the latter alternative seems to me to rest on a rather futile hope. Monetary changes come about through changes in the monetary funds of individuals within a community. The nature and extent of these monetary changes depend largely on who gets the 'money,' when it is received, and how and when it is spent. Only by examining the detailed structure of monetary relationships it is possible to isolate the effects of monetary policy on specific demand curves. And even if this is possible, the resultant demand curve is applicable to future periods only if detailed forecasts of monetary policy are also made. It is not surprising that blanket 'deflation' of prices does not improve the statistical demand curve, judged even by statistical criteria." George J. Stigler, "The Limitations of Statistical Demand Curves," Journal of the American Statistical Association, XXIV, September, 1939, pp. 472-73. 


\section{SHORTCOMINGS OF DEFLATING}

The shortcomings of this deflating procedure (and of the mathematical trend fitting procedure also) were illustrated even in the meticulous work of Henry Schultz, in his monumental Theory and Measurement of Demand. He fitted trends to the data for the annual per capita consumption of corn (corrected for size of crop and real, i. e., deflated price) for three periods of time, the last one being 1915-29, excluding the war years of 1917 to 1921 . The straight line trend in this last period ${ }^{5}$ shows a sharp decline, and Schultz regarded this decline in the demand for corn as the most important finding in his corn chapter.

Actually, however, the downward slope of the trend results almost entirely from the inclusion of the two prewar years, 1915 and 1916, with the postwar years, 1922 to 1929 . The whole price level for corn shifted suddenly downward during the postwar deflation in 1920. If 1915 and 1916 are left out, as they should be (since they belong to the prewar period), the postwar trend of the demand, from 1920 on, is practically horizontal. ${ }^{6}$

By calculations based upon the later year, 1934, Schultz attempted to check the accuracy of his conclusion that the trend had declined. These calculations confirmed his conclusion. But it is a curious fact that this check was itself erroneous, and instead of revealing his previous error, merely covered it up. The 1934 data "confirmed" Schultz's results merely because his deflator was inaccurate. The Bureau of Labor Statistics index of the general wholesale commodity price level in December, 1934, had fallen to 75 (base, $1926=100)$. It is well known that when the general price level changes, the accompanying percentage changes in prices at the farm are greater than the percentage changes in the general price level, because of the comparative fixity of middleman's charges between producer and retailer. This is shown by the fact that while the Bureau of Labor Statistics index of the general level of prices was 75 in December, 1934, the index of the prices of farm products at the farm was 62 (base in both cases, 1926=100). The general relation between the two series for the period 1921 to 1938 is shown in Figure 38 to be 1 to 1.5 .

\footnotetext{
${ }^{5}$ Schultz, op. cit.: Figure 42, p. 258; Figure 43, p. 259; and Figure 47, p. 268.

${ }^{6}$ For a discussion in greater detail, see Geoffrey Shepherd, Demand Curves: Elasticity, Shifts, Rotation, Shape, Document No. 1219, American Documentation Service, Washington, D. C. Paper presented at the Cowles Commission Conference on Econometrics, Colorado Springs, Colorado, July, 1939, by the present author.
} 


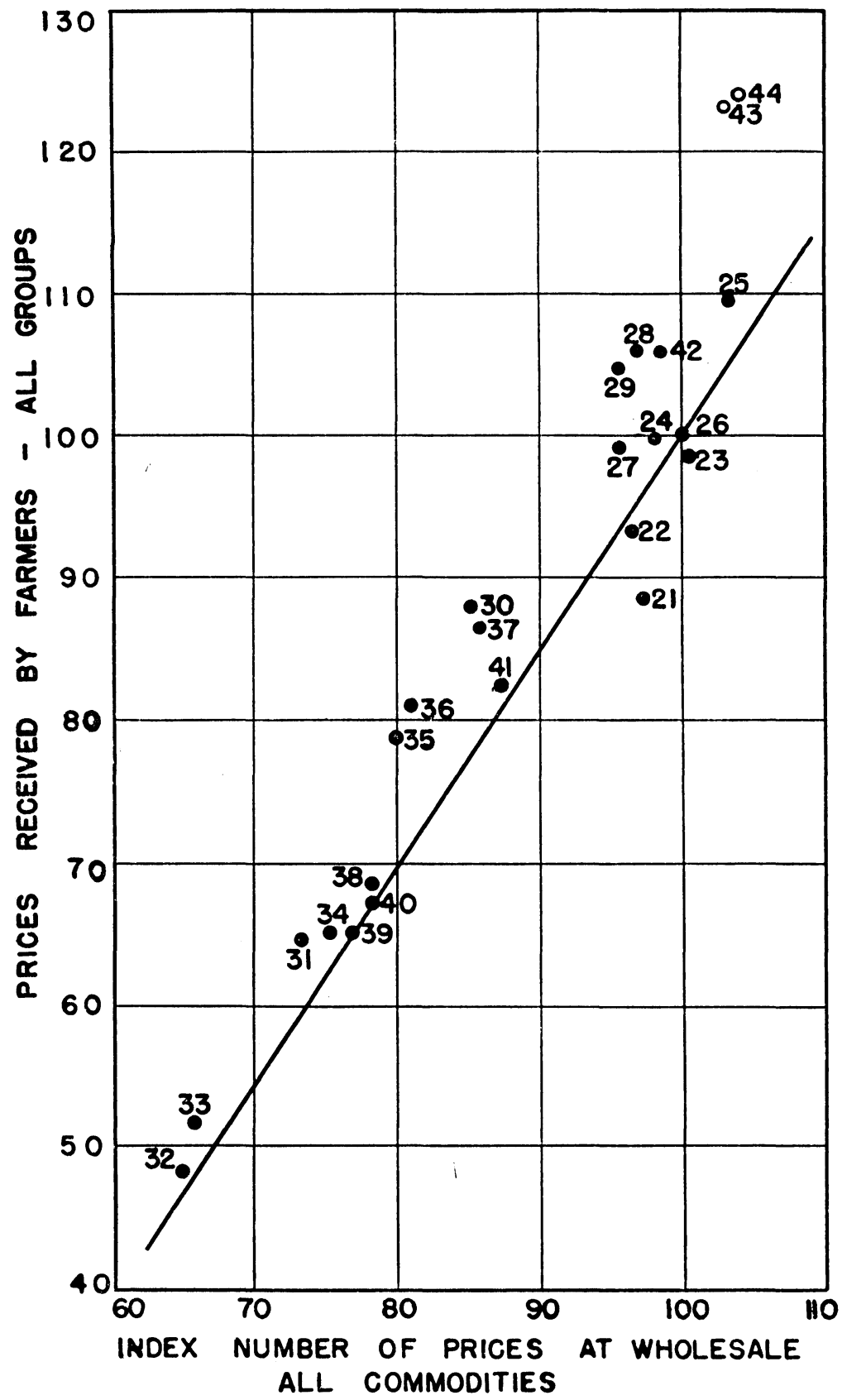

FIG. 38.-Relation between the index of prices received by farmers and the Bureau of Labor Statistics index of all commodity prices at wholesale, 1922-44. (Source, Statistical Abstracts of the United States, 1944-45, USDC, p. 417.) 
The price of corn in 1934 was lower than a 1 to 1 relationship with the general price level, not because the trend of the demand for the corn had declined, but because the general price level had declined during the depression and this had caused a greater than proportional decline in corn prices. The second error happened to be in the same direction as the first. If the general price level in 1934 had been higher than in 1926, the deflated price of corn would have been higher than the size of the crop would have indicated, and this would have seemed to indicate a rise in the trend of the demand for corn. But this would have been just as erroneous as the downward trend which Schultz believed he had found.

The general price level may be used as a deflator for corn prices, without leading to this sort of error, if its movements are first "inflated" by the actual relation between those movements and the movements in the price of corn. An analysis of corn prices, in which the Bureau of Labor Statistics index of the general price level at wholesale is used as a separate variable, shows that corn prices are related to the general price level in the ratio not of 1 to 1 , nor even of 1 to 1.5 (the relationship shown in Figure 38), but of about 1 to 1.7. Corn is farther from the consumer, economically speaking, than the average of the products used in the farm products price level index. If the investigator wishes to divide his corn price series through by the index of the general price level, he should multiply that index throughout by 1.7 and subtract 70 from the products, and use that index to deflate his corn prices, in order to do the job properly. ${ }^{7}$ The correlation between corn supplies per animal unit and corn prices deflated by the index of the general price level is 0.79 ; when the same index is "inflated" as described above, the correlation rises to 0.93 . This is shown graphically in Figure 39.

\section{DEVELOPMENTS IN THE 1930's}

In spite of the shortcomings of the early methods for removing the effect of trends and fluctuations in demand, a good deal of use-

\footnotetext{
${ }^{7}$ This, of course is still not a satisfactory procedure. It is only one step better than deflating by the original general price level directly. It assumes that the changes intervening between the corn producer and the general wholesale market (itself an ambiguous term) remain fixed when the general price level changes, not only for a year or two, but for periods five or ten years long. This is not true. Some of the important changes, such as railroad freight rates, change only slightly, and only after a period of years; but many other charges give way more readily. I do not know of any simple arithmetical method for taking this into account. The problem is not solved even by using the general price level as a separate variable instead of as a deflator; the same difficulties remain.
} 


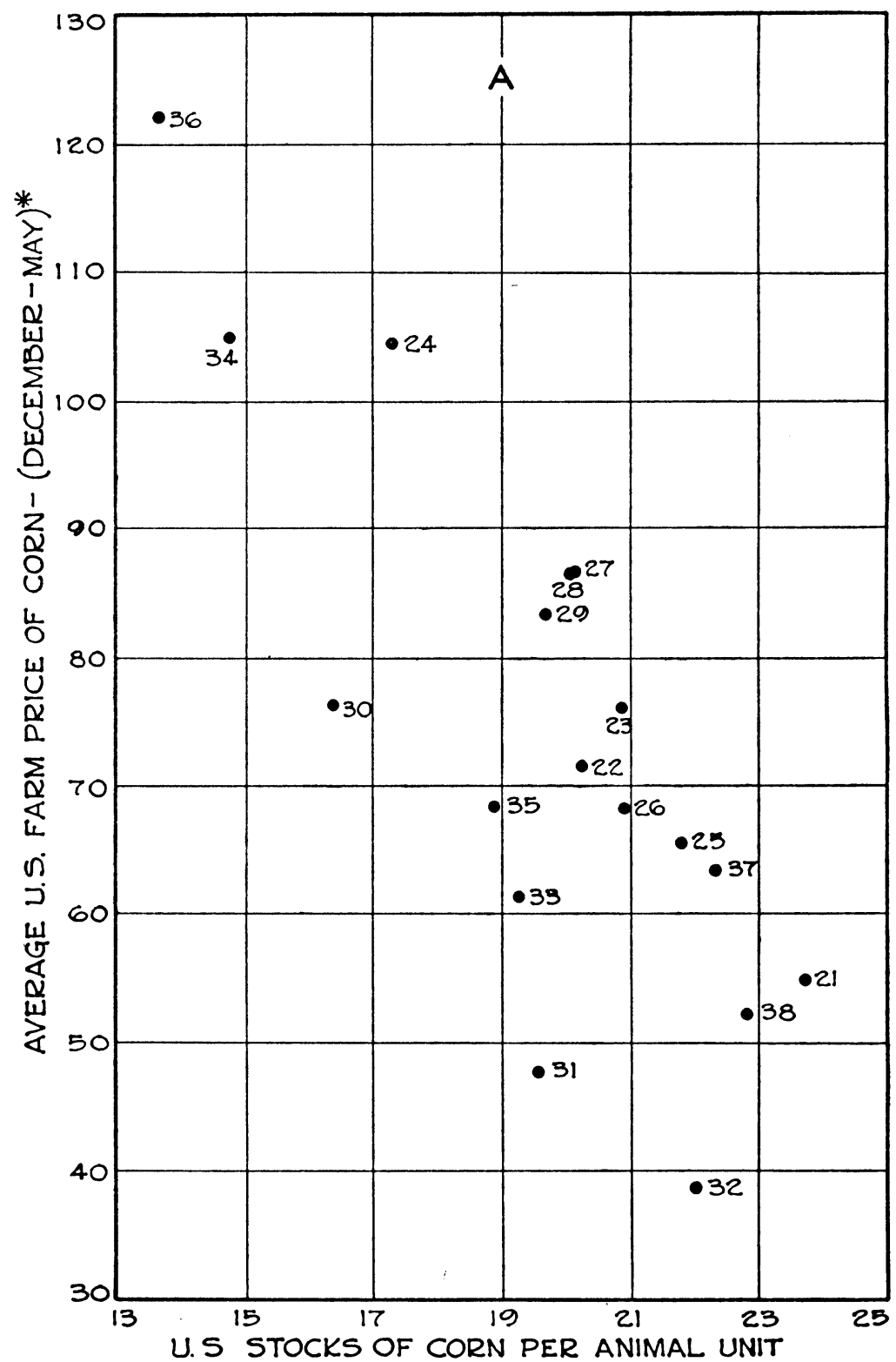

Frg. 39.-Relation of United States stocks of corn per animal unit, December 1, to the average United States farm price of corn, December-May, deflated by (A) the Bureau of Labor Statistics index of the general level of wholesale prices, and (B) that index multiplied by 1.7, minus 70, 1922-38. 


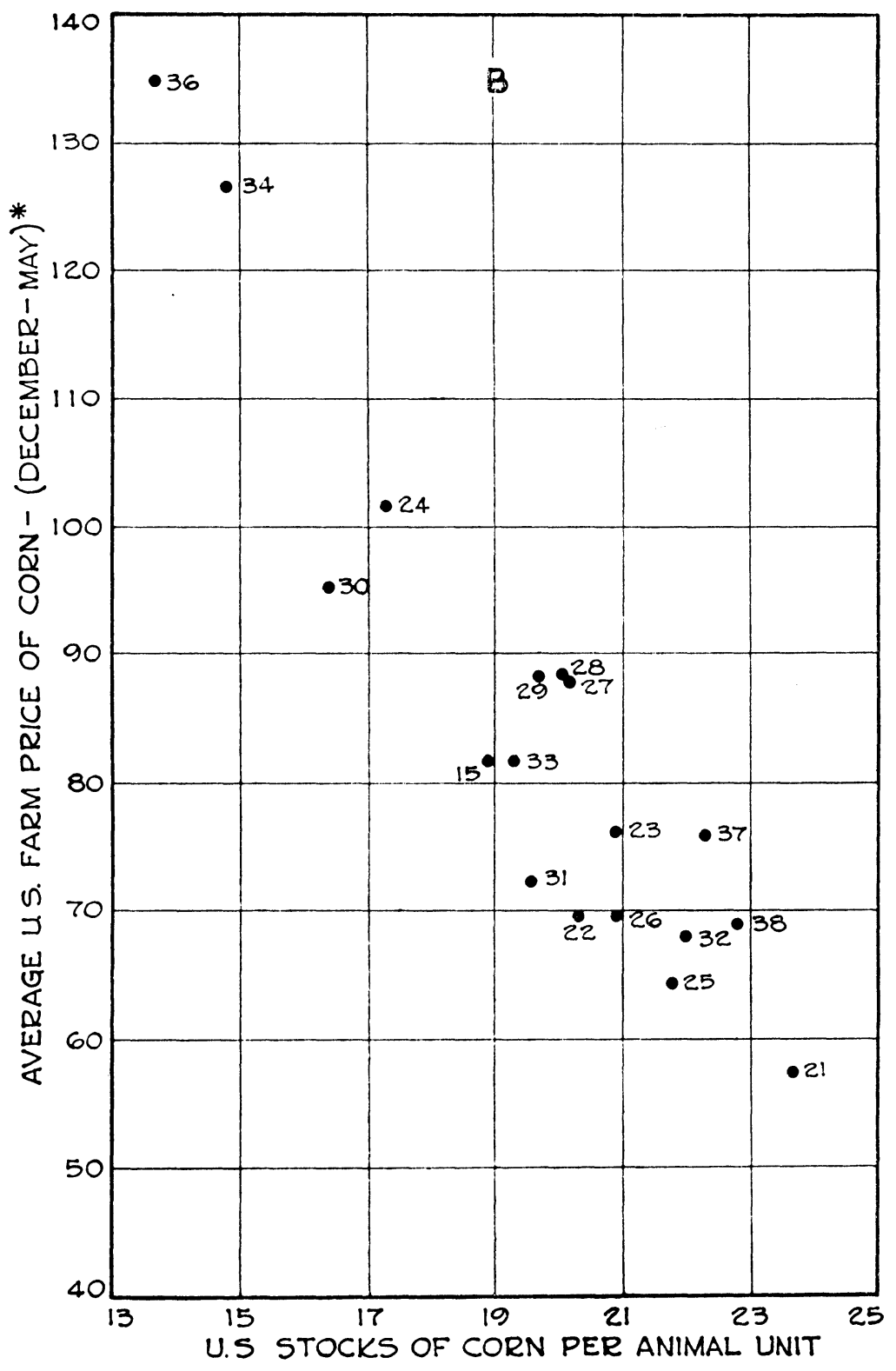


ful work was done during the 1920's with their aid. Then several forces combined to bring about a change. They were (1) the popularization of multiple correlation methods, (2) the development of labor-saving mechanical calculating machines and graphic methods, and finally (3) the onslaught of the great depression in 1929. The overwhelming importance of changes in demand became clear; economists realized that trends could not only rise, they could flatten out, and violently fall. No longer could trends be easily fitted as straight lines. And even if properly curved lines could be fitted, and the trend thus "removed," economists began to realize that they did not want to "remove" one of the main characters in the cast; they wanted to measure it, not in order to throw it away, but in order to include its influence in the analysis.

Furthermore, as the depression deepened, the disparity in the rates at which different prices fell became more and more striking, and the inaccuracy of deflating price series (or inflating them, as the process actually became) by division by an index of the general price level, or any other over-all index, became more and more apparent. The necessity of measuring changes in demand directly, and using that measure as a separate variable, became clear, and the spread of the use of labor-saving computing machinery and graphic methods made the use of additional variables in multiple correlation studies easier. The lengthening of the postwar series with the passage of time also permitted the use of larger numbers of variables. Today, therefore, many price analysts prefer not to fit trends or deflate prices in their analytical price studies, but to use some measure of changes in demand as a separate variable.

\section{TWO KINDS OF CHANGES IN DEMAND}

But this has not solved the problem of measuring changes in demand; it has merely revealed it more clearly. The problem thus revealed is: What variable or variables should be used to measure (in the earlier terminology, "remove") changes in demand?

This problem consists of two parts:

(1) What variable or variables should be used to measure changes in demand affecting all commodities over the country as a whole, the sort that take place when the country swings from prosperity to depression and back? This kind of change can be referred to as a change in the general demand.

(2) What variable or variables should be used to measure 
changes in demand for the specific commodity being investigated, independent of changes in the general demand which affect all commodities? This kind of change can be referred to as a change in the specific demand for the commodity.

These two kinds of changes in demand are discussed in order below.

\section{CHANGES IN GENERAL DEMAND}

The first kind of change in demand itself consists of two elements, which may be referred to as (a) monetary, and (b) physical or real.

The index of the general price level, used as a separate variable, "removes" only the changes in demand that express themselves in the general price level. Are there not other changes in general demand which do not show up in the general price level? From 1922 to 1929 , industrial production and payrolls rose 34 and 29 points respectively; this certainly would seem to indicate that demand also increased. Yet over the same period the general price level did not rise; it fell 1.4 points. This low correlation between industrial production and the general price level is not an isolated case. The relation between the two variables over the whole period from 1925 to 1940 is shown in Figure 40. If the dots for the worst depression years, 1932-33, were omitted, the correlation would be practically zero.

Perhaps the general price level measures only what has been called monetary changes in demand, while indexes of production measure physical or real changes in demand. ${ }^{8}$ Without going into the distinction between these two measures at length here, we may say that either concept (and either measure) is valid. Over periods of time when both the general price level and the total industrial production change markedly, both should be used, or reasons for using only one should be specified.

Another measure, total national income, takes both kinds of changes in general demand into account. This is not always recognized. Some observers believe that the country was less well off in 1939 than it was in 1929 (even though more goods were being produced in 1939 than in 1929) because the total national income in 1939 was lower than it was in $1929.9^{9}$ But the national income alone

\footnotetext{
${ }^{8}$ E. J. Working, "Indications of Changes in the Demand for Agricultural Products," Journal of Farm Economics, XIV, No. 2, April 1932, p. 240.

${ }^{\circ}$ Leonard Ayres, The Cleveland Trust Company Business Bulletin, The Cleveland Trust Company, Vol. 21, No. 9, September 15, 1940, p. 4.
} 
does not tell how well off a nation is, otherwise Germany during its inflation period after World War I would have been fantastically wealthy. It is what the income will buy that counts.

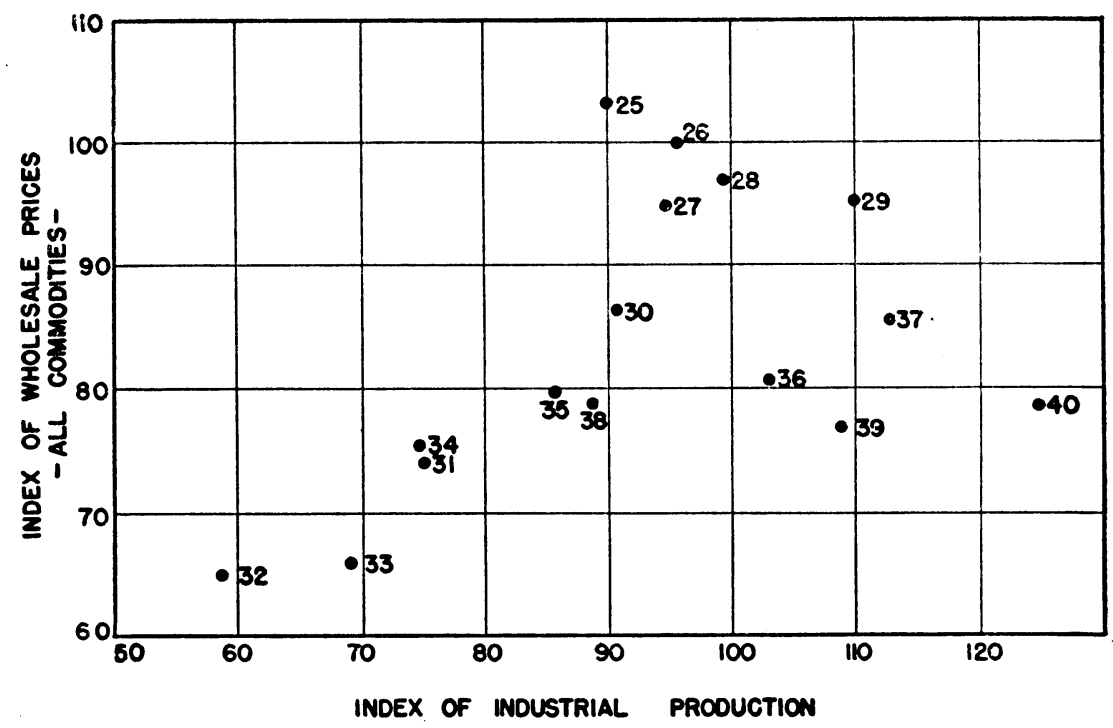

Fig. 40.-Relation between the Bureau of Labor Statistics index of allcommodity prices at wholesale and the Federal Reserve Board index of industrial production, 1925-40. (Source, Statistical Abstracts of the United States, 1944-45, USDC, pp. 417, 496.)

Another measure of demand that combines monetary and real elements is the index of the income of industrial workers. This is more sensitive than the total national income. It is less representative of the country as a whole than the total national income, but it may reflect changes in the demand for farm products more accurately, since some other components of the national income (dividends, for example) go chiefly to people whose incomes are large and whose demand for farm products does not change much with changes in their incomes.

\section{SPECIFIC CHANGES IN DEMAND}

An analysis that is based on general demand factors only is deficient in two respects: (a) The connection between the general change in demand and the price of the particular commodity is not direct; there may be a good deal of loose play between the two. (b) 
Changes in the demand for the particular product only-what may be called specific changes in demand-are left out of account.

Specific changes in demand are more concrete and definite than the general changes in demand discussed in the preceding section. For example, whenever the price of livestock rises, Cornbelt farmers are willing to pay more per bushel for corn to feed to that livestock. This may be regarded as causing the demand curve for corn to rise. Whenever the number of livestock increases, farmers need more corn to feed them. This may be regarded as causing the demand curve for corn to shift to the right.

A rough price analysis for a specific commodity can be made by taking into account only those general changes in demand for all commodities represented by changes in the general price level. A more thorough analysis should include some additional factors representing changes in specific demand. It would be possible to deflate the price series for these other factors by dividing it through in turn by each of these other factors. But the shortcomings of the deflating procedure when only one deflator is used would be multiplied if several deflators were used; the errors resulting from the true relationships not being 1 to 1 would cumulate. A much better procedure is to use the method of multiple correlation analysis, which enables the investagator to determine what each of the true relationships is. The standard mathematical methods of multiple correlation are well described in many statistics textbooks. The more recently developed graphic method is explained in the next chapter. 


\section{The Measurement of Changes in Demand: Multiple Correlation}

The graphic method of multiple curvilinear correlation is, as it were, an $F_{2}$ product. It is an offshoot of an offshoot of the standard mathematical method of linear multiple correlation.

The first offshoot originated fifteen or twenty years ago in the fertile mind of Mordecai Ezekiel. ${ }^{1} \mathrm{He}$ was working with the problem of curvilinear regressions (curved lines of relationship between different series of data). The simplest form of the standard mathematical method involves the assumption that the data are related in straight-line fashion. If this assumption is not valid-if the regressions are actually curvilinear-the standard method yields inaccurate results; before accurate results can be obtained, the curves must be represented by mathematical equations incorporated in the basic formula.

But the regressions cannot be determined accurately until the nature of the curvature is known, and the nature of the curvature cannot be determined accurately until the regressions are known. Ezekiel broke through this impasse by the method of successive approximations, starting with mathematically determined straight lines and adjusting them by graphic methods. ${ }^{2}$

\footnotetext{
${ }^{1}$ Mordecai Ezekiel, "A Method of Handling Curvilinear Correlation for any Number of Variables," Journal of the American Statistical Association, XIX, No. 148, 1924, p. 441. See also the more recent presentation in his book Methods of Correlation Analysis, John Wiley \& Sons, 1941, Chap. 14.

${ }^{2}$ In his own words: "The linear partial regressions are ... computed [by the standard mathematical correlation method]. Then the dependent variable is adjusted for the deviations from the mean of all independent variables except one, and a correlation chart, or dot-chart, is constructed between these adjusted values and that independent variable. This provides the basis for drawing in the first approximation curve for the net regression of the dependent variable on that independent variable. ... The dependent variable is then corrected for all except the next independent variable, the corrected values plotted against the values of that variable, and the first approximation curve determined with respect to that variable. This process is carried out for each independent variable in turn, yielding a complete set of first approximations to the net regression curves. These curves are then used as a basis for correcting the dependent factor for the approximate curvilinear effect of all independent variables except one, leaving out each in turn; and second approximation curves are determined by plotting these corrected values against the values of each independent variable in turn. New corrections are made from these curves, and the process is continued until no further change in the several regression curves is indicated."Ezekiel, op. cit., Chap. 14, p. 223.
} 
This first offshoot of the standard mathematical method of linear multiple correlation, therefore, was a hybrid, a combination of mathematics and graphics. Then Louis Bean developed the second offshoot. ${ }^{3}$ This second offshoot shed the mathematics inherited from its grandparent completely and became entirely graphic. In effect, Bean said, it is a waste of time to fit straight-line curves mathematically, and then modify them graphically, freehand, to make them fit any curvature existing in the regressions. Don't bother with any mathematics, he said; put the regression lines in freehand in the first place, curves and all.
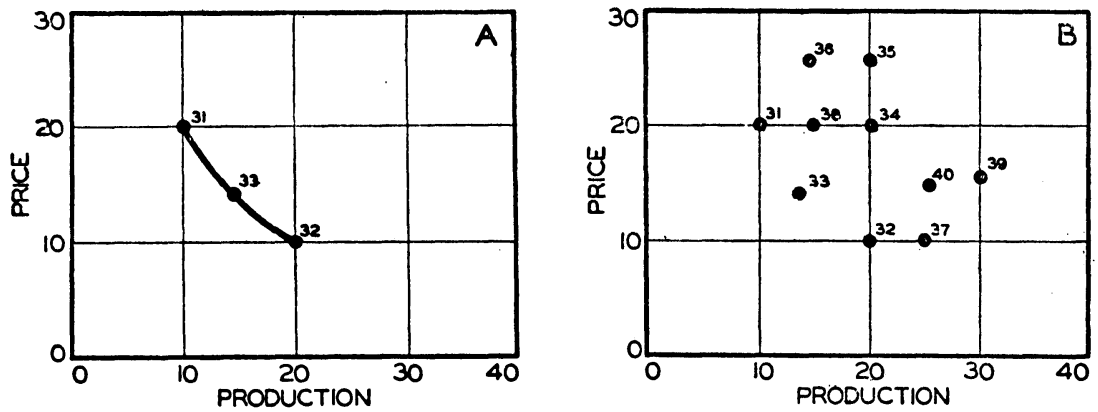

Fig. 41.-Hypothetical price and production data.

But how does one know where to draw in the regression lines right off? The essence of Bean's contribution is his simple answer to this question.

In simple correlation, the dependent variable, for example price, is related to one independent variable, for example production. One simply plots price against production in a scatter-diagram, and draws in the regression line, straight or curved, wherever the dots indicate that it should go. This is illustrated in section A of Figure 41, based upon the first three price and production items in Table 14.

In the simplest case of multiple correlation, the dependent variable price is related to two independent variables, for example production and demand. Two scatter-diagrams are required here - one to show the regression of price on production (or in more everyday language, the influence of production on price) indepen-

${ }^{3}$ L. H. Bean, Applications of a Simplified Method of Graphic Curvilinear Correlation, BAE, USDA, April, 1929, mimeo.; and "A Simplified Method of Graphic Curvilinear Correlation," Journal of the American Statistical Association, XXIV, December, 1929, pp. 386-97. 
dent of the influence of demand on price; and the other to show the influence of demand on price independent of the influence of production on price.

In handling a multiple correlation problem of this sort, the first

TABLE 14

Price, Quantity, and Demand Schedule (Hypothetical Data)

\begin{tabular}{|c|c|c|c|}
\hline Year & Price & Production & $\begin{array}{l}\text { Index of } \\
\text { Demand }\end{array}$ \\
\hline $\begin{array}{l}1931 \ldots \ldots \\
1932 \ldots \ldots \ldots \\
1933 \ldots \ldots \ldots \ldots \\
1934 \ldots \ldots \ldots \ldots \ldots \ldots\end{array}$ & $\begin{array}{l}20 \\
10 \\
14 \\
20 \\
25\end{array}$ & $\begin{array}{l}10 \\
20 \\
14 \\
20 \\
20\end{array}$ & $\begin{array}{r}10 \\
10 \\
8 \\
20 \\
25\end{array}$ \\
\hline 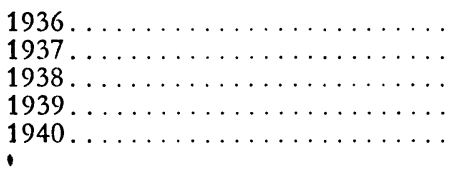 & $\begin{array}{l}25 \\
10 \\
20 \\
15 \\
15\end{array}$ & $\begin{array}{l}15 \\
25 \\
15 \\
30 \\
25\end{array}$ & $\begin{array}{l}20 \\
15 \\
15 \\
25 \\
20\end{array}$ \\
\hline
\end{tabular}

thing to do is to plot the dependent variable price with one of the independent variables, say production, in a simple scatter-diagram. The price and production data from Table 14 are thus plotted in section B of Figure 41.

The dots in this section B are scattered about with no evidence of any relationship. But this may be because the influence of production on price is obscured by the co-existing influence of demand on price. What we want is the net influence of production on pricethe influence of production on price independent of the influence of demand on price.

This word "independent" is the key to the graphic method. One way to determine the influence of production on price independent of the influence of demand on price is to choose two years in which the values of the demand variable are identical. Any change in price from one of these years to the other then must show the influence of production on price independent of the influence of demand on price, since demand did not change from the one year to the other. A line connecting these two years would then be a preliminary indication or estimate of the influence of production on price independent of the influence of demand on price.

Inspection of Table 14 shows that there are several pairs of years 
in which the values of the demand variable are identical (within each pair). The years 1931 and 1932, for example, both carry demand values of 10 . The dots for these two years may therefore be connected by a light line, as shown in section A of Figure 42.

This is a beginning. If now another pair of years can be found in which the demand values are identical, another line can be drawn in connecting these two years. Two such years are 1934 and 1936. This provides a second estimate of the influence of production independent of the influence of demand. Additional pairs of years, in
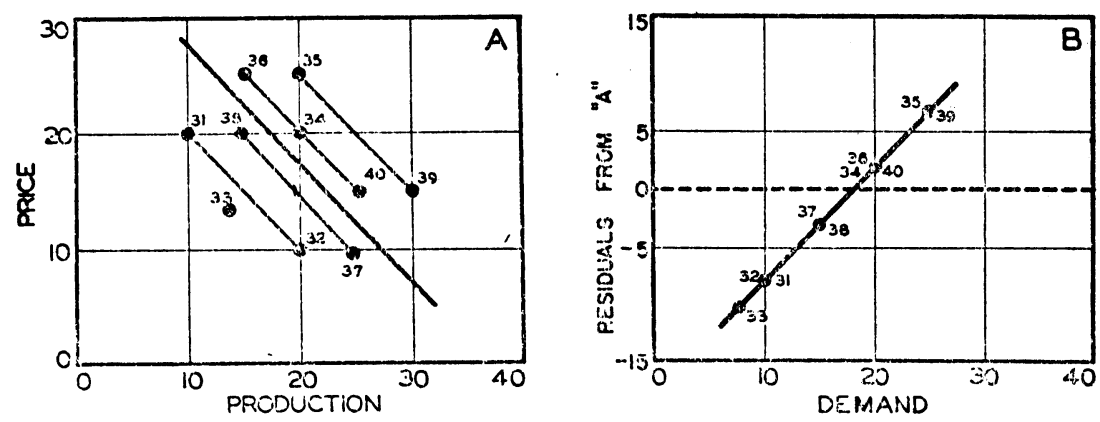

FIG. 42.-Hypothetical price and production data. Net regression curves.

each of which the demand values are identical, may also be connected, providing additional estimates.

By now the chart looks like a piece of prehistoric bedrock with scratches on it showing the direction in which a glacier passed over it. A long heavy line can now be drawn in freehand, passing through the dots with a slope representing the general average slope of various short lines on the chart. It should go through the general mean. This line is shown in section $\mathrm{A}$ of Figure 42. It is a first approximation to the net regression line desired.

The determination of the net influence of demand on price is then simple. If the heavy line just drawn in shows the net influence of production on price, the vertical distances of the individual dots above and below this line must show the net influence of demand on price. The way to reveal this net influence clearly is to take these vertical distances or residuals and plot them against demand in a second chart. In this chart, the demand scale runs along the bottom, like the production scale in the first chart. A horizontal line is drawn across the middle of the chart (about half way up). This 
line is regarded as zero on the vertical scale. The vertical distances of individual dots above or below the preliminary regression line in the first chart are then plotted above or below the horizontal line across the middle of the second chart against the respective demand readings along the bottom of the second chart. A line drawn through the dots in the second chart then represents the net influence of demand on price-net, because the dots were plotted from the regression line on the first chart which showed the net influence of $\mathrm{A}$ on $\mathrm{X}$.

If the first approximation line in the first chart is correct, and if the dependent variable price is completely determined by the two independent variables, production and demand, the line drawn through the dots in the second chart will pass through all of them. This is the situation shown in section B of Figure 42.

If, however, some scatter still remains, either the first approximation line in the first chart was not correctly placed, or one or more additional independent variables need to be taken into account.

The test to determine whether additional variables are needed will also show whether the first approximation line was correctly placed. It consists in taking the residuals from the second chart (the vertical distances above and below the net regression line) and plotting them in red or in some other distinguishing manner, above or below the first approximation regression line in the first chart. (Or this first regression line may be traced on a new clean sheet of graph paper, with the same scales as the original chart). If they fall uniformly about this first approximation line, then a second approximation is not required; what is needed is one or more additional variables. If, however, the dots do not fall uniformly about the first approximation line, but have a different curvature or slope, this indicates that the first approximation line was incorrectly drawn. A second approximation line must be drawn, passing as nearly as possible through the red dots, and the residuals of the original black dots from that line plotted in a new second chart (or in different color in the old one) against demand. This may show that the regression line in the second chart needs to be revised. The process is repeated back and forth until the scatter is reduced to the minimum. If some scatter still remains, it means that the study should be extended to include one or more additional variables. In that case the residuals remaining in the second chart should be plotted against a third variable, and so on. 


\section{EMPIRICAL ILLUSTRATION}

The preceding example, based upon hypothetical data with straight-line relationships and perfect correlation among the variables, serves to illustrate the principles of the graphic method under the simplest conditions. A second illustration based upon actual
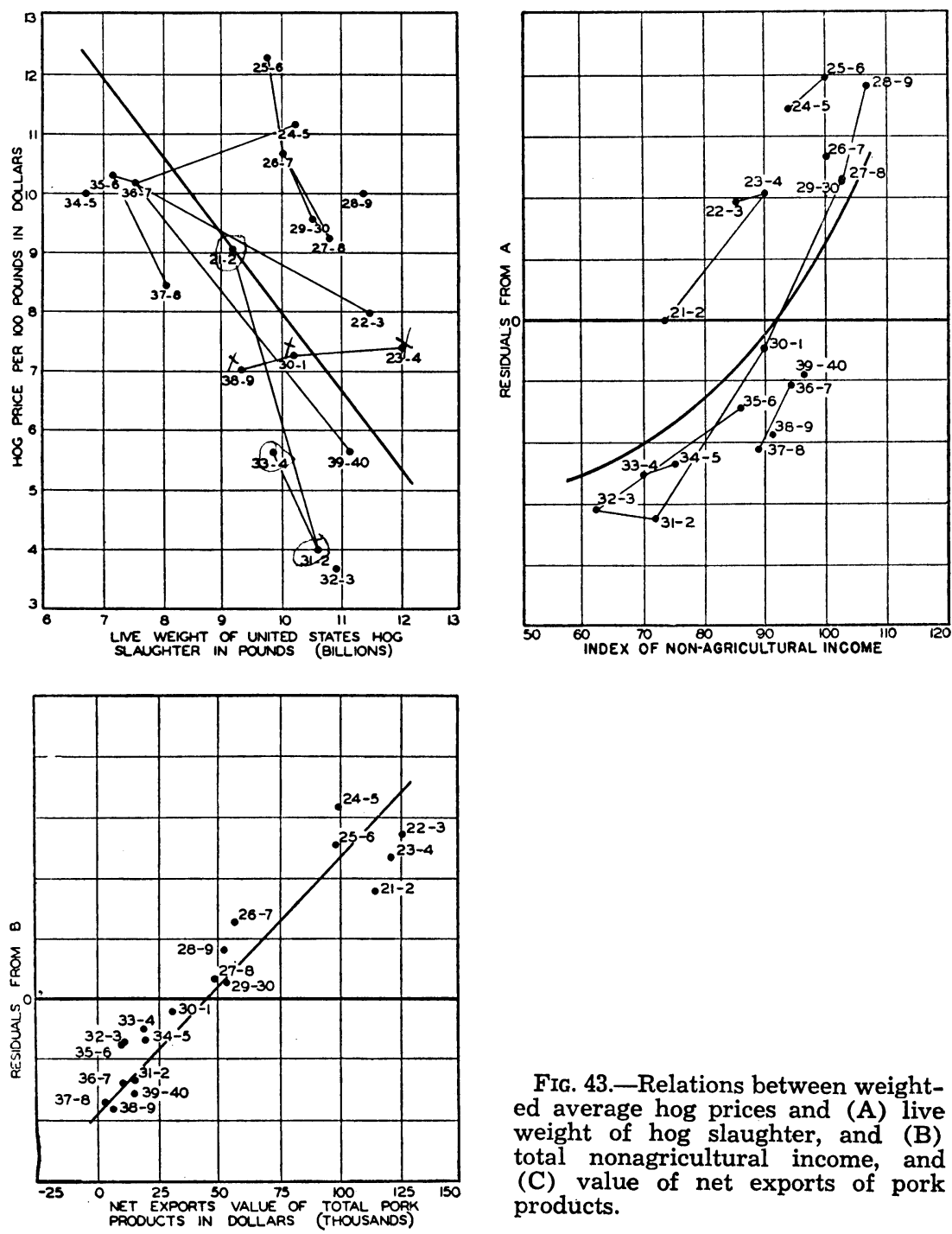

FIG. 43.-Relations between weighted average hog prices and (A) live weight of hog slaughter, and (B) total nonagricultural income, and (C) value of net exports of pork products. 
empirical data of a more complicated kind will now be used. In this illustration there are three independent variables, one or two of the regressions are curved, and the correlation is not perfect. The data for this illustration are given in Table 15.

TABLE 15

United States Prices of Hogs, Nonagricultural Income, Value of Exports of Pork Products, and Total Hog Slaughter

\begin{tabular}{|c|c|c|c|c|}
\hline Year & $\begin{array}{c}\text { Average } \\
\text { Hog Price } \\
\text { (Weighted) } \\
\text { Oct.-Sept. }{ }^{*}\end{array}$ & $\begin{array}{l}\text { Total Live } \\
\text { Weight } \\
\text { of Hogs } \\
\text { Slaughtered } \\
\text { Oct.-Sept. } \dagger\end{array}$ & $\begin{array}{c}\text { United States } \\
\text { Nonagricultural } \\
\text { Income } \\
\text { Oct.-Sept. } \ddagger\end{array}$ & $\begin{array}{l}\text { Value of } \\
\text { Net Exports } \\
\text { of Pork } \\
\text { Products } \\
\text { July-June§ }\end{array}$ \\
\hline $\begin{array}{l}1921-22 \ldots \\
1922 \ldots \ldots \\
1923 \ldots \ldots \\
1924 \ldots \ldots \\
1925 \ldots \ldots \\
1926 \ldots \ldots\end{array}$ & $\begin{array}{r}\text { Dollars } \\
9.06 \\
7.98 \\
7.41 \\
11.18 \\
12.29 \\
10.70\end{array}$ & $\begin{array}{c}\text { Millions of lbs. } \\
9,156 \\
11,440 \\
12,013 \\
10,258 \\
9,776 \\
10,009\end{array}$ & $\begin{array}{c}\text { Calendar Year } \\
1926=100 \\
73.6- \\
85.0= \\
90.3 x \\
93.8 \\
99.9 \\
101.8\end{array}$ & $\begin{array}{c}\$(000) \\
114,490 \\
126,739 \\
122,344 \\
98,690 \\
96,009 \\
63,571\end{array}$ \\
\hline $\begin{array}{l}1927 \ldots \ldots \\
1928 \ldots \ldots \\
1929 \ldots \ldots \\
1930 \ldots \\
1931 \ldots \ldots \\
1932 \ldots \ldots\end{array}$ & $\begin{array}{r}9.24 \\
10.01 \\
9.57 \\
7.28 \\
4.05 \\
3.68\end{array}$ & $\begin{array}{l}10,823 \\
11,343 \\
10,530 \\
10,200 \\
10,625 \\
10,918\end{array}$ & $\begin{array}{c}102.9 \\
106.7 \\
102.9 \\
89.9+ \\
71.8- \\
61.8-\end{array}$ & $\begin{array}{l}47,880 \\
53,148 \\
57,962 \\
32,663 \\
14,826 \\
10,856\end{array}$ \\
\hline $\begin{array}{l}1933 \ldots \ldots \\
1934 \ldots \ldots \\
1935 \ldots \ldots \\
1936 \ldots \ldots \\
1937 \ldots \ldots \\
1938 \ldots \ldots \\
1939-40 \ldots\end{array}$ & $\begin{array}{r}5.64 \\
10.00 \\
10.32 \\
10.18 \\
8.41 \\
7.03 \\
5.63\end{array}$ & $\begin{array}{r}9,872 \\
6,742 \\
7,191 \\
7,538 \\
8,089 \\
9,311 \\
11,142\end{array}$ & $\begin{array}{l}69.9- \\
75.1^{-} \\
86.0- \\
94.2 \\
88.1 \\
91.1+ \\
96.4 \|\end{array}$ & $\begin{array}{r}18,294 \\
18,981 \\
8,923 \\
-986 \\
-408 \\
5,985 \\
14,309\end{array}$ \\
\hline
\end{tabular}

* Livestock, Meats and Wool Market Statistics and Related Data, 1938, AMS, USDA, 1939, p. 77. Livestock, Meats and Wool, Market Review and Statistics (weekly), 1940.

† Livestock, Meats and Wool Market Statistics and Related Data, 1938, AMS, USDA, 1940 , p. 79.

"Demand, Credit, and Prices," 1941 Agricultural Outlook Charts, BAE and AMS, USDA, 1940, p. 7.

$\S$ Foreign Crops and Markets (mimeo), USDA, August issue each year, Livestock Meats and Wool, Market Review and Statistics (weekly), 1940.

\|1 10 month average.

The dependent variable, hog prices, is plotted first against the independent variable, hog slaughter (i. e., quantity), as in the previous illustration. The results are shown in section A of Figure 43. Here, as in the other case, the dots are scattered all over the page; 
they do not fall around any clearly defined demand curve. Evidently the demand curve must have shifted up and down (or sideways) during the period so that the slope of the curve is obscured.

What is needed is some measure of these shifts or changes in demand. Several such measures are available. One of the best is the index of national nonagricultural income, which is published monthly by the Bureau of Agricultural Economics in The Agricultural Situation. This index may be used as the second independent variable.

The pairs of years in which the values of the index of demand (nonagricultural income) are nearly identical may then be located, and the two years in each pair joined by light connecting lines. In this case there seem to be several chains or groups of more than two years; the years in each group can be connected in a series. One such series is 1933-34, 1931-32, 1921-22, and 1934-35. Another is 1923-24, 1930-31, and 1938-39. Still another is 1925-26, 1926-27, 1927-28, and 1929-30.

A heavy straight line is then drawn in through the dots with approximately the average slope of these light lines. In the estimation of this average slope, each light line should be given an importance proportional to its length. The reason for this is that if the dots in one pair are only an inch apart, let us say, and one of the dots has been pulled up or down by some other influence a distance of half an inch, the slope of the light line connecting the pair will be very much affected. But if the pair had been four inches apart, the half inch displacement of one of the dots would have only a slight effect on the slope of the line connecting them. The longer the light line, the more likely it is to show the net influence of the variable correctly; the longer lines, therefore, should be given more weight than the shorter. ${ }^{4}$

This suggestion is made merely in the interests of speed. The more nearly correctly the demand curve is drawn in, the less revi-

A. G. Hart makes an interesting suggestion here. He points out that the demand for most products is continually changing with the passage of time and therefore that any index of general demand is likely to measure changes in the demand for a particular product most accurately for years that are close together (in time) and least accurately for years that are far apart (in time). Accordingly, he advocates connecting only the dots for the years (when national income was similar) that are close together in time, or at least giving them the greater importance. This suggestion is particularly apt in this case, where one of the variables (exports) shows a strong downward trend throughout. If this procedure is followed, all of the positively-sloping lines in Figure 31A disappear. 
sion will be required, and the more quickly will the whole job be finished. But there is no question of principle involved. The same final result will be attained no matter what slope is given to the first approximation to the demand curve. ${ }^{5}$ The successive adjustments of the line, described below, will bring it into its proper place eventually, no matter how it was drawn in in the first place. The method is not delicate, unstable, or tricky. Recently a student worked through his first analysis of this kind in some haste, and fell into a considerable error; he confused the first independent variable with the second, and believing that the curve. should have a positive rather than a negative slope, drew it in that way in spite of the evidence of the light lines to the contrary. The slope was $90^{\circ}$ wrong -as far wrong as it is possible to make it. But the successive adjustments of the curve gradually rotated it into its proper position, and his final results were the same as those of others; it merely took him longer to reach them.

\section{PLOTTING THE RESIDUALS}

To return to Figure 43: The residuals from the heavy line drawn in freehand are now plotted against the second variable, total nonagricultural income. The results are shown in section B of Figure 43. The dots in this section fall along a path (the long curved line and the short lines are not put in until later) with a positive slope, but the pathway is rather broad. Either the line in section A must have been incorrectly placed, or else an additional independent variable needs to be brought into the picture.

The standard procedure for testing this, as explained earlier, is to draw a line through the dots in section $B$ of Figure 43 and plot the residuals from that line back against the line in section $A$. With a little practice, however, even this short-cut method can be cut still shorter. We can simply imagine the line drawn through the dots in section B, and observe which dots fall above, and which fall below, the imaginary line. When this is done, it is clear, for example, that the dots for the years from 1921-22 to 1925-26 are all high. Now if the dots for those years in section A all fell in the left or right side of the chart, that would show that the line on that side of section A should be raised (which would have the effect of lowering the dots in section $B$ ).

${ }^{5}$ If the sample is small, the correlation low, or the intercorrelation high, the results from different trials may be only approximately identical. But the differences between them would be small relative to the standard error. 
Inspection shows, however, that the dots from 1921-22 to 1925-26 range pretty well over most of section $\mathrm{A}$. There is some tendency for the dots to lie in the right-hand two-thirds of that section, but other years (for example 1927-28 and 1928-29, and 1931-32 and 1932-33) lie along with them and would be pulled down also (in section B) if the right-hand end of the line in section $A$ were raised.

The preliminary conclusion may be reached, therefore, that the line in section A is correctly placed with respect to the two independent variables $A$ and $B$. The scatter in section $B$, therefore, means that an additional variable needs to be considered. What additional variable should be used? The prices or production of some competing product such as beef, some index of export demand, or what?

The proper procedure is to plot the residuals from a line drawn in through the dots in section $B$ against each of the additional variables that might logically be expected to have an influence on the price of hogs. This procedure can be short-cut, also; it can be done mentally. The residuals from an imaginary line drawn through the dots in section B can be mentally compared with the values of each of the additional variables considered while they are still in tabular form. Only the variables which show some correlation with the residuals need to be considered. In this case, the only variable that meets this test, out of the several investigated, is net exports. This is given in the last column of Table 15. Pairs of years in each of which the values of this variable are nearly identical may then be joined. There is some difficulty in finding pairs of years in this case, because of the marked downward trend in the data over most of the period, but these dots may be joined: 1922-23, 1923-24, and 1921-22; 1924-25 and 1925-26; 1928-29 and 1929-30; 1932-33, 1931-32, 1933-34, and $1934-35 ; 1935-36$ and 1938-39, and 1936-37 and 1937-38. A line may then be drawn in freehand with the average slope of these short lines, as shown in section B.

In this case, the short lines give some indication that the regression is slightly curvilinear, not straight (the short lines are steeper in the upper right-hand part of the chart than in the lower left-hand part). There is nothing sacred about a straight line; as a matter of fact a straight line on arithmetic paper is a curved line on logarithmic paper. There is nothing inherently superior in a straight line except that it is easier to draw. One might have expected the line to curve 
the opposite way, but it does not. It is interesting to see that a BAE study of consumption by different income groups shows the same curvature for pork as this one. ${ }^{6}$

The residuals from the curved line are then plotted against the data showing net exports, with the result shown in section $\mathrm{C}$.

This does not constitute by any means a complete analysis of hog prices. Other factors have been affecting the price of hogs over the period considered. Vegetable oils have been used in increasing quantities, and this has reduced the demand for lard. This downward trend in the demand for lard has paralleled the downward trend in the net export of pork products. In the analysis, all of the decline in hog prices not explained by the first two independent factors (hog slaughter and nonagricultural income) is attributed to the decline in net exports; actually, part of the decline no doubt results from the increasing competition from vegetable oils. The effect of this "intercorrelation" between two independent factors is discussed in more general terms later in this chapter.

\section{INCOME-PRICE CURVES}

The curve shown in the upper left-hand section of Figure 43 is an approximation to a demand curve, subject to the reservations given in Chapter 6 (pp. 64-68). What is the curve in the upper righthand section? It has a positive slope like a supply curve. Is it a supply curve?

It is not. A supply curve shows the relation between price and quantity produced. But the scale along the bottom of the present chart shows a measure of demand (nonagricultural income) not of production. The curve shows the relation between changes in nonagricultural income and the price of hogs. It is an income-price curve, not a price-quantity curve.

This sort of curve is useful for price predicting purposes. If the prediction is made that national income will change by a given amount, the effect of that change in income upon hog prices can be read off the chart and used, in the light of estimates of production, to predict hog prices. ${ }^{7}$

\footnotetext{
${ }^{6}$ The National Food Situation, BAE, USDA, July, 1942, p .18.

${ }^{7}$ For a heroic attempt to apply graphic multiple correlation analysis to the prediction of "postwar conditions in domestic and foreign markets," see Hans Staehle, "Relative Prices and Postwar Markets for Animal Food Products," Quarterly Journal of Economics, LIX, No. 2, February, 1945, pp. 237-79.
} 


\section{APPRAISING THE RESULTS OF GRAPHIC PRICE ANALYSES}

The validity of price analyses of this sort should be judged by three criteria, (1) the closeness of fit of the dots about the lines of net regression, and the conformity of the results (2) with economic theory, and (3) with what is already known about the characteristics of the commodity. Neither one test alone is adequate. An analysis that yielded a positively sloping demand curve, no matter how closely the dots lay about it, would at least call for further investigation, if not rejection; so would an analysis that yielded a demand curve with the expected negative slope but a wide scatter of the dots. A careful worker tests his analyses by these three criteria, subconsciously, as he goes along.

Some controversy has recently arisen over the question whether the investigator should follow "the procedure of determining in advance to fit a specific type of curve or set of curves," or should "more nearly allow the data to determine the shape of the curves by fitting a set of curves of minimum residuals." controversy seems unnecessary; no sensible person follows either procedure alone. ${ }^{9}$ It is easy to carry the spirit of determining what to do in advance so far as to make it unnecessary to make the analysis at all, if the investigator already knows all he will permit himself to learn from it. On the other hand, Bean exposed himself to later criticism because in his earlier work he let his curves follow his data too closely to conform well with economic theory. It would seem sufficient, if not superfluous, now that the pioneer stage is passing, to warn price analysts to use their heads as well as their tools.

In presenting their results, some workers show a final chart in which the prices estimated from the regression lines are plotted along with the actual prices in an ordinary time chart (with the price scale running up the side and time along the bottom). This shows nothing about the amount of the difference between the estimated and actual

${ }^{8}$ W. Malenbaum and J. D. Black, "The Short-Cut Graphic Method: an Illustration of 'Flexible' Multiple Correlation Techniques," Quarterly Journal of Econnmics, LII, November, 1937, p. 66. See also comments by Bean and Ezekiel, on "The Use of the Short-Cut Graphic Method of Multiple Correlation," Quarterly Journal of Economics, LIV, February, 1940, p. 318.

${ }^{\circ}$ If Yntema had determined in advance to fit a markedly curved marginal cost curve to the data from the United States Steel Corporation, similar to the curves that have been accepted in economic theory (see the results of his research, obtainable free from the U. S. Steel Corporation) he would have had to reject the evidence of the data that the curve actually is rather flat. He would have let his preconceptions close his eyes to new knowledge. 
prices that is not already shown in the final regression chart. The scatter of the dots about the line in the final regression chart is the same as the "scatter" of the actual prices about the estimates in the time chart.

It is worth while for purposes of further analysis, however, to plot the residuals from the final regression chart against time treated as an additional variable. This will reveal any serial correlations (cycles or waves) in the residuals, and any trends that may exist. It may be that the residuals gradually rise, or fall, with the passage of time, or show some sort of cyclic movement. If so, plotting them against time will reveal it. If the residuals do rise or fall, the investigator may be tempted to use time as an additional independent variable. But that would be a mistake. Time of itself does not cause residuals to rise or fall; some variable associated with time does it, and the variable itself should be isolated and used, not merely time as such. Otherwise the results may be disastrous, since a variable such as the displacement of horses by tractors that moves in one direction over a certain period of time may cease to move, or reverse the direction of its motion, in another.

\section{THE ORDER OF PRESENTATION}

The results attained will be the same no matter what the order in which the variables are worked through. ${ }^{10}$ The results will be attained more quickly if the variables are taken in the order of their importance, for in that case the first approximation lines are most likely to be accurate. But the lines will be the same whatever the order of the variables may be.

For purposes of presentation, however, one order may be better than another. In some cases attention is being focused in the discussion upon the effect of one particular variable, for instance quantity, upon price. In that case it may be advisable for presentation purposes to use that variable last (even if it is the most important) because the average nontechnical reader is more convinced by the close scatter of the dots around the final variable than by the wider scatter around the earlier ones, though there is actually no real

${ }^{10}$ Warren C. Waite, "Some Characteristics of the Graphic Method of Correlation," Journal of the American Statistical Association, XXVII, No. 177, March, 1932, p. 68; and Mordecai Ezekiel, "Further Remarks on the Graphic Method of Correlation, a Reply to 'Some Characteristics of the Graphic Method of Correlation," " same Journal, No. 178, June, 1932, p. 183. 
difference between them. In an earlier publication, ${ }^{11}$ variables similar to those shown in Figure 43 were used, but in a different order from the order adopted here. The chief item of interest in that case was the elasticity of the demand for hogs. Accordingly, the variables were taken in such order that livestock slaughter was used last; the elasticity was then shown directly by the line drawn through the dots in the last chart.

\section{INTERCORRELATION AND GROSS AND NET REGRESSION}

Whenever there is any correlation between two independent variables, ${ }^{12}$ intercorrelation, it is called, the average slopes of the light lines connecting pairs of years in each of which the values of the next variable are equal will be flatter or steeper than the slope of the group of dots as a whole. Where this happens, the demand curve should be drawn in with reference only to the light lines, not to the group of dots as a whole. For the objective is to ascertain, not gross regression (i. e., simple regression, the regression of $\mathrm{X}$ on $\mathrm{A}^{13}$ ) but net regression (i. e., partial regression, the regression of $\mathrm{X}$ on $\mathrm{A}$ independent of its regression on other variables). The group of dots as a whole shows the gross regression of the dependent variable $X$ upon the first independent variable $A$; but what we are trying to find is the net regression of $\mathrm{X}$ upon $\mathrm{A}$ after the influence of other independent variables has been taken into account.

A more detailed statement of what gross and net regression are may be helpful here. Regression means, roughly, dependence; we may speak of the dependence of $\mathrm{X}$ on $\mathrm{A}$, but it is more direct to speak of the influence ${ }^{14}$ of $A$ upon . When statisticians speak of the regression of $X$ upon $A$, they mean, in everyday language, the influence of $A$ upon $X$. Now the gross influence of $A$ upon $X$ is actually the gross influence of a rather extended phrase, namely "A and everything else correlated with A by chance or otherwise."

${ }^{11}$ See analysis in Geoffrey Shepherd and Walter Wilcox, Stabilizing Corn Supplies by Storage, Iowa Agr. Exp. Sta., Bul. 368, 1937, p. 337.

${ }^{12}$ This sounds like a contradiction in terms, for one might think that if two variables were correlated, they could not be independent. But that would be a mistake. Two variables may be completely independent, completely free of any causal relationship to each other, and yet show some degree of correlation, either because they are both influenced by a third variable, or merely by chance.

${ }^{13}$ Where $X=$ the dependent variable, and $A, B$, etc., = the independent variables.

${ }^{14}$ The word influence is more accurate than the word effect. An influence may be more or less offset by another influence; this is frequently the case in economics. An influence is exerted, but not necessarily registered, whereas an effect is not an effect until it is registered, i.e. effected. 
And this phrase is not merely a qualification seldom required; it is the rule, rather than the exception. In our economic world, so characterized by interdependence, it is only rarely that A is not correlated with other variables that have an influence upon $\mathrm{X}$.

It is indeed impossible, practically speaking, to show the net influence of $A$ upon $X$. What we speak of as the net influence of A upon $\mathrm{X}$, with the net influence of $\mathrm{B}$ taken into account, is actually the net influence of " $A$ and everything else correlated with $A$ by chance or otherwise, except B." What we speak of as the net influence of $\mathrm{A}$ upon $\mathrm{X}$, with the influence of $\mathrm{B}$ and $\mathrm{C}$ taken into account, is actually the net influence of " $A$ and everything else correlated with A by chance or otherwise, except B and C." And so on for additional variables.

In a world full of complex interrelationships, therefore, successive net regressions, as more and more independent variables are taken into account, should be expected to be different, not only from the gross regression, but from each other. They may even be different in sign. One almost hesitates to use concrete illustrations, for so many other intercorrelations are involved than the one selected for the illustration. But consider the net influence of hog prices upon corn prices, before the influence of hog numbers has been taken into account (and assuming that there are no changes in the general price level to complicate the picture). Hog prices are negatively correlated with hog numbers. If the net influence of hog numbers is greater than the net influence of hog prices, then the net influence of hog prices alone before hog numbers are taken into account would be more than offset by the effect of hog numbers, and would appear actually negative. But the addition of hog numbers as an additional variable would change the influence of hog prices (change the slope of the hog price regression curve) to its proper sign, positive.

This means that absolute net relationships are unattainable, because we can only ascertain absolute net influence if we take all other influences into account-literally hundreds of them. And this is a practical impossibility. But from a practical point of view, absolute net influences can be closely approximated. Economic reasoning and published studies in the field of agricultural economics both indicate that serviceably accurate results can be attained in most cases by the use of a relatively small number of variables. Practically all of the published studies use only two or three independent variables. While interdependence is ubiquitous, its quantitative importance diminishes rapidly after the most influential variables 
have been taken into account; and these most influential variables are usually few in number.

Some of the problems of intercorrelation are not as baffling as they appear at first sight. A concrete case will illustrate this. An analysis of the United States average farm price of corn ${ }^{15}$ shows that the elasticity of the demand for corn is about 0.65 . The bulk of this corn is No. 3 Yellow. But if the price of No. 2 Yellow corn were used as an additional independent variable, the elasticity of the demand for No. 3 corn would become almost infinitely great; that is, the regression of No. 3 Yellow corn prices on corn production would be practically a horizontal straight line. This results from the fact that the price of No. 2 Yellow corn is so highly intercorrelated with the dependent factor that there is not much left over for the other independent variables to explain.

What does this result mean? What is the real or true elasticity of demand for No. 3 Yellow corn-is it 0.65 , or is it practically infinity?

The answer is, both. In both cases, the coefficient of elasticity shows what happens to prices when production changes, "the other independent variables being held constant," as it is often expressed, or more accurately, "independent of the accompanying variation of the other variables." "1s If the price of No. 2 Yellow corn were in actual fact "held constant," it is clear that changes in corn production would have very little effect on the price of No. 3 Yellow corn. Or to use the more accurate phrase above, there is very little fluctuation in the price of No. 3 Yellow corn independent of the fluctuation in the price of No. 2. When the price of No. 2 corn is included as one of the variables, the regression of the price of No. 3 corn should be practically zero, as in fact it is. This is merely an extreme illustration of the fact that the addition of another independent variable changes the so-called "net" regression of the dependent on the independent variables whenever (as usually happens) the additional variable is correlated with any of the other independent variables.

\section{CORRELATION AND CAUSATION}

One must clearly keep in mind the difference between correlation and causation. Two series may be highly correlated, and this corre-

${ }^{15}$ Shepherd and Wilcox, op. cit., p. 341.

${ }^{18} \mathrm{H}$. A. Wallace and G. W. Snedecor, Correlation and Machine Calculation, Official Publication, Iowa State College, 1931, p. 56. 
lation may be used (wrongly) to demonstrate that the one is the cause of the other. But actually the causation may run the other way; or there may be no causal relationship between the two whatever.

About all that can be deduced from a correlation coefficient is that the higher the coefficient the more likely it is that the relationship between the two variables is not due to chance, but is due to some definite relationship, such as cause and effect, between them. For data that are random in character, the standard statistical tests of significance put this statement in precise numerical form. ${ }^{17}$ Since most economic time series are not random, however, these tests of significance have only a restricted validity in economics. This matter is discussed at some length in Chapter 13.

As to the nature of the relation between two variables, a correlation coefficient gives no answer. The relation may be one of cause and effect, as in the case of corn production and corn prices (though the correlation shows nothing as to which is cause and which is effect). Or both variables may respond to a third causal factor, as when the prices of two unrelated agricultural products are both affected by industrial prosperity or depression. Or the relationship may result entirely from chance.

\section{ADVANTAGES AND LIMITATIONS}

The graphic method has several advantages over the standard method of mathematical correlation analysis, and several limitations. The advantages will be considered first.

1. The graphic method enables the investigator to see just what he is doing. With the mathematical method, he merely feeds the data into the machine and comes out with some numerical coefficients. He does not know without additional testing whether his multiple correlation coefficient, for example, is 0.8 rather than some higher figure because the relationships are curvilinear, because one or two exceptional years were far out of line, or because additional variables are needed. But with the graphic method, he can see just what the curvilinearity is, just how many and which years are exceptional, and whether additional variables are needed, or not. These are ponderable advantages.

These advantages have been arithmetically demonstrated by

\footnotetext{
${ }^{17}$ See, for example, George W. Snedecor, Statistical Methods, The Iowa State College Press, 1946, Table 7.3, p. 149.
} 
Elmer Working. ${ }^{18}$ He set up four different pairs of variables and plotted each pair in a scatter-diagram to show the relation between each pair of items. The four scatter-diagrams are shown in Figure
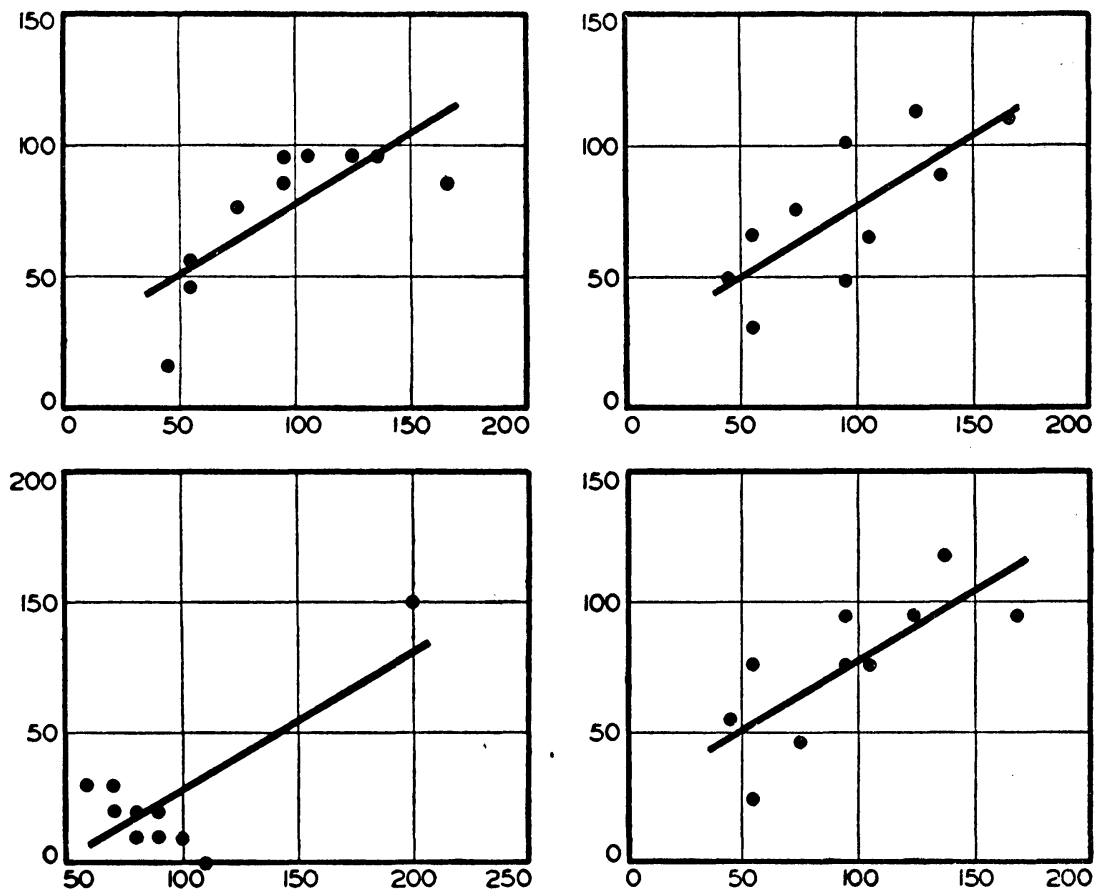

FIG. 44.-Linear regression lines fitted to four pairs of variables. Hypothetical data provided by Elmer Working.

44. Two of the relationships shown are curvilinear, one is linear, and one is based upon a very abnormal distribution. Yet the mathematical coefficients-standard deviations and correlation coefficients -are practically identical. This example illustrates how graphic methods would protect the investigator from errors he might not otherwise have discovered (although the fact that the correlations in this example are "significant" but just barely "highly significant" should put him on his guard).

${ }^{18}$ E. J. Working, "Graphic Methods in Price Analysis," Journal of Farm Economics, XXI, No. 1, February, 1939. 
2. In the second place, the graphic method usually saves a good deal of time and energy. "In many cases where problems of the same number of observations and variables were treated by both methods, the graphic method proved just as accurate but consumed from onefourth to one-third of the time." 19 The greatest saving comes in connection with rather short series, say from fifteen to twenty items, such as are common in economic price analysis. The work calls for no more training-in fact, probably for less training-on the part of the worker than is required for the formal mathematical method, and it requires no more complicated computing machinery than a pencil and ruler. In a large research department with plenty of mechanical computing equipment, this consideration is not very important; but in other cases it is.

The saving of time is greatest where the regressions are curvilinear. With the graphic method, it is just as easy to put in a curve freehand as a straight line. But with the mathematical method, the process is complex and laborious. First, the investigator must run the regular straight-line multiple correlation computation. Next, he must test each regression mathematically for curvilinearity. If it exists, he has then to select the mathematical curve most nearly appropriate to the data, add one or more extra terms to his equation, and run the multiple correlation computation again. Finally, he comes out with the coefficients expressing the relationships numerically.

3. Economic data do not usually follow any mathematical formula. They do not arrange themselves, like snowflakes, in geometrical patterns. There is no reason, for example, that the demand curve for wheat should be a straight line, a parabola, a hyperbola, or any other mathematical curve. It is determined by the physiological reactions of consumers, the distribution of income, the effect of different volumes on the intervening charges between producer and consumer, and so forth. The total effect of these things is unlikely to follow any simple mathematical formula.

Accordingly, mathematical curves cannot be expected to fit economic data very accurately. The final result is merely a compromise between the characteristics of the curve chosen by the investigator, and the characteristics of the data. The investigator has to use his judgment in selecting the type of curve to fit, and his

\footnotetext{
${ }^{10}$ R. G. Hainsworth, Graphic Methods Used in Presenting Agricultural Economics to the Public, BAE, USDA, 1938, mimeo., pp. 7-8.
} 
choice of curve determines in considerable part the results he gets. ${ }^{20}$ The mathematical method, therefore, is not purely objective; it has a large element of subjectivity in it. The results obtained depend to a considerable extent upon the mathematical curve selected.

The graphic method is similarly subjective. The curves are drawn in freehand, and some judgment is required, as for example in deciding how much weight to give one or two extreme items. No two investigators will draw two curves in exactly alike, any more than they will agree on the exact length of a bar they may measure. So exact tests of significance, standard errors, correlation coefficients, betas, etc., cannot be computed. This appears to be a fairly important weakness. Yet tests of significance are so inapplicable to economic time series that it is doubtful whether the weakness is as great as it seems.

With mathematical methods, if two different investigators choose the same mathematical curves, their results will agree out to as many decimal places as they may wish. When the differences resulting from choosing different mathematical curves may run into whole numbers, however, the identicality of results out to several decimal places is more misleading than confirmatory. For mathematical straight lines or curves are unlikely to fit the data any more exactly than two graphic workers fit their data freehand. And the inexactitude of the freehand line is at least clearly shown in the charts, while that of the mathematical method is covered up by figures running with a great profession of accuracy out to several decimal places.

Comparisons between the graphic and mathematical methods have sometimes approached the proportions of a controversy over the relative merits of the two. To the writer, such a controversy appears rather superficial. Practically all of the real issues involved in the use of either method-representativeness of sample, serial correlation, intercorrelation, multiplicative relationship, etc.-are common to both. Any careful user of the mathematical method would use scatter-diagrams (i. e., make an informal use of graphic methods) in deciding whether to use straight lines or curves in his formulae; for him, the graphic method is a useful exploratory tool. Conversely, any graphic worker who wished to take the time could well go ahead after he had completed his graphic analysis and

${ }^{20}$ This is clearly revealed by the twelve different mathematical curves that have been fitted to corn price and production data by different investigators, shown in G. F. Wären and F. A. Pearson, Interrelationships of Supply and Price, Cornell Univ. Agr. Exp. Sta., Bul. 468, 1928, pp. 122-23. 
express his results in mathematical form. The differences of opinion as to the merits of the two methods then reduce merely to differences in the emphasis to be given to each. The mathematical statistician regards the graphic method as an exploratory tool, useful in preparing the way for mathematical analysis; the economic statistician, on the other hand, is inclined to regard the graphic analysis as the main job, and publish the mathematical coefficients in a footnote. ${ }^{21}$

This difference in emphasis is nothing to provoke serious controversy. It results primarily from the differences in the kind of data with which mathematicians and economists generally work. The graphic method is most useful in problems: (1) Where the number of items is small, not over twenty or thirty for example; with longer series, the labor of plotting may be as great as the labor of computing the coefficients mathematically. (2) Where the number of variables is small, say three or four; with a larger number, the process of working back and forth becomes complicated. (3) Where the correlation is rather high; this reduces the judgment required in drawing in the curves. These conditions are frequently met in economic problems, and this is probably the reason why the graphic method has been used so widely by agricultural economists.

${ }^{21}$ During the discussion following the presentation of two papers on the graphic method of correlation at the meetings of the American Farm Economics Association at New Orleans on December 27-29, 1940, Don Anderson objected to the term "exploratory" if that meant trying out a large number of different variables and selecting those that merely showed a high correlation with the dependent variable. Warren Waite had pointed out that such a procedure applied to numerous purely random series, such as consecutive numbers out of a telephone directory, would result in fairly high but purely chance correlations. Waite replied that he agreed with Anderson's objection to that sort of procedure. He thought the word "exploratory" should be replaced by the word "preliminary."

The present author has no objection to either term. To him, "exploratory" in this case does not mean selecting a few series from a large number taken at random, but selecting on a priori grounds the series that clearly has a causal connection with the dependent variable (corn production, for instance, if the dependent variable is corn prices) and exploring the elasticity and curvature of the relationship by graphic methods. This paves the way for the selection of the approximate mathematical curves to be used with the mathematical method.

For a more detailed treatment of some of the questions discussed in the present chapter, see Richard J. Foote and J. Russell Ives, The Relationship of the Method of Graphic Correlation to Least Squares, BAE, USDA, 1940, mimeo. 


\section{Individual Sales and Cost Curves}

The theory of price determination discussed in the preceding chapters runs in terms of elasticities and changes in demand and supply. This broad general theory is simple, just as most of the general theories of the natural sciences are simple. It is the bringing of these theories closer to earth, closer to reality, that makes them complicated.

Both in economics and the natural sciences, it is advantageous to start at a high level of abstraction, with the most general laws that underlie diverse particular applications, in order to provide the student with broad working concepts. The student can then apply these broad concepts, with appropriate modifications and specialized additional concepts, to particular cases. These broad concepts are necessary but not sufficient for an explanation of the phenomena of the world about us. The modifications and additions may be more important than the broad general concepts, in explaining actual phenomena.

To be specific in the case of economics: The general laws of supply and demand, necessary as they are, are not sufficient to explain business cycles, the comparative stability of industrial prices, the cyclic behavior of hog prices, and a host of such phenomena. It would be possible, and in some respects desirable, to begin with specialized explanations of these particular phenomena and then move to the broader and more general underlying principles. The opposite approach is generally used, however, for two reasons: (1) There are so many diverse specialized applications that if the student started with those, before he had begun to specialize within the field, he would acquire more diverse bits of truth than he could assimilate or organize later on. But the broad explanations are needed in all specialized subfields; the student can use them in whatever subfield he decides to specialize in later on. (2) The second reason for beginning with the broad principles is that they are simpler than the specialized ones. "Economists, like other scien- 
tists, have chosen the hypothesis from which they set out, and which they offer to beginners, because it is the simplest, and not because it is the nearest to the facts." 1

\section{INDIVIDUAL SALES AND COST CURVES UNDER PERFECT COMPETITION}

We begin, then, with the principles of price determination under conditions of perfect competition, just as the physicist begins with $1 / 2 \mathrm{gt}^{2}$, the formula for the velocity of a body falling in a perfect vacuum-though neither a perfect vacuum nor perfect competition has ever existed on this earth.

Under conditions of perfect competition, prices and production are determined by the intersection of the demand and supply curves for the commodity. The positions and elasticities of the demand and supply curves determine how prices and production will change when any disturbance strikes the system. In the simplest expositions of the law of supply and demand it is assumed that the demand curve has a negative slope and the supply curve has a positive slope. So the law is formulated in two parts, thus: When the demand increases (the supply remaining constant) production increases and prices rise; when the supply increases (the demand remaining constant) production increases, but prices fall. The reverse situation holds for decreases in demand and supply. This is familiar ground to any high school student nowadays, and we do not need to elaborate upon it any further.

The real task is to go behind or break down the supply and demand curves, and find out what determines them. They merely show mass behavior; they represent the sums of the reactions of individual producers and consumers. We need to study now what these individual reactions are and how they add up to the sort of demand and supply curves we have been dealing with up to this point, which may be called "general" demand and supply curves. We turn now from these general curves to consider the individual curves that make them up.

\section{INDIVIDUAL SALES CURVES}

Under conditions of perfect competition (a large number of buyers and sellers of a homogeneous commodity, freedom of entry

\footnotetext{
${ }^{1}$ John Maynard Keynes, The End of Laissez Faire, Hogarth Press, London, 1926, p. 28.
} 
into and exit from the industry, and perfect knowledge of supply, demand, and prices on the part of all participants) the individual producer is so small an element in the total situation that the amount he produces has no appreciable effect on the price of the commodity as a whole. If a man can produce and sell 10 pounds of butterfat at 22 cents per pound, he can sell 100 pounds, or 1,000 pounds, at the same price. The demand curve for this producer's butterfat, therefore, is a horizontal straight line at 22 cents. It is (within reasonable limits) infinitely elastic.

The concept of the demand schedule for an individual producer's product just presented is essentially simple. The description or name, however, as given in the preceding sentence, is long and clumsy. The shorter phrase, "individual producer's demand curve" is inaccurate; it is likely to be misunderstood as the individual producer's demand curve for the raw materials he buys, rather than for the finished products he sells. The term "individual producer's sales curve" has recently been proposed, ${ }^{2}$ and will be adopted here.

\section{INDIVIDUAL SUPPLY CURVES}

The individual producer of butterfat incurs certain costs of production. Some of these costs are rather fixed, and remain much the same for the farm as a whole whether he raises much or little. Examples of these fixed costs are: interest on investment, or rent if he does not own the farm, and taxes. Since these costs remain fixed, in total for the farm, regardless of how much butterfat is produced, it follows that the fixed costs per pound of butterfat vary inversely with the number of pounds produced. This is shown in column 3 of Table 16 and the lower curve in Figure $45 .^{3}$ This curve is a rectangular hyperbola, the equation being of the form $x y=c$.

\footnotetext{
${ }^{2}$ Robert Triffin, Monopolistic Competition and General Equilibrium Theory, Harvard University Press, 1940, p. 5.

${ }^{3}$ The discussion in this chapter runs in terms of short-run costs. Here, as in the case of supply curves discussed in Chapter 6, the longer the time involved, the greater the elasticity of the cost curve. In fact, a single producer's long-time cost curve is not one curve but a series of U-shaped short-time curves like the one shown in Figure 45 ranged along a broader U-shaped long-time curve like oyster shells along the edge of a plate. Each small curve shows the cost conditions for a given size of plant; the large curve shows the costs for different-sized plants. For a full discussion of this matter, see Jacob Viner, "Cost Curves and Supply Curves," Zeitschrift Fur Nationalölconomie, Sonderabdruck aus Band III, Heft 1; Benjamin Higgins, "Indeterminacy in Non-Perfect Competition," American Economic Review, XXIX, No. 3, September, 1939, pp. 469, 471-475; and George Stigler, "Production and Distribution in the Short Run," Journal of Political Econcmy, XLVII, No. 3, June, 1939, p. 305.
} 
The producer also incurs variable costs. The more cows he milks, the more feed he has to raise (or buy), the more labor he uses, and the more equipment he needs. These costs vary with the number of cows the farmer milks, and are called variable costs for that reason.

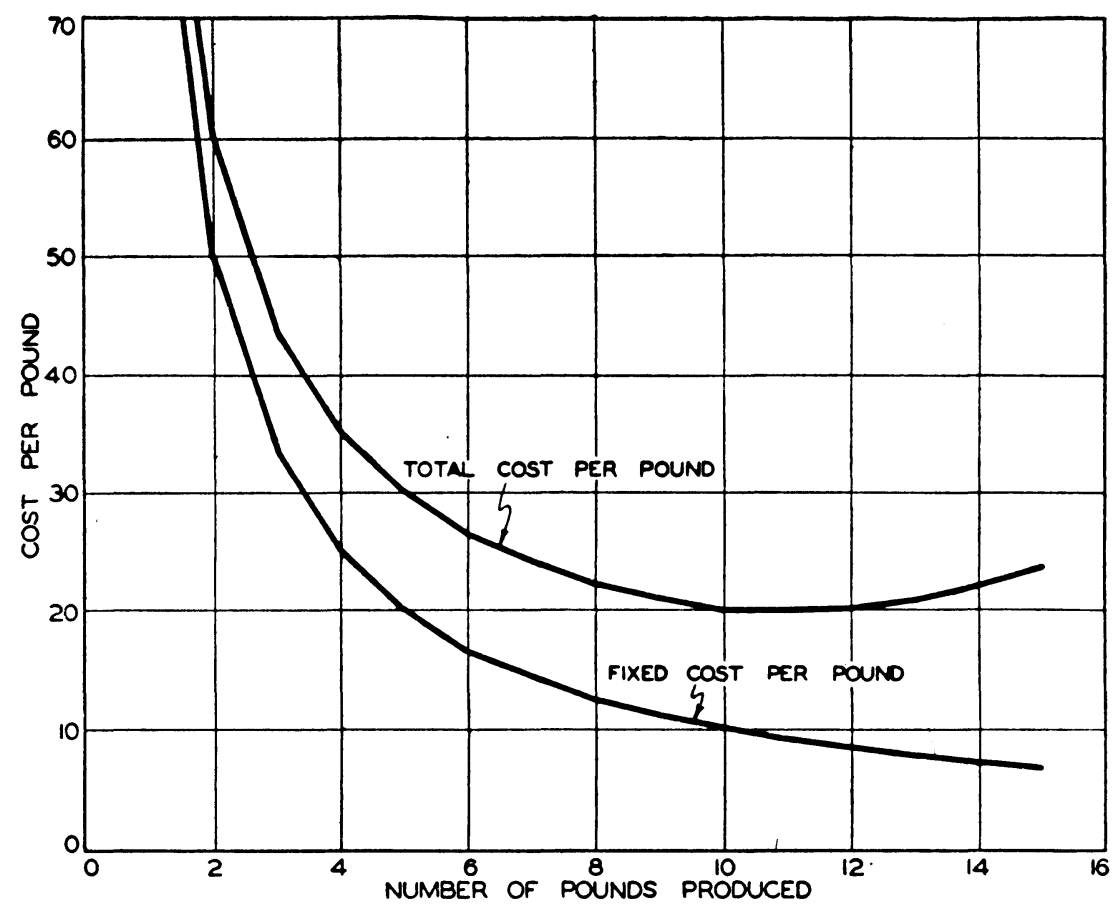

Fig. 45.-Effect of quantity produced upon fixed cost and total cost per unit. Hypothetical data.

Expressed as so much per pound of butterfat, the variable costs may remain constant at so much per pound as the scale of milk production increases; but as the number of cows becomes very large, diminishing returns set in and these variable costs per pound of butterfat begin to rise. This is shown in column 5 of Table 16 . Beyond a certain point this rise in variable costs per pound more than offsets the decrease in fixed costs per pound (especially since these fixed costs fall rapidly for the first few thousand pounds of total output, but more and more slowly for larger and larger outputs) and the total costs per pound begin to rise.

The phrase, total costs per pound, is clumsy, and the briefer 
phrase, average total costs, or still more briefly, average costs, is generally used instead. The nature of a typical average cost curve is shown by the upper line in Figure 45. In this figure the variable costs per unit are added to the fixed costs per unit to give the average

TABLE 16

Cost Schedule for Different Outputs

(Hypothetical Data)

\begin{tabular}{|c|c|c|c|c|c|c|}
\hline $\begin{array}{c}\text { Number } \\
\text { of } \\
\text { Pounds }\end{array}$ & $\begin{array}{c}\text { Total } \\
\text { Fixed } \\
\text { Cost }\end{array}$ & $\begin{array}{l}\text { Fixed } \\
\text { Cost per } \\
\text { Pound }\end{array}$ & $\begin{array}{c}\text { Total } \\
\text { Variable } \\
\text { Cost }\end{array}$ & $\begin{array}{c}\text { Variable } \\
\text { Cost per } \\
\text { Pound }\end{array}$ & $\begin{array}{c}\text { Total } \\
\text { Fixed } \\
\text { and } \\
\text { Variable } \\
\text { Costs }\end{array}$ & $\begin{array}{c}\text { Total } \\
\text { Cost per } \\
\text { Pound } \\
\text { (Average } \\
\text { Cost) }\end{array}$ \\
\hline 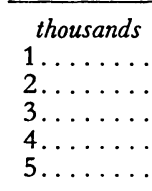 & $\begin{array}{c}\text { dollars } \\
1,000 \\
1,000 \\
1,000 \\
1,000 \\
1,000\end{array}$ & $\begin{array}{l}\text { cents } \\
100 \\
50 \\
33.3 \\
25 \\
20\end{array}$ & $\begin{array}{r}\text { dollars } \\
100 \\
200 \\
300 \\
400 \\
500\end{array}$ & $\begin{array}{l}\text { cents } \\
10 \\
10 \\
10 \\
10 \\
10\end{array}$ & $\begin{array}{c}\text { dollars } \\
1,100 \\
1,200 \\
1,300 \\
1,400 \\
1,500\end{array}$ & $\begin{array}{l}\text { cents } \\
110 \\
60 \\
43.3 \\
35 \\
30\end{array}$ \\
\hline $\begin{array}{r}6 \ldots \ldots \\
7 \ldots \ldots \\
8 \ldots \ldots \\
9 \ldots \ldots \\
10 \ldots \ldots\end{array}$ & $\begin{array}{l}1,000 \\
1,000 \\
1,000 \\
1,000 \\
1,000\end{array}$ & $\begin{array}{l}16.7 \\
14.3 \\
12.5 \\
11.1 \\
10\end{array}$ & $\begin{array}{r}600 \\
700 \\
800 \\
900 \\
1,000\end{array}$ & $\begin{array}{l}10 \\
10 \\
10 \\
10 \\
10\end{array}$ & $\begin{array}{l}1,600 \\
1,700 \\
1,800 \\
1,900 \\
2,000\end{array}$ & $\begin{array}{l}26.7 \\
24.3 \\
22.5 \\
21.1 \\
20\end{array}$ \\
\hline $\begin{array}{l}11 \ldots \ldots \\
12 \ldots \ldots \\
13 \ldots \ldots \\
14 \ldots \ldots \\
15 \ldots \ldots\end{array}$ & $\begin{array}{l}1,000 \\
1,000 \\
1,000 \\
1,000 \\
1,000\end{array}$ & $\begin{array}{l}9.1 \\
8.3 \\
7.7 \\
7.1 \\
6.7\end{array}$ & $\begin{array}{l}1,210 \\
1,440 \\
1,690 \\
1,960 \\
2,250\end{array}$ & $\begin{array}{l}11 \\
12 \\
13 \cdot 4 \\
15 \\
17\end{array}$ & $\begin{array}{l}2,210 \\
2,440 \\
2,690 \\
2,960 \\
3,250\end{array}$ & $\begin{array}{l}20.1 \\
20.3 \\
21.0 \\
22.1 \\
23.7\end{array}$ \\
\hline
\end{tabular}

costs shown by the upper line. This average cost curve has a characteristic broad $U$ shape.

\section{THE MOST PROFITABLE SCALE OF PRODUCTION}

Figure 45 shows that the farmer reaches his lowest cost of production ( 20 cents) when he produces 10 units.

In the section dealing with demand, we saw that this producer's sales curve was a horizontal straight line at 22 cents. Under those conditions how many thousand pounds of butterfat will this man produce?

He will naturally carry his production to the point where he is making the greatest profit. One might reply offhand, then, that he would produce 10 thousand pounds, since his costs of production reach a minimum (20 cents) at that figure. But a little arithmetic 
shows that this is incorrect. If he stopped at 10 thousand pounds, his net profit (his total returns minus his total costs) would be $\$ 2,200-\$ 2,000=\$ 200$. But if he went to 12 thousand pounds, his net profit would be $\$ 2,640-\$ 2,440=\$ 240$. His total profit at 12 thousand pounds is greater than at 13 thousand pounds.

The exact point at which he would stop can be determined by making separate calculations of this sort for each quantity. But the point can be determined more neatly and quickly by use of the concept of marginal rather than the average cost.

\section{MARGINAL COST}

An earlier chapter dealt with marginal revenue-the increase in total revenue when $x+1$ units are sold, over the total revenue when only $x$ units are sold. Marginal cost is analagous to this marginal revenue. Marginal cost is the increase in total cost when $x+1$ units are produced, over the total cost when only $x$ units are produced. Here, as with marginal revenue, the concept of marginal cost is precise only in the limiting sense, as the units get smaller and smaller.

Marginal costs are independent of the amount of the total fixed costs. The amount of the total fixed costs affects the average costs per unit, but not the marginal costs. This follows directly from the definition of marginal costs (the difference between successive total costs) since if the fixed costs remain constant, as they must by definition, the differences between successive total costs are the same whether the fixed costs (which enter alike into all the total costs, and therefore cancel out in the subtractions or differences) are $\$ 1,000, \$ 100$, or zero. The significance of this will become apparent later.

It is clear from these definitions that a man will increase his production all the time that his marginal revenue is greater than his marginal cost. That is, if producing one unit more than before adds 50 cents to his total cost, but selling one unit more adds 60 cents to his total revenue (that is, if his marginal cost is $\mathbf{5 0}$ cents and his marginal revenue 60 cents) he will produce and sell that one unit more, for it will add 10 cents to his total profit. He will as a matter of fact keep on expanding his production until his marginal cost becomes as great as his marginal revenue. That maximizes his total profits.

A table showing the average, total, and marginal costs of pro- 
ducing various quantities in one part, and average, total, and marginal revenues from the sale of various quantities in another, can be used to show where equilibrium will be reached. Hypothetical cost and revenue data of this sort are shown in the two parts of Table 17.

TABLE 17

Cost and Revenue Schedule

(Hypothetical Data)

\begin{tabular}{|c|c|c|c|c|c|c|}
\hline \multirow[b]{2}{*}{ Quantity } & \multicolumn{3}{|c|}{ Cost Data } & \multicolumn{3}{|c|}{ Revenue Data } \\
\hline & $\begin{array}{c}\text { Total } \\
\text { Cost }\end{array}$ & $\begin{array}{c}\text { Average } \\
\text { Cost }\end{array}$ & $\underset{\text { Cost }}{\text { Marginal }}$ & $\begin{array}{c}\text { Total } \\
\text { Revenue }\end{array}$ & $\begin{array}{l}\text { Average } \\
\text { Revenue }\end{array}$ & $\begin{array}{l}\text { Marginal } \\
\text { Revenue }\end{array}$ \\
\hline $\begin{array}{l}1 \ldots \ldots \\
2 \ldots \ldots \\
3 \ldots \ldots \\
4 \ldots \ldots \\
5 \ldots \ldots \\
6 \ldots \ldots \\
7 \ldots \ldots\end{array}$ & $\begin{array}{r}64 \\
83 \\
101 \\
118 \\
134 \\
149 \\
163\end{array}$ & $\begin{array}{l}64 \\
41.5 \\
33.7 \\
29.5 \\
26.8 \\
24.8 \\
23.3\end{array}$ & $\begin{array}{l}64 \\
19 \\
18 \\
17 \\
16 \\
15 \\
14\end{array}$ & $\begin{array}{r}20 \\
40 \\
60 \\
80 \\
100 \\
120 \\
140\end{array}$ & $\begin{array}{l}20 \\
20 \\
20 \\
20 \\
20 \\
20 \\
20\end{array}$ & $\begin{array}{l}20 \\
20 \\
20 \\
20 \\
20 \\
20 \\
20\end{array}$ \\
\hline $\begin{array}{c}8 \ldots \ldots \\
9 \ldots \ldots \\
10 \ldots \ldots \\
11 \ldots \ldots \\
12 \ldots \ldots \\
13 \ldots \ldots \\
14 \ldots \ldots\end{array}$ & $\begin{array}{l}176 \\
188 \\
200 \\
213 \\
227 \\
242 \\
258\end{array}$ & $\begin{array}{l}22.0 \\
20.9 \\
20.0 \\
19.4 \\
18.9 \\
18.6 \\
18.4\end{array}$ & $\begin{array}{l}13 \\
12 \\
12 \\
13 \\
14 \\
15 \\
16\end{array}$ & $\begin{array}{l}160 \\
180 \\
200 \\
220 \\
240 \\
260 \\
280\end{array}$ & $\begin{array}{l}20 \\
20 \\
20 \\
20 \\
20 \\
20 \\
20\end{array}$ & $\begin{array}{l}20 \\
20 \\
20 \\
20 \\
20 \\
20 \\
20\end{array}$ \\
\hline $\begin{array}{l}15 \ldots \ldots \\
16 \ldots \ldots \\
17 \ldots \ldots \\
18 \ldots \ldots \\
19 \ldots \ldots \\
20 \ldots \ldots \\
21 \ldots \ldots \\
22 \ldots \ldots \ldots\end{array}$ & $\begin{array}{l}275 \\
293 \\
312 \\
332 \\
353 \\
375 \\
398 \\
422\end{array}$ & $\begin{array}{l}18.3 \\
18.3 \\
18.4 \\
18.4 \\
18.6 \\
18.8 \\
19.0 \\
19.2\end{array}$ & $\begin{array}{l}17 \\
18 \\
19 \\
20 \\
21 \\
22 \\
23 \\
24\end{array}$ & $\begin{array}{l}300 \\
320 \\
340 \\
360 \\
380 \\
400 \\
420 \\
440\end{array}$ & $\begin{array}{l}20 \\
20 \\
20 \\
20 \\
20 \\
20 \\
20 \\
20\end{array}$ & $\begin{array}{l}20 \\
20 \\
20 \\
20 \\
20 \\
20 \\
20 \\
20\end{array}$ \\
\hline
\end{tabular}

The marginal cost in each case is simply the difference between two successive total costs; the same thing holds with marginal revenues.

It takes only a moment to determine from this table that production will be carried out to 18 quantity units, for at that point marginal costs are equal to marginal revenues; they are both $\$ 20$.

The location of this equilibrium point is particularly simple in this case, for the marginal revenues are the same $(\$ 20)$ for all quantities. The reason for this is that average revenues remain constant (this is a case of perfect competition). No matter what quantities are produced, the sale of one more unit always brings in 
another $\$ 20$; so the marginal revenue (addition to total revenue) is always $\$ 20$.

A little more light is thrown on the subject if the data shown in Table 17 are plotted in graphic form. This is done in Figure 46.

This figure shows how the marginal cost curve at first falls, and then rises, to cut the average cost curve at its lowest point. It must necessarily do this, because a very small section of the average cost curve at its lowest point may be regarded as a horizontal straight line, and we saw (in connection with average and marginal revenue curves) that where the average curve is a horizontal straight line the marginal values are necessarily the same as the average values.

The figure also shows that at the point where the marginal cost equals the marginal revenue, the total revenue rises to its greatest height above the total cost. That is, the difference between the total revenue and the total cost (i. e., the profit) is the greatest at that point. This also is necessarily true.

Finally, the figure shows that under conditions of perfect competition, the average revenue and marginal revenue curves coincide throughout their length. It shows, furthermore, that production is carried on at the lowest possible average cost-almost. The reason for the "almost" is that prices in the illustration used here exceed average costs, at the point to which production is carried, and profits (in excess of wages of management, interest on capital, and all other normal costs) exist. If these profits induced others to enter this field of production, as they would under perfect competition, supplies would increase and prices would fall to equality with the lowest point on the average cost curve. These are important results or concomitants of perfect competition, as we shall see. ${ }^{4}$.

\section{INDIVIDUAL SALES AND COST CURVES UNDER IMPERFECT COMPETITION}

Under perfect competition, each producer sells so small a part of the total production of a commodity that his actions have a negligible effect upon the price; his sales curve is a horizontal straight line.

This used to be regarded as the typical case, and the major part of the structure of economic theory rested on that foundation, the assumption of perfect competition. But it is now being recognized

${ }^{4}$ The relation between prices and costs is examined in factual detail in the next chapter. 


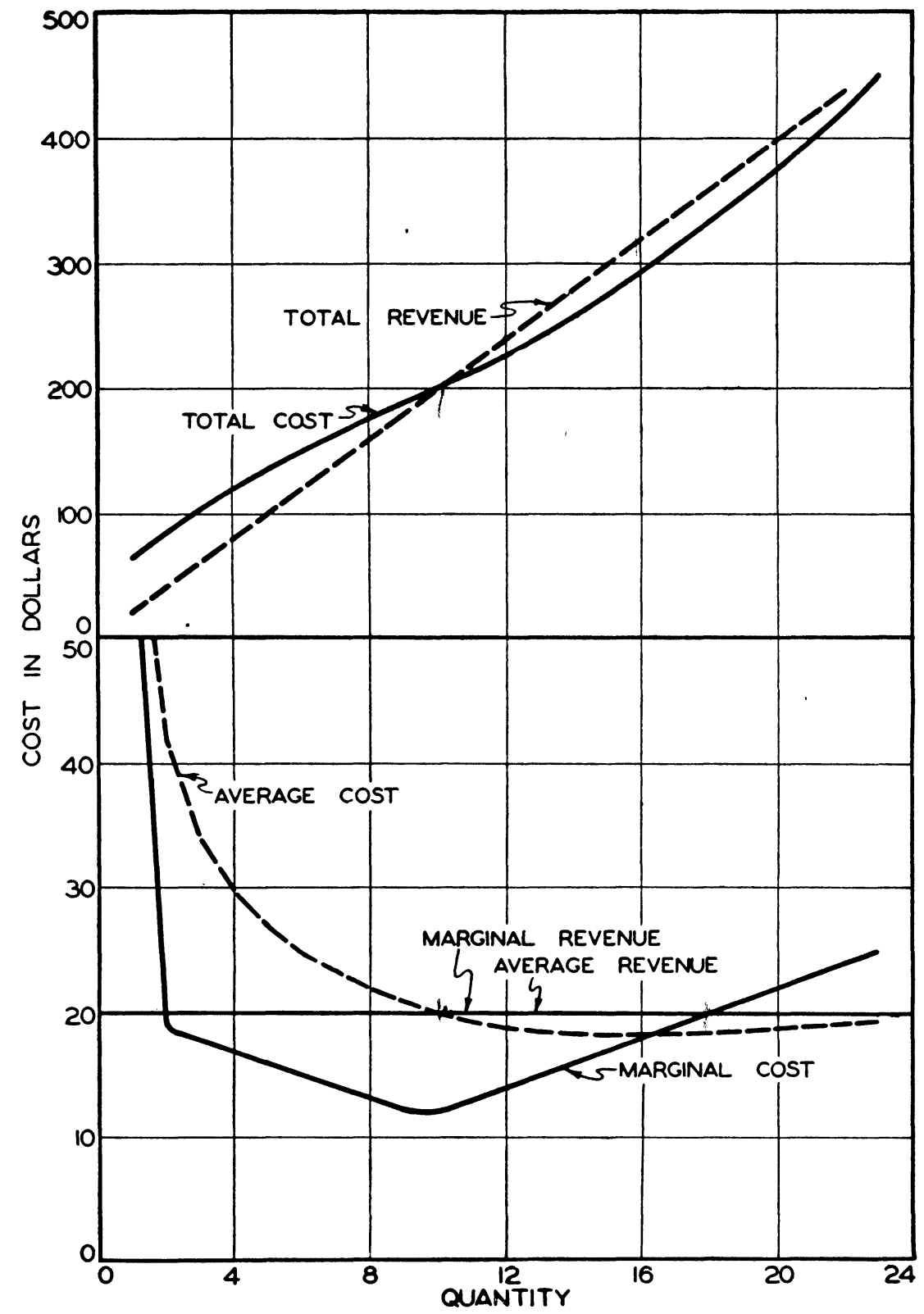

Fig. 46.-Effect of quantity produced upon total, average, and marginal revenue and cost. Hypothetical data. 
that this is not the typical case; it (perfect competition) is merely the limiting case at one end of a scale. At the other end of the scale is perfect monopoly.

In actual fact, there is no such thing as perfect monopoly (monopoly means "single seller") any more than there is any perfect vacuum in actual life. It is possible to conceive of a pathological case, however, to illustrate the point. A man may be held for ransom, under threat of death. His abductors have a perfect monopoly of his freedom, within the range of his pocketbook. He will offer $\$ 1,000$, $\$ 5,000, \$ 10,000$, etc., as far as his resources go. His demand curve for his life is a vertical straight line; there is no substitute for life. But this concept of perfect monopoly is merely a convenient bench mark at one end of the scale, rather than an important case.

The important cases in actual life are those where the monopolist has control of àn essential product such as salt (which as a matter of fact is controlled by a government monopoly in many countries). Or, to take a less extreme case, we may consider aluminum, which before World War II was produced only by one corporation in the United States, the Aluminum Company of America. The demand curve confronting the producer of these products was not completely inelastic. The curve for aluminum no doubt had a considerable degree of elasticity, even though aluminum production was "completely monopolized," that is to say, in the hands of only one producer.

\section{WHAT IS MONOPOLY?}

The criterion of monopoly is, however, not the numbers of sellers of the commodity. Colgate is the sole producer and seller of Colgate's toothpaste. He has a monopoly of that product. But if several other kinds of toothpaste are very similar to Colgate's, and if consumers have no preference for any one brand, then Colgate's monopoly of Colgate's toothpaste doesn't mean much. The monopoly of aluminum possessed by the Aluminum Company of America meant more, because it was more difficult to substitute other metals for aluminum than it is to substitute other toothpastes for Colgate's. The basic criterion of monopoly is not the number of sellers so much as it is the width of the gap between the monopolized product and the next nearest substitute.

Monopoly, therefore, can be defined in terms of cross-elasticity of demand. This is measured by plotting the quantity of the commodity 
concerned not against its own price but against the price of its nearest substitute. Under perfect monopoly, the cross-elasticity of demand for the nearest substitute is zero; under perfect competition, it is infinitely large. These are merely limiting cases. The great bulk of the situations in actual life fall between these two extremes.

Monopoly, in this wider view, is not an absolute, to be clearly differentiated from competition as black from white. In fact, there is no such thing as monopoly to be sharply distinguished from nonmonopoly or competition; there are only different degrees of monopoly. The thing that determines the degree of monopoly is the ease or difficulty of substituting other products for the monopolized product. There is a high degree of monopoly in the salt industry, because it is so difficult for the consumer to substitute any other product for salt. There would be a lower degree of monopoly in the aluminum industry than in the salt industry, even if practically all of the aluminum industry in America were in the hands of one large concern, because aluminum consumers will turn to other metals if the monopolist gets his prices unduly high. The degree of monopoly in the textile industry, or in the toothpaste industry, is still lower; and so on.

It might be thought that this line of reasoning, sound as it may be when applied to different products, does not apply within products, that is, to different producers of the same product. But it does apply thus, for two reasons.

\section{WHAT IS "A PRODUCT"?}

The first reason is the inherent ambiguity of the term "product." For what is a "product"? Aluminum is a different product from steel, yes; but the one will be substituted for the other if their prices get far out of line. Is a Ford a different product from a Chevrolet? An Arrow shirt from another make? There is really no sharp or definite distinction between different products and different producers' makes of a product. Each producer strives to make it appear that his make of automobile, or breakfast food, or antiseptic, is in a different class from other makes, i. e., is a different product. Here again the question is not a simple yes-or-no type of question-whether one product is or is not different from another product. Strictly speaking, every producer's "product" is different from every other producer's "product," and every producer is a monopolist. But the range of differences between "products" runs all the way from very 
great in the case of salt, to moderate in the case of aluminum, to small in the case of automobiles or shirts, to nearly zero in the case of wheat or hogs. The range of degrees of monopoly corresponds with this range of differences between products.

The situation may be represented graphically by filling in the gap between a steeply sloping line representing a high degree of monopoly and a horizontal line representing perfect competition, by a series of individual producer's sales curves grading down from inelastic to elastic and very elastic. The almost completely inelastic curve at one end of the scale represents the sales curve for some commodity such as salt, for domestic household purposes, where the differences between it and its substitute are very wide and the amounts purchased take only a very small proportion of the buyers' total income. Next comes a less inelastic curve, for aluminum, let us say. Next, a curve for some other metal which is more susceptible to substitution; this curve is relatively elastic. Next, the curve for a certain manufacturer's clothing material, highly elastic, and so on, until finally we reach individual farmer's sales curves for corn, or beef cattle, or hogs, which for all practical purposes are horizontal.

The second reason why the theory of imperfect competition applies within "products," if the producers are few in number, is this: Even when each producer is not able to differentiate his make of product greatly from those of other producers, he sets his production and price with close attention to theirs. For if he disregarded them, and expanded his production and lowered his prices in an attempt to hog the whole market, in the great majority of cases the other producers would meet his price cuts with equal price cuts, each would retain his share of the market, and all would lose.

Accordingly, each producer refrains from this sort of price cutting. There may be no overt collusion or conscious collective action among the producers, but the effects upon production and prices are substantially the same as if the production were all in the hands of one producer. Each producer's sales curve becomes as inelastic as the total demand curve for that "product." The whole industry then behaves, as far as prices and production are concerned, as if it were in the hands of one monopolist, even though the industry is, like the automobile industry, "fiercely competitive." This situation is described as "oligopoly" (a few sellers). 
WHERE MARGINAL COST EQUALS MARGINAL REVENUE

In earlier chapters the concepts of marginal revenue and marginal costs were set forth, and it was shown that under conditions of perfect competition (where marginal revenue and average revenue curves are coincidental horizontal straight lines) profits were maximized at the point where marginal costs equalled marginal revenue. Does this hold true also for imperfect competition, where the average revenue and marginal revenue curves both have a negative slope?

A moment's mental exercise with these concepts shows that it does hold true. The point of greatest profit is that point at which marginal cost equals marginal revenue, under all conditions-imperfect competition as well as perfect competition. If you do not trust your powers of reasoning, set up a hypothetical average revenue curve, together with its marginal revenue curve, and go through the arithmetic.

\section{EFFECT ON PRODUCTION, PRICES, AND PROFITS}

It was shown earlier that under perfect competition, wherever the (horizontal) marginal revenue curve lies above the lowest point of the average cost curve, then prices are higher than costs and the profits will induce increased production. Prices, therefore, will fall until the marginal revenue curve shifts downward to the point of tangency with the average cost curve at its lowest point. This is the point at which the marginal cost curve rises from below to cut the average cost curve. So at that point, average costs are at their lowest point, marginal cost equals average cost and average revenue and price, and there are no profits. This situation is shown in the upper left-hand section of Figure 47.

But under imperfect competition, the average and marginal revenue curves have some negative slope, and they do not coincide. The marginal revenue curve lies below the average revenue curve; and the steeper the slope of the average revenue curve, the farther does the marginal revenue curve lie below the average revenue curve. The marginal cost curve therefore intersects the marginal revenue curve some distance to the left of the point where the two would intersect under perfect competition. This is shown in the upper right-hand section of Figure 47.

The effect is more pronounced if the degree of monopoly is greater and the slope of the average revenue curve steeper, as shown in the 
lower left-hand section of Figure 47. Here it is evident that production is much reduced, and prices are considerably higher than under free competition. Production stops short of the point of lowest possible cost, by a wide margin. This situation may or may not be accompanied by high profits to the monopolist. In Figure 47 it is not. But if (a) the cost curve were lower, or the average revenue curve were higher, and (b) entry into the field were difficult, profits would be high.
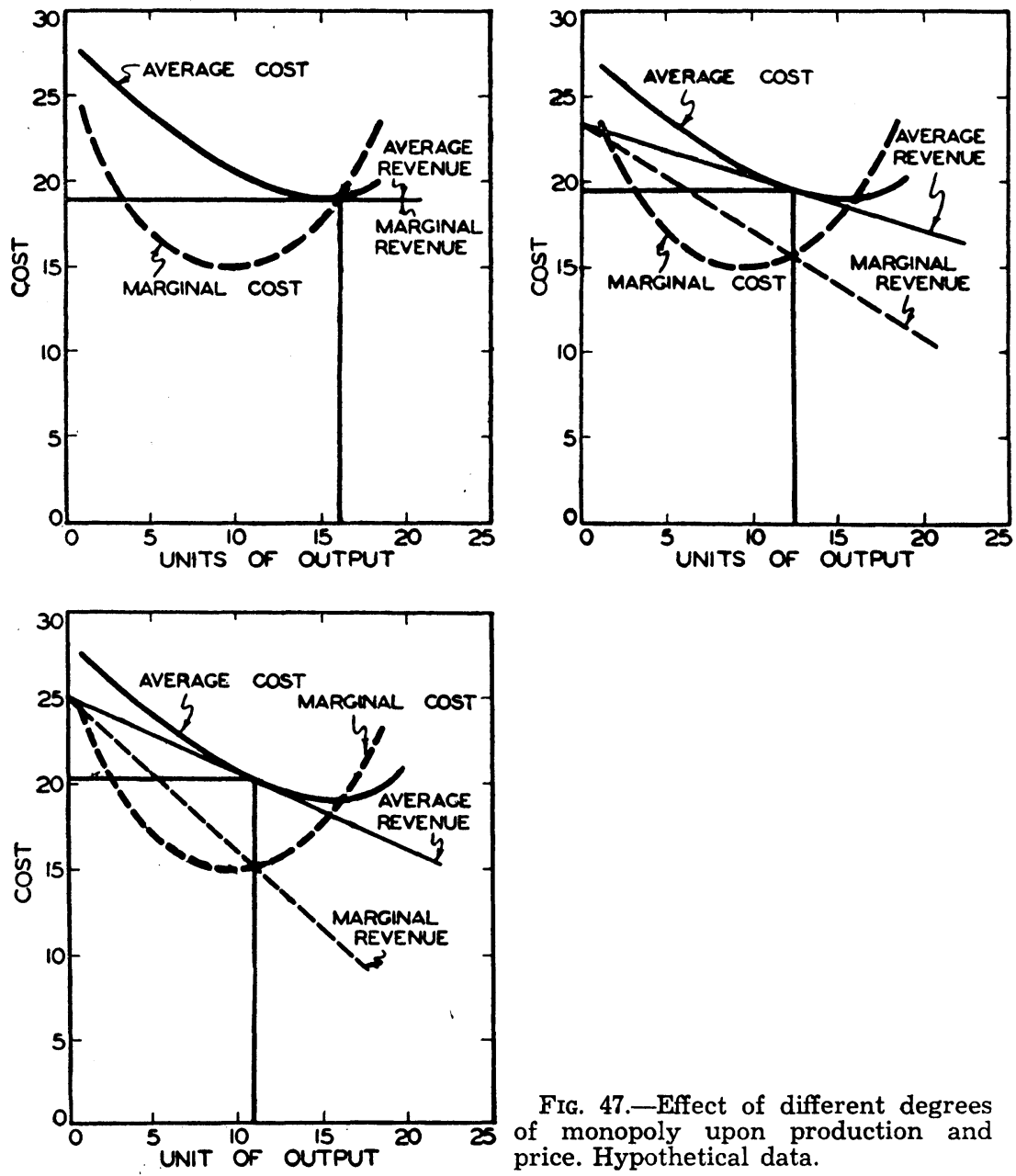

FIG. 47.-Effect of different degrees of monopoly upon production and price. Hypothetical data. 
While production will be smaller and prices higher under imperfect competition than under perfect competition, an important point should be made clear here that is not always emphasized in the literature of imperfect competition. If free competition were enforced in the automobile industry, for example, by breaking the industry up into a large number of small producers, each producer's scale of production would be smaller. The scale of production might be so small that unit costs and prices might be higher, and total production less, than at present. When the statement is made that under imperfect competition production is less and price higher than under perfect competition, what is really meant is that under imperfect competition total production is less and prices are higher than if competitive conditions were enforced among the existing few large producers. 


\section{The Relation Between Prices and Costs}

The relation between the price and the cost of producing a commodity is a perennial problem, and a thorny one, in agriculture.

Basically, this relation is simple. It is the same in agriculture as in other lines. The price must cover the cost of production, or to look at it the other way around, the cost of production must be lower than the price; otherwise the producer sooner or later will run out of money and quit producing.

The direction of causation from the one to the other, however, is a more complicated matter. A good many farmers believe that the line of causation runs from costs to prices in most of the industrial world. They believe that manufacturers, distributors, the service trades, etc. compute their costs, add a margin for profit, and set their prices accordingly. But farmers seem to run under opposite conditions. They are confronted by a price for their products, and they have to cut their costs below the price, or go broke.

Farmers maintain that what is sauce for the goose ought to be sauce for the gander; they ought to operate under the same sort of rules as business. If it costs farmers 60 cents to produce a bushel of corn, surely the price ought to be set high enough to cover those costs, plus a modest profit.

The things farmers buy appear to them to be priced according to their costs, at each step of the way from the manufacturer to the retailer. When the cost of living goes up, labor demands higher wages (higher prices for their labor). When labor asks for higher wages, manufacturers point out that this will increase their costs and that they, the manufacturers, will have to pass these increased costs on in the form of higher prices. The "cost-plus" basis upon which building contractors bid appear to offer another example of the use of cost of production. The local storekeeper provides another. $\mathrm{He}$ takes the wholesale price plus transportation as his cost, adds a standard margin to cover his costs and profits, and sets his retail price accordingly. He does not ask the farmer what price he is 
willing to pay for a can of beans; he tells him what price he will have to pay. Yet when the farmer takes his hogs to market, he cannot compute his costs and name his price as the retailer does. He has to ask the packer what he will pay, and take it or leave it.

Accordingly, it appears to many farmers that they are not getting a square deal. They get it in the neck both coming and going. They seem always to be asking the other fellow-buyer and seller as well-what his price is. They never seem to be able to name their own prices, but the buyer always names his. If, as it appears, others base their prices on their costs of production, or processing, or marketing, it seems to farmers that they ought to be able to do the same.

Are they right, and if so, is their desire attainable?

\section{COST OF PRODUCTION IN INDUSTRY}

The appearance that industry simply uses cost of production as the basis for its prices is misleading. There is a more direct relation between costs and prices in industry than in agriculture, but the line of causation runs from prices to costs as well as from costs to prices. This is true of merchandising as well as manufacturing.

\section{MERCHANDISING}

"Merchants, engaged in buying and selling finished goods, customarily raise and lower their selling prices in accordance with current changes in wholesale prices, although sometimes with a considerable lag in time. They are able to do this only through changes in the quantity of goods sold. If the retail grocer started out with a definite number of cans of evaporated milk to sell each month, he would have to adjust his price to a point necessary to move this quantity from his shelves, regardless of the cost price. Actually, he first adjusts his retail price to the wholesale cost, then obtains from the wholesaler only as many cans as he is able to sell at that price. Of course, if farmers could first set a price based on cost and then place on the market only the amount of the commodity that would sell for that price, they, too, could get cost of production. However, this is impossible because of the peculiarities of farming and farm products.

"It should be noted, however, that the merchant's position is far from being as pleasing as the foregoing might indicate. If his own operating costs, which he adds to the wholesale price in setting his 
retail selling price, are higher than competition will allow, his volume of sales will be so small that he will be forced out of business. This actually happens, it is estimated, to perhaps 90 per cent of retail store ventures. Thus, the ordinary merchant's ability really is to name a cost price rather than to get it. The farmer, also, could name his cost price, but like many merchants he may be unable to sell at that price.

\section{MANUFACTURING INDUSTRIES}

"The greater ability of manufacturers, as compared with farmers, to both name and receive a price covering cost of production is due largely to three conditions:

"1. Manufactured goods are continuously rather than seasonally produced. Because of this, adjustments in production can be made immediately, whereas with most farm products such adjustments require at least a season, and even then farmers may expect price conditions to change, further prolonging adjustments.

"2. Manufactured goods usually are nonperishable and can be stored in order to take up the 'slack' in the market. If the supply of goods offered by the manufacturer of a certain commodity will not sell at a price high enough to cover cost, he may store enough so that the remainder will sell for the cost price. At the same time, he is able, because of continuous production, immediately to cut down output so that stocks will not accumulate at too rapid a rate. Here we see the essential difference in farming. We cannot store strawberries. We might store part of the cotton crop for sale in succeding years; but unless we made a compensating cut in production, this would merely postpone the trouble.

"3. Production of manufactured products can be speeded up or contracted much more easily and quickly than the production of farm products. In farming, the vagaries of the weather may upset the best laid production plans, so far as any one year is concerned. But there are other and even more important reasons why it is difficult to adjust agricultural production to prices. The proportion of fixed to variable expense is exceptionally large. When the manufacturer reduces output, he also reduces his labor, power, and materials expense, which are relatively large items. The farmer, on the other hand, cannot greatly reduce his costs by reducing output, because the most important items of expense, such as interest, taxes, and family labor, are fixed. If the farm is heavily mortgaged, 
the farmer may be compelled even to increase his output, in order to keep out of the hands of the sheriff, even though his returns are less than his total fixed and variable costs.

"4. If the price of some manufactured product should fall far below the costs of production of individual manufacturers, the latter would be driven out of business very quickly, thus decreasing supply and tending to raise prices. It is a difficult matter, however, to drive the farmer out of business, because of his ability to get along over a long period of below-cost prices by gradually using up his capital investment and reducing his standard of living. The difference between farmers and manufacturers in this respect is shown in Table 18. Even if the farmer were forced to relinquish his farm,

TABLE 18

Difference in Effect on Farm and Manufacturing Enterprises of a 10 Per Cent Annual Operating Loss

\begin{tabular}{|c|c|c|}
\hline & $\begin{array}{c}\text { Manufacturing } \\
\text { Enterprise }\end{array}$ & Farm \\
\hline 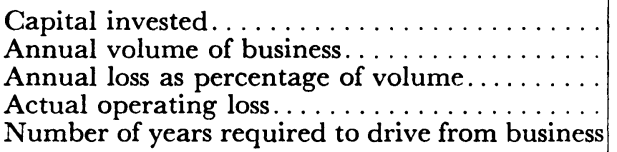 & $\begin{array}{r}\$ 25,000 \\
\$ 200,000 \\
10 \\
\$ 20,000 \\
1\end{array}$ & $\begin{array}{r}\$ 25,000 \\
\$ 4,000 \\
10 \\
\$ \quad 400 \\
20 \text { to } 35\end{array}$ \\
\hline
\end{tabular}

some one else would quickly replace him. Falling prices breed idle factories but not idle farms."

\section{DIFFICULTY OF DETERMINING THE COST OF PRODUCTION}

The cost-of-production approach is weak in another important respect. Some practical difficulties stand in the way of even determining the cost of producing a farm product, let alone setting a price that will cover it.

\section{DIFFICULTY OF DETERMINING JOINT COSTS OF PRODUCTION}

When two products are produced jointly and inseparably, for instance wool and mutton, what is the cost of producing each one?

What Marshall calls the "supply price" for one product may be derived by subtracting the "demand price" for all the other products from the "supply price" of the two or more products that are jointly produced. ${ }^{2}$

${ }^{1}$ F. L. Thomsen, Agricultural Prices, McGraw-Hill, 1936, pp. 78-80.

${ }^{2}$ Alfred Marshall, Principles of Economics, Macmillan, 1922, pp. 388-91. 
This, however, makes the "supply price" (the price at which a given quantity will be produced for market) partly dependent on the "demand price" (the price at which a given quantity will be bought). If the demand price is low, that lowers the supply price. That is the sort of thing that farmers who want cost of production are trying to get away from.

The problem is still more difficult in the case of many farms that produce more than two products. What are the separate costs of producing corn, oats, clover, hogs, and beef cattle on Cornbelt farms? That problem is practically insoluble.

\section{WHOSE COST OF PRODUCTION?}

Even in the simplest case of a single product (produced on farms that produce no other products), almost insuperable practical difficulties arise.

The cost of producing corn in Palo Alto County, Iowa, for example, was computed separately for 14 producers in $1928 .^{3}$ The results are shown diagrammatically in Figure 48. The cost for the most efficient producer was 28 cents a bushel. The cost for the least efficient producer was $\$ 1.18$. What was the cost of producing corn in that county?

If the price were to be set at 28 cents, most of the producers in that county would go broke. If it were set at $\$ 1.18$, that would be such an attractive price for most farmers that they would expand their production beyond the quantity that could be sold at that price.

A compromise solution would be no more satisfactory. If the price were set at the average for all 14 producers, that would have been 49 cents. (This is lower than the average of the extreme low and high costs, because it takes all 14 producers' costs into account, and most of those costs were close to the lower extreme.) At that price about half the producers would have difficulty making ends meet, and the quantity produced might be more, or less, than the quantity that could be sold at that price. And what price should be set in Van Buren County, where the average cost was 77 cents28 cents higher than the average cost in Palo Alto County?

Similar variations were found in the costs of producing cattle. The lowest cost was $\$ 45$ per steer. The highest cost was over $\$ 200$. The same sort of thing was true of hogs. Their costs ranged from

${ }^{3}$ H. L. Thomas and John A. Hopkins, Costs and Utilization of Corn in Seven Iowa Counties, Iowa Agr. Exp. Sta. Bul. No. 289, 1932, pp. 20-22. 
$\$ 8$ to $\$ 15$ per 100 pounds. What was "the" cost of production in these cases?

Another illustration is the cost of production estimates that are published annually for three crops-corn, wheat, and oats-by the

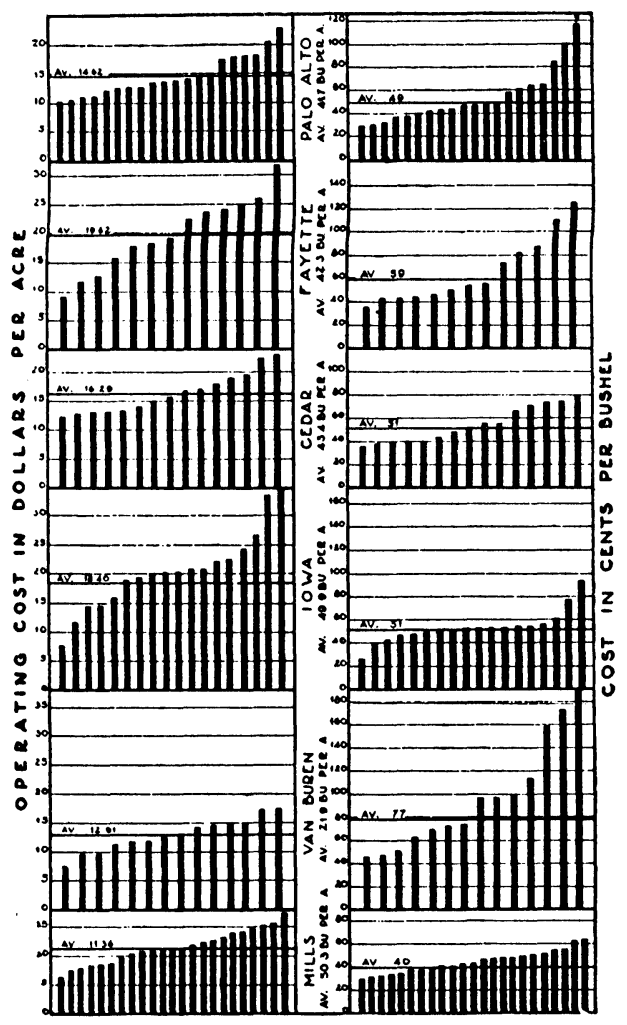

FIg. 48.-The variation in costs per acre and per bushel between fields by Iowa counties, 1928.

BAE. These estimates are published separately by groups of states and for the United States as a whole.

The estimates usually show a range from low to high such that the cost in the high group of states is more than twice as great as the cost in the low group. The annual data from 1934 to 1942 are shown in Table 19. The range in costs shown in this table is much wider than the range of prices that usually exists in the market, by groups of states. If the costs of production for the different 
TABLE 19

Corn (for Grain): Estimated Cost of Production, by Selected States and Groups of States, 1934-42*

\begin{tabular}{|c|c|c|c|c|c|c|c|c|c|}
\hline \multirow[b]{2}{*}{ State or Group } & \multicolumn{9}{|c|}{ Net Cost per Bushel, Including Rent } \\
\hline & 1934 & 1935 & 1936 & 1937 & 1938 & 1939 & 1940 & 1941 & 1942 \\
\hline 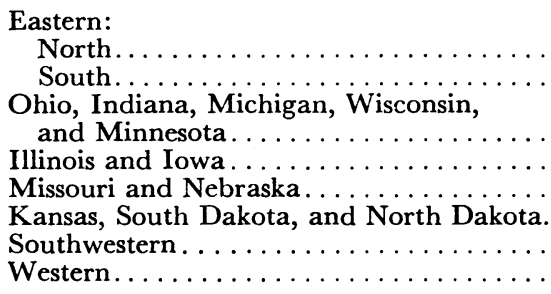 & $\begin{array}{r}\$ .73 \\
1.01 \\
\\
.72 \\
.71 \\
4.48 \\
6.90 \\
1.49 \\
1.91\end{array}$ & $\begin{array}{r}\$ .84 \\
1.15 \\
\\
.57 \\
.49 \\
.92 \\
.96 \\
.83 \\
.90\end{array}$ & $\begin{array}{r}\$ .92 \\
1.22 \\
\\
.79 \\
.82 \\
3.18 \\
7.95 \\
1.09 \\
1.05\end{array}$ & $\begin{array}{r}\$ .81 \\
1.12 \\
\\
.58 \\
.47 \\
.83 \\
.90 \\
.84 \\
1.10\end{array}$ & $\begin{array}{r}\$ .77 \\
1.08 \\
.59 \\
.47 \\
.71 \\
.73 \\
.82 \\
.86\end{array}$ & $\begin{array}{r}\$ .83 \\
1.30 \\
\\
.52 \\
.43 \\
.73 \\
.76 \\
.90 \\
.98\end{array}$ & $\begin{array}{r}\$ .83 \\
1.21 \\
\\
.65 \\
.47 \\
.67 \\
.74 \\
.73 \\
.86\end{array}$ & $\begin{array}{r}\$ .86 \\
1.18 \\
.62 \\
.48 \\
.63 \\
.66 \\
.97 \\
.77\end{array}$ & $\begin{array}{r}\$ 1.00 \\
1.44 \\
\\
.67 \\
.53 \\
.62 \\
.62 \\
1.18 \\
.93\end{array}$ \\
\hline 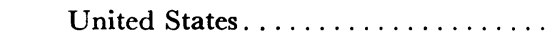 & .95 & .70 & 1.02 & .66 & .65 & .63 & .67 & .68 & .73 \\
\hline
\end{tabular}

* Source: Agricultural Statistics 1944, USDA, Table 51, p. 46. 
groups of states were used as the basis for setting prices for those groups, most of the corn would promptly be drained from the low cost (and price) areas to the high cost and price areas. Feeders and industrial users in the low cost and price areas would not be able to obtain supplies at all.

If the cost for the United States were used all over the United States, instead of the separate costs by groups of states, opposite difficulties would arise. Corn then would all stay in the low cost surplus producing areas, for the price would be the same all over the United States and there would be no price incentive to ship it anywhere.

It is interesting further to compare the annual figures for the

TABLE 20

Corn: Estimates of Cost of Production, Including Rent, and Market Price, 1934-42* (cents per bushel)

\begin{tabular}{|c|c|c|c|}
\hline Year & Cost & Price $\dagger$ & Price Minus Cost \\
\hline $\begin{array}{l}1932 \ldots \ldots \\
1933 \ldots \ldots \\
1934 \ldots \ldots \\
1935 \ldots \ldots \\
1936 \ldots \ldots \\
1937 \ldots \ldots \\
1938 \ldots \ldots \\
1939 \ldots \ldots \\
1940 \ldots \ldots \\
1941 \ldots \ldots \\
1942 \ldots \ldots\end{array}$ & $\begin{array}{r}49 \\
57 \\
95 \\
70 \\
102 \\
66 \\
65 \\
63 \\
67 \\
68 \\
73\end{array}$ & $\begin{array}{r}31.6 \\
52.2 \\
81.5 \\
65.5 \\
104.4 \\
51.8 \\
48.6 \\
56.8 \\
61.8 \\
75.1 \\
91.7\end{array}$ & $\begin{array}{l}-17.4 \\
-4.8 \\
-13.5 \\
-4.5 \\
+2.4 \\
-14.2 \\
-16.4 \\
-6.2 \\
-5.2 \\
+7.1 \\
+18.7\end{array}$ \\
\hline
\end{tabular}

* Source: Agricultural Statistics, USDA, 1943, pp. 37, 46, and 1942, p. 60.

$\dagger$ Season average price received by farmers.

United States with the annual prices for corn that existed in the market place. This comparison for the years 1932 to 1942 is shown in Table 20.

The table shows that, with the exception of the two war years when prices were rising rapidly, the price received was lower than the estimated cost of production every year but one (the drouthand-business-recovery year 1936). The average price over the nine years 1932-1940 was 9 cents lower than the average cost. The cost and price data for wheat and oats show similar conditions for those crops.

Similar results are shown by studies of other crop costs and 
prices. The estimated costs of producing butterfat in the Los Angeles County marketing area for eighty-one producers ranged from 46 cents to 67 cents in 1939, and from 87 cents to $\$ 1.36$ in $1943 .{ }^{4}$ The blend price of milk was high enough to cover the cost of less than 35 per cent of the producers in both years. Yet the area had an abundance of milk during 1939 and 1940, and the quantity produced increased constantly up to 1943.

Farmers are inclined to say "There. That proves it. We told you prices aren't high enough to cover cost of production. Prices ought to be set higher, so we could cover our costs."

But if prices had been set higher, so as to cover the average cost of production, half the producers still would have had higher than average costs; those costs would not have been covered by the price. And the higher price would have reduced consumption and increased production, so that the program sooner or later would have broken down under a flood of surplus production.

For the reasons given above, "the" cost of production has continued to be a fruitful source of controversy, but has not been found adequate or workable as a basis for agricultural prices.

\section{RAISING WAGES AND RAISING PRICES}

A final problem remains: Labor unions consistently strive to raise wages and get more money for labor; and except when they go to extremes, their efforts in this direction are approved by most economists. Yet when farm organizations try to do the same thing, and raise the price of farm products so as to get more money for farmers, practically all economists unite in pointing out how bad this is and what serious adverse consequences will follow.

Why is this? Why is sauce for the goose not sauce for the gander? If raising wages is good, why is raising prices bad?

\section{HOURLY RATES VS. PIECE RATES}

The answer to this question involves two things: First, wages are hourly or daily wages to laborers, but prices are piece-wages to farmers. Real wages depend fundamentally upon production per worker, and production per worker increased about 3 per cent per year from 1910-14 to 1940, and faster than that during World War II, as shown in Figure 49. Industrial real wages therefore should in-

\footnotetext{
${ }^{4}$ G. M. Beal, Economic Factors Affecting the Production of Fluid Milk in the Los Angeles County Marketing Area, Bureau of Market Enforcement, California State Printing Office, Sacramento, March, 1944, pp. 14-17.
} 
crease at about the same rate. That is the reason that most economists approve of increases in labor's wages; wages should increase with increasing production.

INDEX NUMBERS $(1910-14=100)$

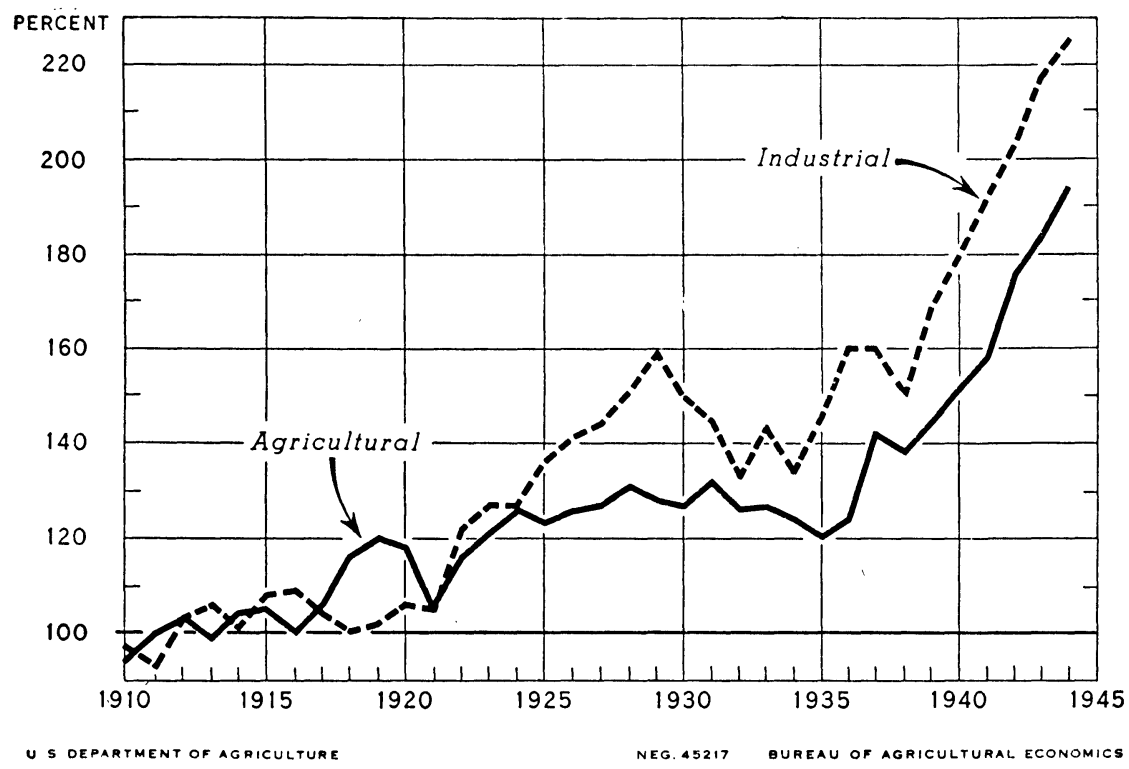

Frg. 49.-Production per worker: agricultural and industrial, United States, $1910-44$.

Figure 49 shows that production per worker in agriculture has been increasing also, although at a slower rate than in industry. The rate from 1910-14 to 1940 was about 2 per cent per year. Farm "wages" (income) therefore, should have increased at the same rate-2 per cent per year.

This means that the real prices of farm products should have been maintained at a constant level, not increased. Constant real prices would have increased farmers' real wages in line with their increasing production per man.

\section{RELATIVELY SLOW-MOVING AND INELASTIC DEMAND}

If that were all that was involved, parity prices for farm products as a group would be a reasonable goal. That goal would insure that farmers' wages increased in line with their production. 
But that is only half the picture. In determining wages, the demand for the product is as important as the supply. The physical quantities produced are only one of the factors that determine wages; the prices at which those quantities will sell are equally important.

Those prices depend upon two things-the relative increase of supply and demand (relative shifts in the supply and demand curves) for the product, and the elasticity of the demand.

Up to 1920, the demand curve for farm products in terms of population growth had been shifting to the right at about the same rate as agricultural supply in terms of production, as shown early in this book in Figure 3. The increasing income per person therefore showed up as an increasing demand for farm products, and the relative prices of those products rose, as shown in Figure 2.

Since 1920, however, except for World War II, the demand curve has been moving to the right and upwards at a slower rate than the supply curve, and relative (real) agricultural prices have been declining. And the prospects are that this relative slowing down of the demand curve will continue and become more marked in the future, for reasons given in the text accompanying Figure 3.

This relative decline in demand will have pronounced effects on agricultural prices, because of the relative inelasticity of the demand for farm products. The income elasticity for food in terms of quantities of food is only about $\mathbf{0 . 2}$, and in terms of expenditures for food, about 0.4. The price elasticities must be greater than these, but are probably well below unity. Thus a relative decline in the demand for farm products of $x$ per cent will depress the prices of farm products more than $x$ per cent, and therefore decrease total returns.

. Programs designed to hold the relative prices of farm products up merely by price fixing which does not alter the fundamental conditions which cause the prices of farm products to decline, therefore, are unlikely to be successful. Their progress is limited by the fundamental inelasticity of the human stomach.

This analysis shows, however, how programs to maintain relative agricultural prices can succeed. The solution is to reduce the supply of farmers in line with the relatively slow growth of the demand for farm products, so that the total agricultural income pie will be cut into fewer pieces, and therefore into larger pieces per farmer.

This solution calls for measures which range far from the starting point-direct action to raise prices. It requires recognition of the 
fundamental fact that birth rates in agriculture are nearly 50 per cent higher than necessary to maintain a stationary farm population. ${ }^{5}$ The more difficult it is to move this continuing excess population off farms, and the more farmers there are on farms, the lower will income per farmer decline.

The first fundamental requisite for high income per person in agriculture, therefore, is a group of measures that will facilitate the continuous transfer of people out of agriculture and into other lines of work. This calls for equalizing educational opportunities on and off farms; for training some farm boys and girls for urban occupations; for adequate employment services, and so on. These measures will reduce the friction that retards the flow of people out of agriculture. The closer this flow can be made frictionless, the closer will per capita income on farms rise to equality or parity with per capita incomes for equal ability elsewhere in the country.

${ }^{5}$ The net reproduction rate (a measure which indicates the extent to which a population is potentially able to reproduce itself) tells the story. In 1940, the urban net reproduction rate in the United States was 74 (a rate of 100 is required to maintain a stationary population if birth and death rates remain unchanged). The rural nonfarm rate was 114. The rural farm rate was 144 . See: "Population Net Reproduction Rates by States (Preliminary)," Sixteenth Census of the United States, Series P-5, No. 13, 1940, p. 2. 


\section{The Theory of Price Stabilization and Price Discrimination}

It was shown in earlier chapters that the effect of productioncontrol programs on the total revenue from the sale of the crop depends upon the elasticity of the demand for that crop. It will be shown in the present chapter that the effect of price stabilization programs on the total revenue from the sale of the crop depends primarily upon the curvature of the demand curve for the crop, and secondarily upon its elasticity.

There appears to be a general belief that in actual life most demand curves are curved lines, concave from above, on arithmetic paper. Practically all of the hypothetical curves found in economic textbooks are thus curved. These concave curves are also common in technical articles in professional journals.

These curves are misleading in two respects. Most of them apparently reflect the belief that the demand curve characteristically is more elastic at the lower end of the curve than at the upper end. This sounds like a reasonable assumption, yet it is incorrect in two respects: (1) Most of the hypothetical curves which are shown as concave on arithmetic paper are actually convex on logarithmic paper, and therefore are less elastic at the lower end than at the higher, as shown in Figure 50.1 And (2) most of the demand curves for agricultural products which have been empirically derived are not concave curves on arithmetic paper; they are approximately straight lines; accordingly, they are strongly convex on logarithmic paper, which means that they are much less elastic at the lower end than at the upper.

This is shown by a study of a considerable number of demand curves empirically derived from market statistics. These curves are shown on logarithmic paper in Figure 50. The curves are taken from the published charts, without any comment as to their accuracy other than the closeness (or lack of it) of the scatter of the dots

\footnotetext{
${ }^{1}$ Sources of data are given in the Journal of Farm Economics, XX, No. 4, November, 1938, p. 806.
} 

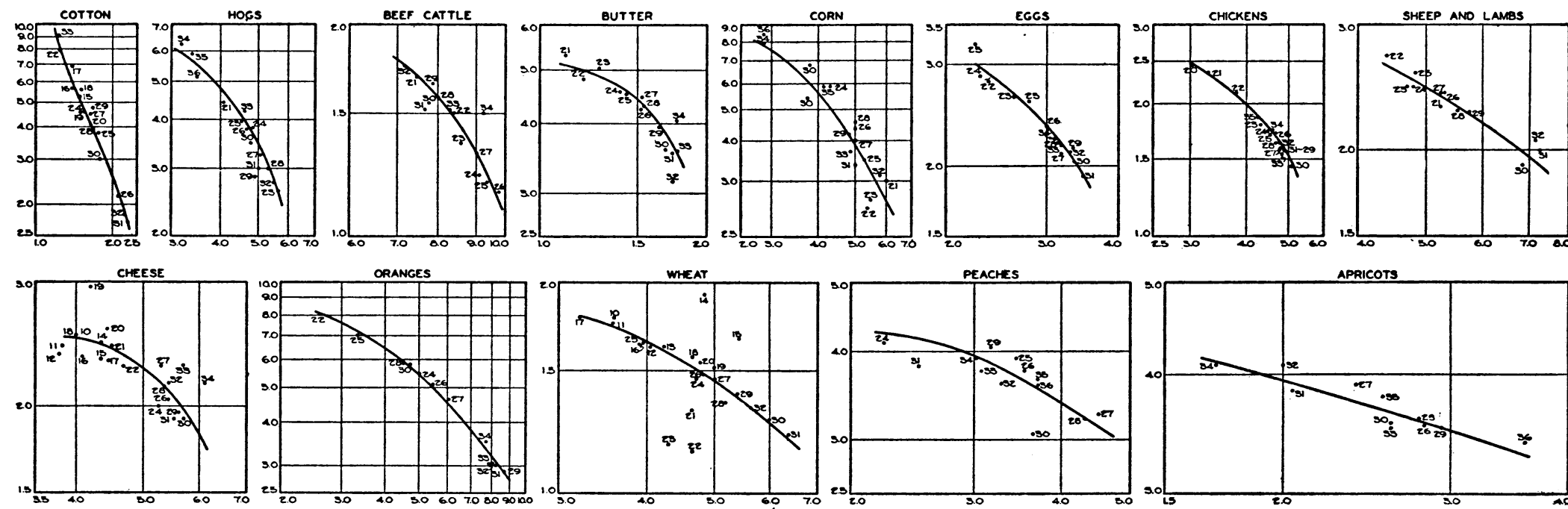

FIG. 50.-Empirically derived price-quantity curves for various farm products. 
about the curves, which is shown in each case. These analyses are the most recent ones available, but some of them are several years out of date, and several of them would be improved by the use of better indexes of demand than were available when the studies were made. They should all be brought up to date, but nobody competent to do the job seems to have time to do it. Figure 50 should be regarded only as tentatively establishing a hypothesis that needs to be investigated more thoroughly and confirmed, amended, or proven erroneous. ${ }^{2}$

All of the curves were published on arithmetic paper in the original analyses. Many of them were straight lines on arithmetic paper. On logarithmic paper, as shown in Figure 50, they are all convex, with the exception of the curve for apricots and the upper end of the curve for cotton.

This means that the elasticity is high in the upper part of the curve and low in the lower part. This in turn means that in the simplest case of a straight line demand curve on arithmetic paper with an average elasticity of unity, both a small crop and a large crop are worth less than an average-sized crop. For the elasticity in the upper half of the curve is higher than unity, so a small crop is worth less than an average crop. Conversely, the elasticity in the lower half of the curve is lower than unity, so a small crop is worth more than an average crop. The crop that is worth the most is the averagesized crop that cuts the whole curve at the middle where the elasticity is unity. This means that stabilization of supplies by storing surpluses from large crop years over to small crop years would not only stabilize prices but would also increase total incomes from the sale of the crop.

This can be shown clearly with the help of a few hypothetical figures. The prices and total revenues for a crop with a straightline demand curve (on arithmetic paper) with an average elasticity of unity are shown briefly in Table 21. The data are all in index form with an average equal to $100 .^{3}$

It is clear from Table 21 that a large crop, for instance 130 per cent of average in size, which would sell for an index price of 70 , would bring in a total revenue of only 91 . A small crop, 70 per cent of average in size, would sell at 130 and also bring in a total revenue

'Adolf Kozlik, "Shape of Total Revenue Curves," Journal of Farm Economics, XXIII, No. 4, November, 1941, pp. 843-54.

${ }^{3}$ These relationships were shown in graphic form in Figure 25, Chapter 5. 
of 91. These two crops, then (a large crop and a small crop), would bring in total revenues averaging only 91 per cent of normal. If the surplus (the excess over 100) were withheld from the large crop and added to the small crop, that would convert them both into average-sized crops. They would bring in an average total revenue

TABLE 21

Prices and Total Revenues for Various Quantities: Straight Line Demand Curve With an Average Elasticity of Unity

\begin{tabular}{|c|c|c|}
\hline $\begin{array}{c}\text { (1) } \\
\text { Size of Crop in } \\
\text { Percentage of Average }\end{array}$ & $\begin{array}{l}\text { (2) } \\
\text { Price per Unit in } \\
\text { Percentage of Average }\end{array}$ & $\begin{array}{c}\text { (3) } \\
\text { Total Revenue in } \\
\text { Percentage of Average } \\
((1) \times(2) \text { omitting } 00)\end{array}$ \\
\hline 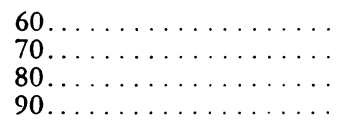 & $\begin{array}{l}140 \\
130 \\
120 \\
110\end{array}$ & $\begin{array}{l}84 \\
91 \\
96 \\
99\end{array}$ \\
\hline $\begin{array}{l}100 \ldots \ldots \\
110 \ldots \ldots \\
120 \ldots \ldots \\
130 \ldots \ldots \\
140 \ldots \ldots\end{array}$ & $\begin{array}{r}100 \\
90 \\
80 \\
70 \\
60\end{array}$ & $\begin{array}{r}100 \\
99 \\
96 \\
91 \\
84\end{array}$ \\
\hline
\end{tabular}

over the two years of 100 per cent of normal. Stabilizing supplies in this case would not only stabilize prices, but would also increase total revenues from the sale of the crops.

What is the effect of a stabilization program in cases where the demand curve is not a straight line on arithmetic paper, but has some sort of curvature?

If the demand curve is so shaped that it has a constant elasticity of unity throughout its length, then no matter what the size of the crop-large, average, or small-it brings in the same total revenue. In fact, a curve with constant unit elasticity is the same thing as a constant revenue (or constant total value) curve. In that case, of course, stabilization operations have no effect on total revenue, since the total revenue is unaffected by the size of the crop. But if a demand curve with an average elasticity of unity is more concave than a constant total revenue curve, then a large crop and a small crop are both worth more than an average crop, and stabilizing supplies would decrease total revenues.

The section can be summarized in these terms: the way to maxi- 
mize total revenue is to produce the amount that will cut the demand curve as close as possible to the point where the elasticity is unity (where the marginal revenue is zero and the total revenue is the greatest). Where the demand curve is inelastic, reducing the size of the crop (cutting the demand curve at a higher point) will increase total revenue; where the demand curve is elastic, increasing the size of the crop will increase total revenue. In the case of straight-line demand curves with an average elasticity of unity, the elasticity of the demand curve is less than unity in the lower part of the curve and greater than unity in the upper part, and the way to maximize total revenue is to move toward the-center from both directions, that is, to convert both large crops and small crops to average-sized crops by storing the excess over average from the large crops and adding it to the small crops. The more convex the demand curve is, the more will stabilizing supplies add to total revenue, and the more concave it is, the less it will add, until the point is reached where the curve is more concave than a constant-total-revenue curve; beyond that point stabilizing supplies will decrease total revenue.

\section{DEMAND CURVES WITH CONSTANT BUT NOT UNIT ELASITICITY}

If the demand curve has a constant elasticity that is greater or less than unity, the situation is more complicated. The total revenue curves then are not straight lines, as they are when the demand curve has a constant elasticity of unity. If the elasticity of the demand curve is constant, but less than unity, the total revenue curve associated with it has a concave curvature. It has the same shape as a constant total returns curve; that is, it is a symmetrical hyperbola approaching the $x$ and $y$ axes as asymptotes. In Figure 26, Chapter 5 , a demand curve with a constant elasticity of -0.5 is shown both on logarithmic and arithmetic paper, in the upper part of the chart, and the total revenue curve associated with it is shown in the lower part of the chart. (The elasticity figure, -0.5 , written beside the curves shows the elasticity of the original demand curve for purposes of identification, not the elasticity of the total revenue curve; that is -1.0.)

In that case, a large crop, represented by six quantity units along the scale at the bottom of the chart, is shown to bring a total revenue of about 1.5. A small crop, represented by two quantity units, brings a total revenue of 5. The sum of these two total revenues is 6.5. But if the excess of the large crop over average were removed from the 
large crop and added to the short crop, that would convert them into two average-sized crops (four quantity units) each of which would bring in a total revenue of about 2.5; the sum of these two total revenues would therefore be 5 , and this is less than the sum of the large and small crop, 6.5, computed above. A stabilization program in this case would therefore reduce total revenues.

The opposite is true of demand curves with a constant elasticity greater than unity. A curve of this sort, with a constant elasticity of -2.0 , is also shown in the upper part of Figure 26, with the total revenue curve associated with it in the lower part. The total revenue curve in this case is convex from above; it is a parabola with apex at the origin of the $X$ and $Y$ axes. Stabilizing supplies in this case would increase total revenues.

“STANDARD" DEMAND CURVES WITH STRAIGHT-LINE TOTAL REVENUE CURVES

It was shown earlier that a demand curve with a constant elasticity of unity makes a convenient standard for determining whether stabilization of supplies would increase or decrease total returns. If the demand curve for the particular crop considered has an average elasticity of unity but is less concave than this standard curve (if, for example, it is a straighter line, or a convex line) then stabilization would increase total revenues; if it is more concave than this standard curve, stabilization would decrease total revenues.

It was shown above that this standard applies only to demand curves with an average elasticity of unity. Is there another convenient standard or set of standards that can be used for crops whose demand curves have other elasticities than unity?

There is. The criterion for such a set of standard curves is that the total revenue curves associated with them must be straight lines. In that case stabilization will have no effect on total revenues over a period of large and small crops. Figure 26 shows that demand curves of constant elasticity (other than unity) cannot be used as standards because their total revenue curves are not straight lines. They may have a positive slope (as where the demand curve is elastic) or a negative slope (as where the demand curve is inelastic) but they must be straight.

Adolf Kozlik has worked out mathematically the sort of demand curves required here, and shown graphically that they are merely curves of constant unit elasticity shifted up or down by constant 
absolute amounts all along the curve. ${ }^{4}$ The validity of this standard set of curves can be understood in everyday language thus: The total revenue curve associated with a constant-unit-elasticity demand curve is a horizontal straight line. If now the demand curve is shifted up one price unit all along its length, the resulting total revenue curve will start in, at the first quantity unit, one value unit higher than the original total revenue curve $(1 \times 1=1)$; at the second quantity unit it will be two value units higher $(2 \times 1=2)$; at the third, three units higher, and so on. This total revenue curve therefore will be a straight line, with a positive slope. Similar calculations apply to demand curves lower by constant amounts than a curve with a constant elasticity of unity.

If the demand curve for the particular crop concerned, therefore, has an average elasticity other than unity, stabilization would increase or decrease total revenues accordingly as the demand curve is more or less curved than the appropriate standard curve for that elasticity. Since these standard curves are ordinary constantunit-elasticity curves shifted up (for elastic demand curves) or down (for inelastic demand curves) the comparison of the standard demand curve with the demand curve for the particular crop can be made by sliding a transparent chart with a family of constant-unitelasticity curves up and down on it (but keeping the $Y$ axes on the two charts superimposed) until a section of one of the standard curves is found which has the same average elasticity as the demand curve for the crop in question. If the demand curve for the crop is less concave from above (that is, if it is straighter than the standard curve, or actually convex), then stabilization of that crop would increase total revenues. If, on the other hand, the demand curve is more concave (more curved) than the standard curve, stabilization would decrease total revenues.

${ }^{4}$ Adolf Kozlik, "Conditions for Demand Curves Whose Curves of Total Revenue, Consumers' Surplus, Total Benefit, and Compromise Benefit are Convex," Econometrica, VIII, No. 3, July, 1940, pp. 263-71.

A short mathematical proof of this runs as follows:

The total revenue curve $R(Q)$ of a demand curve with the equation $F(Q)=$ $a / Q+b$ is $R(Q)=Q \cdot F(Q)=a+b Q$. This is a straight line, because $R$ increases proportionally with $Q$. The demand curve whose total revenue curve is a straight line is a demand curve of constant unit elasticity $F(Q)=a / Q$ shifted up and down by the amount $b$. The total revenue curves of demand curves which are more concave than these demand curves are concave, and the total revenue curves of demand curves which are more convex than these are convex. 


\section{DOES STABILIZATION BENEFIT CONSUMERS?}

It could be argued that consumers are harmed by stabilization to the same extent that farmers are benefited by the increased total value of their crops, for the increased total value of crops to farmers emerges as an increase in the cost of food to consumers. If stabilization increases the total value of a series of crops 6 per cent, as in the illustration just used, it must increase the cost of consumers' purchases by the same amount.

The harm or benefit to consumers cannot be measured, however, merely by the increase or decrease in the amount of money they pay for corn. If a monopolist restricted the production of his product, and the demand for that product were inelastic, consumers would pay more for the small quantity than they did before. They would clearly be harmed, but the harm would not be measured by the extra amount of money they had to pay. For if the demand were elastic instead of inelastic, consumers would pay less for the small quantity than before. No one could claim that they would be benefited because their total outlay for the product had been reduced; least of all could anyone claim that they would be benefited by the amount of the reduction in their total outlay for the product.

The question can be approached from a different direction. Any one consumer gets more satisfaction from a fairly even consumption of a particular food than he does from a scarcity at one time and a glut at another. In technical terms, the total-utility curve is convex from above. A stable supply is therefore worth more to him than a fluctuating supply. The extra worth of the stable supply may be greater or less than the extra money he has to pay for it-there is no way of telling which-so the consumer may benefit by more or less than the extra money he pays. The important point is merely that he does benefit to some extent; the extra money he pays is not all loss, and may even be less than the benefit he receives.

But fluctuations in the production of different foods have a differential effect on different classes of consumers. When supplies and prices fluctuate, consumers with low incomes can make those incomes go farther by buying most heavily of those foods that are cheapest at the time, and buying least heavily - or perhaps not at all-of those foods that are temporarily scarce and high priced. At first thought, therefore, it would appear that stabilizing supplies would work some hardship on the low-income groups; they would be obliged to pay more for their food. 
F. V. Waugh has made a further point. He shows that consumers are harmed if the price of any product is stabilized at the simple arithmetic mean of the fluctuating prices. This point is independent of the points made above. It is based upon the concept of consumers' surplus, and depends only upon the fact that the elasticity of the demand curve is negative. ${ }^{5}$

Waugh shows that with any negatively-sloping demand curve (sloping downward to the right) the loss in consumers' surplus from averaging two prices is always greater than the gain. For example, when egg prices vary from 40 cents to 60 cents a dozen, consumers' surplus is greater than it would be if the price were stabilized at 50 cents a dozen. He then confirms this conclusion by an analysis based on indifference curves.

Waugh's theorem is illustrated in Figure 51. This figure shows that the gain to consumers when prices are below average is always greater than the loss when prices are above average. That is, the area in Figure 51 marked G (for gain) is always necessarily larger (because of the negative slope of the demand curve) than the area marked L (for loss). Thus consumers are harmed by price stabilization. This is true not only of consumers as a group, but of each consumer separately.

This theorem appears to run counter to common sense, but so far it has stood up pretty well under criticism. Two critics ${ }^{6}$ have made the point that the theorem is true only if prices are stabilized at or above the arithmetic mean of the variable prices. They point out that if prices are stabilized at or below the weighted average of the prices (weighted by the consumption at each price), consumers would be benefited, not harmed, by the stabilization. This reduces the status of Waugh's theorem from a general rule to a special case.

The argument then arises as to which is the more reasonable level for prices to be stabilized-at or above the arithmetic mean, or at or below the weighted average? Lovasy points out that the weighted average is the more reasonable level, since it would maintain producers' incomes at the same average level as before, and benefit them by reducing risks and lowering costs. Waugh replies

\footnotetext{
${ }^{5}$ F. V. Waugh, "Does the Consumer Benefit From Price Instability?", The Quarterly Journal of Economics, August, 1944, pp. 602-14.

${ }^{8}$ L. D. Howell, "Does the Consumer Benefit From Price Instability?, Comment," pp. 287-95; Gertrud Lovasy, "Further comment," pp. 296-301; Frederick V. Waugh, "Reply," pp. 301-303. The Quarterly Journal of Economics, LIX, No. 2, February, 1945, Harvard University Press, Cambridge, Mass.
} 
that producers would not be interested in stabilization at that level; they would want a level at least as high as the arithmetic mean. This argument gets out of the field of statistics and economic theory. But

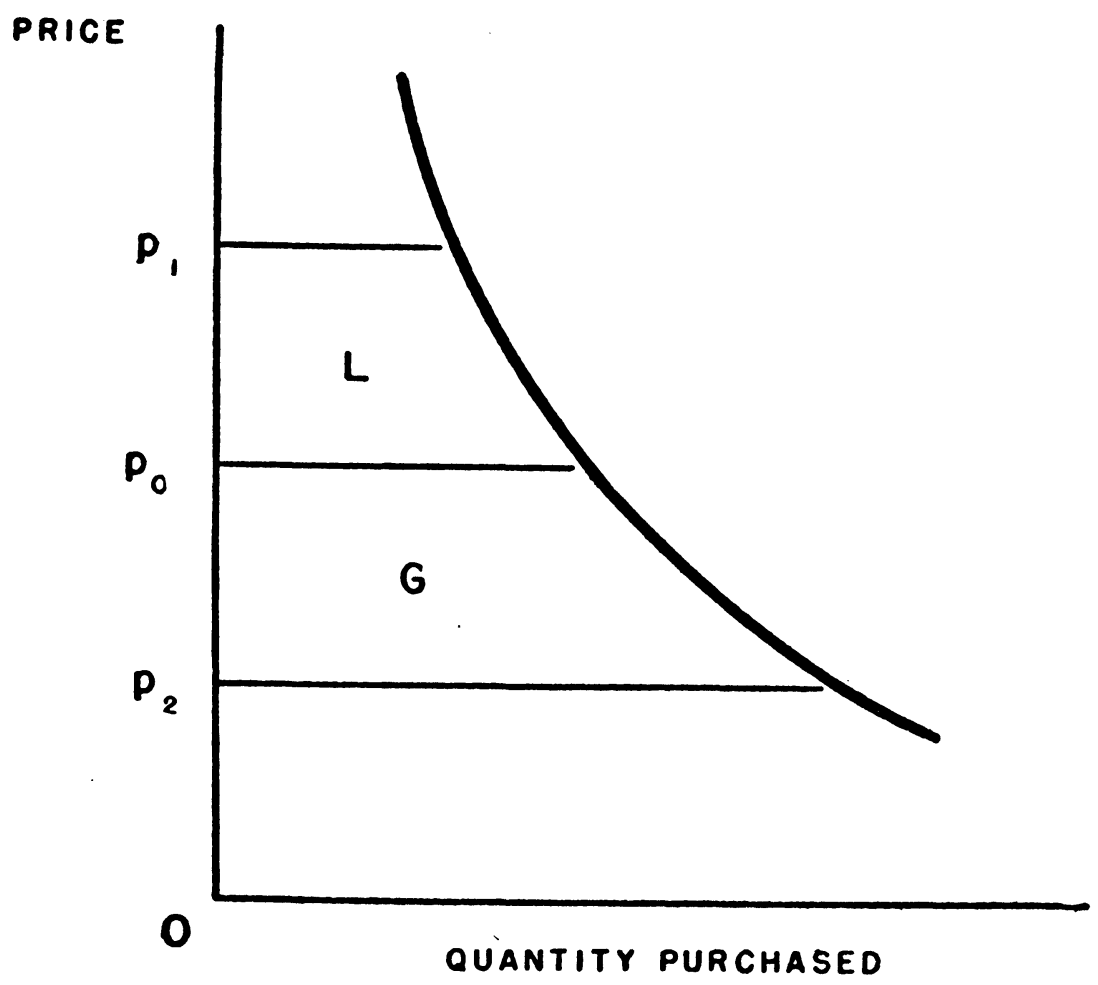

FIG. 51.-Comparison of loss and gain from fluctuating prices, showing that the gain is greater than the loss.

it seems to me that it would be settled by the curvature of the demand curve, not by the desires of producers.

An additional point has been made by D. Gale Johnson, who shows that stabilizing supplies at the arithmetic mean of the fluctuating supplies always benefits society as a whole (at least, if carrying costs are neglected). In some cases this would reduce consumers' surplus, but in all such cases this loss would be more than offset by a gain in producers' income. ${ }^{7}$ In all such cases the pro-

\footnotetext{
"See his Ph.D. Thesis, "The Theory of Forward Prices for Agricultural Products," Department of Economics, Iowa State College.
} 
ducers could afford to pay consumers compensation for their losses, and would still have a net profit from stabilizing supplies.

\section{THE THEORY OF PRICE DISCRIMINATION}

The theory of price stabilization outlined above is in essence the theory of equalizing prices in different time-markets-that is, in markets separated by intervals of time. It is comparatively simple; it is based directly on the relations between point elasticity and marginal, average, and total revenue laid down in earlier chapters. The theory of price discrimination is in essence the theory of unequalizing prices. The basic theory of price discrimination is the same as the basic theory of price stabilization. Its exposition is more complicated, however, because it involves two or more different demand curves. The theory of price stabilization involves two or more curves also, one for each year, but they are not different curves; they are identical curves, and are therefore treated as one.

The theory of price discrimination and of price stabilization both call for maximizing total revenue by cutting the demand curve (or curves) as close as possible to the point (or points) of unit elasticity. But whereas the theory of price stabilization deals with a succession of identical demand curves in markets separated by intervals of time, the theory of price discrimination deals with two or more different demand curves in contemporaneous markets separated in space, in form, or in some other basic characteristic. Export-dumping plans are examples of price discrimination between two or more markets separated in space. Milk price plans are examples of price discrimination between two or more markets separated in form (the original product is sold in two or more different forms, fluid milk, and butter, cheese, ice cream or some other manufactured product). The food stamp plan is an example of price discrimination between two income-group markets.

The general principle underlying price discrimination has not always been adequately stated in the literature of the subject. Joan Robinson wrote, "If it is possible for a monopolist to sell the same commodity in separate markets, it will clearly be to his advantage to charge different prices in the different markets, provided that the elasticities of demand in the separate markets are not equal. For if he charges the same price in each market, he will find that, at that price, the marginal revenue obtained by selling an increment of output in each market separately is greater in some markets than in 
others. He can, therefore, increase his profit by selling less in those markets where the elasticity of demand is less and the marginal revenue smaller, and selling more in those markets where the elasticity of demand is higher and the marginal revenue greater. $\mathrm{He}$ will, therefore, adjust his sales in such a way that the marginal revenue obtained from selling an additional unit of output in any one market is the same for all the markets." 8

This is a good clear statement, but it is incorrect in two respects. In the first place, it is not necessary that the elasticities in the different markets be different, in order for total revenues to be increased by price discrimination, as we shall see later. And in the second place, the statement gives the conditions for maximizing or minimizing total revenues; it gives only the necessary, not the necessary and sufficient, conditions for maximizing total revenues. The same shortcoming appears to be evident in the statement from another source:

"If the purpose of discriminative marketing is to obtain the greatest possible net income for a given supply to be marketed, the principle to be followed is not that of equal net prices in all markets, but the principle of equal marginal net returns from all markets."9

In this case, however, the shortcoming results only from the summary nature of the statement and the prominence that is given to it. At several points further on in their paper, the authors point out that under certain conditions, which are specified, the equalization of marginal returns will minimize, not maximize, total returns. They also give a good mathematical treatment of the subject. The principle can be put in everyday words as follows:

\section{GENERAL THEORY OF PRICE STABILIZATION AND PRICE DISCRIMINATION}

Total revenues are maximized or minimized by the equalization of the marginal revenues in the different markets. In price stabilization, the demand curves in the separate markets (in time) are identical; the equalization of marginal revenues is accomplished by the equalization of the prices in the different markets. This maximizes total revenues if the demand curves are less concave than the

${ }^{8}$ Joan Robinson, Economics of Imperfect Competition, Macmillan, London, 1933, p. 181.

'F. V. Waugh, E. L. Burtis, and A. F. Wolf, "The Controlled Distribution of a Crop Among Independent Markets," Quarterly Journal of Economics, LI, November, 1936 , p. 6. 
"standard" curves defined above (whose associated total revenue curves are straight lines). It minimizes total revenues if the demand curves are more concave than the "standard" curves.

The principle for price discrimination runs in similar but opposite terms. In this case the demand curves in the separate markets may be identical, or they may be different. The principle is the same in either case, but it can be most simply stated for the case where the curves are identical. In that case, the equalization of the marginal revenues may require unequalizing prices-charging different prices in the different markets. This maximizes total revenues if the demand curves are more concave than the "standard" curves, and minimizes total revenues if they are less concave. If the demand curves in the different markets are not identical, the principle is the same, but a full exposition of it requires somewhat complicated mathematics. The general idea can be conveyed verbally in terms of the total revenue curves associated with the two demand curves. It is phrased in terms of two different markets here. The principle is the same for more than two markets; only its exposition is more complicated. If the total revenue curves are both concave from above, price discrimination carried to the point where marginal revenues are equal maximizes total revenues; if they are both convex, price discrimination minimizes them. If one of the curves is concave, and the other one is convex, the outcome depends on which curve has the greater curvature. This curvature may be measured by the absolute value of the second derivate of the curve. If the algebraic sum of the two second derivatives is positive, then price discrimination carried to the point where marginal revenues are equal maximizes total revenues; if the sum is negative, it minimizes it. 


\section{The Significance of the Results of Price Analyses}

When price analysts investigate prices, they necessarily investigate prices that have happened. Most price analysts, however, do their work not merely because they want to explain what has happened in the past, but because they believe that their explanation will have some usefulness in meeting current and future problems. For example, a price analyst discovers by study of past statistics that the demand for potatoes had (he cannot, strictly speaking, say "has") an elasticity between -0.3 and -0.4 . He does this not because he is a historian, but because he believes that this finding will be useful in the solution of current potato production and marketing problems.

How well founded is this belief? How likely is it that the quantitative relations revealed by the analysis of past statistics of prices, production, income, etc., will be valid guides to action in the present and future?

Let us illustrate the problem by an extreme case, and then proceed to more typical cases. Suppose that an investigator were analyzing the price of eggs, and had only two annual price data to work with; eggs were 30 cents a dozen in 1940 and 40 cents in 1941. If he plotted these prices against any other variable that changed in value from one year to the other, he would get a perfect positive or negative correlation. He could thus "explain" the price of eggs in terms of any other variable he chose. In this case the explanation would be so obviously absurd that nobody would consider it, because the number of variables is equal to the number of observations and there are no degrees of freedom left.

But suppose the investigator had data for three years. Some of the innumerable economic series available would still, purely by chance, have a high correlation with the price series. If he had data for four years, fewer series would correlate highly with the prices, and data for five and more years would correlate highly with still fewer series. Statisticians have worked out tables showing, for 
random data, how high the correlation must be for any given number of variables and of items in each series, in order to be adjudged "significant" or "highly significant" and not merely the result of chance. ${ }^{1}$

Thus, a correlation of plus or minus 1.0 between two series, with only two items in each series (for instance, annual data covering only two years) would not mean a thing as an explanation; it would have no real significance; it would not be statistically significant. Tests of significance show that in the case of two series, each three years long, the correlation would have to be 0.997 or higher before it could be considered significant. If the series were each four years long, the correlation would have to be 0.950 or higher, and so on up.

The application of tests of significance to economic data, especially to time series, may give an unwary investigator a confidence in his results which is entirely unwarranted. A series of monthly prices, two years long, would have twenty-four items. A correlation coefficient between it and some other monthly series in excess of 0.404 would be adjudged significant by the application of statistical tests; yet in actual fact the correlation might have no more real significance than the correlation that would result if the monthly data were made into annual data, in which case there would be only two items in each series and the correlation would be perfect.

Other illustrations bring out the point further. Mr. Yule's classic table and chart twenty years ago ${ }^{2}$ showed a high correlation (0.9512) between the annual data showing the proportion of Church of England marriages to all marriages and the standardized mortality per 1,000 persons for the same years, over a period of 45 years. For that number of years, any correlation over 0.290 would be adjudged statistically significant. Yet, as he pointed out, all he had there was in "nontechnical language, a fluke"-a purely chance correlation between two trends, both declining without any causal relation between them. The one series was not in any sense an explanation of the other.

Another illustration is the course of prices during a business

${ }^{1}$ George Snedecor, Statistical Methods, The Iowa State College Press, 1946, p. 149. The meaning of "significant" here is that the correlation coefficient would be as high as (or higher than) the specified figure, in 5 per cent of a large number of such cases taken at random. The term "highly significant" is similar, but applies to the 1 per cent level.

${ }^{2}$ G. Udny Yule, "Why Do We Sometimes Get Nonsense Correlations Between Time Series?" Journal of the Royal Statistical Society, Vol. 89, No. 1, 1926, pp. 1-64. 
cycle. The annual prices of butter from 1929 to 1936 show a high correlation with the prices of cranberries, but nobody would claim that the one was an explanation of the other. Both were affected by the same decline and recovery of demand. The correlation coefficient is highly (statistically) significant, but not economically significant.

\section{MOST ECONOMIC DATA ARE NOT RANDOM IN CHARACTER}

The development of statistical tests of significance, therefore, has not helped the economic statistician very much. For tests of significance, and established statistical methods generally, are designed for use with data that have several important characteristics. These characteristics are: (1) The population must be homogeneous, (2) the distributions of the values of the variables must be approximately normal, (3) each observation must be independent of the others, and (4) the sample must be selected from the parent universe at random.

If the conditions just given are met, even if only approximately, the standard tests of significance of the results of the analysis of a sample measure how likely it is that the characteristics of the sample are true of the population as a whole. But economic data, especially economic time series, clearly do not meet these conditions: (1) The population from which the sample (the data for a certain period of years) is drawn is not homogeneous. A price analyst, investigating the factors determining the price of barley in the United States before 1918, could not rely on tests of significance of his results, because the advent of prohibition in 1918 changed the population. (2) The condition that the data must be normally distributed may be reasonably closely met, although it is more likely that the logarithms of such economic data as prices have normal distributions, than it is that the original data are normally distributed. (3) Each observation is usually not independent of the others. This is true both of successive items in one price series, and of corresponding observations (in time) in different price series. The price of corn in February is not independent of the price of corn in January and March, for all three of these prices are determined (in a given demand situation) by the size of the same corn crop. Similarly, in a given supply situation, the prices of different goods are related to each other at any one time (they are all high or low) according to the prosperity or depression of the country as a whole. 
And finally, (4) the sample (the period of years chosen) is usually not selected at random. It generally begins either when the data first became available, or just after World War I or some other sort of bench mark, and runs up to World War II, or in some cases up to the present time.

\section{WHAT CAN BE DONE?}

Is there any way to render economic time series more amenable to statistical analysis? A careful student of this question brings in a rather discouraging report. ${ }^{3}$

"This problem has been dealt with somewhat satisfactorily mainly in two different ways. The first is the Variate Difference method as proposed by 'Student' and O. Anderson.* This method is essentially based on the assumption that the systematic or non-random part of the time series is such that it can be wholly or partly eliminated by finite differencing. It is a very well-known fact that a polynomial can be entirely eliminated by forming enough differences. But the Variate Difference Method demands such behavior in a restricted neighborhood only. It is not necessary that the whole series behaves like a polynomial over the entire range. $\dagger$ The two authors mentioned above developed this idea statistically by the large sample approach (standard errors). I tried to give recently an extension of it which may be applicable even in the case of short series.f It gives exact tests of significance, but is not 'efficient' in the sense of Fisher's criterion. I propose to make selections from the data and to utilize only part of the available material, in order to create artificial independence. Some of the available information is hence lost and the method is not efficient.

"The other approach is from the point of view of serial correlation and was first investigated by Yule.§ A recent book by Wold\| presents a very extensive treatment of this interesting subject, which

\footnotetext{
${ }^{3}$ Gerhard Tintner, "The Analysis of Economic Time Series," Journal of the American Statistical Association, XXXV, March, 1940, pp. 95-96.

* "Student:" "The Elimination of Spurious Correlation Due to Position in Time or Space," Biometrika, X, 1914, pp. $179 \mathrm{ff}$. O. Anderson: Die Korrelationsrechnung in der Konjunkturforschung, Bonn, 1929, See also G. Tintner, The Variate Difference Method, Bloomington, Indiana, 1940.

$\dagger$ G. Tintner, op. cit., pp. 7, 106.

¥G. Tintner, op. cit., pp. 73 ff, 124 ff. See also: "On Tests of Significance in Time Series," Annals of Mathematical Statistics, X, 1939, pp. 139 ff.

$\S$ G. U. Yule: "Why Do We Sometimes Get Nonsense-Correlations Between Time Series," Journal of the Royal Statistical Society, Vol. 89, 1926, pp. $123 \mathrm{ff}$.

\|H. Wold: A Study in the Analysis of Stationary Time Series, Uppsala, 1938.
} 
is closely related to the investigation of differences and also to harmonic analysis. The practical statistical, as distinguished from the probability, aspect of this theory has been, however, very much neglected. It is still far from a solution which is reasonably satisfactory for the application of modern statistics to practical problems. The mathematical difficulties involved are very great.

"But even if the problem of separation of the non-random from the random part of the time series has been solved we are still left with a problem of an entirely different nature. It is often desired by economic statisticians to analyze the non-random part of economic time series further into its components. T The components which have been distinguished conventionally are: The seasonal with a period of twelve months, the business cycle with a period of between three and ten years, and the trend and longer waves with long periods. (Kondratieff.**) Several procedures have been proposed for the separation of those components. But the methods of analysis up to now seem not to be very satisfactory."

The use of Fourier series has been recommended for dealing with seasonal variation, ${ }^{4}$ but this method is not flexible enough to be used with most other less regular kinds of variation.

Other workers have dealt with the problem of homogeneity. "In analyzing poultry prices, the Division of Statistical and Historical Research has recently begun to test the variables used in correlation analyses for homogeneity. The test used is based on standard methods, but, so far as is known, little use of it has been made in testing agricultural time series. The variance of the means of groups of four consecutive time units in a time series is tested for homogeneity by the standard methods of analysis of variance. The variance of the standard deviations of these groups is tested by comparing the actual variance of the group standard deviations with the estimated variance, computed from the standard deviation of the sample as a whole. In each case the $F$ test is used to determine whether the group means and group standard deviations vary more

II W. C. Mitchell: Business Cycles, The Problem and Its Setting, New York, 1927. S. Kuznets: "Time Series" in Encyclopaedia of the Social Sciences, New York, 1935. J. A. Schumpeter: Business Cycles, New York, 1939, I, pp. 193 ff.

** N. D. Kondratieff: "The Long Waves in Economic Life," Review of Economic Statistics, XVII, 1935, pp. 105 ff.

"Alexander Sturges, "The Use of Fourier Series in the Analysis of Seasonal Variation," Report of Fifth Annual Research Conference on Economics and Statistics, held at Colorado Springs, Colorado, July 3-28, 1939, Univ. of Chicago, 1939. 
than would be expected by random sampling from a homogeneous population. In the poultry price work the method has been applied largely to time series which have been transformed into first difference logarithms. Production series appear to be more homogeneous than do price series, although there is much variation in results between the different variables for each type of series." 5

The most recent contribution to the solution of the problem of rendering economic time series amenable to statistical analysis has been made by an astronomer. ${ }^{6}$ He uses what he describes as the Bartels technique. His article may be summarized as follows:

If the items in a universe $u$ are independent of one another, the standard deviation of the means of random samples, each sample consisting of $h$ items, is:

In terms of variance:

$$
\begin{aligned}
\sigma(h) & =\frac{\sigma(u)}{\sqrt{ } h} \\
\sigma(h)^{2} & =\frac{\sigma(u)^{2}}{h}
\end{aligned}
$$

Then the ratio $r$

$$
r=\frac{h \sigma(h)^{2}}{\sigma(u)^{2}}
$$

should be constant and equal to unity if the sample is large enough. ${ }^{7}$ (The standard deviation of $u$ is not usually known, but the standard deviation of the largest possible sample is taken as the best approximation to it.)

If the items in a universe are not independent of one another, then as larger and larger samples are taken (as $h$ increases) the value of the ratio will stabilize at some figure greater than unity. The fact that stability is reached at some figure greater than unity shows that the items are not independent, and the figure at which the value of the ratio stabilizes shows how many items are required in order to eliminate the influence of the serial correlation on the standard deviation of the means of the samples.

Thus Yule's original "nonsense correlation" example covered

5 "Statistical News and Notes," Journal of the American Statistical Association, XXXIV, No. 205, March, 1939, p. 377.

'L. R. Hafstad, "On the Bartels Technique for Time-Series Analysis," Journal of the American Statistical Association, June, 1940, pp. 347-61.

${ }^{7}$ Using $\sigma(h)^{2}=\frac{\sigma(u)^{2}}{h}$ in equation (2) we obtain $r=\frac{h \sigma(u)^{2}}{h} / \sigma(u)^{2}=1$ 
forty-five years, for which by ordinary tests the correlation of 0.95 would be rated highly significant. But application of the procedure described above shows that the size of the sample required to bring the ratio to stability is about fifteen. The forty-five years, therefore, are equivalent only to three independent items; and for series as short as three a correlation coefficient of 0.95 is not significant.

The procedure just outlined has been published so recently that it has not been tested or criticized by other workers. No doubt that will come shortly. Meanwhile, one or two less technical observations may be made about economic time series. While change is the order of the day in economics, so that populations (of economic data) are not homogeneous, it is also true that some of these changes are gradual, not sudden; they are evolutionary, not revolutionary. Thus, while tractors and trucks have displaced half the horses and a quarter of the mules in the country since the time of World War I, the change did not take place all at once, but at the rate of only 1 or 2 per cent per year. Any forecasts which left this important and obvious change out of account would have been only 1 or 2 per cent wrong per year-and forecasts are not usually required to predict changes more than one or two, or at least only a few years ahead. When, as in this case, the direction and extent of a change can be foreseen for several years ahead, its influence can be taken into account. An analysis which includes all the factors that change in the future is really dealing with a homogeneous population. It is changes in factors that are not included in an analysis that change a population and render tests of significance unreliable for that reason. If the number of horses and mules are included as a factor in a price analysis, then (1) future changes in these numbers will not destroy the validity of the analysis, and (2) in this case at least the future changes in this factor can be forecast with some degree of accuracy.

Finally, it must be recognized that there are large random elements in economic data, particularly agricultural economic data. Crop production series meet the requirements for random data rather closely, in those cases where acreage does not change greatly from year to year, since yields fluctuate from year to year chiefly in response to changes in the weather, which are random in character. Fluctuations in demand may be cyclic rather than random in character, but that part of a statistical price analysis which deals with the relation between production and price is related to random changes 
(in yields) and therefore approaches the requirements for random data laid down earlier in this chapter, and is more nearly amenable to statistical analytical methods. ${ }^{8}$

The foregoing considerations mean that the significance of economic analyses depends, not so much upon objective statistical tests, as upon the conformity of the analysis with economic theory on the one hand and with the characteristics of the commodity concerned on the other. It is not sufficient for a price analyst to be familiar with economic theory and statistical methods, although that is indispensable; in addition, he must know a good deal about the particular commodity or service concerned.

\footnotetext{
${ }^{8}$ For useful observations on this subject, see Mordecai Ezekiel, Methods of Correlation Analysis, Wiley \& Sons, 1941, pp. 349-58.

A group of economists at the University of Chicago is attacking the problem from a new angle that looks promising, but their work has not yet been developed to the stage of general application.
} 


\section{CHAPTER 14}

\section{Parity Prices for Farm Products ${ }^{1}$}

Most of this book deals with the analysis of actual market prices. No book dealing with agricultural prices, however, would be complete without an analysis of those politico-economic prices known as "parity prices."

The roots of the present "parity price" concept lie chiefly in the events of the first World War and in the depression that immediately followed it.

During World War I, as Figure 52 shows, farm prices rose somewhat faster than other prices, but they also dropped faster and farther than other prices in 1920 and 1921. As a result of this drop in prices there was a great deal of agitation for some form of agricultural relief during 1921 and 1922. Almost without exception, the ideas and devices that were eventually written into the Agricultural Marketing Act of 1929, the Agricultural Adjustment Act of 1933, the Agricultural Marketing Agreement Act of 1937, and the Agricultural Adjustment Act of 1938 can be traced back to this general agitation for farm relief that was first started on a nationwide scale during 1921 and 1922.

Some of the agricultural organizations and farm journals in the Midwest were then asking for corn acreage control; groups throughout the country were considering the cooperative approach to controlling agricultural supplies and raising farm prices; and a great many of the farmers and their representatives were in favor of some kind of arrangement that would increase the export movement of our commodities and so shorten supplies in the domestic market.

${ }^{1}$ The descriptive material in this chapter is adapted from (1) Howard $R$. Tolley, chief of the BAE, USDA, Address before the National Cooperative Milk Producers Federation, Chicago, Ill., November 11, 1941; (2) Parity Prices: What They Are and How They Are Calculated. BAE, USDA, mimeo., June 30, 1942;

(3) Fats and Oils Situation, BAE, USDA, February, 1942, pp. 11 and 12.

This chapter originally appeared in Agricultural Price Control, The Iowa State College Press, 1945, by the present author. It is being replaced there in later editions by a briefer, less technical discussion. 
In 1921 George Peek and Hugh Johnson prepared their brief of "equality for agriculture" that was to serve as a basis for the McNary-Haugen fight from 1924 to 1928. In this brief the need for raising farm income was set forth, and the suggestion was made

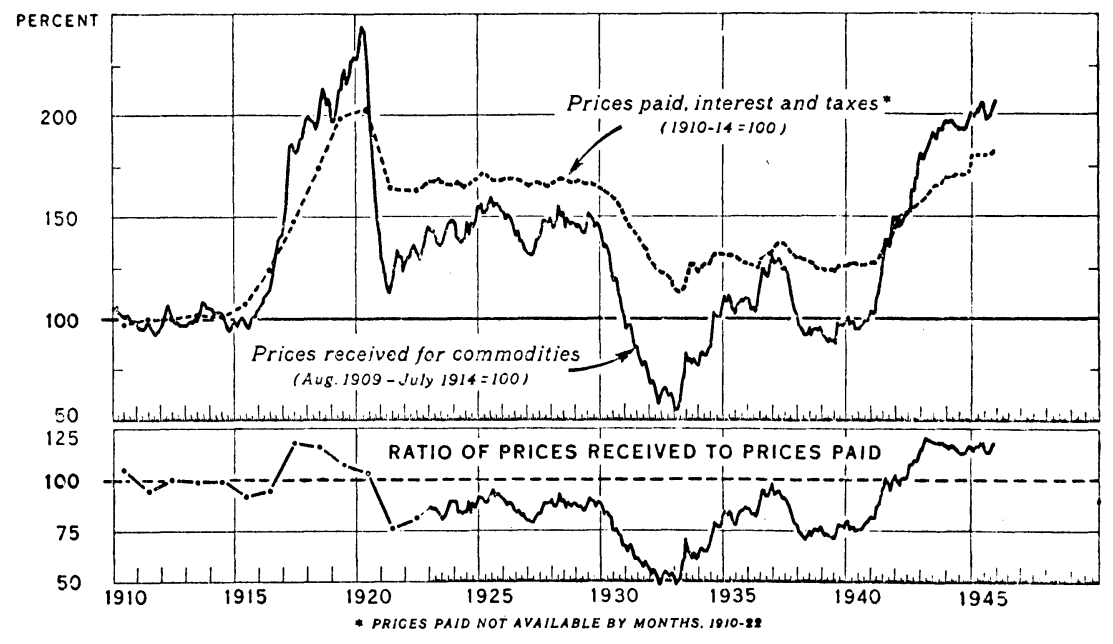

U. S. DEPARTMENT OF AGRICULTURE

NEg. 3ggas guaEaU OF AGRICULTURAL ECONGMics

FIg. 52.-Prices received and paid by farmers, index numbers, United States, $1910-45$.

that sufficient surpluses be diverted from the domestic market to maintain a "fair exchange value" or raise farm prices to the same relative level as existed in the ten years, 1906 to 1915 .

About this same time George Warren, who was in charge of agricultural economics at Cornell University for so long, came to Washington and worked out the index for farm prices that was presented in United States Department of Agriculture Bulletin 999. In developing this first index of prices paid to farmers-or, as the term is now used, of prices received by producers-the prices for the several commodities were indexed on the basis of the sixty months, August, 1909, through July, 1914.

The reasons for selecting these five years as a base were:

(1) A base prior to the outbreak of the war in 1914 was considered desirable, since it was believed that a reasonably normal relationship existed between the prices of the several commodities and between the returns to the several groups of producers in the period preceding the World War; and 
(2) Although prices of the chief agricultural commodities had been collected for December 1 of each year since the Civil War, the collection of prices on a monthly basis was started during 1909, so that monthly estimates of prices received by farmers were not available prior to 1909 .

These two reasons, then, very largely determined the base period that is now used in calculating parity prices and parity income-that is, the five years 1909 to 1914 .

\section{PARITY: EQUALITY WITH PURCHASING POWER IN 1909-14}

Warren also compared farm prices with all wholesale prices in order to obtain a rough measure of the purchasing power of farm products. A few sentences from his bulletin show the background of his thinking and the atmosphere of the times:

"Practically nothing that the farmer sells can be exchanged for the usual quantity of other things. It is physically impossible for farmers to absorb the products of factories. Farm prices have dropped much more than wholesale or retail prices of farm products. The low purchasing power of farm products has made it impossible for farmers to buy the normal amount of other things and has been a contributing cause of unemployment."

The comparison between prices received by farmers and all prices at wholesale was not, of course, an entirely satisfactory comparison. Farmers do not spend their money for goods at wholesale. Accordingly, Dr. O. C. Stine, with the help of some others in the Bureau of Agricultural Economics, worked out an index of prices paid by farmers in local markets for goods used in family living and production. This index was first published in 1928. Since that time, the comparison between prices received for the main agricultural commodities and this index of prices paid by farmers has been the generally accepted measure of the parity relationship.

Of course, a great many other ideas and devices for measuring economic equality between farmers and nonfarmers were advanced during this period. But the parity yardstick was finally accepted in 1933, because it measured off what seemed to be a fairly reasonable goal and could itself be definitely measured.

THE LEGAL BASIS OF PARITY

The original legal definition of parity is given in the Agricultural Adjustment Act of 1933, which declares that it is the policy of 
Congress, among other things, to "reestablish prices to farmers at a level that will give agricultural commodities a purchasing power with respect to articles that farmers buy, equivalent to the purchasing power of agricultural commodities in the base period. The base period in the case of all agricultural commodities except tobacco shall be the prewar period, August, 1909, to July, 1914. In the case of tobacco, the base period shall be the postwar period, August, 1919, to July, 1929."

While this formula has been amended and reenacted several times since 1933, it has not been essentially changed, except that allowances for interest payments per acre on farm indebtedness secured by real estate and tax payments per acre on farm real estate have been added to the purchasing power calculations for all commodities for which the base period is 1909 to 1914 , and the base period for Burley and flue-cured tobacco has been shifted to August, 1934, to July, 1939.

The current legal bases for calculating parity are found in Section 301 of the Agricultural Adjustment Act of 1938, as amended, and Sections 2 and 8 (e) of the Agricultural Marketing Agreement Act of 1937. Section 2 of the Agricultural Marketing Agreement Act is in effect a reenactment of the definition of parity prices as contained in the Agricultural Adjustment Act of 1933, as amended, which is the same essential definition as used in the Agricultural Adjustment Act of 1938, as amended. Section 8 (e) of the Agricultural Marketing Agreement Act of 1937 sets forth the procedure to be used when satisfactory data cannot be obtained for the base period, 1909 to 1914. It provides that "in connection with the making of any marketing agreement or the issuance of any order, if the Secretary finds and proclaims that, as to any commodity specified in such marketing agreement or order, the purchasing power during the base period specified for such commodity in Section 2 of this title cannot be satisfactorily determined from available statistics of the Department of Agriculture, the base period, for the purposes of such marketing agreement or order, shall be the postwar period, August, 1919, to July, 1929, or all that portion thereof for which the Secretary finds and proclaims that the purchasing power of such commodity can be satisfactorily determined from available statistics of the Department of Agriculture."

Other amendments also are of interest, but they supplement rather than change the original formula. Under the Agricultural 
Marketing Agreement Act of 1937 the Secretary is directed to consider "the price of feeds, the available supplies of feeds, and other economic conditions which affect market supply and demand" in determining prices for milk and its products in areas where marketing agreements are in effect.

In certain cases, the Congress has provided that "comparable prices" can be calculated which shall in effect be substituted for the parity prices as calculated according to the regular method. This authority is contained in the so-called "Steagall Amendment," or Sections 4 (a) and 4 (b) of Public No. 147, Seventy-seventh Congress, which read:

"(a) Whenever, during the existing emergency, the Secretary of Agriculture finds it necessary to encourage the expansion of production of any nonbasic agricultural commodity, he shall make public announcement thereof, and he shall so use the funds made available under Section Three of this Act or otherwise made available to him for the disposal of agricultural commodities, through a commodity loan, purchase, or other operation, taking into account the total funds available for such purpose for all commodities, so as to support a price for the producers of any such commodity with respect to which such announcement was made of not less than 85 per centum of the parity or comparable price therefor. The comparable price for any such commodity shall be determined and used by the Secretary for the purposes of this section if the production or consumption of such commodity has so changed in extent or character since the base period as to result in a price out of line with parity prices for basic commodities. Any such commodity loan, purchase, or other operation which is undertaken shall be continued until the Secretary has given sufficient public announcement to permit the producers of such commodity to make a readjustment in the production of the commodity. For the purposes of this section, commodities other than cotton, corn, wheat, tobacco, and rice shall be deemed to be nonbasic commodities.

"(b) It is hereby declared to be the policy of the Congress that the lending and purchase operations of the Department of Agriculture, other than those referred to in subsection (a), shall be carried out so as to bring the price and income of the producers of nonbasic commodities not covered by any such public announcement to a fair parity relationship with other commodities, to the extent that funds for such operations are available after taking into 
account the operations with respect to the basic commodities and the commodities listed in any such public announcement and the ability of producers to bring supplies into line with demand."

\section{DETERMINATION OF COMPARABLE PRICES}

So far, the only commodities for which comparable prices have been calculated are soybeans, peanuts for oil, and dry field peas, all of which are commodities which have come into general use since 1929. The method used in determining comparable prices for these three commodities is based upon the calculation of a series of base prices which "bear the same relation to the average base prices of corn, cotton, wheat, rice, and tobacco as the actual prices of the same commodities were to the average actual prices of these five basic commodities in the sixty months, August, 1934, through July, 1939."

In keeping with the language of Section 4 of Public Law No. 147, Seventy-seventh Congress, base prices from which comparable prices for soybeans and peanuts for oil may be computed currently were determined by dividing the average price for each commodity in the period, August, 1934, to July, 1939, by two factors: (a) The average percentage ratio of prices for the five basic agricultural commodities to their parity prices in that period, and (b) the average index number of prices paid by farmers for commodities purchased, including interest and tax payments $(1910-14=100)$. Average prices for the five basic commodities were equal to 79 per cent of the parity prices for those commodities in the period, August, 1934, to July, 1939, ${ }^{2}$ while the index number of prices paid, including interest and taxes, averaged 129. These two factors were combined (.79 and 1.29) to give a single divisor of 1.02 .

Dividing the average price of the given commodity by 0.79 raises the price, in effect, to a fair parity relationship with the parity prices for the basic commodities in the 1934-39 period. Dividing by 1.29 merely translates the adjusted price back to the prewar, 1910-14, base period.

The calculation of comparable prices currently from the 1910-14 base price is the same as the calculation of parity prices for most

\footnotetext{
${ }^{2}$ The figure of 79 per cent is obtained by weighting the actual prices and the parity prices of the basic commodities (corn, wheat, cotton, rice, and tobacco) in the 1934-39 period by the average production of these commodities in the same period. The weighted aggregate of the actual prices was divided by the weighted aggregate of the parity prices.
} 
commodities. That is, the $1910-14$ base price is multiplied by the current index number of prices paid by farmers for commodities purchased, including interest and tax payments. In mid-January, 1945 , this index number was 172 , or 72 per cent higher than in the 1910-14 period.

The five years, August, 1934, to July, 1939, were selected for determining the base prices for peanuts for oil and soybeans mainly because prices in that period represent as nearly as possible the normal relationships among prices of the commodities involved under conditions of production and consumption recently existing. This period antedates the recent world conflict and coincides with the most recent base period selected by Congress for use in making parity price computations (flue-cured and Burley tobacco).

The basic data, method of computation, and results for soybeans for January, 1945, are shown in Table 22.

TABLE 22

Soybeans: Average Price per Bushel Received by Farmers, August, 1934-July, 1939, and January, 1945, Base Price, and Comparable Prices in January, 1945

\begin{tabular}{c|c|c|c}
\hline \hline$(1)$ & $(2)$ & $(3)$ & $(4)$ \\
\hline $\begin{array}{c}\text { Average Price, } \\
\text { August, 1934- } \\
\text { July, 1939 }\end{array}$ & $\begin{array}{c}\text { Base Price, } \\
(1) \div 1.02^{*}\end{array}$ & $\begin{array}{c}\text { Comparable Price, } \\
\text { January 15, 1945 } \\
(2) \times 1.72 \dagger\end{array}$ & $\begin{array}{c}\text { Actual Price, } \\
\text { January 15, 1945 }\end{array}$ \\
\hline 0.98 & 0.96 & 1.65 & 2.06 \\
\hline
\end{tabular}

Columns (1) and (4), Agricultural Marketing Service and Surplus Marketing Administration. Columns (2) and (3) computed.

* The divisor, 1.02 , is obtained by multiplying the 1934-39 average ratio of prices received by farmers for the five basic commodities to parity prices for the five basic commodities (weighted aggregates, using production weights) by the average index number of prices paid by farmers, including interest and taxes, in the same period $(1910-14=1.00)$. The computation is as follows: $0.79 \times 1.29=1.02$.

$\dagger$ The factor, 1.72, is the index number of prices paid by farmers, including interest and taxes, for January 15, $1945(1910-14=1.00)$.

\section{PARITY PRICES ARE FARM PRICES}

Parity prices are calculated in terms of prices received by farmers in the local markets in which they ordinarily sell. This means that parity prices apply to the average of all classes and grades of the commodity as sold by all farmers in the United States, except as otherwise specified. Fruits and vegetables for fresh use and for pro- 
cessing are usually considered as separate commodities, and special parities are sometimes calculated for commodities produced in certain areas where such commodities are covered by a marketing agreement or order program.

Where necessary, of course, average or normal differentials for different varieties, classes, or grades of a commodity and average or normal spreads between different markets, methods of sale, or locations can be calculated and applied to the average parity price for the nation. These spreads or differentials, however, should not themselves be considered parities, as they will often need adjusting or recalculating due to changes in methods of processing, in marketing and transportation costs, and in the distribution of supplies relative to demand. Parity prices also may be corrected for seasonal differences, especially where there is a reasonably regular and well defined seasonal movement.

Grade and location differentials are worked out and used in connection with almost all commodity loans made by the Commodity Credit Corporation, as well as in connection with most of the pricesupport programs under Section 4 (a) of Public No. 147, Seventyseventh Congress.

Beef cattle prices by grades at the farm are not available. The different grades cover a wide range of values, so the regular parity price, representing the average price of all classes and grades at the farm, is unsatisfactory for comparison with the actual prices received for the various classes and grades of cattle sold at the terminal markets. The Department of Agriculture, therefore, computes and publishes each month in "Agricultural Prices" a series of parity price equivalents for the several classes and grades of beef cattle at Chicago.

These parity price equivalents are computed by multiplying the regular parity price each month by the appropriate ratio for each class and grade of cattle. These ratios are the ratios of the annual and monthly market prices by classes and grades at Chicago, to the United States average prices received by farmers for beef cattle, over the twenty-year period, January, 1922, to December, 1941. These ratios are shown in Table 23. The Chicago market equivalent of parity prices, by grades, for any month can be computed by multiplying the regular parity price for that month by the ratio for the corresponding month shown in the table for the grade concerned.

Different ratios are used for the separate classes and grades of 
TABLE 23

Ratio of Cattle Prices at Chicago and Average Cost to Packers to the United States Average Price Received By Farmers for Beef Cattle, 1922-41 Average by Months for Selected Glasses and Grades*

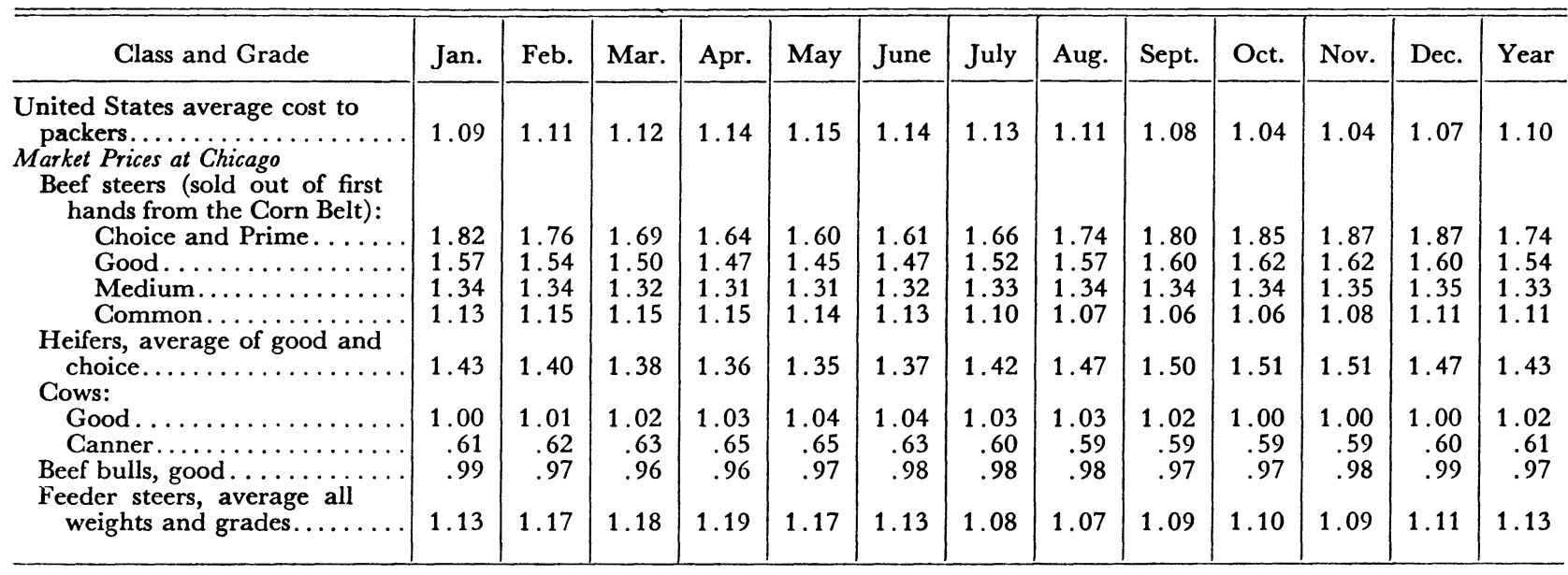

Source: The Livestock Situation, BAE, USDA, April, 1942, p. 16.

* Based on the 3-month moving averages of ratios of 1922-41 average prices. 
cattle in each month of the year. This is necessary because the relationship of the prices of the several classes and grades to the average price received by farmers fluctuates in a more or less regular fashion from season to season each year. The 1922-41 average ratios shown in this table are indicative of the usual seasonal relationships between prices of the several classes and grades of cattle sold by farmers throughout the year.

It should be emphasized that the basis for the official parity price for beef cattle is still the United States average price received by farmers; it will be compiled and published in the future as it has been in the past. The concept of parity refers only to prices received by farmers at local markets. The figures computed by the use of the ratios given in Table 23 are not parity prices by classes and grades of beef cattle, but are the average or normal equivalents of parity for the specified classes and grades of beef cattle marketed at Chicago. These market equivalents are subject to revision as additional data become available, or whenever it appears that marketing conditions have changed substantially.

The published parity prices for eggs, butterfat, and wholesale milk are corrected for seasonal variation. This is done by multiplying the 1909-14 base price by the index of prices paid, including taxes and interest, and then multiplying the resulting parity price by the appropriate seasonal factor for the particular month. These factors, as well as seasonal indexes for a considerable number of other agricultural commodities, originally given in the Midmonth Local Market Price Report for May 15, 1942, are reproduced in Table 24.

\section{THE COMPUTATION OF THE INDEX OF PRICES PAID BY FARMERS}

Parity prices, therefore, are based upon two things: (1) the price of the farm product during the base period, in most cases, 1909-14, and (2) the current index of the prices paid by farmers. The method of computing the prices of farm products was explained above. The index of the prices paid by farmers is computed as follows:

The index of prices paid by farmers, including taxes on real estate and interest paid, is calculated currently each month. It includes the prices of eighty-six items used in family living and ninetyfour items used in farm production. These items include clothing; household supplies; food; furniture and furnishings; building materials; automobiles, trucks, tractors, gas, oil, and tires; feed; farm 
TABLE 24

Index Numbers of Seasonal Variation in United States Average Farm Produgt Prices, * Calbndar Years, 1922-41

\begin{tabular}{|c|c|c|c|c|c|c|c|c|c|c|c|c|c|}
\hline Commodity & Jan. & Feb. & Mar. & Apr. & May & June & July & Aug. & Sept. & Oct. & Nov. & Dec. & Ave. \\
\hline Wed & 82.4 & 02.4 & $0<.7$ & 02.8 & & 9.9 & 7.2 & .0 & 0.9 & .8 & 8.0 & 100.5 & .0 \\
\hline & 92.3 & 4.0 & 5.3 & 98.4 & 103.0 & 105.5 & 109.9 & 111.8 & 110.0 & 8.2 & 90.6 & 91.0 & 100.0 \\
\hline - & 102.5 & 104.2 & 104.2 & 105.0 & 105.4 & 102.5 & 100.2 & 92.1 & 93.7 & 93.9 & 96.2 & 100.1 & 100.0 \\
\hline ey & 102.3 & 103.2 & 103.7 & 104.2 & 104.3 & 93.9 & 95.0 & 97.1 & 98.0 & 98.6 & 98.9 & 100.8 & 100.0 \\
\hline wh & 95.0 & 96.1 & 98.0 & 99.1 & 102.0 & 105.7 & 109.5 & 107.7 & 103.8 & 95.3 & 93.5 & 94.3 & 100.6 \\
\hline eed & 102.4 & 102.4 & 102.4 & 103.0 & 103.0 & 99.6 & 99.4 & 97.3 & 97.0 & 97.0 & 97.2 & 99.3 & 100.0 \\
\hline (1) & 100.4 & 100.6 & 101.0 & 101.9 & 103.1 & 103.6 & 102.5 & 98.0 & 95.4 & 95.5 & 98.6 & 99.4 & 100.0 \\
\hline Jo & 97.7 & 98.8 & 100.4 & 100.4 & 101.7 & 101.9 & 104.5 & 102.0 & 101.6 & 97.8 & 97.2 & 96.0 & 100.0 \\
\hline$d$ & 99.0 & 100.5 & 102.2 & 104.5 & 106.0 & 103.1 & 100.6 & 94.8 & 95.6 & 96.0 & 98.8 & 98.9 & 100.0 \\
\hline & 96.7 & 98.4 & 100.2 & 102.5 & 102.9 & 103.1 & 113.6 & 113.5 & 97.1 & 87.9 & 91.2 & 92.9 & 100.0 \\
\hline & 89.3 & 95.2 & 100.2 & 104.3 & 108.2 & 10 & 110.7 & 121.6 & 105.8 & 90.3 & 80.7 & 84.4 & 100.0 \\
\hline & 9 & 98.4 & 101.9 & 102.7 & 105.1 & 104.9 & 103.9 & 103.8 & 102.3 & 95.1 & 94.8 & 91.9 & 10 \\
\hline & 98 & 103 & 105.7 & 110.0 & 11 & 12 & 110.1 & 88.0 & 81.5 & 0 & 0 & 92.2 & 10 \\
\hline & 10 & 10 & 10 & 102 & 10 & 100.2 & 9 & & 97.5 & .7 & 99.5 & 100.5 & 1 \\
\hline & 1 & 102 & 9 & 96 & 9 & 90 & 93 & 9 & 101.7 & 10 & 108.2 & 10 & 10 \\
\hline & & 9 & 10 & 10 & 10 & 103 & 103 & 10 & 101.3 & & 2 & .4 & 1 \\
\hline & 105 & 10 & 1 & 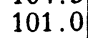 & & 9 & 9 & & 9 & 9 & 108.4 & 111.3 & \\
\hline & 94.2 & 98 & 1 & 10 & 9 & 97 & 10 & 10 & 11 & 1 & 94.7 & & \\
\hline & 97.5 & 98 & 101.5 & 103 & 10 & 102 & 102.2 & 10 & 10 & 2 & 8 & & \\
\hline & 101.1 & 103.9 & 103 & 100.3 & 98 & 97.3 & 97.7 & 98 & 102.9 & 101.9 & 2 & 2 & 10 \\
\hline & 99.1 & 102.2 & 105 & 106.4 & 10 & 10 & 99.7 & 95.6 & 95.9 & & & & 10 \\
\hline מ & 102.8 & 103.1 & 104.9 & 109.9 & 114 & 10 & 100.3 & 90.2 & 90.2 & & & & \\
\hline nol & 105.9 & 102.7 & 98.4 & 93.8 & & 89 & 93.0 & 98.0 & 103.0 & 106.7 & 110.1 & 10 & \\
\hline ry & 96.1 & 97.4 & 98.7 & 100.0 & 103.0 & 103.7 & 104.1 & 104.1 & 102.5 & 98.2 & 96.8 & & \\
\hline$y$ & 102.7 & 103.0 & 102.7 & 101.7 & 101.6 & 98.2 & 97.2 & 95.8 & 97.6 & 98.4 & & & 100.0 \\
\hline & 101.2 & 101.0 & 100.7 & 98.5 & 98. & 98.0 & 99.0 & 99.0 & 100.0 & 101.0 & 101.4 & & 100.0 \\
\hline & 103.9 & 102.5 & 101.5 & 99 & 94 & 91 & 93 & & 99.4 & & 106.2 & & 100.0 \\
\hline $\mathrm{Eg}$ & 95.0 & 88.0 & 82.0 & 82.0 & 82 & 79 & 90 & 9 & 114 & & 14 & 12 & 100.0 \\
\hline 0 & 101.0 & 92.0 & 84.0 & 84.0 & 85. & 86.0 & 93.0 & 98.0 & 110.0 & 119.0 & 128.0 & 120.0 & 100.0 \\
\hline
\end{tabular}

Source: Bureau of Agricultural Economics.

* Average of ratios to 12-month moving average centered, adjusted to add to 1,200 and to eliminate abnormal fluctuations.

+ Based on 1931-41, monthly prices not available for earlier years.

$\ddagger$ Based on 1924-41, monthly prices not available for earlier years.

$\$$ Weighted average price of milk, wholesale, and milk equivalent price of butter and butterfat.

Based on 1934-41, monthly data not available for earlier years.

B Based on 1937-41.

** These index numbers apply only to 1942 since a moving seasonal is used for eggs to take account of changes in the conditions affecting the seasonal movement of egg prices.

†† For July, 1944 to June, 1945, as published in Agricultural Prices, September, 1944, p. 23. 
machinery; fertilizer; general equipment and supplies; at seed. The estimated quantity of each commodity used by farments used to weight both the prices paid in 1910-14 and current priees, in order to obtain the necessary ratios of indexes of prices paid. The tax and interest data are calculated as rates per acre and converted into index form.

There are now about ten thousand dealers in agricultural products reporting to the Department the current prices paid to producers (that is, received by farmers). Similarly, approximately fourteen thousand local merchants servicing the farm population report retail prices in rural areas which are the chief bases of the prices paid by farmers, although some other sources also are used.

Briefly, the steps in computing this index of prices paid, interest, and taxes, are as follows.

(a) The prices paid for individual commodities are averaged by states and then weighted together by the estimated purchases made by farmers in each state to obtain an average for the nation.

(b) National average prices are combined into various subindexes-food, clothing, feed, etc.-by giving each item a weight based upon the average quantity purchased per farm during the six years, 1924-29. The sub-group values or aggregates thus obtained are then expressed as a percentage of the values or aggregates for the same commodities during the base period, 1910-14.

(c) The sub-indexes are then combined into an index of prices paid for commodities used for family living and an index of prices paid for commodities used in farm production. These two indexes are then combined into a single over-all index of prices paid by farmers by weighting each according to its relative importance with regard to farm expenditures during the six years, 1924-29.

(d) The index of prices paid by farmers for commodities is combined with interest per acre on mortgage indebtedness secured by farm real estate and taxes per acre on farm real estate, to obtain the index of prices paid, interest and taxes, by giving prices paid for commodities a weight of 86 per cent, interest 7.2 per cent, and taxes 6.8 per cent. The 86 per cent allotted to the prices-paid index is distributed as follows: commodities used for family living, 48.6 per cent (food, 17.5; clothing, 14.8; supplies, 6.8; furniture and furnishings, 2.9; building materials for house, 3.6; and automobiles, 3.0), and commodities used for farm production, 37.4 per cent (feed, 10.1; machinery, 4.2; autos and trucks, 4.5; tractors, 1.2; fertilizer, 3.2; 
building and fencing materials, 5.9; equipment and supplies, 6.9 ; and seed 1.4).

It will be noted that this index of prices paid by farmers does not include any allowance for sums spent for farm labor. During 1942 parity prices would have been raised about three points if an allowance for wage rates had been included. Wages cannot be included without a legislative amendment.

\section{THE CALCULATION OF CURRENT PARITY PRICES}

The first step in calculating the parity price for a farm product is to look up the average price of that product in the base period (in most cases, August, 1909, to July, 1914). This price is published in the monthly mimeographed BAE report, "Agricultural Prices." The price of wheat during this base period, for example, is given as 88.4 cents per bushel.

The next step is to look up the current index of the prices paid by farmers. This is given in the same publication. The base price of the product then is multiplied by this current index of prices paid. If the index of prices paid stands at 200 , that means that prices paid by farmers are twice as high as they were in the base period 1910-14. In that situation, the parity price for wheat would be $88.4 \times 200=176.8$ 100

cents per bushel. That is, wheat prices, in order to give wheat the same purchasing power as it had in 1909-14, would have to be twice as high as they were in 1909-14.

Parity prices have been calculated and published for 164 items, of which only 61 remain on the 1909-14 prewar base. Nearly onehalf of the items have bases in the 1919-29 period. However, those items which remain on the original base account for about fourfifth of the cash income to farmers. ${ }^{3}$

For several commodities, chiefly fruits and vegetables, which have only recently come into general use or for which earlier data are not available, the base period is August, 1919, to July, 1929, while for Burley and flue-cured tobacco, as mentioned above, the base period is August, 1934, to July, 1939. Parity for these commodities is calculated in exactly the same manner as for other commodities, except that allowances for interest and taxes are not included.

Parity prices calculated according to this formula are published

${ }^{3}$ O. C. Stine, "Parity Prices," Journal of Farm Economics, XXVIII, No. 1, February, 1946, p. 303. 
TABLE 25

Untred States Party and Comparable Prices for farm Products and Actual Prices Regetved Expressed as a Percentage of Partty, and Comparable, January 15, 1945, With Comparisons*

\begin{tabular}{|c|c|c|c|c|c|c|c|c|}
\hline \multirow{2}{*}{\multicolumn{2}{|c|}{ Commodity and Unit }} & \multirow{2}{*}{$\begin{array}{c}\text { Average } \\
\text { Base Period } \\
\text { Prices } \\
\text { Aug., } 1909 \\
\text { July, 1914 }\end{array}$} & \multicolumn{3}{|c|}{ Parity or Comparable Prices } & \multicolumn{3}{|c|}{$\begin{array}{l}\text { Actual Prices as a Percentage } \\
\text { of Parity or Comparable } \dagger\end{array}$} \\
\hline & & & $\underset{1944}{\text { Jan. } 15, \ddagger}$ & $\begin{array}{l}\text { Dec. 15, } \\
1944\end{array}$ & $\underset{1945}{\operatorname{Jan} .15}$ & $\underset{1944}{\operatorname{Jan} .15, \ddagger}$ & $\begin{array}{l}\text { Dec. 15, } \\
1944\end{array}$ & $\underset{1945}{\text { Jan. 15, }}$ \\
\hline 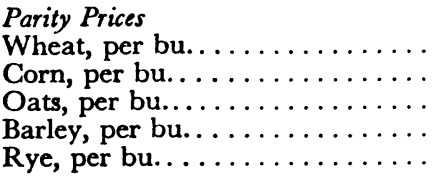 & $\begin{array}{c}\text { dollars } \\
" 6 \\
" 6 \\
"\end{array}$ & $\begin{array}{l}.884 \\
.642 \\
.399 \\
.619 \\
.720\end{array}$ & $\begin{array}{l}1.49 \\
1.08 \\
.670 \\
1.04 \\
1.21\end{array}$ & $\begin{array}{l}1.51 \\
1.10 \\
.682 \\
1.06 \\
1.23\end{array}$ & $\begin{array}{l}1.52 \\
1.10 \\
.686 \\
1.06 \\
1.24\end{array}$ & $\begin{array}{r}98 \\
105 \\
116 \\
104\end{array}$ & $\begin{array}{r}96 \\
96 \\
102 \\
93 \\
86\end{array}$ & $\begin{array}{r}96 \\
97 \\
105 \\
96\end{array}$ \\
\hline 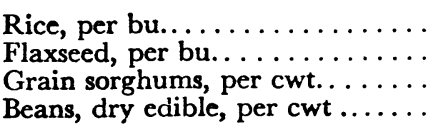 & $\begin{array}{l}\text { "6 } \\
\text { " }\end{array}$ & $\begin{array}{l}.813 \\
1.69 \\
1.21 \\
3.37\end{array}$ & $\begin{array}{l}1.37 \\
2.84 \\
2.03 \\
5.66\end{array}$ & $\begin{array}{l}1.39 \\
2.89 \\
2.07 \\
5.76\end{array}$ & $\begin{array}{l}1.40 \\
2.91 \\
2.08 \\
5.80\end{array}$ & $\begin{array}{l}137 \\
101 \\
107\end{array}$ & $\begin{array}{r}126 \\
100 \\
70 \\
108\end{array}$ & $\begin{array}{r}125 \\
75 \\
107\end{array}$ \\
\hline 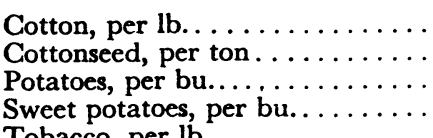 & $\begin{array}{l}\text { cents } \\
\text { dollars } \\
\text { "، }\end{array}$ & $\begin{array}{r}12.4 \\
22.55 \\
1.12 \S \\
.878\end{array}$ & $\begin{array}{r}20.83 \\
37.90 \\
1.22 \\
1.48\end{array}$ & $\begin{array}{r}21.20 \\
38.60 \\
1.24 \\
1.50\end{array}$ & $\begin{array}{r}21.33 \\
38.80 \\
1.25 \\
1.51\end{array}$ & $\begin{array}{l}97 \\
1136 \\
136\end{array}$ & $\begin{array}{r}98 \\
138 \\
121 \\
117\end{array}$ & $\begin{array}{l}95 \\
126 \\
126\end{array}$ \\
\hline 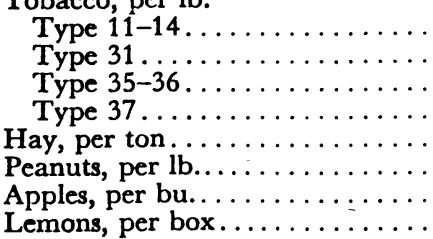 & $\begin{array}{l}\text { cents } \\
" ، \\
" ، \\
\text { dollars } \\
\text { cents } \\
\text { dollars } \\
\text { " }\end{array}$ & $\begin{array}{l}22.9 \\
22.2 \\
10.98 \\
14.68 \\
11.87 \\
4.8 \\
.96 \\
2.028\end{array}$ & $\begin{array}{l}31.8 \\
30.9 \\
11.9 \\
15.9 \\
19.90 \\
8.06 \\
1.61 \\
2.20\end{array}$ & $\begin{array}{r}32.5 \\
31.5 \\
12.1 \\
16.2 \\
20.30 \\
8.21 \\
1.64 \\
2.24\end{array}$ & $\begin{array}{l}32.7 \\
31.7 \\
12.2 \\
16.4 \\
20.40 \\
8.26 \\
1.65 \\
2.26\end{array}$ & $\begin{array}{r}147 \\
226 \\
222 \\
79 \\
89 \\
170 \\
106\end{array}$ & $\begin{array}{r}135 \\
142 \\
199 \\
160 \\
81 \\
99 \\
142 \\
124\end{array}$ & $\begin{array}{r}143 \\
184 \\
195 \\
84 \\
99 \\
149 \\
85\end{array}$ \\
\hline 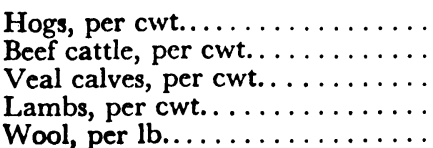 & $\begin{array}{c}" 6 \\
" ، \\
\text { cents }\end{array}$ & $\begin{array}{l}7.27 \\
5.42 \\
6.75 \\
5.88 \\
18.3\end{array}$ & $\begin{array}{r}12.20 \\
9.11 \\
11.30 \\
9.88 \\
30.7\end{array}$ & $\begin{array}{l}12.40 \\
9.27 \\
11.50 \\
10.10 \\
31.3\end{array}$ & $\begin{array}{r}12.50 \\
9.32 \\
11.60 \\
10.10 \\
31.5\end{array}$ & $\begin{array}{l}105 \\
123 \\
112 \\
127\end{array}$ & $\begin{array}{l}108 \\
124 \\
112 \\
123 \\
129\end{array}$ & $\begin{array}{l}111 \\
126 \\
114 \\
129\end{array}$ \\
\hline
\end{tabular}


TABLE 25-continued

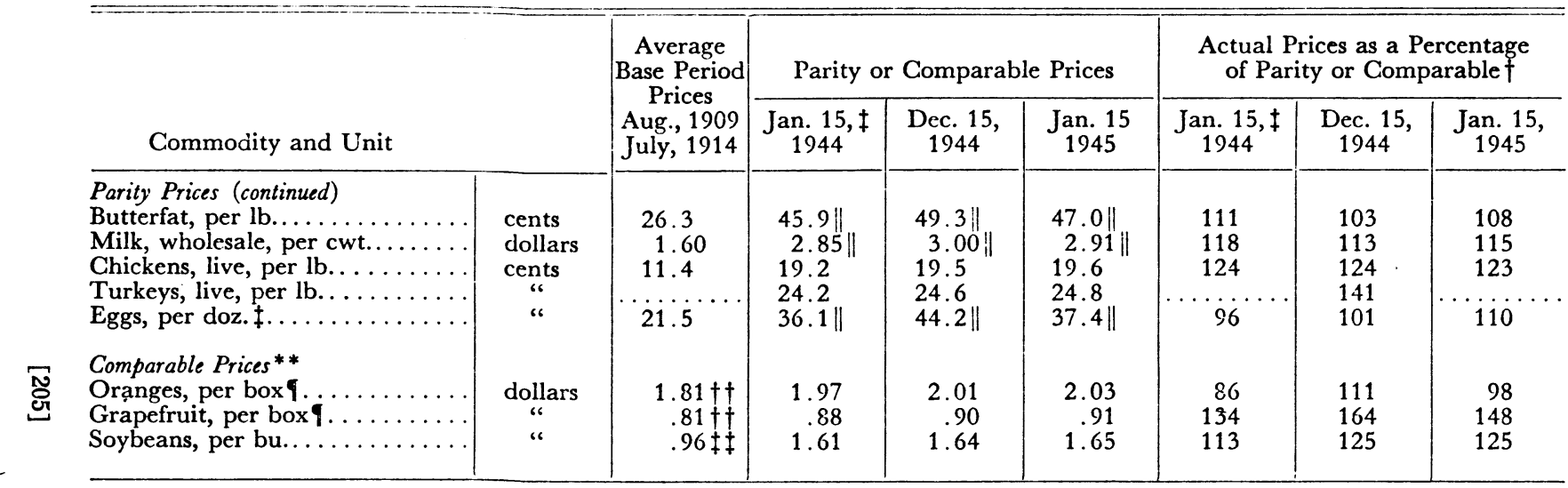

* Based on local market prices; does not include conservation, parity, dairy, production, or other Government payments made direct.

$\dagger$ Percentages of parity not shown for commodities, other than cotton, for which sales do not amount to as much as 5 per cent of the season's total in a given month.

$\ddagger$ Revised.

Ten-season average, 1919-28.

Equivalent on-tree returns for all methods on sale.

Adjusted for seasonal variation.

** Computed under Section 3(b) of Price Control Act.

$\dagger \dagger$ Derived base period price, 1919-29.

$\ddagger \ddagger$ Derived base price. 
every month in the BAE report, "Agricultural Prices," which also carries prices received by farmers on the fifteenth of the month. A typical table from that report is reproduced herewith, in Table 25, showing the data for January 15, 1945. The "parity index" (the index of the prices paid by farmers) on that date was 172 . 


\section{CHAPTER 15}

\section{Appraisal of Parity Prices}

For the first few years after the parity principle was developed, it was used only as a yardstick to measure how well off or badly off agriculture was, or as a general objective for agriculture. But in the Agricultural Adjustment Act of 1938, certain percentages of parity were written into law as the ranges within which the CCC was directed to set its loan rates on the "basic" commodities. In 1941 these ranges were replaced by a single figure, 85 per cent of parity, and the same percentage was prescribed for the price floors for nonbasic products. During the war, these percentages were increased to 90 per cent. Price ceilings that would result in prices for farm products below parity were also prohibited by law. And farm products acquired by the federal government may not be sold at less than parity prices.

Under present legislation, the prices of farm products ${ }^{1}$ are to be supported at not less than 90 per cent of parity ( 92.5 per cent in the case of cotton) for two full calendar years after the end of World War II has been formally proclaimed. Carrying this program through could easily involve losses or expenditures of a billion dollars or more.

Parity thus has become very important. It involves hundreds of millions of dollars in CCC loans, directly affects the incomes of farmers, and indirectly affects the nation as a whole. It is essential, therefore, that parity be given a careful appraisal commensurate with its importance.

This appraisal is offered below in two parts. First, an appraisal by H. R. Tolley, formerly chief of the Bureau of Agricultural Economics, well balanced but necessarily circumscribed by the circumstances of his position, is reproduced verbatim. Second, an appraisal of our own follows.

${ }^{1}$ Not all farm products, but products which amount to about two-thirds of the total value of agricultural production. 


\section{BAE APPRAISAL OF PARITY ${ }^{2}$}

"The current parity formula does not attempt to measure cost of production in any of the usually accepted senses in which that term is used. Nor does the current parity formula endeavor to give farm and nonfarm families an equal standard of living. Instead, so far as it applies to standards of living, it is devised to give farm families an income that has the same relative purchasing power when compared with the incomes of nonfarm families as existed in the base period 1910-1914.

"There are, it might be noted, several distinct advantages that attach to the current method. To begin with, it is generally accepted among a surprising number of people-among farmers, consumers, administrative officials of the government, and legislators. This is an advantage that cannot be brushed aside or easily overlooked. After all, a method that has developed through almost two decades of controversy has proved its merit. There should be a strong case against it, before a suggestion that it be materially changed is really in order. Second, agricultural prices as a whole were at a relatively higher level as compared with nonagricultural prices during the five years preceding World War I than at any other time since the short war period, 1916 through 1918. This means that efforts to raise parity prices must either lead toward different base periods for different commodities or to a shift toward a substantially different method. And third, statistics for determining parity prices as they are now calculated are fairly easily available and, for the most part, are reasonably adequate. Some of the proposals now being discussed would either require statistics that are not now available, or would involve the use of statistics and methods that are none too logical. I am not saying this in an effort to prove that agricultural prices and farm returns were satisfactory in 1910 to 1914, but only to indicate some of the factors that must be considered if a shift is seriously proposed.

"There are, of course, any number of proposals for shifting the whole concept and method of calculation. Perhaps the best way to consider these proposals is to outline certain classes of approaches rather than to try to consider any specific proposal as such. There is always a tendency for the suggestions developed by different indi-

${ }^{2}$ Agriculture and the Parity Yardstick, by H. R. Tolley; address before the National Cooperative Milk Producers Federation, Chicago, Ill., November 11, 1941, BAE, USDA, pp. 7-10. 
viduals and different groups to fall within a relatively small number of classes, even though each suggestion does have its own identifying differences and does become associated with some different group or background.

"One series of current suggestions proposes that the present parity method be replaced by a cost of production approach. As I have already indicated, this is one of the oldest suggested ways for measuring equality or fair returns for agriculture. So far, the cost of production proposals have always led to differences when the particular methods of calculating costs are discussed. That is, as an abstract proposal, the cost-of-production concept seems logical and is easily argued. But as a concrete proposal, it raises so many questions of judgment with respect to values to be placed on the labor of the farmer and his family and on farm land and equipment, and profits to be allowed, that it has generally been passed over whenever the effort was to work out a practical or administrable approach.

"A second series of suggestions proposes that the comparisons between farm and nonfarm prices be shifted to some other basis, or that some other index be substituted for the current index of prices paid. For the most part, these suggestions would take specially computed indexes for a commodity or type of farming, or some other economic index that would give a higher parity level than is provided by the index now being used. Proposals that special indexes be used for each of the important agricultural commodities, or for each of the important agricultural regions or types of farming, have considerable merit. As you all realize, it can very well be argued that a national index of prices paid, interest, and taxes is not the best index to use in comparing prices for milk with the cash costs of dairy farmers in the Northeast or the Midwest, or in the milkshed of some particular city like San Francisco or Detroit. But the statistical task of determining a whole series of regional or commodity indexes, and the arguments that would be raised along the route, make this approach difficult. And proposals simply to shift the basis for comparison away from the index of prices paid to some more favorable general index are, of course, always open to question, unless the new index better measures prices paid by farmers than does the current index.

"Another series of suggestions would require that the current parity prices for all commodities be redetermined in such a manner as to modernize the relations between prices received for each of the several commodities and yet leave the average level of parity prices 
unchanged. This proposal, you understand, would say to consumers that the average parity price level for all commodities would remain unchanged, but in order to distribute more equitably the costs and benefits of the farm program, the parity prices for each of the individual commodities will be recalculated in such a way that all of them will be equally close to or equally far below the parity level. It is usually suggested that the price relations prevailing during 1934-1939 be used. Considered as an abstract suggestion, this proposal has merit. But you all will recognize that, practically, it would mean that parity prices of about one-half of the commodities would be raised above the present parity level and the parity prices for the other half would be lowered. The one-half of the farmers whose parity prices were raised would, of course, not seriously object, but the other half of the farmers would be almost certain to raise a big question, if not a big howl.

"And finally, there is a series of suggestions that assumes that farmers should obtain the same absolute income in dollars per capita or per family as nonfarmers, or at least a considerably greater relative income per capita than is provided by the definitions of agricultural prices and income carried in current farm legislation. Some of these suggestions ask that a weight of as much as 50 per cent be given to wage indexes of industrial and other nonfarm workers, while others assume that parity income should give farmers an absolute dollar income equal to one-half or two-thirds or the same total dollar income as is received per capita by the nonagricultural group. The proposal to use a wage index along with the prices-paid index has certain drawbacks. As far as prices paid by farmers are concerned, the wages of industrial labor are necessarily included in the prices paid for processed food or farm machinery or cotton clothing or whatever else is bought. As a result, this aspect of the wage situation is already measured in the prices-paid index. On the other hand, if it is argued that the wage indexes are used to measure the income that farmers should have available for family living and for savings, it would seem more appropriate to use average income per capita of the entire nonagricultural group than to use industrial wage rates or even weekly or monthly earnings of industrial workers, since the parity concept or principle should measure the differences between farmers and nonfarmers, rather than differences between farmers and some special classes or groups in the nonagricultural field. As for the proposals to give farmers some specified or 
relative income, they often fall in much the same class as the cost of production proposals, as well as bring up the question of whether dollar incomes of farmers and nonfarmers can be directly compared.

"In conclusion, I should like to point out that the welfare of farm people is dependent upon many other things besides parity prices and the methods by which they are calculated. Parity income and parity prices are important, of course, but they serve only as standards against which to measure prices and incomes received from commercial sales by all farmers. There are many other ways by which farm standards of living can be improved. The whole parity price and income concept, for example, has little bearing on the incomes and standards of living of that 50 per cent of the farm population who operate very small farms or who work as farm laborers and who account for not more than 15 or 20 per cent of our total farm production. There are plenty of other problems in the farm field; and although we want to work out the best parity price and income measures that can be devised, we must never forget that these are, after all, only a part of our whole farm program."

\section{OUR APPRAISAL OF PARITY}

Our own appraisal of parity deals with its accuracy as a yardstick for measuring the economic well-being of farmers, and as an objective for price policy.

The call for parity is basically a call for the same prices for farm products that existed in 1909-14. But the prices of the goods and services that farmers buy have risen since that time, so the 1909-14 prices are multiplied by the current index of the prices of the goods and services that farmers buy. That is all that parity means-1909-14 prices, raised or lowered to the same extent that the prices of the goods and services that farmers buy have risen or fallen since then. The concept of parity, therefore, is essentially simple. How well does it stack up as a yardstick of agricultural well-being?

1. One of the good features of the parity concept is that it does not call for absolute prices- $\$ 1$ per bushel for wheat, for examplebut for prices that change with changes in the cost of things that farmers buy. The prices of these things change sluggishly, somewhat later than the prices of farm products, and they change less than farm prices; but at least, they usually change in the same direction. Thus the law calling for loan rates at certain fixed percentages of parity is more realistic than a law that would call for loan rates at 
certain fixed figures in dollars and cents. Except for the lag, parity prices could represent a reasonable compromise between the fixed prices that some farmers would like to have and the extremely flexible prices that they have had in the past.

2. One of the obvious shortcomings of parity is the fact that it does not include the most important item of cost-farm labor. In 1933 , the cost of hired labor amounted to 10 per cent of the total production expenses of farm operators; in 1945, it amounted to 20 per cent. Labor is the biggest single item of expense in the farm budget. It is four or five times as large as item as taxes. ${ }^{3}$. But taxes are included in the computation of parity, while the cost of labor is not.

During the first part of 1943 , legislative attempts were made to get the cost of farm labor included in the parity formula. The reason for these attempts was the fact that farm labor costs had risen. Including them in the formula would have raised parity prices by several points. During depressions, the inclusion of labor costs would decrease parity prices. The attempt, therefore, was made to have labor costs included only for the duration of the war-that is, only while it would raise parity. The propriety of this attempt was open to some question, and the attempt itself proved unsuccessful. It seems obvious that the accuracy of the parity formula would be increased if it included farm labor costs, in peace time as well as in war.

3. In order to measure the economic status of farmers accurately, an index of parity would need to be an index of parity incomes, not prices. It would have to take into account the quantities produced per farm or per person on farms, as well as the prices per unit of the goods sold. In other words, it would have to be an index of gross income.

But of course even an index of gross income would not measure economic status. Gross income may increase, but if costs rise more, net income will be less, not more, than before. Accordingly, what is needed is not only an index of gross income (prices $X$ quantity produced) but also an index of the costs of producing the commodity, to be subtracted from the gross income to give the net income.

Agricultural production in the United States for sale and for consumption in the farm home increased from an index of 82 during

\footnotetext{
${ }^{3}$ The Farm Income Situation, BAE, USDA, June, 1946, p. 26.
} 
1910-14 (the base being $1935-39=100$ ) to 128 in 1943,136 in $1944,{ }^{4}$ and 135 in 1945. This is an average increase of 62 per cent over the 1910-14 base period. The number of people on farms decreased 20 per cent over the same period, ${ }^{5}$ so agricultural production per person on farms more than doubled (80 goes into 162 more than twice). If parity prices had been attained in 1943-45, gross incomes per person on farms would have been more than twice parity; for the volume of sales per person on farms would have doubled.

These are gross income figures. The net income per person on farms is more difficult to estimate, but the BAE puts the 1943-45 net income at 412 per cent of the 1909-14 average. ${ }^{6}$ The data by years since 1910 are given in Table 26 .

With the passage of time since 1909-14, then, parity prices now understate per capita agricultural gross income about 50 per cent, and net about 75 per cent. They do not bring parity income. They bring double or quadruple parity income. The actual economic status of agriculture exceeds the status indicated by the parity yardstick by the percentages just given. No engineer could get along with a yardstick that measured a space of one foot as two or three feet. Economists have similar difficulties with parity.

4. The index of prices paid by farmers is inaccurate for the same reason that the index of prices received is inaccurate. It shows only the prices of the things that farmers buy, not the quantities. It therefore does not show the total amount of money paid out by farmers, any more than the index of prices received shows the total amount of money received by farmers. The index of the prices of things farmers buy might stand at 100 , but if farmers now buy twice as much machinery, fertilizer, etc., as they did in 1909-14, they would be paying out an amount that should be represented by 200 , not 100 . The index shows only the prices, not the cost (prices $X$ quantities) of things that farmers buy.?

The index of the prices paid by farmers is inaccurate for another reason. It is a single factor for the whole United States. This index is based upon the prices of 180 goods and 2 services (interest and taxes) used for living and production, with each good and service

'Agricultural Statistics, 1945, USDA, p. 437.

${ }^{5}$ The Farm Income Situation, BAE, USDA, June, 1946, p. 23.

Ibid., p. 23.

The weights used in the calculation of the price index are rather out of date. They are based upon expenditures in 1924-29. 
TABLE 26

Income per Farm, Income per Person on Farms and Not on Farms, Wages per Industrial Worker, and Income Parity Index, United States, 1910-45

\begin{tabular}{|c|c|c|c|c|c|}
\hline Year & $\begin{array}{l}\text { Net Income } \\
\text { From } \\
\text { Agriculture } \\
\text { per Farm }\end{array}$ & $\begin{array}{l}\text { Net Income } \\
\text { From } \\
\text { Agriculture } \\
\text { per Person } \\
\text { on Farms }\end{array}$ & $\begin{array}{l}\text { Income per } \\
\text { Person Not } \\
\text { on Farms }\end{array}$ & $\begin{array}{c}\text { Ratio per } \\
\text { Capita Farm } \\
\text { Income to per } \\
\text { Capita Non- } \\
\text { farm Income } \\
(1910-14 \\
=100)\end{array}$ & $\begin{array}{c}\text { Average } \\
\text { Annual } \\
\text { Wages per } \\
\text { Industrial } \\
\text { Worker }\end{array}$ \\
\hline $\begin{array}{l}1910 \ldots \ldots \\
1911 \ldots \ldots \ldots \\
1912 \ldots \ldots \ldots \\
1913 \ldots \ldots \\
1914 \ldots \ldots\end{array}$ & $\begin{array}{l}699 \\
613 \\
675 \\
680 \\
697\end{array}$ & $\begin{array}{l}139 \\
122 \\
135 \\
136 \\
140\end{array}$ & $\begin{array}{l}482 \\
468 \\
483 \\
521 \\
484\end{array}$ & $\begin{array}{r}105 \\
95 \\
101 \\
95 \\
105\end{array}$ & $\begin{array}{l}573 \\
562 \\
575 \\
600 \\
603\end{array}$ \\
\hline $\begin{array}{l}1915 \ldots \ldots \\
1916 \ldots \ldots \\
1917 \ldots \ldots \\
1918 \ldots \ldots \\
1919 \ldots \ldots\end{array}$ & $\begin{array}{r}674 \\
771 \\
1,274 \\
1,482 \\
1,527\end{array}$ & $\begin{array}{l}135 \\
155 \\
258 \\
304 \\
319\end{array}$ & $\begin{array}{l}502 \\
580 \\
640 \\
671 \\
762\end{array}$ & $\begin{array}{r}97 \\
97 \\
146 \\
164 \\
152\end{array}$ & $\begin{array}{r}622 \\
694 \\
818 \\
1,064 \\
1,188\end{array}$ \\
\hline $\begin{array}{l}1920 \ldots \ldots \ldots \\
1921 \ldots \ldots \ldots \\
1922 \ldots \ldots \ldots \\
1923 \ldots \ldots \ldots \\
1924 \ldots \ldots \ldots\end{array}$ & $\begin{array}{r}1,298 \\
584 \\
745 \\
876 \\
876\end{array}$ & $\begin{array}{l}265 \\
119 \\
153 \\
180 \\
180\end{array}$ & $\begin{array}{l}878 \\
720 \\
718 \\
815 \\
792\end{array}$ & $\begin{array}{r}109 \\
60 \\
77 \\
80 \\
82\end{array}$ & $\begin{array}{l}1,411 \\
1,234 \\
1,182 \\
1,274 \\
1,273\end{array}$ \\
\hline $\begin{array}{l}1925 \ldots \ldots \\
1926 \ldots \ldots \\
1927 \ldots \ldots \\
1928 \ldots \ldots \\
1929 \ldots \ldots\end{array}$ & $\begin{array}{l}1,078 \\
1,044 \\
1,009 \\
1,067 \\
1,072\end{array}$ & $\begin{array}{l}223 \\
216 \\
209 \\
222 \\
223\end{array}$ & $\begin{array}{l}812 \\
858 \\
820 \\
830 \\
871\end{array}$ & $\begin{array}{r}100 \\
91 \\
92 \\
97 \\
93\end{array}$ & $\begin{array}{l}1,293 \\
1,318 \\
1,311 \\
1,323 \\
1,334\end{array}$ \\
\hline $\begin{array}{l}1930 \ldots \ldots \\
1931 \ldots \ldots \ldots \\
1932 \ldots \ldots \ldots \\
1933 \ldots \ldots \ldots \\
1934 \ldots \ldots \ldots\end{array}$ & $\begin{array}{l}813 \\
545 \\
350 \\
445 \\
522\end{array}$ & $\begin{array}{r}170 \\
114 \\
74 \\
93 \\
111\end{array}$ & $\begin{array}{l}761 \\
605 \\
442 \\
419 \\
488\end{array}$ & $\begin{array}{l}81 \\
68 \\
61 \\
81 \\
83\end{array}$ & $\begin{array}{r}1,249 \\
1,130 \\
929 \\
900 \\
983\end{array}$ \\
\hline $\begin{array}{l}1935 \ldots \ldots \\
1936 \ldots \ldots \\
1937 \ldots \ldots \\
1938 \ldots \ldots \\
1939 \ldots \ldots\end{array}$ & $\begin{array}{l}742 \\
807 \\
943 \\
798 \\
847\end{array}$ & $\begin{array}{l}159 \\
171 \\
197 \\
165 \\
173\end{array}$ & $\begin{array}{l}540 \\
626 \\
671 \\
622 \\
663\end{array}$ & $\begin{array}{r}107 \\
99 \\
107 \\
96 \\
95\end{array}$ & $\begin{array}{l}1,058 \\
1,130 \\
1,219 \\
1,134 \\
1,205\end{array}$ \\
\hline $\begin{array}{l}1940 \ldots \ldots \\
1941 \ldots \ldots \\
1942 \ldots \ldots \\
1943 \ldots \ldots \\
1944 \ldots \ldots \\
1945 \ldots \ldots\end{array}$ & $\begin{array}{r}898 \\
1,251 \\
1,876 \\
2,349 \\
2,385 \\
2,509\end{array}$ & $\begin{array}{l}181 \\
253 \\
389 \\
522 \\
550 \\
585\end{array}$ & $\begin{array}{r}720 \\
849 \\
1,045 \\
1,250 \\
1,320 \\
1,294\end{array}$ & $\begin{array}{r}90 \\
107 \\
133 \\
149 \\
149 \\
162\end{array}$ & $\begin{array}{l}1,273 \\
1,495 \\
1,848 \\
2,176 \\
2,324 \\
2,250\end{array}$ \\
\hline
\end{tabular}

Source: BAE, USDA, Net Farm Income and Parity Report: 1943, July, 1944, pp. 12, 14, and 16, and The Farm Income Situation, BAE, USDA, June, 1946, pp. 23-4. 
weighted according to its purchases by farmers, as shown above. The index thus shows the cost of goods and services for the average farmer in the United States.

But actual farmers are not average farmers. They are cotton farmers, using cotton machinery, fertilizer, and labor; they are Cornbelt farmers, using corn planters, pickers, etc.; they are wheat farmers, using "one-way's" and combines; they are truck farmers, ranchers, fruit growers, etc., each with his own list of goods and services purchased, differing from that of the others. The United States (average) index doesn't accurately represent any of them.

Attempts to correct this inaccuracy of parity would probably bog down in complications. A separate index of the prices of goods and services bought by farmers could be constructed for each state. But that would not be accurate either, for most states include several different types of farming, each with its different costs. In addition, the indexes would differ from state to state (else there would be no need for constructing state indexes). So parity prices for the same commodities would differ from state to state, in ways that would not necessarily conform to actual market price differences among different states.

Since states are arbitrary political divisions cutting across economic divisions, a better procedure would be to set up separate indexes of the prices of goods and services bought by farmers, not by states but by commodities or types of farming. But this, too, would run into complications. An index for wheat or for wheat farming built on the cost of growing wheat in the western plains would not fit the central or eastern states, where binders and threshing machines are used rather than combines. There would have to be a break between the two areas, or a gradual shading from the one to the other. The results in any case would show only the prices per unit of goods and services bought, not the cost (prices $X$ quantities).

5. Parity prices suffer from the fundamental conceptual defect that they apply the same standard to all agricultural commodities, with their great heterogeneity; and the standard is more than thirty years out of date.

Parity prices might be defended on this score on the grounds that they are fair; they treat the producers of all the different crops alike. But there is an obvious fallacy in this defense. The crops are different, and their costs of production have changed by different amounts since 1909-14. Even if the relative changes that have taken 
place in demand could be ignored (which they cannot be) the costs of producing different crops have changed since 1909-14, and price controls that are based on 1909-14 prices do not now treat the producers of different crops alike.

It is difficult to get accurate estimates of changes in costs of production, but good estimates have been made of changes in the largest single item of cost, man-hours per unit of product. The man-hours required to produce 100 bushels of wheat in the United States have been cut in half since World War I. They declined from 89 in 1909-13 to 41 in 1934-36; in the small grain region they dropped from 78 to . 31 , as compared to a decline from 128 to 93 in the northeastern states. The man-hours required to produce 100 bushels of corn, however, declined only from 109 to 90 for the United States as a whole; they fell from 57 to 49 hours in the corn area and remained virtually unchanged in the southeastern part of the United States. ${ }^{8}$ The data for vegetables go back only to 1918-21, but they show that the manhours required in this case rose $\mathbf{5}$ per cent as yields in some areas declined and as trouble with diseases and insects increased. ${ }^{9}$

Another more recent study, giving average labor requirements for different crops over the period 1930-39, states that the man-hour requirements for producing 100 bushels of wheat in the plains states averaged about 50, while the requirements for corn in the Corn Belt averaged about 65. (Data for the United States as a whole are not given in this study.) These figures are both higher than the figures quoted above in the earlier investigation for 1934-36. The two studies are not strictly comparable, because of the differences in the dates, and perhaps for other reasons as well. But both of them show that the labor requirements per bushel for wheat in the main Wheat Belt are lower than the labor requirements for corn in the main Corn Belt. ${ }^{10}$

A considerable decrease has taken place in the labor requirements for corn since the periods covered by these two studies (1934-36 and 1930-39) owing to the extensive use of hybrid corn. This has increased yields 15 to 20 per cent. It has increased the labor requirements per acre only to a small extent, if at all (the increased number of bushels per acre increases the cost of harvesting

\footnotetext{
${ }^{8} \mathrm{John}$ A. Hopkins, Changing Technology and Employment in Agriculture, BAE, USDA, May, 1941, pp. 118 and 123.

'J. C. Schilletter, Robert B. Elwood, and Harry E. Knowlton, Vegetables, WPA, National Research Project, September, 1939, p. 85.

${ }^{10}$ M. R. Cooper, W. C. Holley, H. W. Hawthorne, and R. S. Washburn, Labor Requirements for Crops and Livestock, BAE, USDA, mimeo., May, 1943.
} 
only if the husking is done by hand on a payment-by-the-bushel basis; most of the corn nowadays is harvested by machine, and the increased number of bushels per acre increases only the costs of hauling the corn away). Not much change has taken place in wheat labor requirements during the past few years. Even a 15 or 20 per cent reduction in corn labor requirements per bushel, however, still leaves them higher than the labor requirements for wheat.

To the extent that these changes in labor requirements represent relative changes in costs of production, they show that it is not fair to give all producers the same percentages of parity. For the labor requirements of some crops have declined more than 50 per cent while those of others have risen 5 per cent. If the cost of producing wheat has declined, let us say, 35 per cent, while the cost of producing vegetables has risen 5 per cent, it is obviously not fair, but unfair, to give both of those crops parity prices now.

If proper account were taken of changes in costs, changes in demand also would need to be reckoned with. The 1909-14 parity price for horses in January, 1945, for example, was $\$ 136 \times 1.72=$ $\$ 233.92$ per head. But the demand for horses has declined so much that the actual price on that date was only $\$ 64.60$. The parity price was clear out of line with economic realities. The same thing is true, only in lesser degree, of some other farm products.

Parity prices for most industrial products would be as unsatisfactory as they are for some farm products. Farmers would not want to pay automobile manufacturers 1909-14 parity prices for automobiles, for they would average over $\$ 2,000$. Nor would they want to pay parity prices for electric light bulbs, for they would average over $\$ 1.00$.

6. Finally, prices are one of the chief instruments for controlling production. Adherence to parity requires restoration of the 1909-14 relationships, but those are entirely obsolete. The demands for different products have changed greatly since 1909-14 and will continue to change in the future. The relative costs of production have also changed. Thus, the relative prices that will call forth the desired production of different farm commodities have changed markedly since 1909-14. The great weakness of parity is that it looks backward at the past instead of forward into the future. It is like the legendary bird that flies backward because it is more interested in where it came from than in where it is going.

Schultz puts it in a nutshell. "Parity prices as defined in farm legislation are wholly obsolete, backward looking, and inappro- 
priate criteria for determining the price relationships between farm commodities. While it is neither possible nor necessary to formulate at this time the price relationships that will be appropriate in the postwar period, it is possible to lay down the principles that should determine farm prices. It is the function of farm prices to guide and direct the use of agricultural resources. To do this, farm prices must be forward-looking; they must reflect the food situation in prospect, the expected demands and supplies which represent food needs, and the capacity of agriculture to produce. It is not the function of farm prices to maintain the status quo of farmers' prices or incomes; nor to maintain food prices to consumers at a given level. Farm prices are not an appropriate means for maintaining a given distribution of farm income except as this occurs coincidentally with the better use of agricultural resources. To do the job of production, farm prices cannot be static; they cannot be governed by the dead hand of past price relationships. To make them historical is to destroy their usefulness as a means for directing agricultural production."11.

\section{PARITY NET INCOME}

By all odds, net income provides a more accurate measure of agricultural well-being than prices. A good deal depends, however, upon the definition of parity income.

During the 1930's, the concept of parity income developed as an extension of the parity price concept. It first appeared in legislation in 1936. A declared purpose of the Soil Conservation and Domestic Allotment Act of 1936 was the "reestablishment, at a rapid rate as the Secretary of Agriculture determines to be practicable and in the general public interest, of the ratio between the purchasing power of the net income per person on farms and the income per person not on farms that prevailed during the 5-year period August 1909-July 1914, inclusive, as determined from statistics available in the United States Department of Agriculture and the maintenance of such ratio."

There was a good deal of criticism of this definition of parity income. ${ }^{12}$ In the Agricultural Adjustment Act of 1938, therefore, the

${ }^{11}$ This paragraph is taken from "Transition Readjustments in Agriculture," by T. W. Schultz, Journal of Farm Economics, XXVI, February, 1944, No. 1, p. 83.

${ }_{12}^{3}$ See the discussion of "Income Parity for Agriculture," by O. C. Stine, M. R. Benedict, and J. D. Black in Studies in Income and Wealth, I National Bureau of Economic Research, 1937). 
definition was changed to read as follows: “'Parity', as applied to income, shall be that per capita net income of individuals on farms from farming operations that bears to the per capita net income of individuals not on farms, the same relation as prevailed during the period from August 1909-July 1914." A supplementary definition of parity income to be used in apportioning parity payments among individual crops appears in later legislation. But the definition quoted above remains in effect for the general purpose of appraising the economic status of farmers.

The 1938 definition of parity income differs from the 1936 definition in four respects. (1) The term "net" is used; it is applied to per capita income of persons not on farms as well as to that of persons on farms. (2) The "purchasing power" provision in the 1936 definition was omitted in the 1938 definition. (3) The income of persons on farms includes income from farming operations only. (4) The limitation "as determined from statistics available in the USDA" is omitted.13

The 1938 definition avoids some of the difficulties inherent in measurements of net income. The existing farm income statistics need substantial revision before they can be used for current comparisons with nonfarm incomes. The estimates of net income per person in agriculture do not include income from nonagricultural sources (the estimates of net income per person not on farms do include income from agricultural sources). The net income to persons on farms from nonagricultural sources is a considerable item. In 1935-39 it averaged 2.1 billion dollars, compared with 5.4 billion dollars from farming operations. It would seem that the estimates of income per person in agriculture should include the income from all sources if they are to be compared with the estimates of income per person outside of agriculture. One of the reasons why the income from nonagricultural sources is not included in the income parity computations is that estimates are not available for the base period 1909-14. This reason would disappear if a more recent base period were adopted.

The inclusion of income from nonagricultural sources still would leave some considerable inaccuracies in the estimates for purposes of comparison with the net incomes of other groups. Farmers

${ }^{13}$ A more detailed appraisal of these and other points is given in $\mathbf{E}$. W. Grove's able article, "The Concept of Income Parity for Agriculture," Studies in Income and Wealth, VI, National Bureau of Economic Research, 1943, pp. 97-139. 
ordinarily get only about 50 per cent of the retail value of the food they produce. The estimates of net farm income, however, value the farm products consumed by the farm household at farm prices. If those products were valued at retail prices, as they should be for comparability with nonfarm conditions, that would have increased the net income to persons of farms in 1939 by more than 20 per cent. The rental value of farm dwellings, estimated in 1939 at $\$ 110$ per year per farm, also is perhaps about 50 per cent low by comparison with the rental value of comparable dwellings and sites in town. Other items-taxes, charges for depreciation on equipment, etc.also may need checking for comparability.

Finally, the existing net income figures do not include the nonmonetary items of income on the farm and off the farm-the independence of the farm operator compared with the dependence of the urban worker on his job, the open air nature of farm work, the generally poorer schools in the country, etc.

The 1938 definition of net income, however, avoids these shortcomings. It does not call for direct comparisons of current net incomes on farms with current net incomes off farms. Thus if current income data showed net farm income to be only half as much as nonfarm income (or twice as much) that would still represent income parity if half (or twice) were the relation that existed in the base period.

This comparison relative to the base period, without reference to changes in the purchasing power of either farm or nonfarm income, assumes that the prices paid by farm and nonfarm people have risen and fallen fairly similarly. It also assumes that the nonmonetary items have not changed much relatively. These assumptions correspond reasonably closely to the facts, and the reference to the base period permits evaluation in terms of real income or purchasing power without deflation of the incomes for changes in the prices of the things those incomes buy. 


\section{Vertical and Horizontal Shifts in Demand and Supply Curves}

The fundamental idea of vertical and horizontal shifts in demand curves is simple. We can deal with it best by starting with the concept of the demand schedule. A typical demand schedule is shown in Table 27, section A.

The demand curve $D$ based on these figures is shown in Figure 53. Both the vertical and horizontal scales in the chart are logarithmic. This preserves parallelism in the curves throughout the various shifts in their position that are considered. The reasoning, however, is independent of the kinds of scales used.

The use of a curved demand line on a logarithmic scale will help to bring out the point more clearly than the use of a straight line, though the reasoning in both cases is the same. Either a concave or a convex curve may be used. We shall start with the former.

Suppose, now, that twenty years elapse and

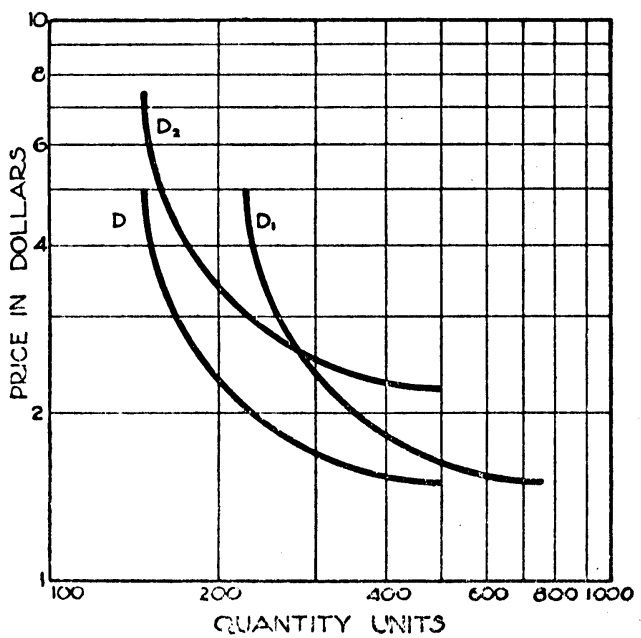

Frg. 53.-Vertical and horizontal shifts in a concave demand curve.

the population consuming the good in question increases 50 per cent. If no changes have taken place in the demand per consumer, 50 per cent more goods could now be sold at each price than formerly. The new situation is represented in Table 27, section B, in which each quantity figure is $\mathbf{5 0}$ per cent higher than the corresponding figure in the left-hand section. The price figures remain unchanged. The new curve, $D_{1}$, is shown in Figure 53.

Now let us suppose that, instead of the population increasing $\mathbf{5 0}$ 
per cent, it had remained unchanged, but the purchasing power of each consumer had increased. No other change in demand took place, but, because of their increased purchasing power, consumers were willing to pay, let us say, 50 per cent more for each quantity than formerly. This situation is shown in Table 27, section C, where each price figure is 50 per cent higher than the corresponding figure in section $\mathrm{A}$, the quantity figures remaining unchanged. The new curve, $D_{2}$, is shown in Figure 53.

A concrete illustration of this sort of change in demand is a rise

TABLE 27

Demand Schedules

(Hypothetical Data)

\begin{tabular}{|c|c|c|c|c|c|}
\hline \multicolumn{2}{|c|}{$\begin{array}{l}\text { A. Original Demand } \\
\text { Schedulc }\end{array}$} & \multicolumn{2}{|c|}{$\begin{array}{l}\text { B. Population Increased } \\
50 \% \text {, Furchasing Power } \\
\text { Unchanged }\end{array}$} & \multicolumn{2}{|c|}{$\begin{array}{c}\text { Purchasing Power } \\
\text { Increascd, Population } \\
\text { Unchanged }\end{array}$} \\
\hline Price & $\begin{array}{l}\text { Quantity } \\
\text { Units }\end{array}$ & Price & $\begin{array}{l}\text { Quantity } \\
\text { Units }\end{array}$ & Price & Quantity \\
\hline $\begin{array}{l}\$ 5.00 \\
4.00 \\
3.00 \\
2.50 \\
2.35\end{array}$ & $\begin{array}{l}150 \\
155 \\
170 \\
190 \\
200\end{array}$ & $\begin{array}{r}\$ 5.00 \\
4.00 \\
3.00 \\
2.50 \\
2.35\end{array}$ & $\begin{array}{l}225 \\
232 \\
255 \\
285 \\
300\end{array}$ & $\begin{array}{r}\$ 7.50 \\
6.00 \\
4.50 \\
3.75 \\
3.52\end{array}$ & $\begin{array}{l}150 \\
155 \\
170 \\
190 \\
200\end{array}$ \\
\hline $\begin{array}{l}2.00 \\
1.90 \\
1.70 \\
1.55 \\
1.50\end{array}$ & $\begin{array}{l}235 \\
250 \\
300 \\
400 \\
500\end{array}$ & $\begin{array}{l}2.00 \\
1.90 \\
1.70 \\
1.55 \\
1.50\end{array}$ & $\begin{array}{l}352 \\
375 \\
450 \\
600 \\
750\end{array}$ & $\begin{array}{l}3.00 \\
2.85 \\
2.55 \\
2.32 \\
2.25\end{array}$ & $\begin{array}{l}235 \\
250 \\
300 \\
400 \\
500\end{array}$ \\
\hline
\end{tabular}

or decline of the general price level. This represents a change in the amounts of money which consumers would offer for the same amounts of goods as before. Another illustration is the effect of the AAA processing tax on hogs, which shifted the demand curve for hogs downward by the amount of the tax.

The curve $D_{1}$ is an illustration of a horizontal shift in the position of the demand curve. The other curve, $D_{2}$, is an illustration of an equal vertical shift. The difference between the two curves seems clear.

\section{EFFECT UPON PRICE PAID AND QUANTITY TAKEN}

One might think that a vertical upward shift in the demand curve would result in a higher price being paid for the same quantity 
of goods as before, and that a shift to the right in the demand curve would result in more goods being sold at the same price as formerly. Conversely, one might reason backwards from the changes in quantity or price, and say that if the price had increased while the quantity taken remained unchanged, the demand curve must have shifted upwards. But this would be wrong. Production and price simply represent the intersection point of a demand and supply schedule. The effect of a horizontal or of a vertical shift in a demand curve depends upon the supply curve as well as upon the demand curve. Whether a shift in the location of a demand curve, either upwards or to the right, will result in an increase in the price or in the quantity taken, or both, depends upon the conditions of supply; that is, upon the slope of the supply curve and changes in its location.

Under conditions of constant costs, for example, a vertical rise in
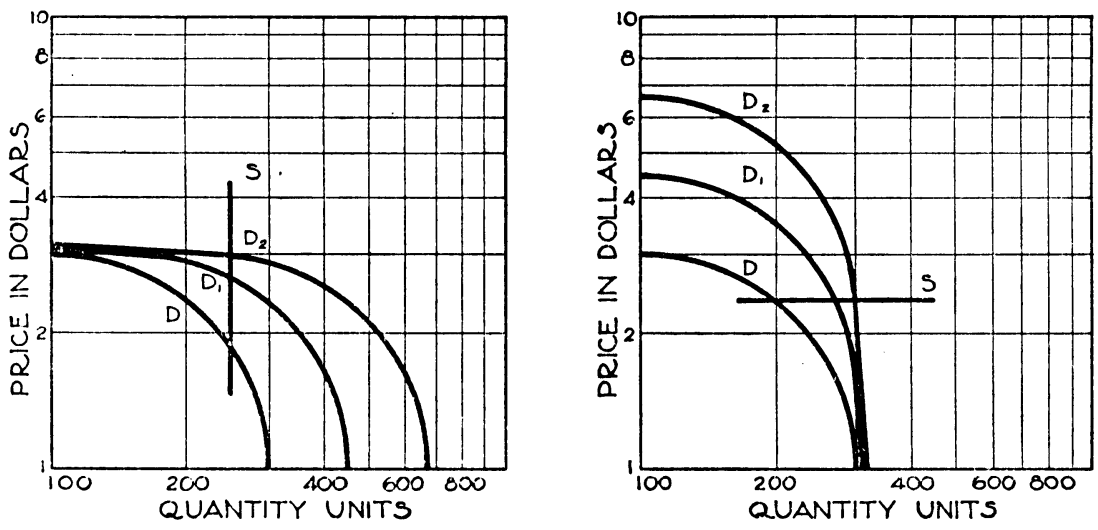

Fra. 54.-Effect of elasticity of supply curve.

the demand curve would result in an increase, not in the price for the same quantity, but in the quantity taken at the same price. Conversely, with a fixed stock of a good, a horizontal shift to the right in the demand curve would result, not in an increase in quantity taken at the same price, but in an increased price paid for the same quantity. The nature of the supply curve, and shifts that may have taken place in its location, determines the proportion in which an increase in demand, either upward or to the right, is expressed as an increase in the price or in the quantity taken.

This point is illustrated in Figure 54. In section A of this figure, 
a convex demand curve is shown shifting to the right. The supply curve, however, happens to be inelastic (fixed stock). As a result, although the demand curve has moved to the right, the intersection point of the demand and supply curves has necessarily (because of the inelasticity of the supply curve) moved upward. A higher price is paid for the same quantity as before.

In section B of Figure 54, the opposite situation is shown. The demand curve shifts upward, but the supply curve happens to be fully elastic (contant costs). The result of the upward shift in the demand curve is a shift of the intersection point to the right; that is, more goods are taken at the same price as before.

Two things, therefore, are evident. (1) Whenever the demand curve is convex or concave the demand curve as a whole is different in its position after a vertical and after a horizontal shift, and (2) the effect of a shift in demand upon price paid and quantity taken depends, not upon the direction of the shift, but upon the nature of the supply curve.

\section{STRAIGHT-LINE DEMAND CURVES}

We come now to the consideration of straight-line demand curves.

Before beginning, we must decide whether we mean straight line curves on arithmetic paper or on double logarithmic paper. Practically all the statistical price-quantity curves published in recent articles and bulletins are drawn on arithmetic paper. But the concept of changes in demand is fundamentally proportional in character, and changes in demand in actual life are usually ${ }^{1}$ proportional. A proportional change in demand shown on arithmetic paper results in a new demand curve that is not parallel with the old. If a proportional change in demand is shown on double logarithmic paper, however, the new demand curve remains parallel with the old. Perhaps the best plan here is to consider separately both arithmetic and logarithmic straight-line demand curves.

\section{ARITHMETIC SCALES}

Let us first consider straight line curves on an arithmetic scale. In this case the difference between the curves resulting from a horizontal and from a vertical shift of $\mathbf{5 0}$ per cent is evident, not only

\footnotetext{
${ }^{1}$ In certain cases a change in demand may be arithmetic. A change in distributors' margins, for example, results in a vertical arithmetic shift.
} 
when elastic and inelastic curves are used, but also when an intermediate curve with slope of -1 is used. This is shown in Figure 55 . The elasticity of the curves remains unaffected, since the changes in demand are proportional changes, but the slope of the curves is altered.

\section{LOGARITHMIC SCALES}

If elastic or inelastic straight line curves on logarithmic scales are used, the position of the curve after a 50 per cent upward shift will be different.from its position after a 50 per cent shift to the right, and so will the price paid and quantity taken.

It is only in the rare case of a straight line demand curve on a double logarithmic scale, with a slope of -1 throughout, that the position of the curve would be the same after either shift. In this case the effect of a horizontal shift in demand upon the location of the intersection point, that is, upon production and price, would be
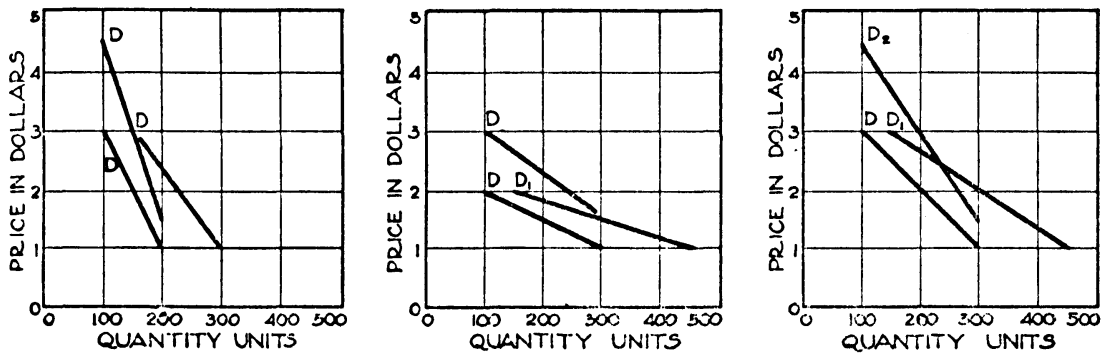

Fig. 55.-Shifts in straight line demand curves. Arithmetic scales.

identical with that of an equal vertical shift. After population has increased 50 per cent, consumers as a group might either pay higher prices for the same quantity as before, or take larger quantities at the same price as before, or some intermediate combination of the two, according to the nature of the supply curve. If the supply curve were a vertical straight line (fixed stock), the consumers would pay more for the same quantity. If the supply curve were a horizontal line (constant costs), they would take a larger quantity at the same price. If the supply curve had a slope intermediate between vertical and horizontal, the effect on price and quantity would be intermediate-both price and quantity would increase, in proportions determined by the slope of the supply curve. 


\section{REASON FOR DISTINCTION}

The reason for distinguishing between vertical and horizontal shifts in demand curves is this: we start with a price series, and find that it fluctuates. What is the reason for the fluctuations? The accepted procedure among economists is to group the possible causes under the two heads, demand and supply. Investigating these two groups, we come to the conclusion that the demand changed, or the supply changed, or both. If our objective is to reduce price fluctuations in the future, we know then whether we need to concentrate our attention upon changes in demand, or in supply, or in both.

The purpose of the distinction between horizontal and vertical shifts in demand (or supply) curves is to enable us to carry our investigation one step further. We have determined, let us say, that the chief cause of the price fluctuations was the changes that took place in demand. The demand curve shifted, and the question is, which way did it shift-up, down, or sideways, or some combination of these?

We cannot answer this question by observing whether the intersection point or the range of actual price-experience on the demand curve (which is merely the range of intersection points) shifted up or sideways. That, as pointed out above, depends on the nature of the supply curve. We can answer the question only by remembering that a demand curve represents demand. Economists define demand as consumers' willingness to buy certain quantities at certain prices; and that willingness exists whether the supply curve has fluctuated enough to reveal it in actual transactions or not. This means that the demand curve extends both ways, beyond the range of past experience in the market-ultimately, until it cuts the vertical and horizontal axes were quantity and price respectively are zero. (The curve will not extend indefinitely; it will cut both axes at some finite points.) ${ }^{2}$

We can tell which way the demand curve has shifted, then, by going behind the original price and quantity data on which the demand curve rests. We are seeking to explain why the data

\footnotetext{
${ }^{2}$ Usually these points, like those shown in Figure 55, will represent prices or quantities not greatly (say 100 per cent) in excess of the highest prices or quantities that have been actually experienced in the market, unless the demand is extremely inelastic, as for salt or water, or extremely elastic, as for human foods than can be fed to livestock if produced in excess. Substitution of other products levels off most demand curves as they approach the vertical axis, and rapidly declining marginal utility with increasing quantity causes most demand curves to cut the horizontal axis at a point not very far out to the right.
} 
changed. It seems obvious that, if population increased 50 per cent and if no other important change took place, the curve moved to the right, not upwards and to the right. The question can be demonstrated statistically when the demand curve is strongly curved, when, for example, it is a convex curve that cuts both axes at almost right angles, or a sloping straight line that flattens out or gets steeper as either axes is approached; it is equally true, only less obvious, when a straight line is used. We are on logically sounder ground in endeavoring to carry our explanation of price movements down to its ultimate causes if we recognize that a demand curve may shift either horizontally or vertically, or some combination of both, independent of which way (if any) the intersection point or the range of intersection points moved. We need to investigate what happened to the demand curve first, and then turn to a study of what happened to the supply curve; for movements in demand curves and supply curves (except in a roundabout sense, as during inflation or deflation) are independent of one another.

We are not studying movements in the intersection points of demand and supply curves; if we were, we would be studying only movements in production and prices. What we are trying to do is to study the movement of demand and supply curves that lie behind and cause these movements in prices and production. Economic theory has provided the research worker with conceptual tools for analyzing movements in prices and production into changes in demand and supply, that is, into movements of demand and supply curves. We are ready now to take the next step and analyze these movements into their horizontal and/or vertical components. As our data concerning population, incomes, pay rolls, wage rate indexes, general price levels, distributive margins, etc. become more detailed and adequate for analytical purposes, they should enable us to carry our economic analysis this one step further and give these questions a quantitative answer. 
-

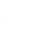




\section{Index}

AAA production control program, 23, 83, 97

Agricultural prices instability of, 20-22, 26-28

long-time relative rise in, 4-8 prospects for future, 17-19

Agricultural production, stability of, 21-23

Allen, R. G. D., 57n, 69n, 73n, 76n, 78n, $100 \mathrm{n}$

Allen, R. H., 64n, 93

Anderson, Don, 142n

Anderson, O., 186

Average cost, 148-50, 151, 155-56

Average revenue, $79-82,149-50,151$, $155-56$

Ayres, Leonard, 119

Barger, Harold, 12n

Bartels technique, 188-89

Beal, G. M., 166n

Bean, Louis H., 10n, 49, 90, 123, 133n

Beef cattle

cost of production, 162-63 cycles in prices and production, 43-47

demand curve, 102, 104 parity prices, by grades, $198-200$

Benedict, M. R., $218 \mathrm{n}$

Bennett, K. R., 8n

Bitterman, Henry J., 97n

Black, J. D., 133n, 218n

Bodin, Jean, 112n

Brewster, John N., 9n, 10n

Burtis, E. L., 181n

Butter production and prices, 107-8

Butz, E. L., 8n

Cannon, K. L., 66n

Cassady, Ralph, Jr., 69

Cassels, John M., 91n

Cobweb theorem, 30-36

Cochrane, W. W., 15n

Comparable prices, 196-97

Cooper, M. R., 216n

Corn

acreage, 41

cost of production, 163-65

demand curve for, 84-85

elasticity of demand, 67, 109

price factors, 83
Corn-continued

prices, relation to general price level, 115-17

production, 41, 42

yield, 41, 42

Cornfield, J., 15n

Correlation

and causation, 137-38

intercorrelation, $135-37$

Cost curves

under imperfect competition, 150-52 155-56

under perfect competition, 143-44, 145-47

Cost of production

for cattle, 162-63

- for corn, 162-65

difficulties in determining, 161-66

in industry, 159-61

for milk, 166

relation to prices, $158-66$

Cotton, elasticity of supply, 90

Cox, Rex W., 51n, 90

D'Avenant, C., 54n

Deflating price series prices of farm products related to general level of prices, 113-15 shortcomings of, 113-15

DeGraff, Henry, 66n

Demand

changes in, 12-14, 22-26

general, 118-20

specific, 120-21

definition, 100-1

elasticity of, $52-70$

future prospects, 18-19

inelastic, for farm products, 167-69

Demand curves

empirically derived, 170-72

straight line, 224-25

straight-line total revenue curves, 175-76

Eggs, elasticity of demand, 66

Elasticity

cross- 70

formula, 57-59

income- $68-69$

long-time, $66-68$ 
Elasticity-continued

middleman's margins, effect on, 63-64

of substitution, 69-70

of supply, graphic representation, 97-98

point-

definition, 71-73

measurement, 76-77

short-time, 65-66

time, effeet of, 64-68

total income and, 73-76

Elasticity of demand

definition, 53, 59

for potatoes, 54-64

graphic representation, 60-64

measurement of, 54-59

Elwood, Robert B., 13n, 216n

Evans, Griffith C., 64n

Ezekiel, M. J. B., 31n, 122, 133n, 134n, $189 \mathrm{n}$

Farm labor force, 9-11

Foote, Richard J., 142n

Fourier series, 187

Graphic method of multiple curvilinear correlation advantages and limitations, 138-42 appraising the results, 133-34 technique of, 122-42

Grove, E. W., 219n

Hafstad, L. R., 188n

Hainsworth, R. G., 140n

Hanson, A. C., 15n

Hart, A. G., 78n, 129n

Hawthorne, H. W., 216n

Hicks, J. R., 100n

Higgins, Benjamin, 145n

Hog-corn price ratio, $38-40$

Hogs

demand curve for, $86-87$

elasticity of

demand based on annual data, 89-90

short-time supply, 88-89

prices, 85-87, 108, 109, 110

cyclic changes, 29-31, 37-42

graphic analysis, 128-32

production

cyclic changes, 37-42

relation to prices, $108,109,110$

supplies, $85-87$

total income from, 85-87

Hole, Erling, 93n

Holley, W. C., 216n

Hopkins, John A., 13n, 43, 44, 162n, 216n

Howell, L. D., 178n
Imperfect competition, effect on production, prices, and profits, 156-57

Income; farm, nonfarm, and industrial worker, 214

Income-price curve, 132

Industrial prices, fluctuations in, 20-22, 26-27

Industrial production, fluctuations in, 24-26

Inflation, effects of, 3-4

Ives, J. Russell, 142n

Jensen, Einar, 92

Johnson, D. Gale, 179

Johnson, Hugh, 192

Kaldor, D. R., 69n

Keynes, John Maynard, 144n

King, Gregory, 54

Klaman, Saul B., 90

Knight, Frank, 53n, 100n

Knowlton, Harry E., 13n, 216n

Kondratieff, N. D., 187

Kozlik, Adolf, 76n, 172n, 175, 176n

Kuznets, S., 187n

Landsberg, Hans H., 12n

Lerner, A. P., 57n

Long-time price movements, 2-4

Lovasy, Gertrud, 178

Malenbaum, W., 133n

Marginal cost, 148-50, 151, 155-56

Marginal revenue, 77-82, 148-50, 151, 155-56

Marshall, Alfred, 58, 64, 78n, 91, 161

Mighell, R. L., 64n, 93

Milk production

cost of, 166

response to price changes, 92-93

Mill, J. S., 100n

Mitchell, W. C., 187n

Monopoly, criterion of, 152-57

Moore, Henry L., 54, 103, 111

Multiple curvilinear correlation, graphic method of (See also graphic method), 122-42

Parity net income, 214, 218-20

Parity price

appraisal of by BAE, 207-11

for beef cattle, by grades, 198-200

calculation of, 203-6

definition, 7-8, 167-69

index paid by farmers, 200-3, 213-15

legal basis of, 193-96

objectives for price pclicy, 211-18

seasonal variation, 200 
Pearson, F. A., 8n, 88, 141n

Peek, George, 192

Population growth agricultural, 109 total, 10-12

Potatoes

crop size and total income, 59-60 cycles in prices and production, 47-51

elasticity of demand, 54-59, 60-64 supply, 90

Price discrimination, theory of (See also price stabilization), 180-82

Price index bases, 6-8

Price stabilization

consumers, benefit to, 177-80

effect of programs on income, 173-76 theory of, $170-82$

Prices

raising prices and raising wages, 166-69

relation to cost of production, 158-66

Prices at wholesale, index of allcommodity, 120

Production, most profitable, scale of, 147-53

Pubols, Ben H., 90

Quintus, Paul E., 90

Regression, gross and net, 135-37

Richards, Preston, 65n

Robinson, Joan, 69n, 73n, 180, 181n

Roos, C. F., 64n, 112n

\section{Sales curves}

under imperfect competition, 150-52 under perfect competition, 143-45

Schilleter, J. C., 13n, 216n

Schultz, Henry, 112n, 113-15

Schultz, T. W., 15, 217, 218n

Significance, tests of, 184-90

Snedecor, G. W., 137n, 138n, 184n

Staehle, Hans, 132n

Steagall Amendment, 195

Stigler, George, 112n, 145n

Stine, O. C., 193, 218n

Stover, Howard J., 65, 89

Strauss, Frederick, 10n

Sturges, Alexander, 187n
Sulfur, annual price and quantity data, 105-7

Supply changes in, 9-12

future prospects, 18

Supply and demand changes in, 8-14 long-time elasticities of, 14-17 measurement of changes in, 99-110 relative increase of, 168-69 two parts of the law, 104

Supply and demand curves correlated shifts in demand and supply curves, 104-10

demand constant and supply fluctuating, 102

shifts, vertical and horizontal, 22127

supply constant and demand fluctuating, 103

uncorrelated shifts in demand and supply curves, 108, 110

Supply curves, one-way, 95-97

Thomas, H. L., 162n

Thomsen, F. L., 73n, 90n, 161n

Time series, statistical analysis of, 186-90

Tintner, Gerhard, $14 n, 64 n, 73 n, 74 n$, $186 \mathrm{n}$

Tolley, Howard R., 191n, 207, 208n

Total revenue, 78-87, 149-50, 151

Triffin, Robert, 145n

Viner, Jacob, 145n

Waite, Warren C., 51n, 69, 134n, 142n

Wallace, Henry A., 103-4, 137n

Warren, G. F., 88, 141n, 192

Washburn, R. S., 216n

Waugh, F. V., 73n, 178, 181n

Weather, fluctuations not cyclic, 40-42

Wells, O. V., 88

Wheat, elasticity of substitution. 69-70

Wilcox, Walter W., 65n, 135n, 137n

Wold, H., 186

Wolf, A. F., 181n

Working, E. J., 64n, 111n, 119n, 139

Yntema, 133n

Yule, G. Udney, 184, 1.86, 188 